Universidad de Lima

Facultad de Ingeniería Industrial

Carrera de Ingeniería Industrial

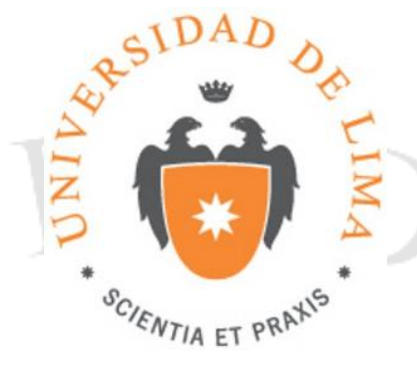

\title{
ESTUDIO DE PRE-FACTIBILIDAD PARA LA INSTALACIÓN DE UNA PLANTA GENERADORA DE ENERGÍA EÓLICA
}

Trabajo de investigación para optar el título profesional de ingeniero industrial

Alfredo Mantovani Escalante

Código 20090668

Carlos Alberto Postigo Toledo

Código 20090905

Asesor

Fabricio Humberto Paredes Larroca

Lima - Perú

Febrero de 2016 


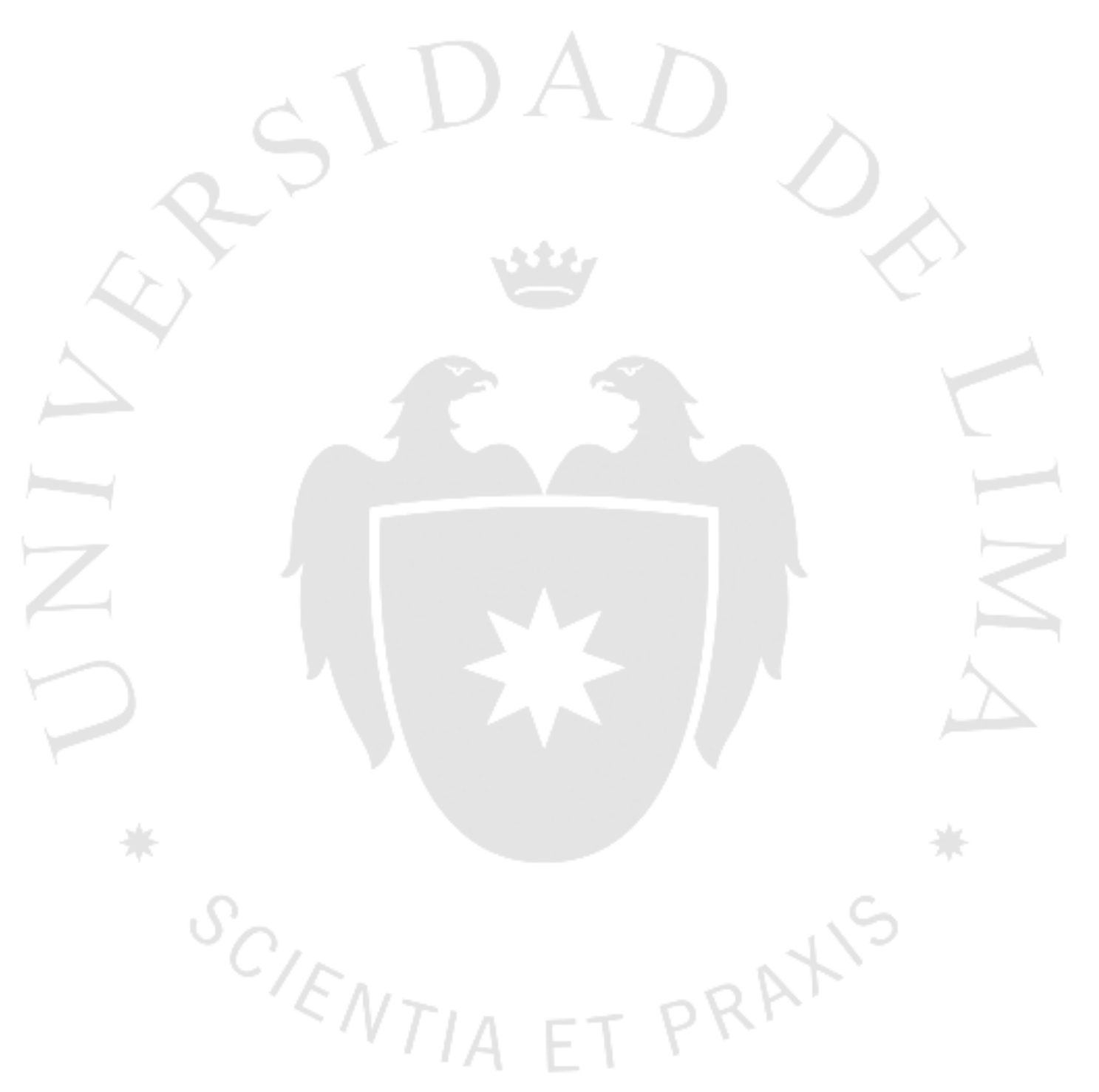




\section{ESTUDIO DE PRE-FACTIBILIDAD PARA LA INSTALACIÓN DE UNA PLANTA GENERADORA DE ENERGÍA EÓLICA}




\section{TABLA DE CONTENIDO}

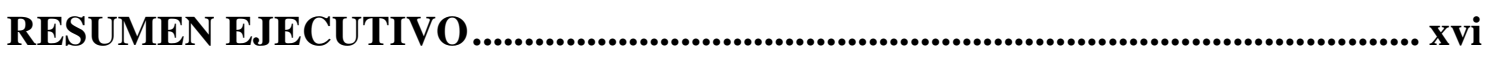

EXECUTIVE SUMMARY ................................................................................... Xviii

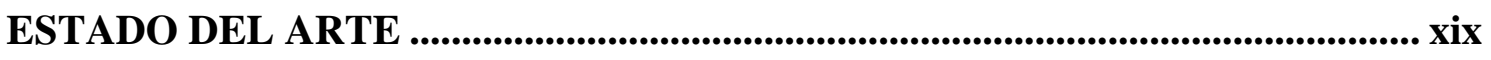

CAPÍTULO I: ASPECTOS GENERALES ............................................................. 1

1.1. Objetivos de la investigación y justificación del tema ................................ 1

1.1.1. Objetivo general …................................................................... 1

1.1.2. Objetivos específicos............................................................... 1

1.1.3. Justificación técnica................................................................... 1

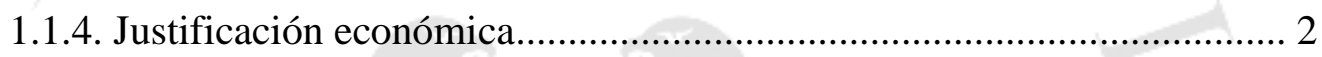

1.1.5. Justificación social....................................................................... 3

1.2. Hipótesis del trabajo …..................................................................... 3

1.3. Marco referencial de la investigación ....................................................... 3

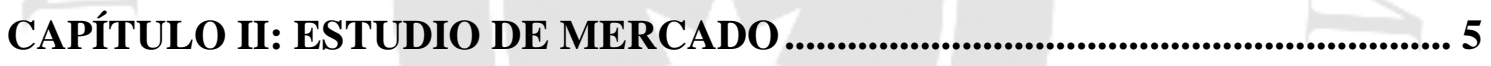

2.1. Aspectos generales del estudio de mercado ............................................ 5

2.1.1. Definición del servicio ............................................................... 5

2.1.2. Principales características del servicio ........................................... 5

2.1.3. Definición del área de influencia del servicio .................................... 6

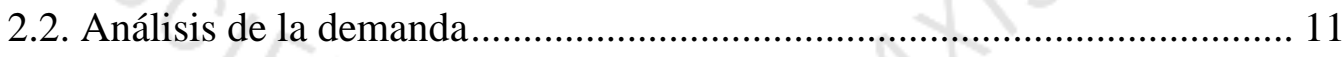

2.2.1. Cuantificación de los posibles mercados objetivos ............................ 11

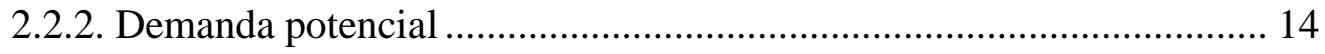

2.2.3. Proyección de la demanda histórica ................................................ 14

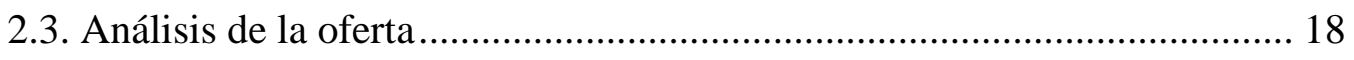

2.3.1. Análisis de la competencia ........................................................ 18

2.3.2. Descripción de las características de la oferta de los principales

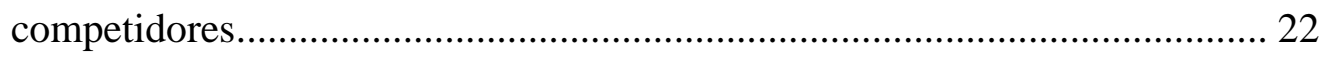


2.4. Demanda para el proyecto ................................................................ 26

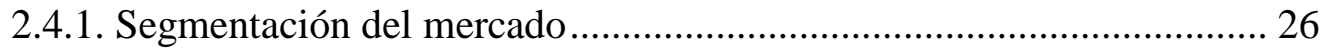

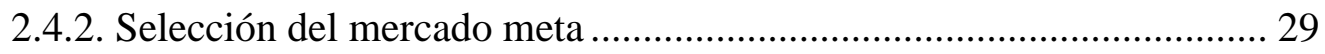

2.4.3. Determinación de la demanda para el proyecto ................................ 30

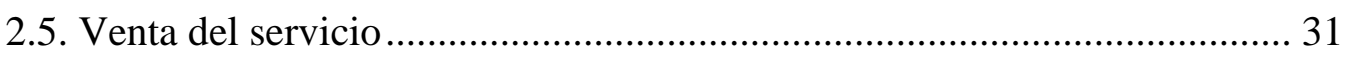

2.5.1. Políticas de venta del servicio .................................................... 31

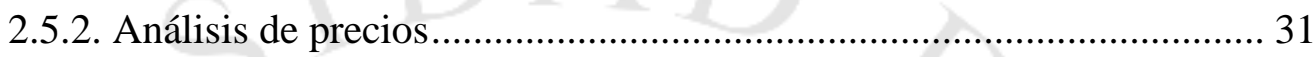

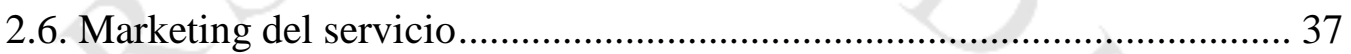

2.6.1. Características principales del servicio .......................................... 37

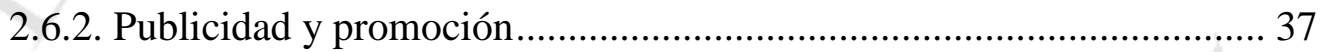

CAPÍTULO III: LOCALIZACIÓN DE PLANTA .......................................................... 39

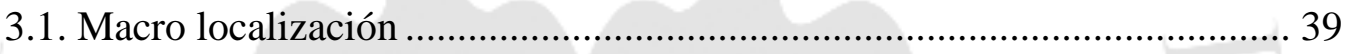

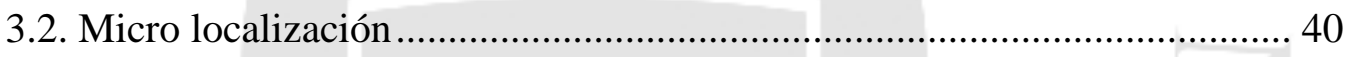

3.2.1. Definición de los factores de localización predominantes .................. 40

3.2.2. Posibles ubicaciones de acuerdo a los factores predominantes ........... 43

3.2.3. Análisis de los factores de localización en las posibles ubicaciones.... 44

3.2.4. Evaluación y selección de la micro localización ................................. 55

CAPÍTULO IV: TAMAÑ̃ DE PLANTA ............................................................... 58

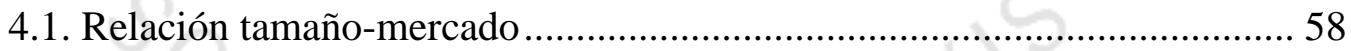

4.2. Relación tamaño-recursos productivos .................................................... 58

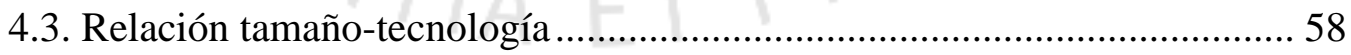

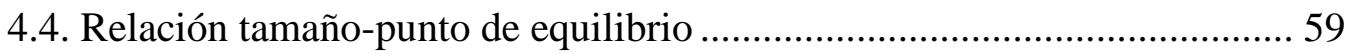

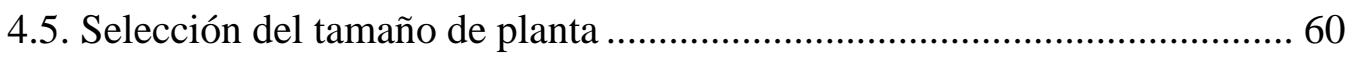

CAPÍTULO V: INGENIERÍA DEL PROYECTO ............................................ 61

5.1. Definición del servicio basada en sus características tecnológicas ............ 61

5.1.1. Especificaciones técnicas del servicio.......................................... 61 
5.2. Tecnología existente y proceso de realización del servicio

5.2.1. Naturaleza de la tecnología requerida ........................................... 62

5.2.2. Proceso de realización del servicio....................................................... 73

5.3. Características de las instalaciones y equipo.......................................... 77

5.3.1. Selección de las instalaciones y equipo ........................................... 77

5.3.2. Especificaciones de las instalaciones y equipo ................................ 78

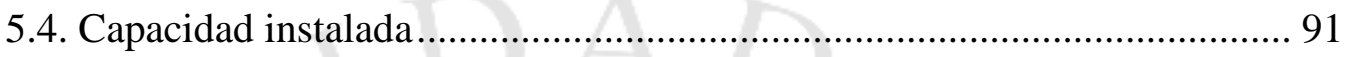

5.4.1. Cálculo de la potencia efectiva ..................................................... 91

5.4.2. Variables que influyen en la potencia aprovechable del viento ........... 94

5.4.3. Cálculo del número de aerogeneradores........................................ 104

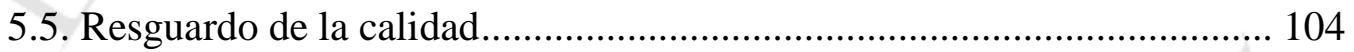

5.5.1. Calidad del proceso y del servicio ................................................. 104

5.5.2. Niveles de satisfacción del cliente................................................ 105

5.5.3. Medidas de resguardo de la calidad............................................ 105

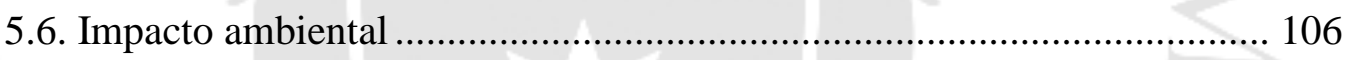

5.6.1. Etapa de construcción............................................................... 106

5.6.2. Etapa de explotación.................................................................... 107

5.6.3. Fase de abandono ................................................................... 108

5.7. Seguridad y salud ocupacional .......................................................... 108

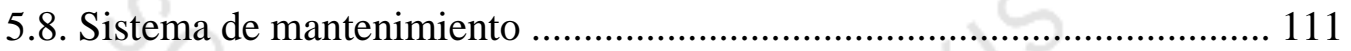

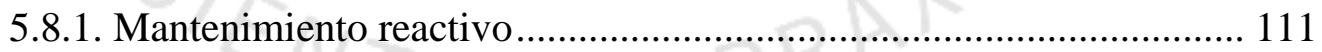

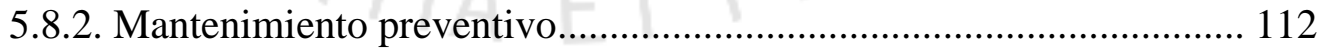

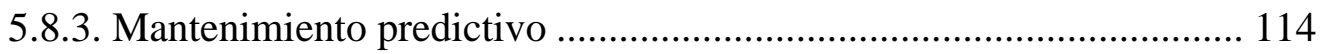

5.9. Programa de operaciones del servicio .............................................. 115

5.9.1. Consideraciones sobre la vida útil del proyecto .............................. 115

5.9.2. Programa de operaciones del servicio durante la vida útil del proyecto 
5.10. Requerimientos de insumos, personal y servicios

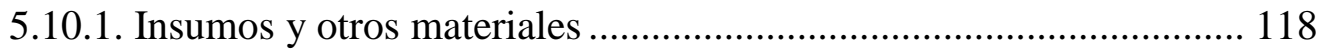

5.10.2. Operarios y trabajadores indirectos .............................................. 119

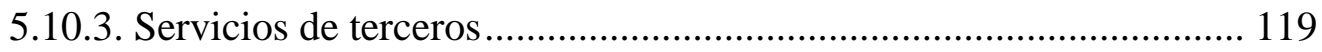

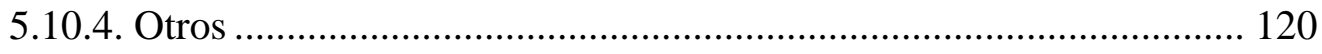

5.11. Características físicas del proyecto ................................................. 120

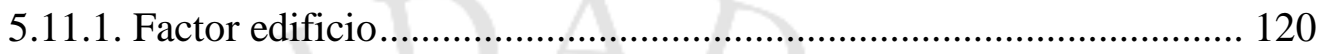

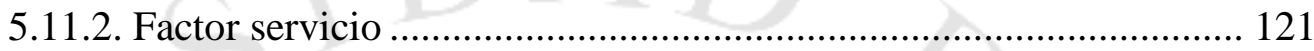

5.12. Disposición de la instalación del servicio ............................................ 124

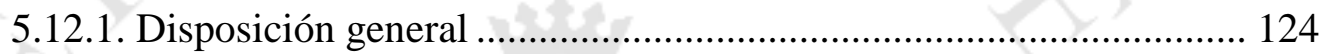

5.12.2. Disposición de detalle.................................................................. 127

5.13. Cronograma de implementación del proyecto ...................................... 134

CAPÍTULO VI: ORGANIZACIÓN ADMINISTRATIVA...................................... 135

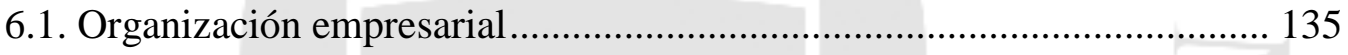

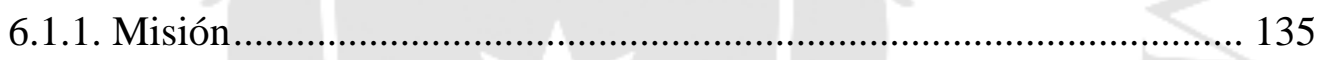

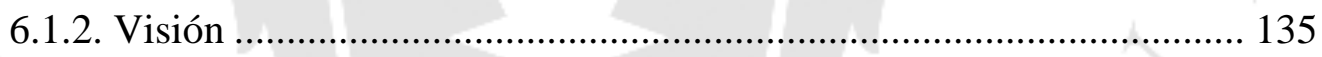

6.2. Requerimientos de personal directivo, administrativo y de servicios ...... 136

6.2.1. Organización para la ejecución del proyecto.................................... 136

6.2.2. Organización y administración para la operación de la empresa ....... 138

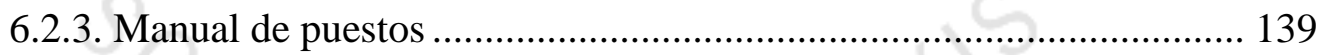

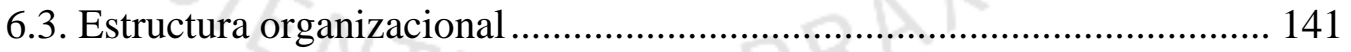

CAPÍTULO VII: ASPECTOS ECONÓMICOS ............................................................ 143

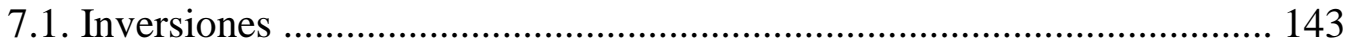

7.1.1. Inversión en la infraestructura para el servicio.................................. 143

7.1.2. Capital de trabajo.................................................................... 147

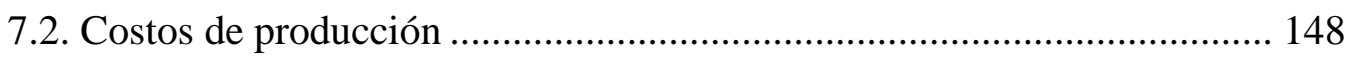

7.2.1. Costos de materias primas, insumos y otros materiales .................. 148 
7.2.2. Costo de los servicios

7.2.3 Costo de la mano de obra ............................................................. 149

7.3. Presupuesto de ingresos y egresos ....................................................... 150

7.3.1. Presupuesto de ingresos por ventas .............................................. 150

7.3.2. Presupuesto operativo de costos de materias primas........................ 151

7.3.3. Presupuesto operativo de gastos administrativos ........................... 153

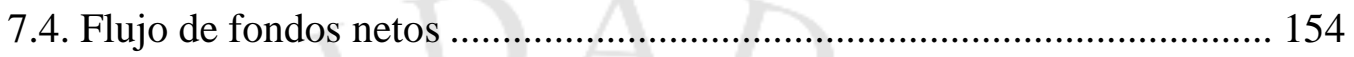

7.4.1. Flujo de fondos económicos ..................................................... 154

7.4.2. Flujo de fondos financieros ................................................... 157

\section{CAPÍTULO VIII: EVALUACIÓN ECONÓMICA Y FINANCIERA DEL}

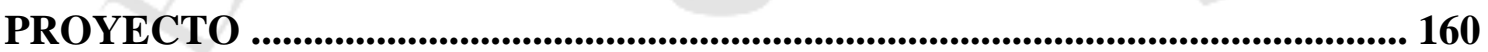

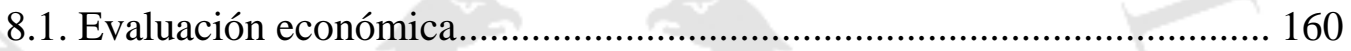

8.2. Evaluación financiera ...................................................................... 160

8.3. Análisis de los resultados económicos y financieros del proyecto ........... 160

CAPÍTULO IX: EVALUACIÓN SOCIAL DEL PROYECTO............................... 162

9.1. Identificación de las zonas y comunidades de influencia del proyecto.... 162

9.2. Impacto de la zona de influencia del proyecto ................................... 163

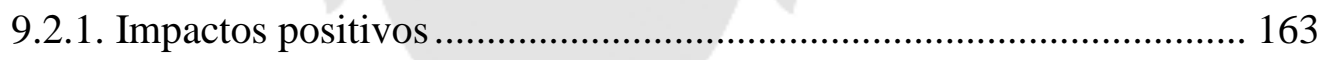

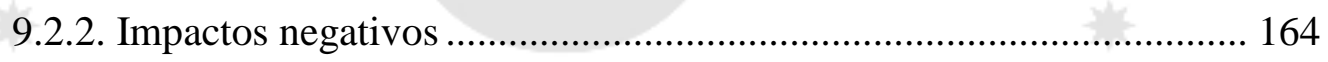

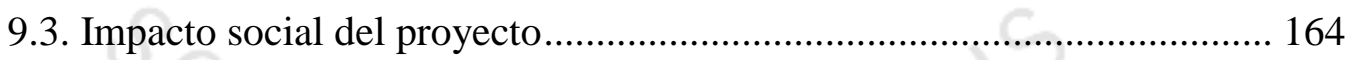

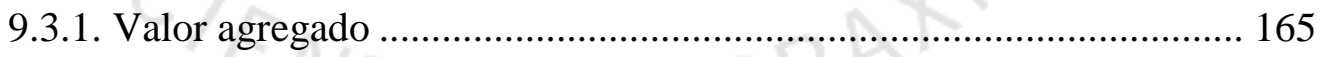

9.3.2. Relación producto/capital ............................................................. 167

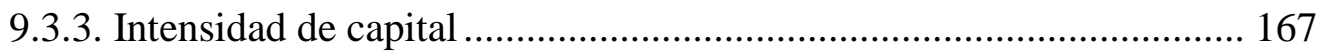

9.3.4. Densidad de capital........................................................................ 168

9.3.5. Productividad de la mano de obra ................................................... 168

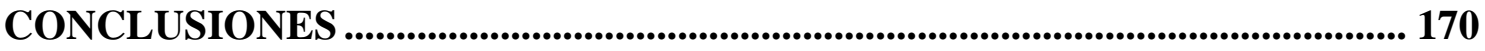

RECOMENDACIONES ............................................................................................. 172 


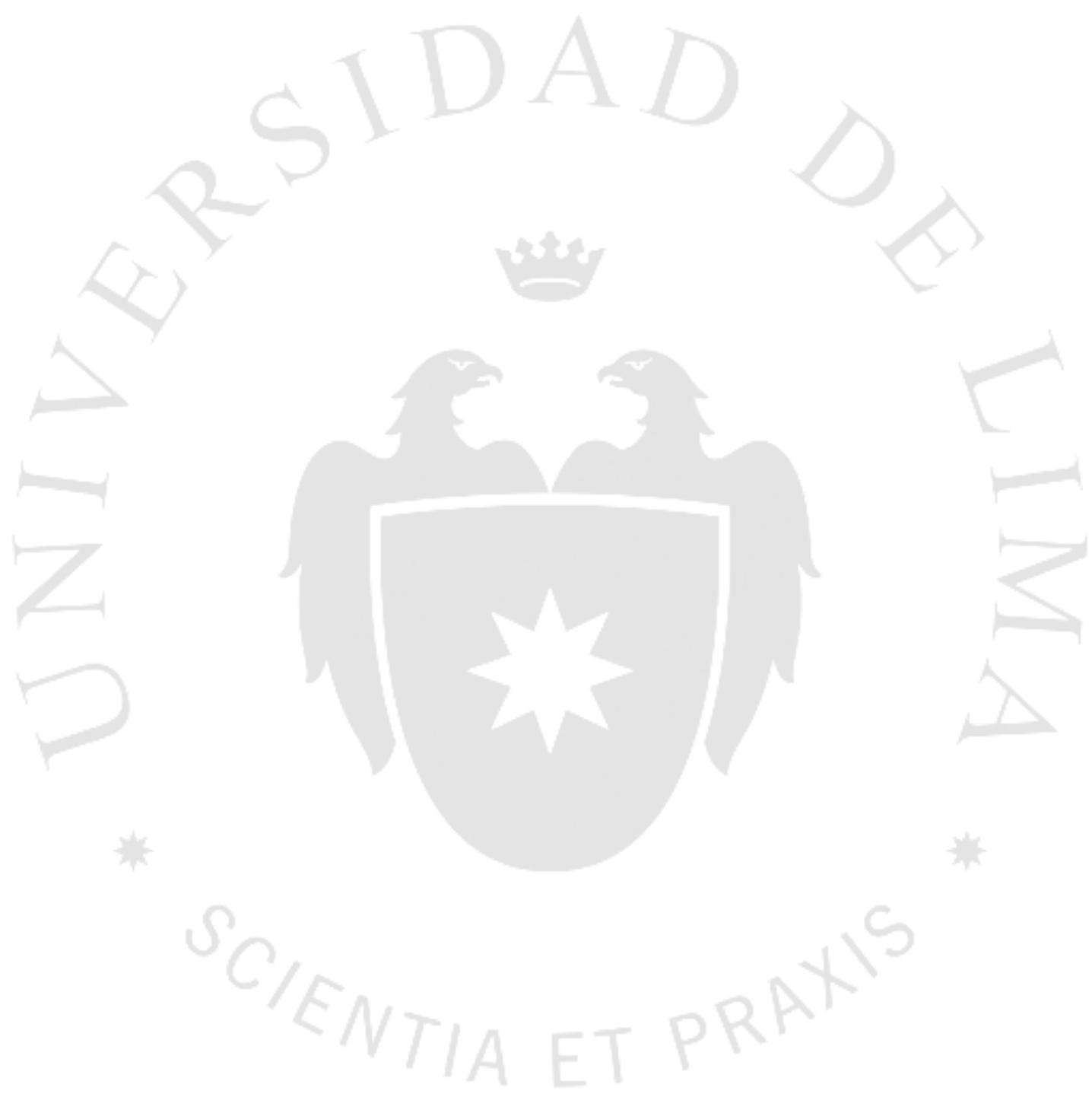




\section{ÍNDICE DE TABLAS}

Tabla 2.1. Potencial eólico nacional................................................ 8

Tabla 2.2. Participación regional de la cartera estimada de proyectos mineros.............9

Tabla 2.1. Potencia requerida de los proyectos mineros en Ica......................... 14

Tabla 2.2. Indicadores del sector eléctrico de la región Ica.............................16

Tabla 2.3. Principales empresas generadoras de energía eléctrica en el Perú............20

Tabla 2.4. Áreas eléctricas del Perú...............................................27

Tabla 2.5. Precios de empresas generadoras de electricidad..........................33

Tabla 2.6. Precio de energía eléctrica por actividad económica...................... 35

Tabla 2.7. Precio de energía eléctrica de proyectos eólicos en Ica..................... 36

Tabla 3.1. Clases de rugosidad ..................................................52

Tabla 3.2. Tabla de enfrentamiento de factores de localización.......................56

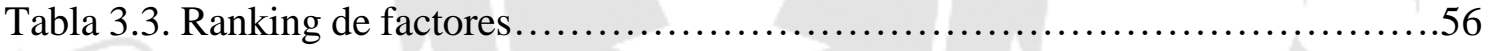

Tabla 5.1. Especificaciones generales del modelo a utilizar..........................78

Tabla 5.2. Especificaciones del aerogenerador Siemens modelo SWT $-2.3-108 \ldots \ldots . .79$

Tabla 5.3. Promedios mensuales de velocidades de vientos a $80 \mathrm{~m}$ de altura en la zona de

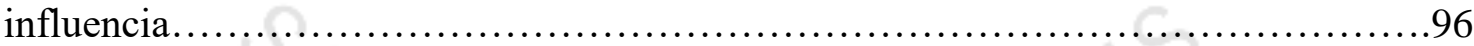

Tabla 5.4. Parámetro de rigurosidad $\mathrm{z}$ para diferentes tipos de terrenos................103

Tabla 5.5. Posibles fallas por equipo y acciones a tomar...........................113

Tabla 5.6. Programa de mantenimiento preventivo propuesto.......................114

Tabla 5.7. Producción den energía eléctrica en MWh anual de acuerdo a distintas velocidades del viento...................................................... 116

Tabla 5.8. Tipo de pérdidas................................................. 117

Tabla 5.9. Producción del parque eólico.........................................117 
Tabla 5.10. Porcentaje de Utilización de la Capacidad Instalada años 2015:2035

Tabla 7.1. Costos de obra civil ............................................ 143

Tabla 7.2. Costos de aerogenerador .......................................... 144

Tabla 7.3. Costos de la subestación..............................................144

Tabla 7.4. Costos de instalación eléctrica.......................................... 145

Tabla 7.5. Costos totales de ejecución.............................................145

Tabla 7.6. Inversión intangible.................................................... 146

Tabla 7.7. Inversiones y financiamiento...................................... 146

Tabla 7.8. Costos de capital de trabajo........................................147

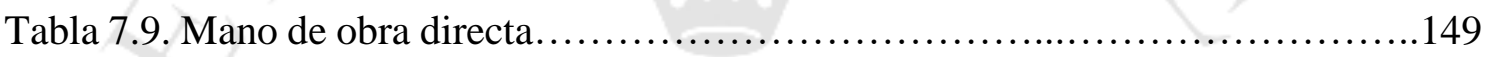

Tabla 7.10. Mano de obra indirecta........................................ 150

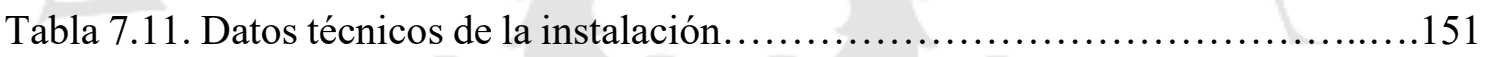

Tabla 7.12. Presupuesto de ingresos......................................... 151

Tabla 7.13. Mano de obra....................................................... 151

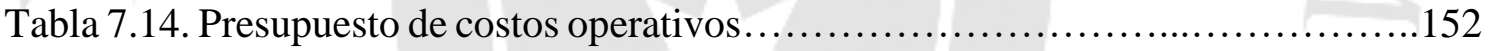

Tabla 7.15. Presupuesto de gastos administrativos en personal.....................153

Tabla 7.16. Presupuesto de gastos administrativos............................... 154

Tabla 7.17. Estado de resultados del FCE ....................................... 155

Tabla 7.18. Flujo de fondos económicos....................................156

Tabla 7.19. Cuadro de servicio de la deuda....................................157

Tabla 7.20. Estado de resultados del FCF.......................................158

Tabla 7.21. Flujo de fondos financieros FCF..................................... 159

Tabla 9.1. Valor agregado por años.......................................... 166 


\section{ÍNDICE DE FIGURAS}

Figura 2.1. Potencial eólico nacional.........................................

Figura 2.1. Participación regional de la cartera estimada de proyectos mineros...........10

Figura 2.3. Ubicación del proyecto de Ampliación Marcona............................12

Figura 2.4. Ubicación del proyecto Llama TY01 .................................13

Figura 2.5. Máxima demanda anual SEIN 2003-2013.............................. 15

Figura 2.6. Consumo de energía eléctrica per cápita en la región Ica...................16

Figura 2.7. Cantidad de clientes de energía eléctrica en la región Ica....................17

Figura 2.8. Producción y ventas de energía eléctrica en la región Ica...................17

Figura 2.9. Esquema de infraestructura eléctrica..............................19

Figura 2.10. Centrales eléctricas de generación mayores a 18 MW ...................21

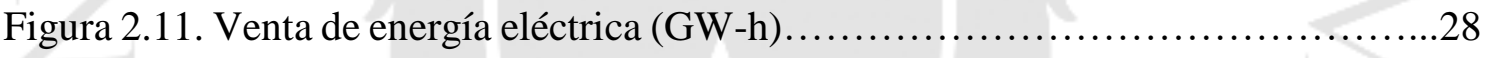

Figura 2.12. Venta de energía eléctrica a usuarios libres por actividad económica (GW-

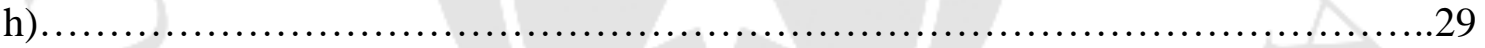

Figura 2.13. Tendencia histórica de precios..................................... 32

Figura 2.14. Precios medios del mercado libre por empresa..........................34

Figura 2.15. Precio de energía eléctrica por actividad económica.....................36

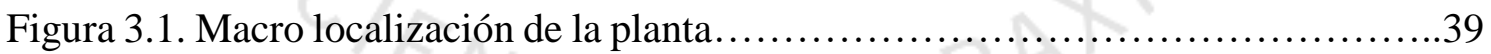

Figura 3.1. Distribución estadística de la velocidad del viento........................41

Figura 3.2. Ubicación del Distrito de Marcona...................................43

Figura 3.3. Ubicación del Distrito de Paracas.....................................44

Figura 3.4. Mapa eólico de Ica en primavera.....................................46

Figura 3.5. Mapa eólico de Ica en verano....................................46

Figura 3.6. Mapa eólico de Ica en otoño.....................................47 
Figura 3.7. Mapa eólico de Ica en invierno........................................47

Figura 3.8. Escala de medición de viento.......................................48

Figura 3.9. Ubicación de Mina Shougang......................................49

Figura 3.10. Minera ilegal en Paracas.........................................50

Figura 3.11. Mapa de la Reserva Natural de Paracas.................................54

Figura 3.12. Localización de la planta...........................................57

Figura 5.1. Modelo simple de un parque eólico.....................................62

Figura 5.2. Aerogenerador tipo Savonius.....................................63

Figura 5.3. Aerogenerador tipo Darrieus.....................................65

Figura 5.4. Aerogenerador con rotor Giromil....................................66

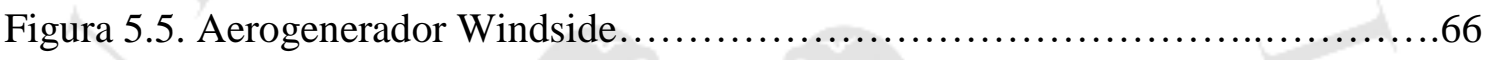

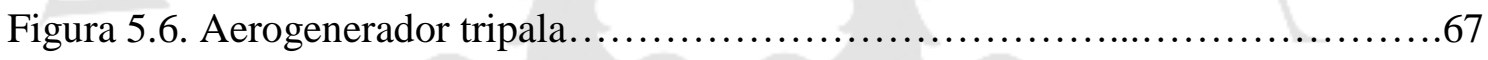

Figura 5.7. Aerogenerador bipala.........................................68

Figura 5.8. Aerogenerador monopala.........................................69

Figura 5.9. Aerogenerador tipo barlovento ....................................69

Figura 5.10. Aerogenerador tipo sotavento.................................. 70

Figura 5.11. Aerogeneradores de baja potencia.................................. 71

Figura 5.12. Aerogeneradores de potencia media y alta............................ 72

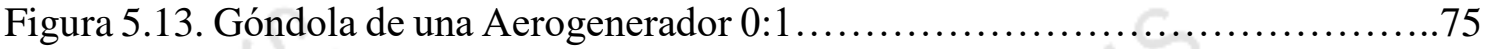

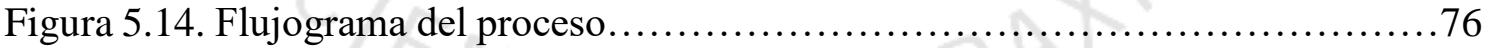

Figura 5.15. Características generales del aerogenerador...........................80

Figura 5.16. Parte interior de la góndola del aerogenerador Siemens SWT-2.3-108_.....81

Figura 5.17. Cable conductor de corriente....................................... 84

Figura 5.18. Aislador polimérico............................................ 85

Figura 5.19. Herrajes de acero forzado y hierro maleable .......................... 85

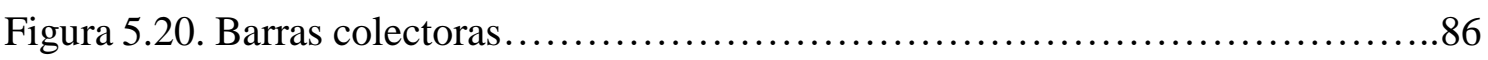


Figura 5.21. Interruptores de potencia......................................... 87

Figura 5.22. Transformador elevador de voltaje.................................88

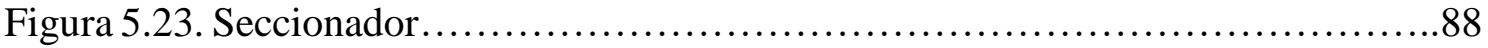

Figura 5.24. Autoválvulas.................................................... 89

Figura 5.25. Estructura de barras..............................................90

Figura 5.26. Curva de potencia de aerogenerador Siemens SWT-2.3-108..............93

Figura 5.27. Sentido de los vientos en la provincia de Marcona.........................97

Figura 5.28. Rosa de los vientos del parque eólico Tres Hermanas, Marcona.............98

Figura 5.29. Distribución Weibull de vientos en la provincia de Marcona................99

Figura 5.30. Mapa de densidad de potencia en la zona seleccionada...................101

Figura 5.31. Efecto colina de los vientos................................... 102

Figura 5.32. Diagrama unifilar del parque eólico y la subestación....................126

Figura 5.33. Distribución óptima del parque en un terreno plano.....................127

Figura 5.34. Distribución de la configuración de un parque sobre colinas redondeadas.128

Figura 5.35. Mapa de ubicación del parque eólico en la provincia de Marcona- Ica......129

Figura 5.36. Plano de distribución del parque.................................. 130

Figura 5.37. Diagrama de dimensiones del aerogenerador........................131

Figura 5.38. Plano de distribución: estación de control: 1er nivel....................132

Figura 5.39. Plano de distribución de la estación de control: 2 do nivel................133

Figura 6.1. Organigrama para el funcionamiento para la ejecución ...................137

Figura 6.2. Organigrama para el funcionamiento del proyecto.......................142 


\section{ÍNDICE DE ANEXOS}

Anexo 1: Determinación de la potencia disponible.................................179

Anexo 2: Distribución óptima de torres en un parque eólico........................180

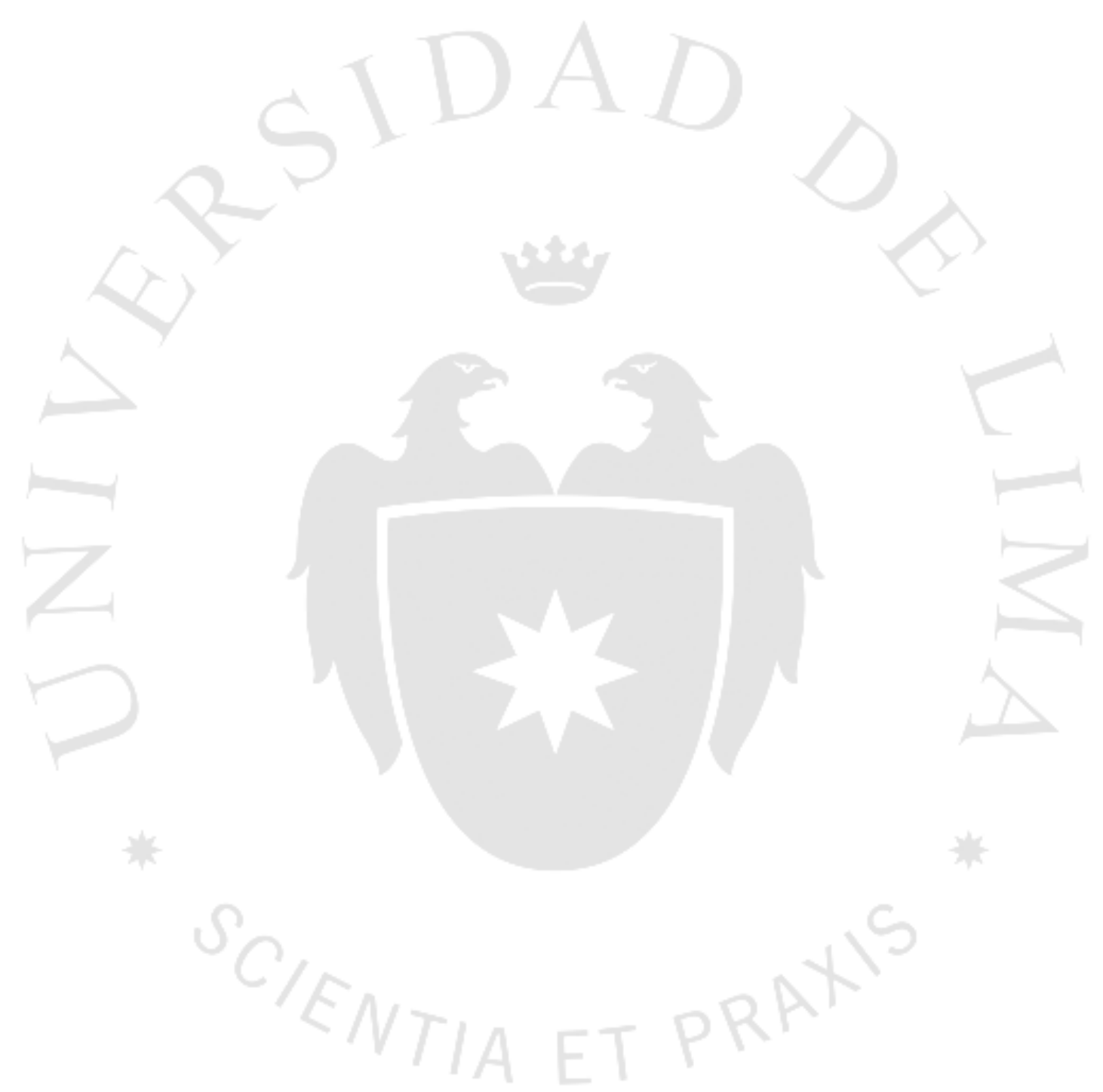




\section{RESUMEN EJECUTIVO}

En los últimos años, la preocupación por el medio ambiente y la búsqueda de nuevas alternativas de producción más limpia han cobrado gran importancia en todo el mundo. Además, la creciente demanda de energía hace que sea necesario desarrollar nuevas fuentes de energía menos contaminantes.

Durante los últimos años, el Perú ha estado experimentando un gran crecimiento económico, el cual se ve evidenciado con el crecimiento del PBI per cápita. Este crecimiento se debe al crecimiento de sectores como la minería, la industria, la construcción, el comercio y los servicios. Así como la economía del país ha ido en aumento en los últimos años, se ha experimentado un considerable crecimiento en el consumo de energía, el cual se relaciona directamente con el crecimiento económico. El servicio de electricidad es fundamental para el desarrollo productivo, económico y social para el país, es por ello que es importante la inversión en el desarrollo de nuevas fuentes de energía.

Las fuentes de energía que tienen mayor participación en el Perú son los hidrocarburos, seguidos de la energía hidráulica y el gas natural proveniente de la explotación de la reserva de gas de Camisea. Las dos últimas fuentes son las principales fuentes de energía eléctrica en el Perú, y ante las altas tasas de crecimiento de la demanda, muy pronto estas dos fuentes no serán suficientes para satisfacer la demanda del país. Teniendo en cuenta la situación actual, el país necesita diversificar su matriz energética para asegurar el abastecimiento energético, y la energía eólica se configura como una excelente oportunidad debido a su alto potencial en el país y el bajo nivel de impactos ambientales que genera.

En el presente informe, se realiza un estudio del desarrollo de una planta generadora de energía eólica en el territorio peruano. En el primer capítulo del informe se realizará una introducción a los aspectos generales del estudio y a los objetivos de la investigación. En el segundo capítulo del informe se realizará el estudio de mercado, donde se identificarán los principales competidores, la demanda que se espera satisfacer y el mercado objetivo. En el tercer capítulo del informe se identificará cuál es la mejor localización para el proyecto, teniendo en cuenta diversos factores. En el capítulo cuatro del informe se determina la capacidad del proyecto. En el quinto capítulo se describe 
detalladamente el proceso, y se determinan las máquinas y equipos que se utilizarán, así como la distribución física del proyecto. Finalmente, se realizará la evaluación económica y financiera para el proyecto. 


\section{EXECUTIVE SUMMARY}

In the last years, the concern about environment new alternatives and cleaner production have become more important in the world. Also, the growing demand of energy makes necessary to develop new and less polluted energy.

During the last years, Peru has experiment a high economic growth which have been lower in recent years but still remains one of the highest in Latin America. The growth is mainly by sectors like mining, trade and services. The energy consumption has been growing directly related with the economic growth. The electric service is fundamental for productive, economic and social development for the country and that's the reason why is important the substantial investment in new energy sources.

The sources of energy which have a greater participation in Peru are hydrocarbons, followed by hydropower and natural gas which comes from the Camisea gas reserves. The hydraulic energy and natural gas are the main sources of energy in Peru and the high growth rates in demand. Considering the current situation, the country needs to diversify its energetic matrix to ensure the energetic supplier. Therefore, the Eolic energy is an excellent opportunity due to the high potential in the country and the low environmental impact levels which generate.

In this report, a study was make for develop a wind power plant in Peru. In the first chapter, there is an introduction to show the general aspects and the research objectives. On the second chapter, there is a study about the market, where there is possible to identify the main competitors, the demand we want to satisfy and the target market.

The third chapter will identify which is the best location for the research, considering various factors. In the fourth chapter, the project's capacity is determined. Besides, in the fifth chapter there is a detailed description of the process, machines and equipment that will be used, as well as the physical layout of the project. The sixth chapter discusses about the administrative organization of the project. Finally, in the last chapters an economic, financial and social evaluation of the plant will be made. 


\section{ESTADO DEL ARTE}

En los últimos 10 años, el tipo de aerogenerador más usado a nivel mundial ha sido el tripala de eje horizontal que alimenta una red trifásica cuya potencia nominal es superior a los $5 \mathrm{MW}$ en la actualidad. Sin embargo, hay que diferenciar dos tipos de aerogeneradores: los sistemas onshore (puestos en tierra) y los offshore (aerogeneradores situados en ultramar), siendo los primeros los más usados debido a que representan un menor costo.

En lo referente a aerogeneradores offshore, uno de los modelos de más alta potencia es Sea Titan 10 MW Wind Turbine. Esta máquina fue diseñada por la compañía americana AMSC y hasta diciembre 2014 ha sido la turbina generadora de vientos más grande a nivel mundial. Algunas de las especificaciones técnicas tomadas de la página web de la compañía están que es una turbina de accionamiento directo, de $190 \mathrm{~m}$ de diámetro de rotor, con capacidad de potencia nominal de $10 \mathrm{MW}$ y una altura de buje de $125 \mathrm{~m}$. La turbina incorpora un generador superconductor a alta temperatura (HTS) con velocidad de $10 \mathrm{rpm}$ que es mucho más pequeño y liviano que un aerogenerador convencional. La fase de diseño empezó en el 2010 y recién culminó en el 2012 y ha sido probado por la marina de EEUU en condiciones marítimas duras.

Entre las ventajas comparativas que posee el Sea Titan 10 MW que se mencionan en el brochure del modelo publicado en su página web están:

- El tipo de cable utilizado: el Amperium de AMSC, que tiene un menor costo y peso ligero, es usado para los rotores HTS en vez de cables de cobre. Estos cables pueden llevan 100 veces más potencia que uno de cobre de dimensiones similares además posee un generador más pequeño, liviano y eficiente que tiene el ratio de potencia-peso más alto del mercado.

- Accionamiento directo: que reduce la necesidad de mantenimiento ya que no usa caja de cambio que es uno de los componentes de turbinas de viento que requieren más mantenimiento y extremadamente costoso para hacerlo en el océano. Además de que ya no se necesita acoplamientos con el accionado directo. 
- Alta eficiencia de generación offshore: La turbina está conectada al generador superconductor a través de una red con un convertidor de escala completa. El convertidor basado en un IGBT con una electrónica de potencia avanzada asegura que el generador trabaja con una alta eficiencia durante toda la gama de revoluciones.

- El sistema avanzado de monitoreo de condición wtCMS de AMSC ofrece una observación continua de los componentes clave del sistema y le da al operador información en tiempo real del estado de las turbinas así como un análisis completo de las herramientas que optimizan las actividades de mantenimiento.

Por otro lado, entre los aerogeneradores onshore líderes en el mercado la empresa española Gamesa ha desarrollado el prototipo de un nuevo aerogenerador de $5 \mathrm{MW}$ de potencia nominal. De acuerdo a su página web, éste tiene un rotor de $132 \mathrm{~m}$ y alcanza una altura total de $186 \mathrm{~m}$. El primer parque eólico equipado con estos generadores se situó en la ciudad costera de Salo, Finlandia, con una potencia instalada de $15 \mathrm{MW}$. El montaje empezó en agosto del 2014 y su puesta en marcha se realizó dos meses después. Para tener en cuenta la potencia, una sola turbina genera energía eléctrica para unos 5000 hogares.

Esta empresa viene desarrollando un aerogenerador de igual potencia pero con un largo de palas inferior longitud el cual alcanzaría un diámetro total de $128 \mathrm{~m}$ que tienen un estimado de electricidad neta de 17.710 MWh/año en un cliente europeo promedio final conectado a $132 \mathrm{kV}$ y considerando un $2 \%$ de núcleo de pérdidas entre el aerogenerador y el punto de conexión de red eléctrica y un $2.2 \%$ de pérdidas aguas abajo adicionales para transmisión y distribución de la electricidad desde el punto de conexión común a un cliente final.

De acuerdo a la descripción medioambiental del producto, publicado en mayo del 2015, las ventajas que tiene este modelo son:

- Ofrece una confianza superior:

- El diseño modular de la nacelle y de las aspas se centra en minimizar el tiempo inactivo.

- Conduzca el tren sin componentes giratorios de alta velocidad. 
○ Cumple con requerimientos de construcción y logística similar a los de GAMESA 2.0-2.5 MW.

- Optimiza el costo de energía:

○ Mayor producción para proyectos con espacio limitado.

○ Optimización de la posición energética.

- Cumple con los requisitos de conexión a red más exigentes: Óptimos de red con tecnología de generador de imanes permanentes + convertidor completo.

- Cumple con las regulaciones ambientales:

○ Reduce el impacto visual.

- Tecnología de reducción de ruidos: Con el sistema Gamesa NRS y un nuevo perfil de palas aerodinámicas.

Asimismo, cabe mencionar algunos diseños vanguardistas y con un alto potencial de comercialización en el futuro. Un modelo innovador de turbina eólica es el sistema llamado BAT.

"Este es capaz de flotar en el aire al estar instalada en un globo especial con forma de cilindro, permite disponer de un aerogenerador fácil de transportar, a diferencia de las torres plantadas en tierra, y aprovecha la mayor fuerza y estabilidad que suelen poseer los vientos a gran altura, sin tener que construir torres altísimas. De hecho, los aerogeneradores de este tipo pueden operar a mayor altura que las torres eólicas más altas que existen. Los aerogeneradores aerostáticos de la empresa Altaeros Energies, fundada por Ben Glass y Adam Rein, dos antiguos alumnos del Instituto Tecnológico de Massachusetts (MIT) en Cambridge, Estados Unidos, son los primeros comerciales de su clase que se han creado en el mundo." (Matheson, 2014, p.23)

Este tipo de aerogenerador ha demostrado producir el doble de energía que las turbinas de tamaño parecido montadas en torre de tamaño parecido. Esto se debe a que pueden alcanzar alturas mucho mayores de 300 a $600 \mathrm{~m}$ donde los vientos soplan con una fuerza de 5 a 8 veces mayor, así como un modo más continuado que los vientos en la cima de las torres a una altura típica entre 30 y 90 metros. Para obtener el viento más fuerte posible, tres cables conectan el BAT a una estación terrestre giratoria que regula la altura 
y la dirección. La transmisión de la energía generada por las turbinas se hace a través de uno de los cables a la estación terrestre.

El primer programa piloto del proyecto BAT se instalará al sur de Fairbanks, Alaska. Donde la población rural que depende de generadores eléctricos de combustible paga hasta 1 dólar por kilovatio-hora y se espera que el BAT instalado con una capacidad de 30 kilovatios, el costo se reduzca hasta unos 18 centavos. Además, con una altura de 300m, el proyecto piloto a escala comercial de Alaska será 83 metros que la turbina eólica que ostenta este record (Vestas, V164-8.0MW).

A pesar de la eficiencia, este aerogenerador no está diseñado para reemplazar a turbinas convencionales sino más bien para llevar energía a áreas remotas desconectadas de grandes redes eléctricas donde las torres eólicas no son prácticas ni factibles económicamente. Además podrá proporcionar cobertura de datos, servicios de telefonía móvil y datos meteorológicos locales. "El proyecto está diseñado para reducir significativamente el alto costo de energía en áreas remotas" (Altaeros Energies, 2014).

Otra innovación en lo referente a aerogeneradores son los molinos de viento sin aspas Vortex. "Consiste en una estructura cilíndrica hueca que se interpone al curso de un fluido como el viento. El fluido forma un patrón cíclico de remolinos de viento espiral que azotan la estructura y la hacen oscilar de un lado a otro...para ello se ha creado Vortex, un aerogenerador sin palas que oscila de un lado a otro de acuerdo con el viento para captar la energía cinética." (Alameda, 2014, pag.24)

De acuerdo al MIT Review, entre las ventajas que presenta están:

- Ahorro en costos de fabricación y transporte: que al no usar palas el molino elimina muchas partes móviles y mecánicas lo que reducirá los costes de fabricación y explotación de energía eólica. Se estima una disminución de costes en el proceso de construcción de un 53\% menos frente a un aerogenerador normal. Además, al tener menos materiales su transporte es mucho más sencillo y al no tener engranajes, no necesita aceite generando una menos huella de carbono.

- Arranque con velocidades de viento menores: Arranca a partir de una velocidad de viento de $1 \mathrm{~m}$ por segundo menor a la de los molinos tradicionales (usualmente $3 \mathrm{~m}$ por segundo). Esta característica le permite generar energía en un rango mayor de velocidades. 
- No necesita un sistema de orientación hacia el viento: Al tener una forma cilíndrica elimina la necesidad de orientar el aerogenerador en dirección a las corriente de aire como sí lo hacen los molinos con palas. La desventaja es que la energía resultante sería un $30 \%$ menor a la de un molino tradicional.

- Reduce el impacto ambiental: Vortex tiene un diseño menos invasivo al paisaje natural, la ausencia de palas lo hacen menos peligroso para las aves y no hace ruido lo que convierte al diseño innovador amigable con el medio ambiente. 


\section{CAPÍTULO I: ASPECTOS GENERALES}

1.1.Objetivos de la investigación y justificación del tema

\subsubsection{Objetivo general}

Determinar la viabilidad de mercado, económica, tecnológica y financiera para la implementación de una planta generadora de energía eléctrica a partir de una fuente eólica.

\subsubsection{Objetivos específicos}

a) Evaluar la viabilidad técnica del proyecto.

b) Determinar si el proyecto es económica y financieramente viable.

c) Identificar y evaluar el mercado de energía eólica existente en el Perú.

d) Identificar la localización idónea para la realización del proyecto.

\subsubsection{Justificación técnica}

El Perú es mundialmente uno de los países más aptos para generar energía eólica en su costa. A causa de una zona de alta presión en el Pacífico Sur que cambia su posición muy poco durante el año, el viento es muy constante y considerablemente fuerte. Es más, se considera que las condiciones peruanas para el desarrollo de este tipo de energía son más favorables que en los países del norte de Europa, donde en algunos países la energía eléctrica producida por fuentes eólicas ya ha superado el 10\% de la energía eléctrica total producida (Deltavolt, 2010). 
Además, existe una gran cantidad de tecnologías para la generación de este tipo de energía, las cuales no producen emisiones durante su operación y consisten principalmente en turbinas que transforman la energía cinética del viento en energía mecánica que luego se convierte en energía eléctrica por medio de un generador. Estos sistemas eólicos tienen un tiempo de vida útil cercano a los 25 años, y pueden ser clasificados según el lugar donde son instalados: onshore (ubicados en tierra firme) y offshore (ubicados en mar abierto).

Entre las tecnologías onshore más utilizadas se pueden mencionar: el síncrono bipolar, el síncrono multipolar, el síncrono de polos variables, los imanes permanentes y el asíncrono. Mientras que como tecnología offshore se puede encontrar el eje horizontal de tres aspas, el cual puede generar hasta 50\% más que los generadores onshore debido a los elevados vientos que podría captar, pero su costo de inversión es considerablemente más alto. Por otro lado, se pueden mencionar sistemas eólicos de baja potencia que generan energía en menor escala y están orientadas a satisfacer demandas menores sin conexión a la red de distribución local, algunas de estas tecnologías que se pueden mencionar son: el eje horizontal de tres aspas, el eje horizontal de varias aspas, el eje vertical Darrieus, el eje vertical Panémona y el eje vertical Savonius.

La eficiencia de conversión teórica máxima de estos sistemas es de 59\%, pero en realidad, la eficiencia siempre será menor a este límite. Sin embargo, la eficiencia del proceso cobra menor relevancia si se considera que el recurso es gratuito.

\subsubsection{Justificación económica}

El gran crecimiento que han estado experimentado sectores económicos como la minería y la industria, implican un gran aumento en la demanda de energía. Además, se estima que para los próximos 25 años la demanda estará por encima de la oferta, a menos que se encuentre una gran cantidad de nuevas fuentes de energía más amigables con el medio ambiente, como la propuesta en este estudio (MINEM, 2010). Es por ello que se puede afirmar que existirán 
personas interesadas en invertir en proyectos como este; y considerando la creciente demanda de energía para los próximos años, se podría estimar una demanda para el proyecto lo suficientemente grande para obtener los beneficios económicos esperados.

\subsubsection{Justificación social}

La energía eólica es un tipo de energía renovable, es limpia ya que no emite gases de efecto invernadero, debido a que no es necesaria la combustión ni la fusión de combustibles. Además, el impacto ambiental de las instalaciones eólicas es muy pequeño ya que el ruido que genera es muy pequeño, el cual incrementa a medida que incrementa el ruido del viento, pero a su vez incrementa el ruido ambiental. A diferencia de la minería, no hay necesidad de grandes movimientos de terrenos, ni arrastre de sedimentos, ni alteración de cauces de agua, ni generación de residuos residuales.

Por otro lado, la energía eólica puede proporcionar muchos puestos de trabajo y es compatible con otras actividades humanas debido a su escasa ocupación real de terreno, con lo cual proporciona diversificación rural y empleo local en la zona donde se ejecute, así como la facilidad de integrarse a las redes de potencia ya existentes. Además, su impacto sobre la salud pública es muchísimo menor que el de otras fuentes energéticas convencionales, como el carbón y petróleo.

\subsection{Hipótesis del trabajo}

La instalación de una planta generadora de energía eléctrica a partir de una fuente eólica es factible, pues existe un mercado que va a aceptar el servicio y además es tecnológica, económica y financieramente viable.

1.3. Marco referencial de la investigación 
a) Estudio de pre-factibilidad para la generación de energía eléctrica mediante la instalación de dos centrales hidroeléctricas de $720 \mathrm{~kW}$ y $1330 \mathrm{~kW}$ aprovechando las rápidas artificiales de la irrigación Santa Rosa. Guillermo Enrique Cox Harman, Lima, 2002.

Esta tesis se basa en el desarrollo de mini centrales hidroeléctricas, y al igual que el tema propuesto, se plantea la generación de un tipo de energía renovable no convencional, pero no es una alternativa tan limpia como la energía eólica.

b) Estudio de pre-factibilidad para instalar una serie de pequeñas plantas de energía solar en las zonas de Chepén y Pacasmayo. Fabricio Humberto Paredes Larroca, Lima, 2000.

Este estudio se basa en el desarrollo de plantas de energía solar en determinados lugares geográficos, y al igual que el estudio anterior, plantea la generación de un tipo de energía renovable no convencional, y puede ser muy útil para el presente estudio. Sin embargo, no brinda información directa sobre el tema de energía eólica, ya que se centra en el desarrollo de la energía solar.

c) Estudio de pre-factibilidad para la producción industrial de aerobombas. Lidia Minerva Mayorga Silva, Lima, 2005.

Este estudio proporciona amplia información sobre uno de los principales insumos para la implementación de una planta generadora de energía eólica. Por ello, esta tesis será de gran utilidad para la obtención de información sobre las aerobombas, ya que presenta puntos sobre las importaciones y exportaciones de estos equipos, así como la factibilidad de producirlos. 


\section{CAPÍTULO II: ESTUDIO DE MERCADO}

2.1. Aspectos generales del estudio de mercado

\subsubsection{Definición del servicio}

El servicio propuesto para el estudio consiste en el abastecimiento de energía eléctrica generada a partir de una fuente eólica, a clientes regulados como a clientes libres. La energía eléctrica generada será distribuida a los clientes finales a través de redes de transmisión y redes de distribución operadas por terceros.

Además, se brindarán servicios como: una rápida y efectiva atención de nuevos suministros o ampliación de capacidad, respuestas rápidas ante emergencias en las instalaciones de energía, servicios de mantenimiento, atención personalizada a cargo de un equipo de profesionales expertos. Así mismo, se contará con un servicio de atención telefónica, donde un equipo especializado atenderá sin demoras y con amabilidad, las 24 horas del día y los 365 días del año, consultas comerciales y atención de emergencias que se presenten.

\subsubsection{Principales características del servicio}

\subsubsection{Usos y propiedades}

La electricidad tiene muchos usos en la vida cotidiana y en la industria, es más, debido a su capacidad de adaptación, en el mundo moderno no existe ninguna actividad económica que no utilice electricidad. Esta es utilizada en las fábricas para el funcionamiento de casi todas las máquinas del proceso productivo y para el alumbrado de las instalaciones. En las oficinas, su aplicación es fundamental para el funcionamiento de sistemas de procesamiento de la información y de telecomunicaciones. En los hogares, la electricidad es muy utilizada para fines térmicos como calefacción y aire acondicionado, además el 
único tipo de energía empleada para el alumbrado y el uso de electrodomésticos.

La utilización de energía eólica para la generación de electricidad, trae consigo muchos beneficios en comparación con otro tipo de fuentes de energía. Entre las principales diferencias son que la energía eólica es una energía limpia, no contamina y sobre todo es inagotable ya que se nutre única y exclusivamente del viento para la generación de electricidad. Además, en su producción se evita la generación de gases tóxicos que contribuyen al efecto invernadero y a la lluvia ácida.

\subsubsection{Servicios sustitutos y complementarios}

Los principales servicios sustitutos para la energía eólica, son otras fuentes de energía eléctrica tanto las renovables como las no renovables. En el Perú es un país con un gran potencial para la generación de energías renovables no convencionales como la energía solar, la energía marítima, la energía geotérmica y la biomasa. Además de las principales fuentes actuales de energía del Perú, como las hidroeléctricas y los combustibles fósiles como el gas natural y el petróleo.

Por otro lado, se puede suponer que la energía eléctrica no posee bienes o servicios complementarios ya que su consumo no se ve afectado por la variación del precio de ningún otro bien o servicio.

\subsubsection{Definición del área de influencia del servicio}

Para la definición del área de influencia del servicio, se realizará un análisis de la situación eólica del Perú, para determinar las regiones en las cuales existe un mayor potencial eólico. Luego de determinar las regiones con el mayor potencial eólico, se analizarán la existencia de proyectos futuros en esas regiones y se compararan. De este modo, se determinará como el área de influencia del servicio, aquella región con un alto potencial eólico y con un alto número de proyectos a realizarse en el futuro. 
La selección del área de influencia del servicio, se realizará del modo descrito en el párrafo anterior, debido al tipo de servicio planteado. Se estima conveniente que el área de influencia del servicio sea la misma que el área donde está localizado el proyecto ya que así se evitarán pérdidas por las largas distancias que deberá recorrer la energía.

A continuación, se presentará una figura y un cuadro, en los cuales se resume el potencial eólico de cada una de las regiones del Perú. Con ello, se seleccionarán las dos mejores alternativas para luego identificar el número de proyectos a realizarse en el futuro en esas regiones y así determinar en cuál de las regiones habrá un mayor requerimiento de energía.

Figura 2.1.

Potencial eólico nacional

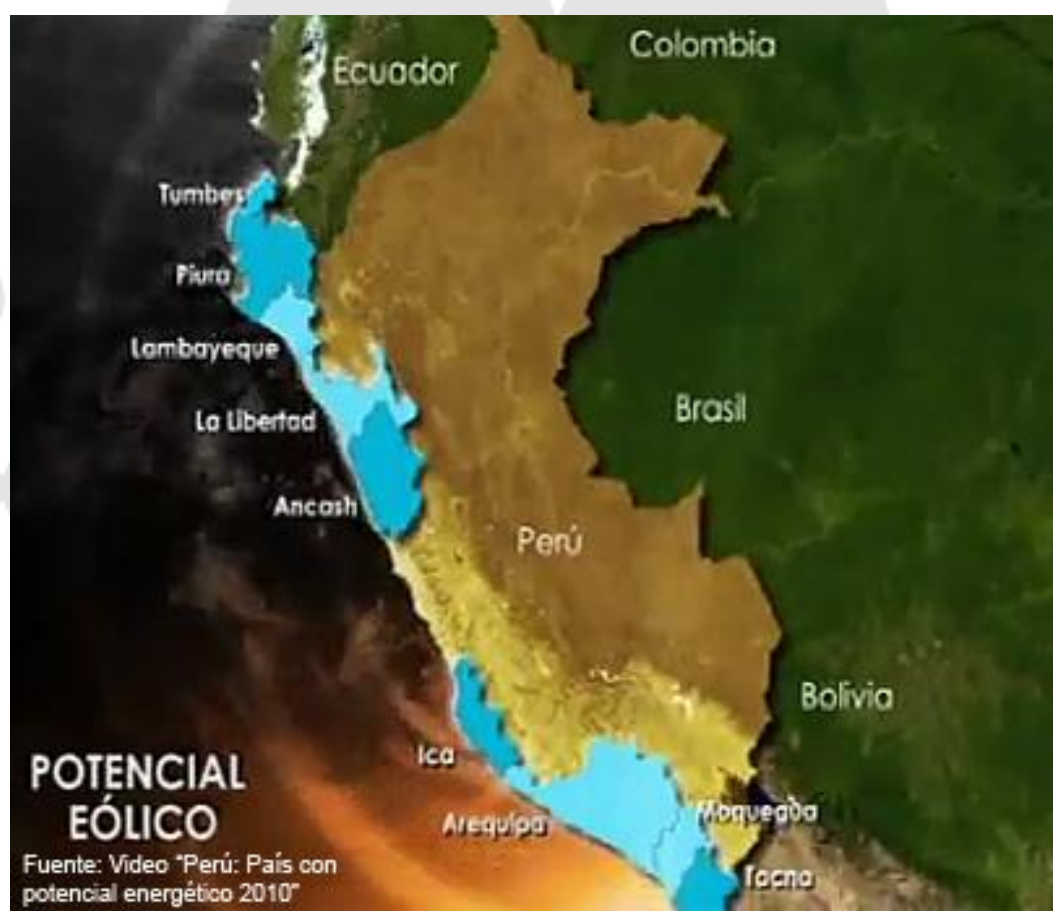

Fuente: Atlas Eólico del Perú 
Tabla 2.1.

Potencial eólico nacional

\begin{tabular}{|c|c|c|}
\hline Departamento & $\begin{array}{c}\text { Potencia Total } \\
(\mathrm{MW})\end{array}$ & $\begin{array}{c}\text { Potencia Aprovechable } \\
\text { (MW) }\end{array}$ \\
\hline Amazonas & 1380 & 6 \\
\hline Ancash & 8526 & 138 \\
\hline Apurímac & 0 & 0 \\
\hline Arequipa & 1992 & 1158 \\
\hline Ayacucho & 114 & 0 \\
\hline Cajamarca & 18360 & 3450 \\
\hline Callao & 0 & 0 \\
\hline Cuzco & 0 & 0 \\
\hline Huancavelica & 0 & 0 \\
\hline Huánuco & 54 & 0 \\
\hline Ica & 18360 & 9144 \\
\hline Junín & 48 & 0 \\
\hline La Libertad & 4596 & 282 \\
\hline Lambayeque & 2880 & 564 \\
\hline Lima & 1434 & 156 \\
\hline Loreto & 0 & 0 \\
\hline Madre de Dios & 0 & 0 \\
\hline Moquegua & 144 & 0 \\
\hline Pasco & 0 & 0 \\
\hline Piura & 17628 & 7554 \\
\hline Puno & 162 & 0 \\
\hline San Martín & 504 & 0 \\
\hline Tacna & 942 & 0 \\
\hline Tumbes & 0 & 0 \\
\hline Ucayali & 0 & 0 \\
\hline TOTAL PERU & 77124 & 22452 \\
\hline
\end{tabular}

Fuente: Atlas eólico del Perú

A partir de los datos presentados anteriormente, se puede concluir que las dos regiones con más potencial eólico en el país son: Piura e Ica. A continuación, se presentará el número de proyectos mineros a realizarse en cada una de estas regiones para los próximos años. Se decidió tomar como base para el estudio el número de proyectos mineros debido a que este tipo de proyectos son los que más necesidad de energía tienen, y además son los que mayores ingresos generan a las regiones. 
A continuación, se presentará una imagen y un cuadro con la los proyectos mineros estimados para los próximos años en el Perú.

Tabla 2.2.

Participación regional de la cartera estimada de proyectos mineros

\begin{tabular}{lcc}
\hline Región & US\$ MM & $\%$ \\
\hline Apurimac & 11860 & $20.66 \%$ \\
Arequipa & 10200 & $17.77 \%$ \\
Cajamarca & 9132 & $15.91 \%$ \\
Moquegua & 6120 & $10.66 \%$ \\
Junín & 5760 & $10.03 \%$ \\
Cusco & 2736 & $4.77 \%$ \\
Piura & 2645 & $4.61 \%$ \\
Ica & 2463 & $4.29 \%$ \\
Lambayeque & 1599 & $2.79 \%$ \\
Ancash & 1220 & $2.13 \%$ \\
Puno & 920 & $1.60 \%$ \\
Huancavelica & 630 & $1.10 \%$ \\
Tacna & 600 & $1.05 \%$ \\
La Libertad & 400 & $0.70 \%$ \\
Ayacucho & 370 & $0.64 \%$ \\
Huánuco & 350 & $0.61 \%$ \\
Pasco & 305 & $0.53 \%$ \\
Lima & 93 & $0.16 \%$ \\
TOTAL US\$ & & \\
MM & $\mathbf{5 7 4 0 3}$ & $\mathbf{1 0 0 \%}$ \\
\hline Fuente: MINEM & &
\end{tabular}


Figura 2.2.

Participación regional de la cartera estimada de proyectos mineros

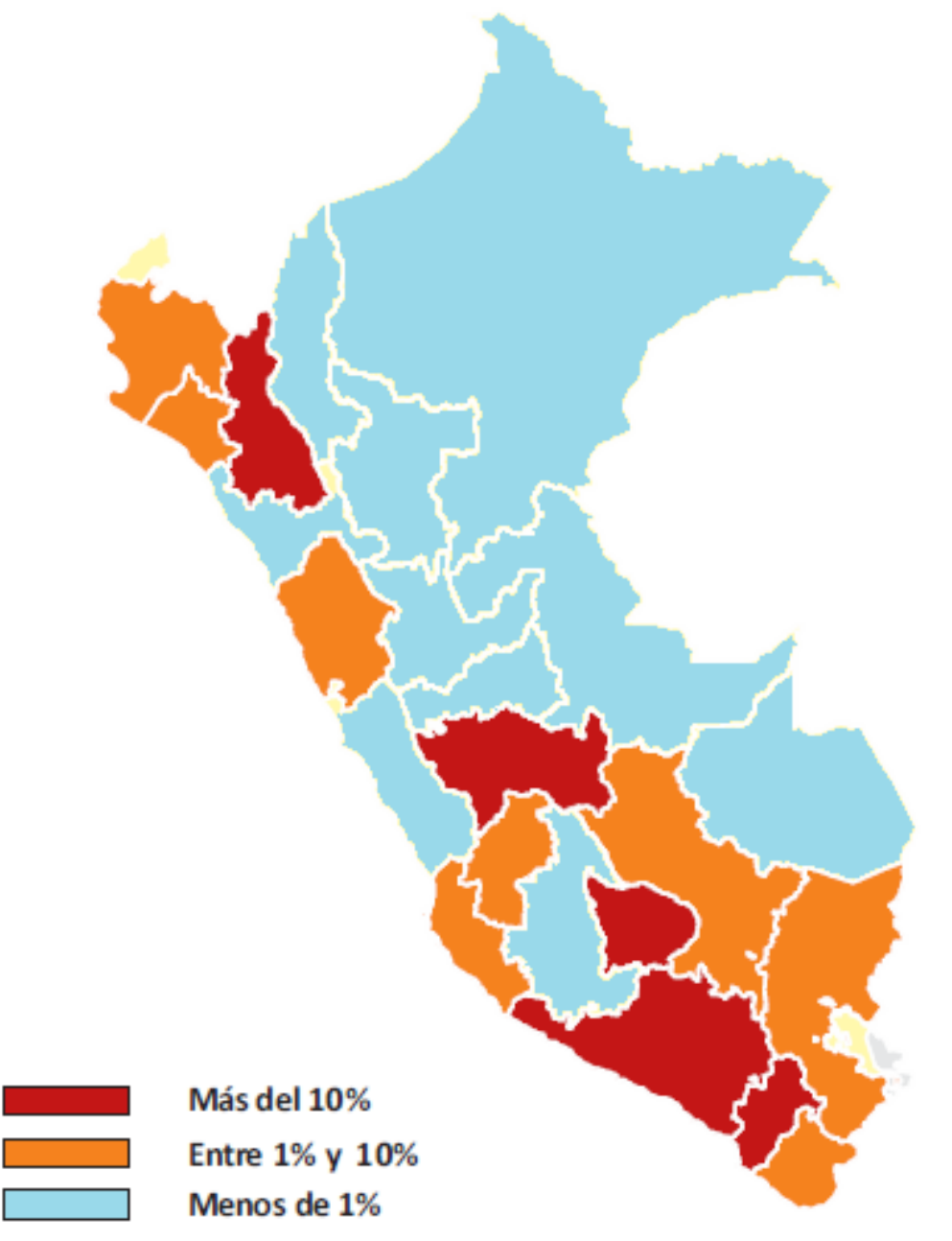

Fuente: MINEM

En la información presentada anteriormente se observa que tanto como para la región de Piura como para la de Ica la participación en la cartera estimada de proyectos mineros se encuentra entre el $4 \%$ y $5 \%$. Es por ello, que se puede suponer que considerando la cantidad de proyectos mineros, la elección de cualquiera de las dos regiones será indistinta.

En vista que la cantidad de proyectos mineros en ambas regiones es similar, se elegirá a la región con mayor potencial eólico aprovechable. Por lo tanto, el área de influencia del servicio será la región de Ica. 


\subsection{Análisis de la demanda}

2.2.1. Cuantificación de los posibles mercados objetivos

En la región de Ica, existen cuatro proyectos mineros a realizarse en el futuro, los cuales representan el mercado objetivo para este servicio. A continuación, se presenta una breve descripción de cada uno de estos cuatro proyectos.

- Proyecto Ampliación Marcona

El yacimiento minero de Marcona es el único productor mineral de hierro en el Perú, y se encuentra ubicado en la localidad con el mismo nombre en la provincia de Nazca, Ica. Actualmente, este yacimiento es explotado por la empresa Shougang Hierro Perú S.A.A. de capitales chinos. Actualmente, el yacimiento opera a 8 millones de toneladas de hierro al año, pero con este proyecto de ampliación, el cual ya fue aprobado por el Ministerio de Energía y Minas, se espera incrementar la capacidad a 10 millones de toneladas anuales.

Según un estudio realizado por el Ministerio de Energía y Minas, (MINEM, 2013) estima que la vida útil del proyecto será de 13 años de producción anual de 10 millones de toneladas de hierro concentrado anuales, ya que el yacimiento posee un potencial de 15000 millones de toneladas de mineral de hierro, clasificado en óxido y primario. Se estima que Shougang realizará una inversión de 1480 millones de dólares, para la ampliación del yacimiento Marcona y la planta de beneficio de la mina. Se espera que el proyecto se dé inicio en el año 2014, y se requerirá alrededor de 3500 trabajadores para la realización del proyecto, y cuando se finalice la etapa de construcción, se necesitará emplear a alrededor de 958 persona y se proyecta que se necesitará alrededor de $240 \mathrm{MW}$ de potencia anuales. 
Figura 2.3.

Ubicación del proyecto de Ampliación Marcona

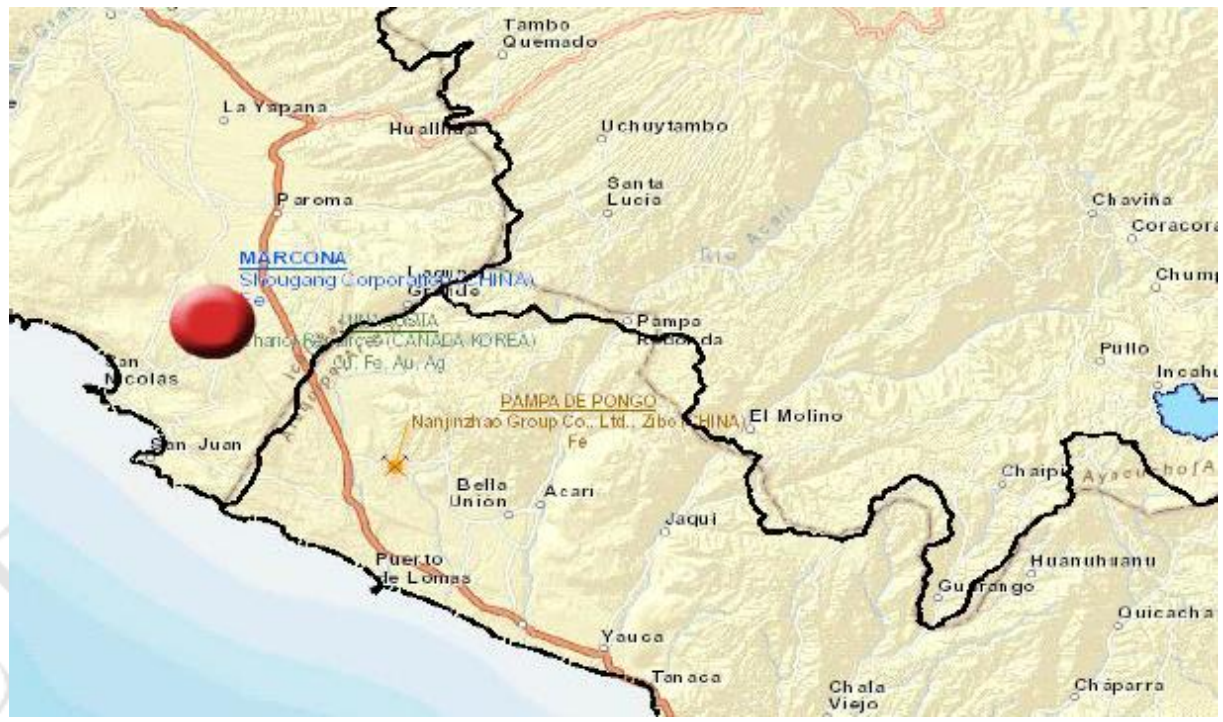

Fuente: MINEM

- Proyecto Explotación de relaves

Este nuevo proyecto se llevará a cabo por la empresa de nombre Minera Shouxin Perú, cuyo accionario está constituido por la empresa Baiyin Nonferrous Group con el $51 \%$ de participación y Shougang Hierro Perú con el 49\%. Esta nueva empresa, que ya tiene el Estudio de Impacto Ambiental aprobado, buscará aprovechar los relaves mineros generados por Shougang en Marcona. La planta contará con una capacidad instalada para procesar 6.8 millones de toneladas de relaves anuales, con una vida útil estimada de 20 años. El proyecto tendrá una inversión de 240 millones de dólares, y se estima que tendrá una producción anual aproximada de 10 millones de toneladas de concentrado de cobre, hierro y zinc. Se espera que el inicio de operaciones sea en el año 2016 (MINEM, 2013).

- Proyecto Marcobre (Mina Justa)

Marcobre es un proyecto de extracción de mineral de cobre, ubicado en el distrito de Marcona, en la provincia de Nazca en la región de Ica. El proyecto es realizado por la empresa Marcobre S.A.C. cuya cartera 
accionaria está compuesta por el Grupo Brescia al 70\%, Korea Resources al $15 \%$ y LS-Nikko Copper al 15\%. Actualmente, el proyecto se encuentra en etapa de exploración y se espera que inicie sus operaciones a fines del año 2016. La inversión realizada para el proyecto bordea los 744 millones de dólares, y se estima que su producción anual será de 110000 toneladas de cobre anuales, y la potencia eléctrica que requerirá será de $30 \mathrm{MW}$ (MINEM, 2013).

- Proyecto Llama TY01

Este proyecto minero es ejecutado por la empresa Jintong Mining Perú S.A.C. de capitales $100 \%$ chinos, y se desarrolla en los distritos de Huancano y Humay en la provincia de Pisco en la región de Ica. Este proyecto aún se encuentra en etapa de exploración y no hay una fecha definida para el inicio de operaciones, pero se estima que hay una gran reserva de mineral oro (MINEM, 2013).

Figura 2.4.

Ubicación del proyecto Llama TY01

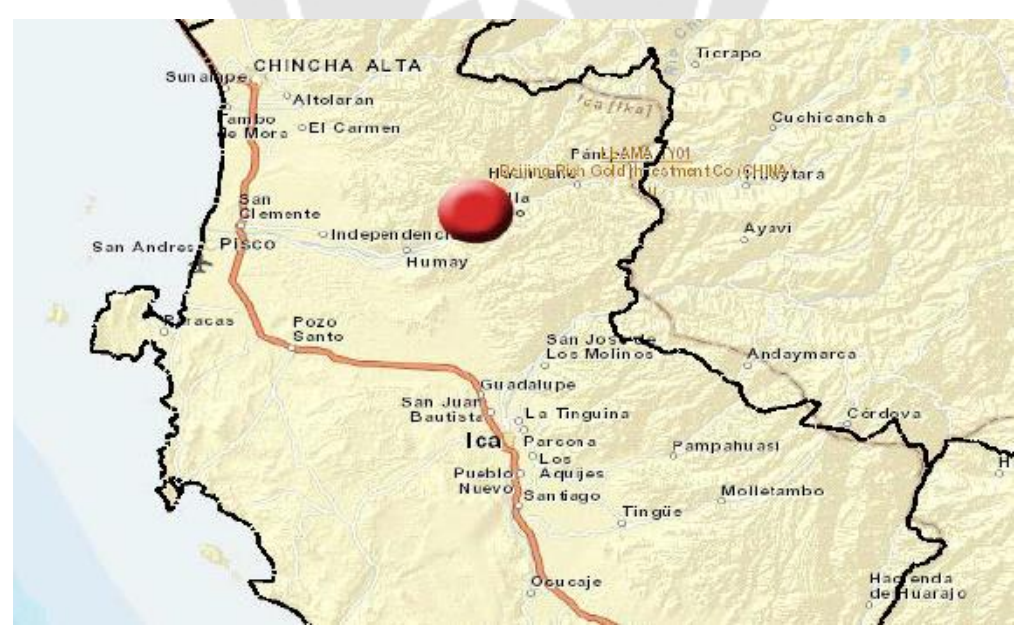

Fuente: MINEM 


\subsubsection{Demanda potencial}

La demanda potencial del proyecto se calculará en base a la potencia energética requerida de los proyectos mineros a realizarse en la región de Ica, los cuales fueron descritos en la sección anterior.

A continuación, se muestra una tabla en la cual se presentan las potencias energéticas requeridas de todos los proyectos mineros que se realizarán en la región de Ica en los próximos años.

Tabla 2.3.

Potencia requerida de los proyectos mineros en Ica

\begin{tabular}{lc}
\hline \multicolumn{1}{c}{ Proyecto Minero } & Potencia Requerida (MW) \\
\hline Proyecto Ampliación Marcona & 240 \\
Proyecto Explotación de Relaves & - \\
Proyecto Marcobre & 30 \\
Proyecto Llama TY01 & - \\
TOTAL & 270 \\
\hline
\end{tabular}

Fuente: MINEM

Cabe resaltar que las potencias requeridas para el Proyecto Explotación de relaves y para el Proyecto Llama TY01 son desconocidas, ya que debido a las etapas en las que se encuentran ambos proyectos no se ha podido determinar el requerimiento exacto. Es por ello, que se considerará como demanda potencial será la de los proyectos con potencia eléctrica requerida conocida. Con ello, se concluye que la demanda potencial será mayor a los $270 \mathrm{MW}$.

\subsubsection{Proyección de la demanda histórica}

Para el análisis de la demanda histórica del servicio, se ha tomado como referencia la máxima demanda anual del Sistema Eléctrico Interconectado Nacional (SEIN) de los últimos diez años, el cual se presenta a continuación. 
Figura 2.5.

Máxima demanda anual SEIN 2003-2013

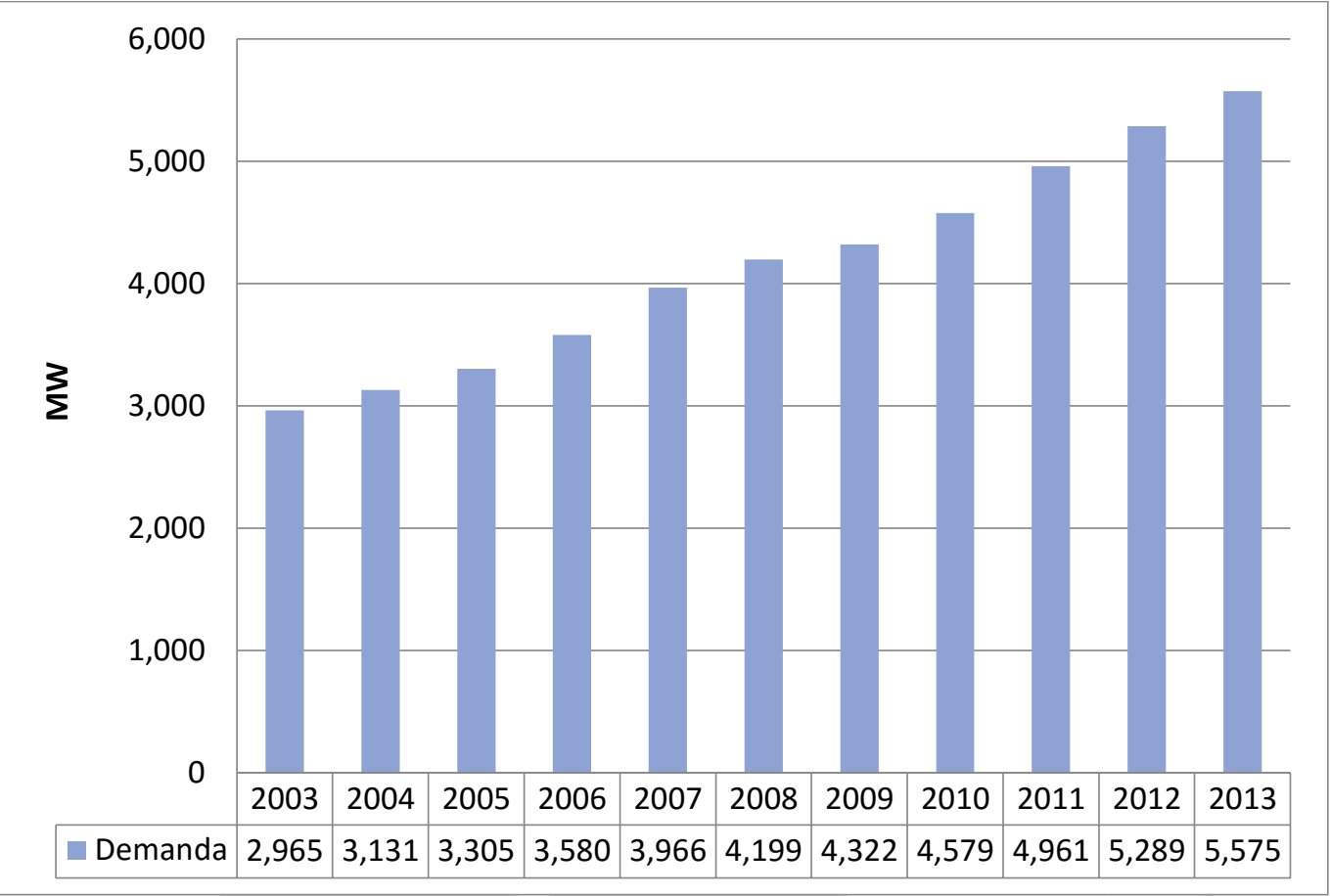

Fuente: MINEM

Además, se tomaron como referencia algunos indicadores sobre el consumo eléctrico en la región de Ica entre los años 2007 y 2013. Los cuales se muestran a continuación. 
Tabla 2.4 .

Indicadores del sector eléctrico de la región Ica

\begin{tabular}{|c|c|c|c|c|c|c|c|}
\hline Año & 2007 & 2008 & 2009 & 2010 & 2011 & 2012 & 2013 \\
\hline $\begin{array}{l}\text { Consumo de energía } \\
\text { eléctrica (GW-h) }\end{array}$ & $1,716.7$ & $1,605.4$ & $1,711.3$ & $1,928.3$ & $2,022.9$ & $2,122.8$ & $2,406.5$ \\
\hline $\begin{array}{l}\text { Consumo de energía } \\
\text { eléctrica per cápita } \\
(K W-h / h a b)\end{array}$ & $1,990.6$ & $2,160.9$ & $2,315.4$ & $2,580.2$ & $2,677.5$ & $2,780.1$ & $3,119.2$ \\
\hline $\begin{array}{c}\text { Potencia instalada } \\
\text { (MW) }\end{array}$ & 110.2 & 118.2 & 226.0 & 227.3 & 231.1 & 233.6 & 236.9 \\
\hline $\begin{array}{l}\text { Producción de energía } \\
\text { eléctrica (GW-h) }\end{array}$ & 100.1 & 307.3 & 233.3 & 179.5 & 544.6 & 556.5 & 643.7 \\
\hline $\begin{array}{l}\text { Venta de energía } \\
\text { eléctrica a clientes } \\
\text { regulados (GW-h) }\end{array}$ & 492.7 & 577.4 & 638.2 & 684.9 & .4 & 810.7 & 841.2 \\
\hline $\begin{array}{l}\text { Venta de energía } \\
\text { eléctrica a clientes } \\
\text { libres (GW-h) }\end{array}$ & 863.3 & 958.8 & 973.7 & $1,122.5$ & $1,134.0$ & $1,186.5$ & $1,426.9$ \\
\hline $\begin{array}{l}\text { Venta de energía } \\
\text { eléctrica (GW-h) }\end{array}$ & $1,356.0$ & $1,536.1$ & $1,611.9$ & $1,807.3$ & $1,899.4$ & 1,997.2 & $2,268.1$ \\
\hline $\begin{array}{c}\text { Número de clientes } \\
\text { regulados }\end{array}$ & 114,956 & 136,661 & 148,032 & 158,962 & 167,549 & 176,788 & 185,577 \\
\hline $\begin{array}{c}\text { Número de clientes } \\
\text { libres }\end{array}$ & 17 & 15 & 17 & 15 & 15 & 14 & 29 \\
\hline $\begin{array}{c}\text { Número de clientes } \\
\text { totales }\end{array}$ & 114,973 & 136,676 & 148,049 & 158,977 & 167,564 & 176,802 & 185,606 \\
\hline
\end{tabular}

Figura 2.6.

Consumo de energía eléctrica per cápita en la región Ica

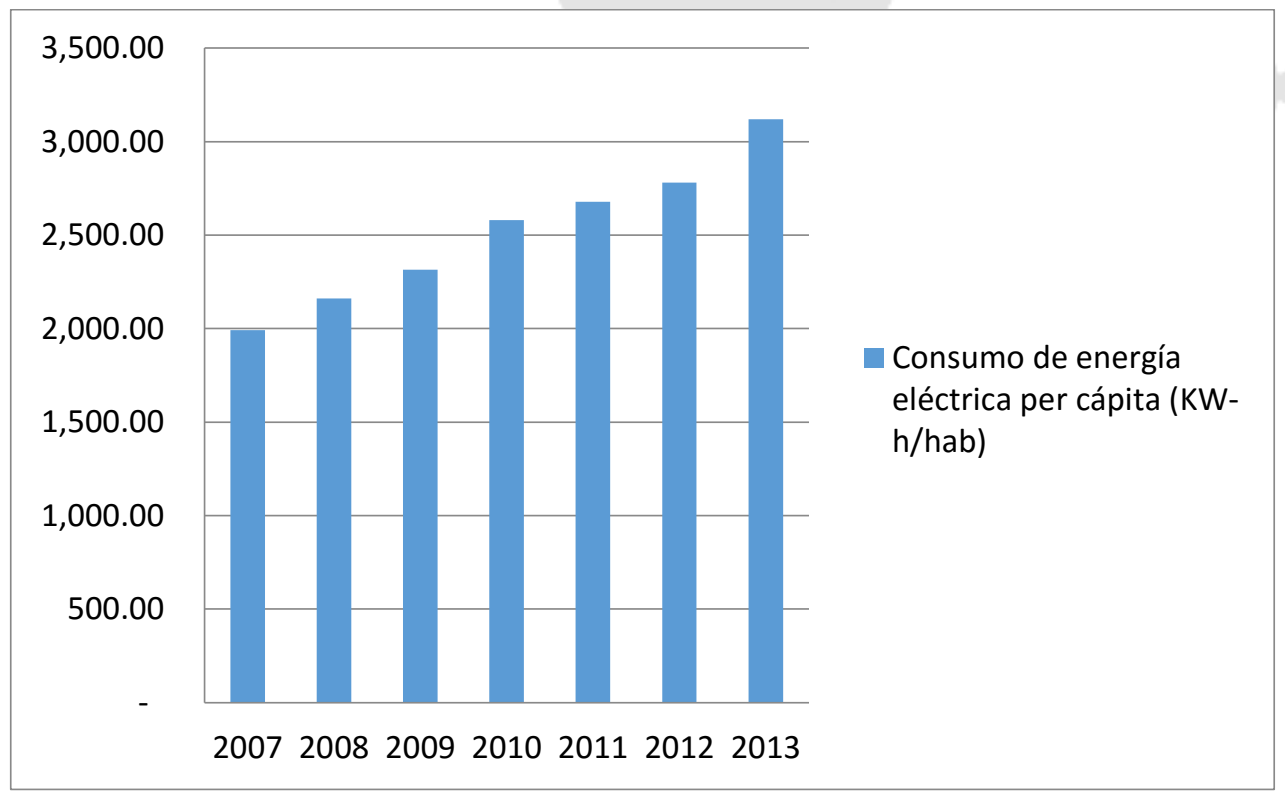

Fuente: MINEM 
Figura 2.7.

Cantidad de clientes de energía eléctrica en la región Ica

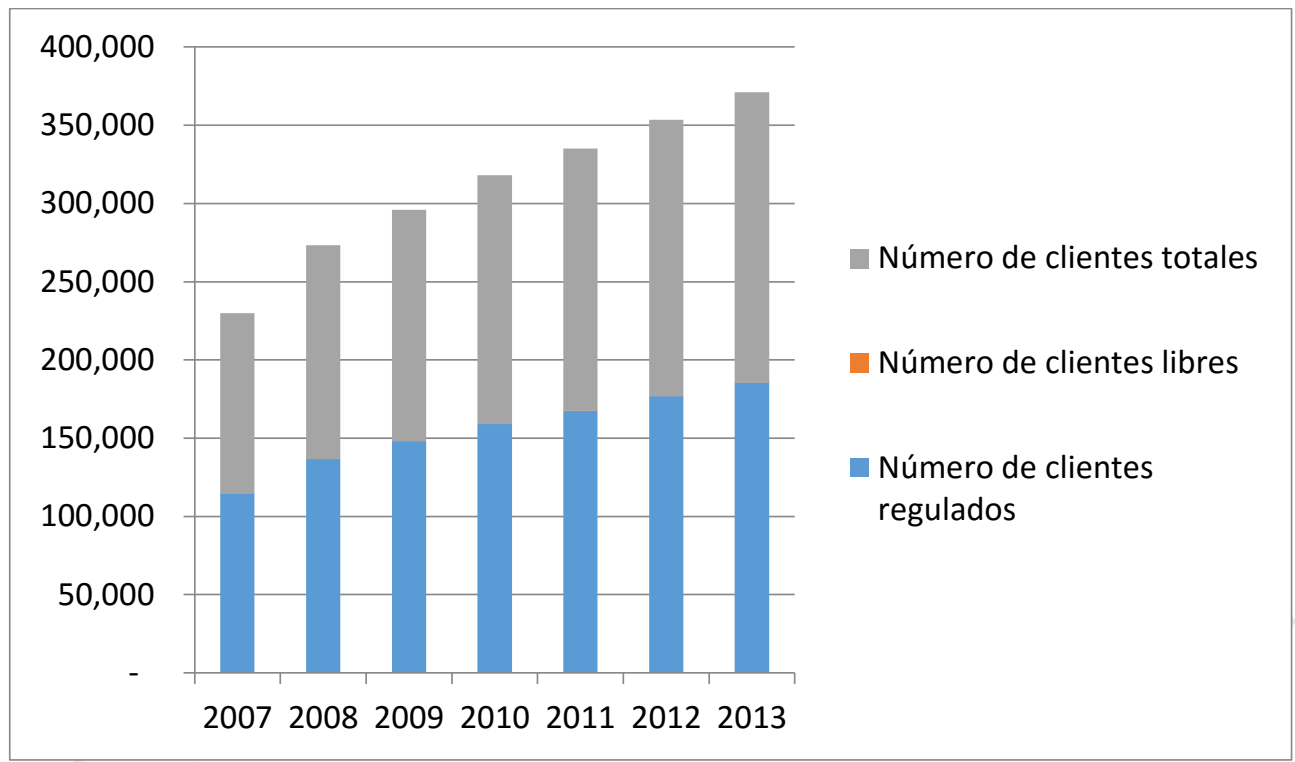

Fuente: MINEM

Figura 2.8.

Producción y ventas de energía eléctrica en la región Ica

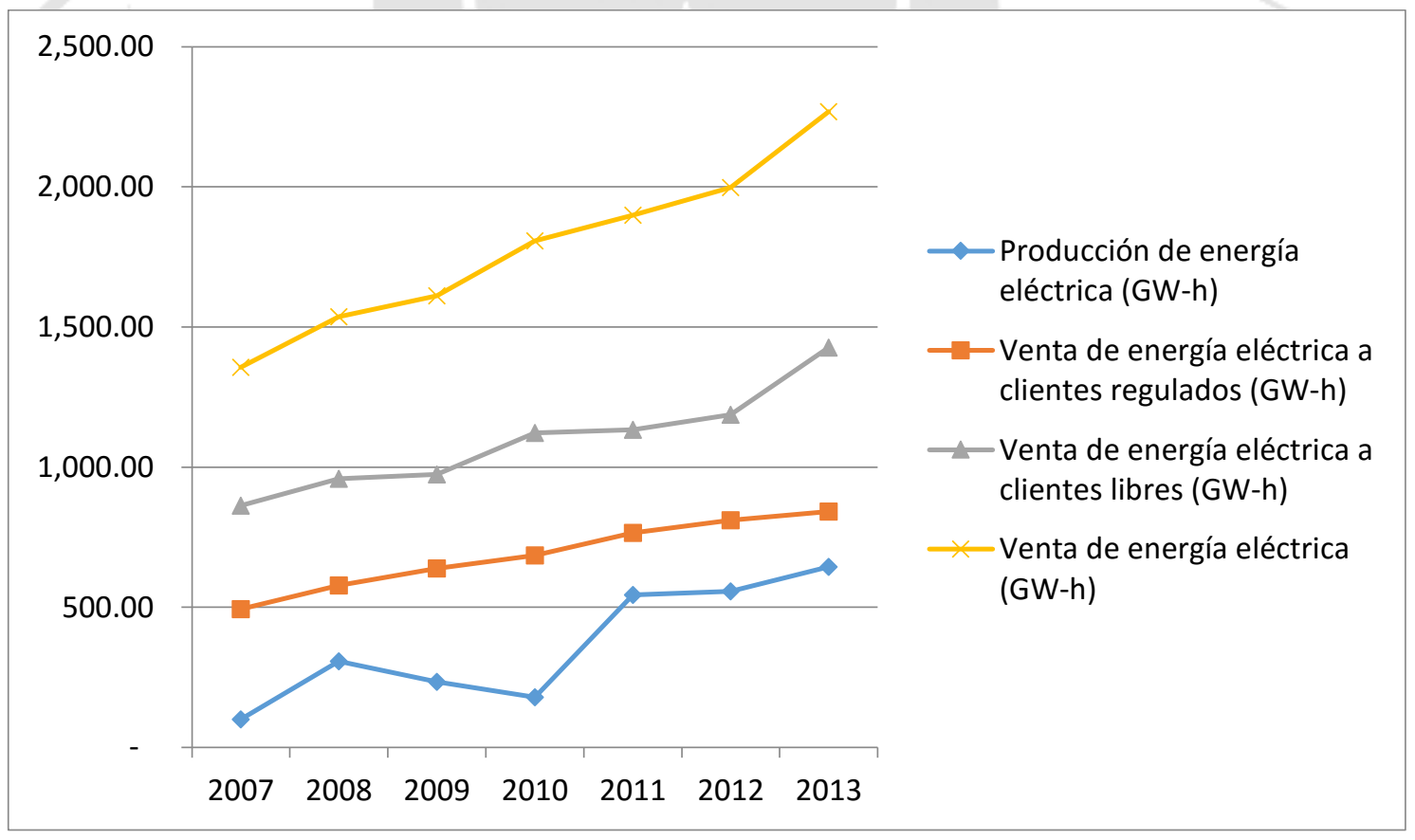

Fuente: MINEM 
Como se observa en los gráficos anteriores, la demanda de energía eléctrica en la región de Ica va en aumento, ya que no solo el número de clientes está aumentando, sino que también el consumo per cápita de energía eléctrica en la región va en aumento. Además, es importante resaltar que la producción de energía eléctrica en la región está muy por debajo de las ventas de energía, lo que hace suponer que gran parte de la energía consumida en Ica es generada en alguna otra región del país, y con ello se puede pensar que la implementación de una planta generadora de energía eléctrica en la región sí podría tener una buena aceptación por parte de los clientes, ya que podrían abastecerse de una fuente más cercana.

\subsection{Análisis de la oferta}

\subsubsection{Análisis de la competencia}

La oferta de energía eléctrica en el Perú está constituida por tres actividades: generación, transmisión y distribución de energía a los consumidores finales. La generación es la producción de energía eléctrica de distintas fuentes. Las empresas de este rubro son las encargadas de la producción y planificación de la capacidad de abastecimiento. La característica principal de este rubro es que es de libre acceso, pero requiere un gran monto de capital. Por otro lado, la distribución es el transporte de energía desde las subestaciones, o barras base, a los consumidores finales, vía líneas de trasmisión de media tensión que antes de llegar a los consumidores finales, se transforma a baja tensión; las distribuidoras reciben la energía de las generadoras o las transmisoras y se encargan de entregarla a la industria, la población y los gobiernos locales para el servicio público. Finalmente, la transmisión se refiere al transporte de energía desde los generadores hacia los centros de consumo y se compone de líneas o redes de transmisión y subestaciones de transformación, o barras bases, y equipos de compensación reactiva; las empresas de este rubro tienen como fin transferir la energía de las generadoras hacia los clientes finales a través de las líneas de transmisión. A continuación, se muestra una figura con la cadena productiva (MINEM, 2012). 
Figura 2.9.

Esquema de infraestructura eléctrica

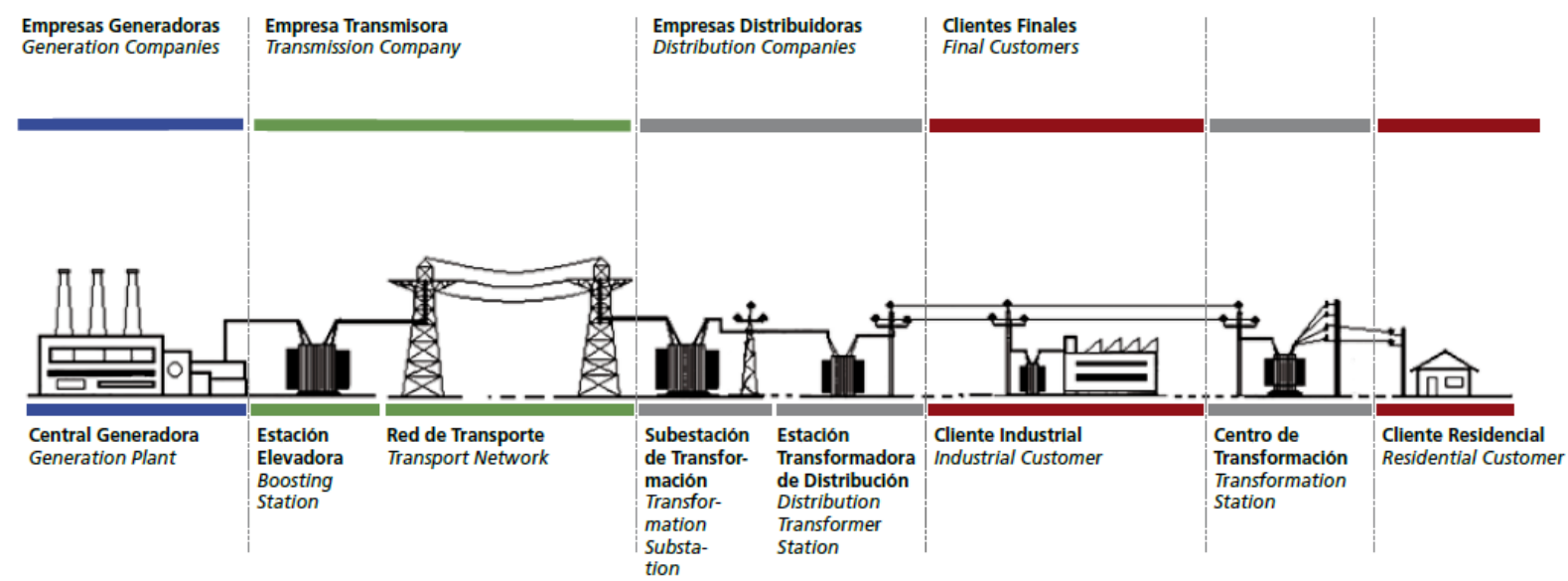

Fuente: MINEM

Para el caso de este proyecto, los competidores principales son las empresas generadoras de energía eléctrica. En el Perú, la generación de energía eléctrica es un mercado de libre competencia. Los precios se definen por contrato y varía según la negociación pactada entre las partes.

Hoy en día, en el mercado eléctrico peruano, participan 27 empresas de generación eléctrica, tanto estatales como privadas. Asimismo, existen las denominadas industrias autogenerdoras que operan centrales de generación eléctrica para abastecer de manera parcial o total sus propias actividades industriales (MINEM, 2013).

A continuación, se presenta un listado de las empresas generadoras de energía eléctrica más representativas a nivel nacional. 
Tabla 2.5.

Principales empresas generadoras de energía eléctrica en el Perú

\begin{tabular}{lccc}
\hline \multirow{2}{*}{ Generadoras } & \multicolumn{3}{c}{ Capacidad instalada (MW) } \\
& Hidráulica & Térmica & Total \\
\hline EDEGEL & 568 & 1015 & 1583 \\
ENERSUR & 130 & 956 & 1086 \\
DUKE EGENOR & 351 & 344 & 695 \\
KALLPA & 0 & 602 & 602 \\
SN POWER & 264 & 0 & 264 \\
CELEPSA & 220 & 0 & 220 \\
TERMOSELVA & 0 & 203 & 203 \\
CHINANGO & 185 & 0 & 185 \\
EEPSA & 0 & 159 & 159 \\
SHOUGESA & 0 & 68 & 68 \\
GEA & 0 & 42 & 42 \\
SINERSA & 39 & 0 & 39 \\
SDF ENERGÍA & 0 & 39 & 39 \\
AIPSAA & 0 & 23 & 23 \\
CORONA & 20 & 0 & 20 \\
SANTA CRUZ & 14 & 0 & 14 \\
GEPSA & 10 & 0 & 10 \\
PETRAMAS & 0 & 5 & 5 \\
MAJA & 3,8 & 0 & 3,8 \\
LANGUI & 3,3 & 0 & 3,3 \\
SANTA ROSA & 2,9 & 0 & 2,9 \\
SAN HILARION & 0,6 & 0 & 0,6 \\
ELECTROPERU & 1008 & 88 & 1096 \\
EGASA & 177 & 154 & 331 \\
SAN GABÁN & 110 & 12 & 122 \\
EGEMSA & 90 & 18 & 108 \\
EGESUR & 36 & 24 & 60 \\
$\quad$ TOTAL & $\mathbf{3 2 3 3}$ & $\mathbf{3 7 5 2}$ & $\mathbf{6 9 8 5}$ \\
\hline FES & & & \\
\hline
\end{tabular}

Fuente: MINEM

El mercado eléctrico peruano tiene un parque de generación compuesto por 45 centrales eléctricas mayores de $18 \mathrm{MW}$, las cuales suman una capacidad instalada de 6963 MW. Este grupo está compuesto por 23 centrales hidroeléctricas que suman $3152 \mathrm{MW}$ y por 28 centrales térmicas que suman 3811 MW. Ninguna de las centrales generadoras de energía eólica existentes figura en está lista. 
En la figura que se muestra a continuación, se observa la ubicación de las principales centrales generadoras a nivel nacional.

Figura 2.10.

Centrales eléctricas de generación mayores a 18 MW

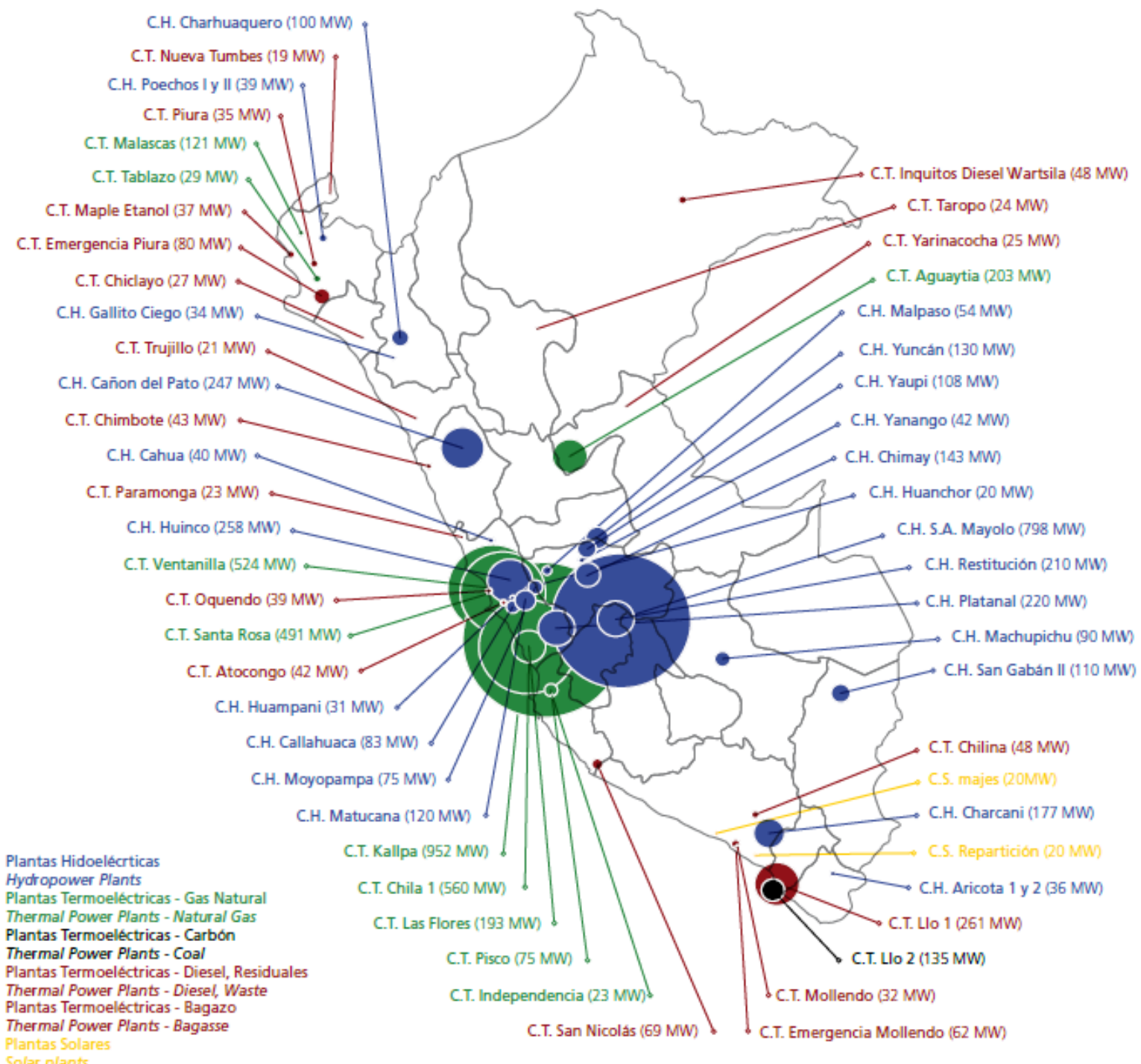

Fuente: MINEM

Como se observa en la imagen anterior, en la región de Ica solo operan tres plantas generadoras de energía eléctrica con potencia producida mayor a 18 MW. Además, se puede apreciar que estas tres plantas generadoras son termoeléctricas. 
2.3.2. Descripción de las características de la oferta de los principales competidores

En la región de Ica, existen tres plantas generadoras de energía eléctrica con una potencia producida mayor a $18 \mathrm{MW}$. Estas tres plantas son: Shougesa S.A.A., Egesur y Egasa. A continuación, se realizará una descripción de cada una de estas plantas.

- Shougesa S.A.A.

Shougang Generación Eléctrica S.A.A. (SHOUGESA) es una empresa de generación eléctrica que posee la Central Térmica San Nicolás con 63 MW de potencia efectiva, la cual está conectada al Sistema Interconectado Nacional. La planta se encuentra ubicada en el distrito de San Juan de Marcona, en la provincia de Nazca, en la región de Ica, en la Costa Peruana a $530 \mathrm{Km}$ al sur este de Lima. La planta ocupa un área de 6.76 hectáreas de terreno. La empresa tiene oficinas ubicadas en Marcona y en Lima.

Shougesa tiene como clientes principales a la minera Shougang Hierro Perú S.A.A. y al Municipio de Marcona. La carga con la que alimenta a Shougang Hierro Perú es de 13.8 kV. La central térmica cuenta con tres turbogeneradores y un grupo electrógeno con las siguientes potencias efectivas: 18.71 MW, 17.71 MW, 25.92 MW y 1.24 MW.

La central térmica inició sus operaciones en el año 1963 con su primer grupo electrógeno de 18.75 MW de potencia, y luego en el año 1967 instaló el segundo de igual potencia, y un tercero en 1972 de 25 MW de potencia. En 1997 Shougesa entra a formar parte del Sistema Interconectado Centro Norte, y en el 2000 la empresa llega a su potencia actual de 63 MW.

La central térmica de Shougesa es una central con turbinas de vapor que dispone de calderas que producen energía calorífica, mediante la transferencia de calor producido en la combustión al agua de alimentación de la caldera. El proceso utiliza petróleo residual como combustible con un contenido de $1 \%$ de azufre y aire del ambiente como comburente. Durante el proceso se producen gases de combustión, los cuales son liberados al 
ambiente que son arrastrados por el viento con dirección al Océano Pacifico.

Una de la principales fortalezas de ésta planta es que es la única generadora de energía eléctrica existente en una zona con gran cantidad de proyectos mineros, y es el principal proveedor de la mina más grande del lugar así como del municipio de la localidad desde hace ya varias décadas. La principal debilidad es que es una central térmica que libera gases de combustión al ambiente.

\section{- EGESUR}

Es una empresa estatal de derecho privado, dedicada a la generación de energía eléctrica. La empresa posee tres plantas en el territorio peruano dos en la región de Tacna y una en la de Ica. La planta generadora de Ica es una central térmica ubicada en el distrito de Independencia, en la provincia de Pisco desde el año 1994. La central tiene una potencia instalada de 25.6 MW.

La empresa comprende la conversión de los motores de 4 grupos electrógenos de 6.4 MW cada uno, que operan con gas R6, el cual se quiere reemplazar por gas natural de Camisea.

Actualmente, la panta libera una gran cantidad de gases de combustión, producto de los procesos de generación, pero tiene planes de mejora para disminuir la cantidad de emisiones.

La principal fortaleza de esta planta es tiene una buena potencia instalada y es parte de una empresa que tiene una fuerte participación en el sector eléctrico en el sur del país. Como principal debilidad se puede mencionar que la empresa genera una gran cantidad de emisiones que afectan el medio ambiente. Además, es importante mencionar que la empresa opera en la misma provincia que otra generadora eléctrica. 
- Egasa

Empresa de Generación Eléctrica de Arequipa (Egasa) es una empresa que se dedica a la generación de energía eléctrica, con sus oficinas principales ubicadas en Arequipa, y cuenta con un gran número de plantas generadoras de electricidad a lo largo del país, entre ellas se pueden mencionar varias hidroeléctricas como la de Molloco y la de Pillones. La empresa posee una central térmica ubicada en el distrito de Independencia en la provincia de Pisco, la cual se inauguró en el año 2011. La planta cuenta con una potencia instalada de 74.80 MW, teniendo como principal insumo el gas natural de Camisea para la combustión.

La principal fortaleza de esta planta es que posee una capacidad instalada muy superior, siendo la planta con mayor potencia en toda la región, además forma parte de una de las empresas privadas más grandes del sector eléctrico del país. La principal debilidad que se puede mencionar es que la planta se encuentra ubicada en el mismo distrito que otra planta generadora.

\subsubsection{Planes de ampliación existentes}

Desde ya hace algunos años, el gobierno está tratando de promover los proyectos que desarrollen las energías renovables no convencionales, es por ello que en el año 2008 se aprobó el Decreto Legislativo 1002 (Ley RER) y el Decreto Supremo 050-2008-EM, los cuales establecen beneficios para el desarrollo de este tipo de energías tales como la eólica, solar, mareomotriz, geotérmica y las mini hidroeléctricas. Entre los beneficios establecidos se incluye la prioridad en el despacho del COES al Sistema Eléctrico Interconectado Nacional, la depreciación acelerada, la devolución anticipada del IGV, así como el establecimiento de una prima de mercado, la cual se le pagará a los generadores de energías renovables anualmente y se calculará entre una tarifa base fijada por OSINERGMIN y el costo marginal del mercado spot, asegurando un retorno mínimo del $12 \%$ a los proyectos según establece la Ley de Concesiones eléctricas vigente. Asimismo, en el año 2013 se promulgó el Decreto Supremo 024-2013-EM, el cual modifica los decretos antes 
mencionados, introduciendo cambios con el objeto de facilitar la ejecución de los proyectos, eliminando restricciones innecesarias e incertidumbres por decisiones administrativas.

Para participar, se realiza una subasta con los proyectos con la finalidad de ganar una participación dentro del $5 \%$ de la demanda nacional de energía eléctrica. Hasta ahora ya se han realizado tres subastas, y se realizó una cuarta a finales del año 2015 .

En el año 2009 fue realizada la primera subasta, en la cual participaron 22 empresas con 33 proyectos, de los cuales solo 26 fueron elegidos. De estos 26 proyectos, 17 son mini hidroeléctricas y ninguna de ellas estará ubicada en la región de Ica. Dos de los proyectos son de biomasa, ambos ubicados en la región de Lima. Cuatro de los proyectos son de energía solar y todos ellos estarán repartidos en las regiones de la costa sur del país: Tacna, Arequipa y Moquegua. Los tres proyectos restantes son de energía eólica, uno de ellos estará ubicado en Piura, otro en La Libertad, y el tercero en Ica.

El proyecto ubicado en Ica, se instalará en el distrito de Marcona, con una altitud de 200 metros sobre el nivel del mar. El proyecto será operado por la empresa Parque Eólico Marcona S.R.L. (Cobra Perú). Se espera que la planta cuente con una potencia instalada de $32 \mathrm{MW}$, con 11 aerogeneradores. Este proyecto inició sus operaciones en el año 2014.

Con respecto a la segunda subasta, que se realizó en el año 2011, se presentaron 21 proyectos de los cuales se adjudicaron solo 10. De los proyectos adjudicados, 7 de ellos son mini hidroeléctricas, y ninguna de ellas se encuentra en la región de Ica. Uno de los proyectos adjudicados es de biomasa, el cual se instalará en la región de Lima. Otro de los proyectos es de energía solar, el cual estará ubicado en la región de Moquegua. El proyecto restante, llamado Parque Eólico Tres Hermanas, es de energía eólica, y este estará ubicado en la región de Ica.

Al igual que el proyecto eólico adjudicado en la primera subasta, el Parque Eólico Tres Hermanas estará ubicado en la localidad de Marcona. El proyecto estará ubicado a 496 metros sobre el nivel del mar y contará con una potencia instalada de 90 MW. La central contará con 45 aerogeneradores dispuestos en 
alineaciones distribuidas perpendicularmente a los vientos dominantes de la zona. El proyecto se encuentra en proceso de estudios de impacto ambiental, y se estima que necesitará una inversión de aproximadamente 180 millones de dólares.

\subsection{Demanda para el proyecto}

\subsubsection{Segmentación del mercado}

En el mercado de energía eléctrica se pueden realizar dos tipos de segmentación, ya que se trata principalmente de un mercado organizacional. En primer lugar, se puede realizar una segmentación geográfica, dividiendo los mercados según el área geográfica donde se encuentren ubicados; este tipo de segmentación es muy importante, ya que la cercanía o lejanía de los clientes a la planta generadora puede determinar la cantidad de pérdidas de electricidad que pueda ocurrir en las líneas de distribución y transmisión.

Actualmente, se encuentran establecidas cuatro zonas eléctricas en el país, que representan las cuatro áreas geográficas de influencia del Sistema Eléctrico Interconectado Nacional (SEIN). En el siguiente cuadro, se presentan las cuatro zonas eléctricas con las respectivas regiones que las componen. 
Tabla 2.6.

Áreas eléctricas del Perú

\begin{tabular}{cc}
\hline Zona & Área de Influencia \\
\hline \multirow{2}{*}{ Norte } & Tumbes \\
& Piura \\
Lambayeque \\
Cajamarca \\
Lorte Medio \\
\\
Ancash (excepto Antamina) \\
Ancash (solo Antamina) \\
Huánuco \\
Ucayali \\
Lima \\
Pasco \\
Junín \\
Ica
\end{tabular}

Huancavelica

Ayacucho

Apurímac

Cusco

Arequipa

Sur

Puno

Moquegua

Tacna

Fuente: MINEM

El segundo tipo de segmentación que se realiza en el mercado de energía eléctrica es la segmentación sectorial, en la cual se dividen a los clientes según el tipo de sector en el que operen, ya que según el tipo de actividades que realicen va a variar la demanda de energía eléctrica.

En el sector eléctrico se distinguen dos tipos diferentes de clientes finales: los regulados y los libres. Los clientes regulados son todos aquellos clientes cuyos consumos de energía sean menores a los $200 \mathrm{~kW}$ de demanda de potencia, este grupo está conformado en su mayoría por los hogares y los pequeños negocios. Mientras que los clientes libres son aquellos que tienen una demanda de energía mayor o igual a los $2500 \mathrm{~kW}$, este grupo está conformado por las grandes industrias. Aquellos clientes cuya demanda se encuentra entre ambos valores, tienen el derecho de poder elegir su condición de cliente. A continuación, se 
presenta un gráfico en el que se muestra el porcentaje de cada tipo de clientes según la demanda total eléctrica del país.

Figura 2.11.

Venta de energía eléctrica (GW-h)

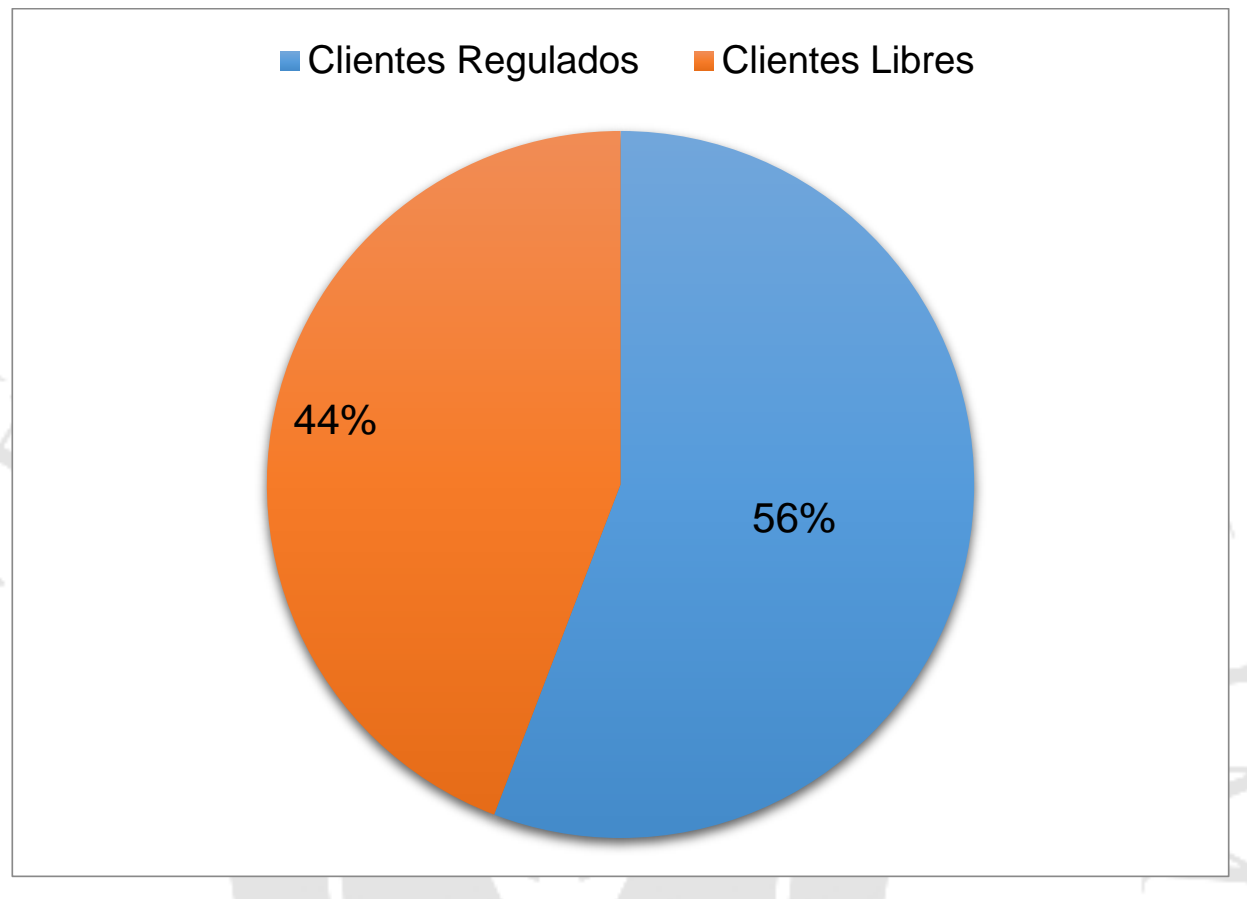

Fuente: MINEM, elaboración propia

Como se observa en el gráfico anterior, casi la mitad de la demanda de energía eléctrica del país es de clientes libres, es decir de distintos tipos de industrias. En el gráfico que se muestra a continuación, se presenta la participación de cada sector económico en la demanda de energía eléctrica de los clientes libres a nivel nacional. 
Figura 2.12.

Venta de energía eléctrica a usuarios libres por actividad económica (GW-h)

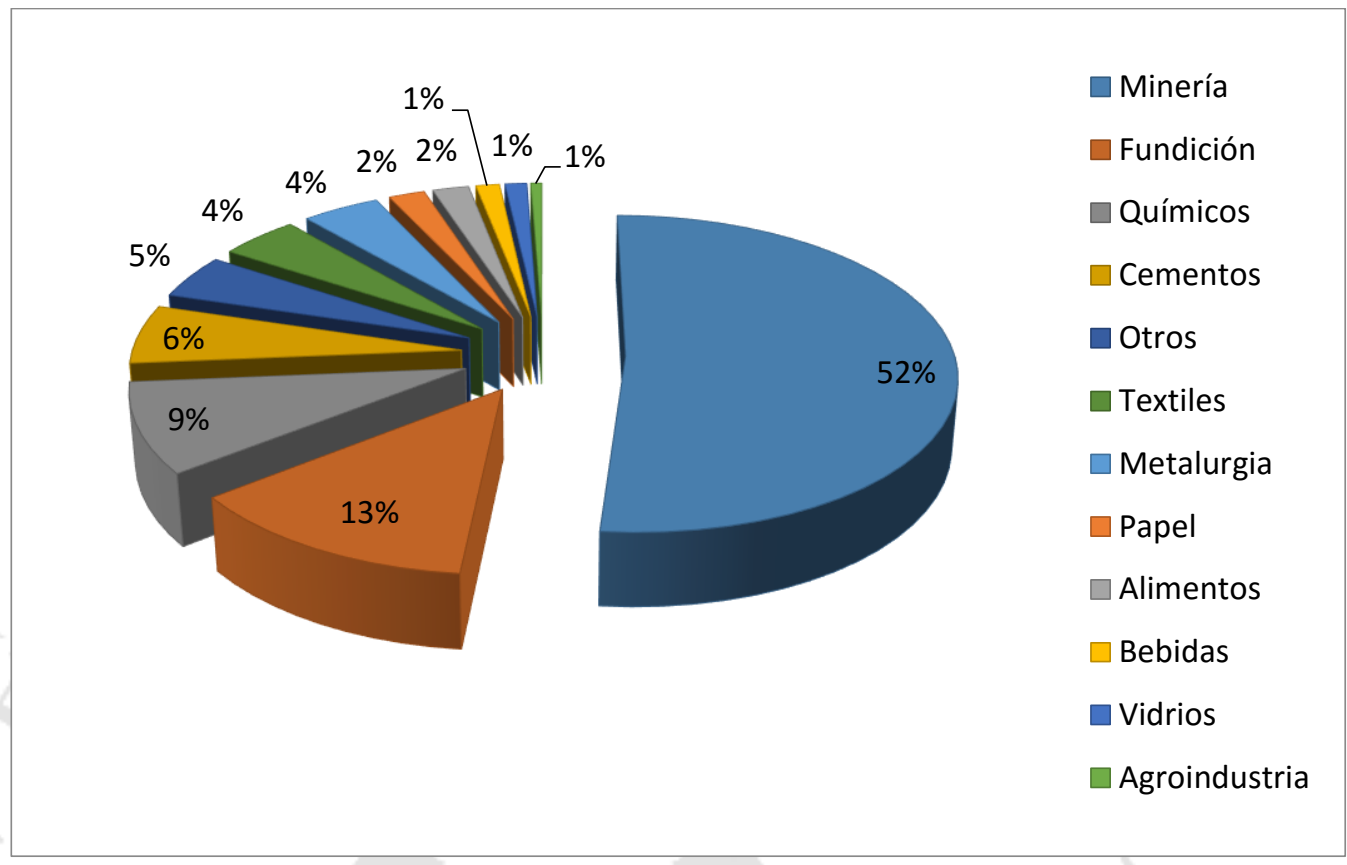

Fuente: MINEM

Como se observa en el gráfico anterior, el sector económico que más energía eléctrica consume en el país es el de minería, que representa más de la mitad de la energía eléctrica total demandada por clientes libres a nivel nacional. En segundo lugar se encuentra el sector de fundición, y en el tercero el sector químico.

\subsubsection{Selección del mercado meta}

Para la selección del mercado meta del proyecto, se considerarán los dos tipos de segmentación mencionados anteriormente, es decir la segmentación geográfica y la segmentación sectorial.

El proyecto atenderá a la demanda de energía eléctrica del país de la región de Ica, la cual se encuentra en la zona eléctrica central del Sistema Eléctrico Interconectado Nacional. Además, se espera que el proyecto realice sus operaciones enfocándose en los clientes libres de la región, y sobre todo atendiendo a las empresas pertenecientes al sector minero, ya que este sector 
es que tiene una mayor demanda de energía eléctrica a nivel nacional. De los proyectos mineros de la región, se espera atender a aquellos proyectos más recientes, ya que estos proyectos necesitarán grandes cantidades de energía eléctrica para realizar sus operaciones, y por ser proyectos nuevos, se puede esperar que tengan un mayor horizonte de vida que los proyectos existentes, lo que podría garantizar una demanda sostenible durante varias décadas.

\subsubsection{Determinación de la demanda para el proyecto}

Como se puede observar en gráficos de secciones anteriores (figuras 2.8, 2.9 y 2.10), la demanda de energía eléctrica de clientes libres en la región de Ica tiene una tendencia creciente, la cual supera a la producción de energía en esa región. Además, para los próximos años se espera que entren en operaciones cuatro proyectos mineros, y con ello la demanda de energía eléctrica aumente aún más.

Considerando que la demanda de energía de todos los proyectos mineros existentes de la región de Ica es cubierta por las empresas generadoras existes, se puede suponer que solo se cubrirá la demanda de los proyectos a realizarse en el futuro, lo que significa que existe una demanda potencial mayor a los 270 MW. Además, se debe considerar que existen dos proyectos de generación de energía eólica en la zona, los cuales tendrán una potencia instalada de 122 MW entre ambos.

Es importante mencionar la existencia de vínculos de dos de los proyectos mineros a realizarse con una de las generadoras termoeléctricas de la región ya que pertenecen al mismo grupo empresarial; es por ello que se puede esperar que gran parte de la potencia requerida por estos proyectos mineros sea abastecida por su empresa generadora. Teniendo en consideración todo lo antes mencionado, se puede estimar que la potencia demanda para el proyecto será similar a la demanda de los otros proyectos de energía eólica de la zona, es por ello que se considerará que la potencia demandada para el proyecto será de alrededor de $35 \mathrm{MW}$. 


\subsection{Venta del servicio}

\subsubsection{Políticas de venta del servicio}

En el mercado de generación eléctrica se producen tres tipos de transacciones: las ventas de energía, las ventas de potencia entre generadoras, y las ventas de energía a empresas de distribución para clientes finales de electricidad.

En las ventas de energía a clientes libres, los precios pagados por estos deben incluir, además de los precios de la energía y potencia que cubren los costos de generación, las tarifas de la transmisión y/o la distribución, regulados por Osinergmin, por lo que en el precio final para un cliente libre hay un componente regulado. Por otro lado, las ventas de potencia y energía entre empresas generadoras, que normalmente se producen cuando ocurren problemas imprevistos en la generación y/o transmisión que hacen que la cantidad ofrecida por una generadora esté por debajo de su demanda y deben realizarse a costos marginales instantáneos o precios spot fijados por el Comité de Operación Económica del Sistema Interconectado Nacional. Finalmente, las ventas de energía y potencia a empresas de distribución eléctrica se hacen a precios regulados por Osinergmin.

2.5.2. Análisis de precios

2.5.2.1. Tendencia histórica de los precios

Para analizar la tendencia histórica de los precios de la energía eléctrica en el Perú, se muestra un gráfico con la tendencia de los precios medios de los últimos diez años. 
Figura 2.13.

Tendencia histórica de precios

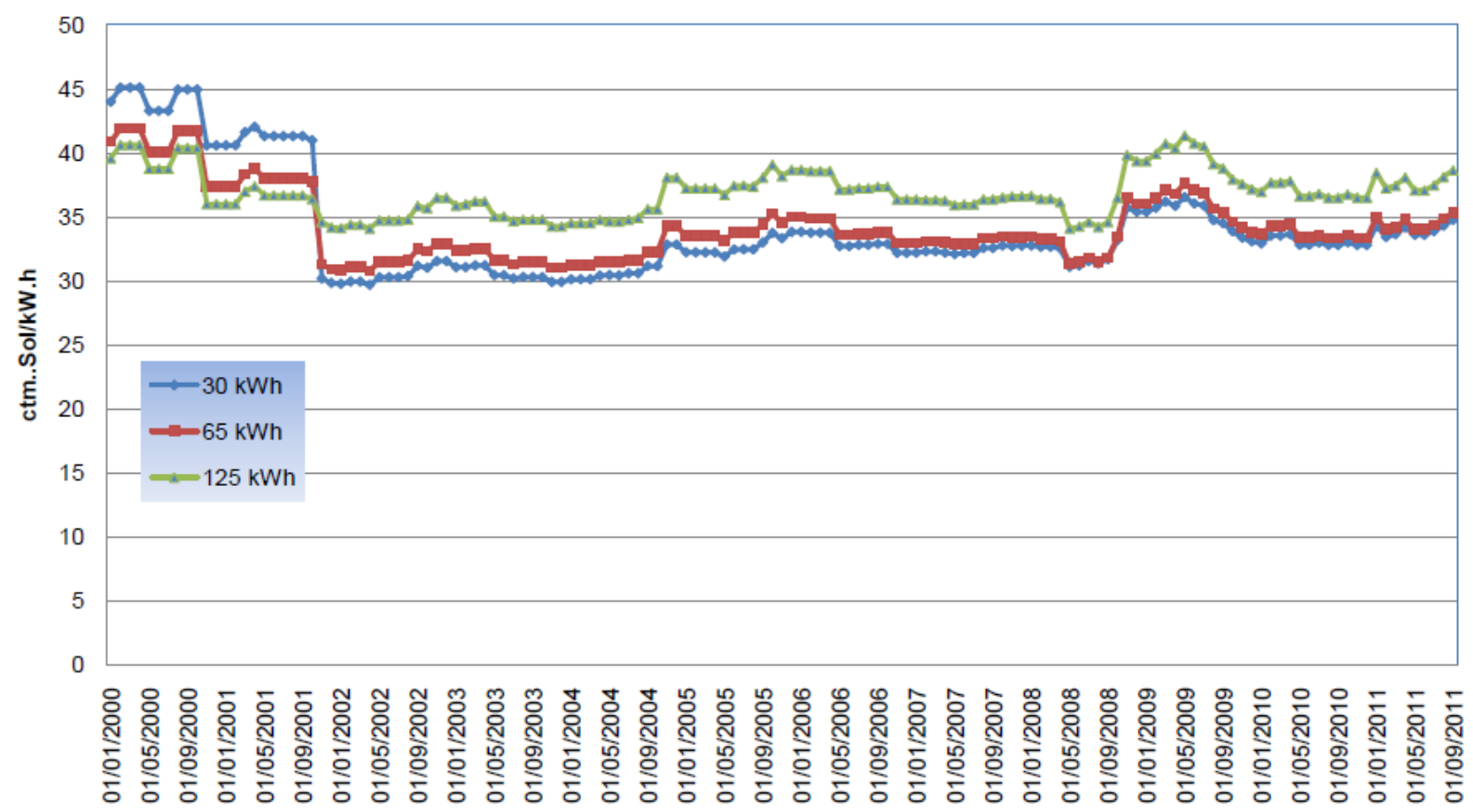

Fuente: MINEM

Como se puede apreciar en el gráfico anterior, durante los últimos diez años, los precios de la energía eléctrica en el país se han mantenido más o menos constantes, con pequeñas fluctuaciones que no escapan de los límites. Es importante mencionar que en los últimos periodos, los precios medios de energía presentan una tendencia creciente.

\subsubsection{Precios actuales}

Los precios actuales de la energía eléctrica a clientes libres varían según la empresa generadora. Además, existen empresas que operan en distintas zonas y los precios de la energía eléctrica que ofrecen varían según la zona. A continuación, se presenta un cuadro con los precios más altos, los precios más bajos y los precios medios de las generadoras más importantes que operan en el país. 
Tabla 2.7 .

Precios de empresas generadoras de electricidad

\begin{tabular}{|c|c|c|c|}
\hline \multirow{2}{*}{ Empresa } & \multicolumn{3}{|c|}{ Precio (ctm S/./kW-h) } \\
\hline & Medio & Más Alto & Más Bajo \\
\hline Cahua & 13.54 & 21.52 & 8.39 \\
\hline Chinango & 13.13 & 13.52 & 10.59 \\
\hline Coelvisac & 13.59 & 14.22 & 12.98 \\
\hline Conenhua & 16.56 & 16.73 & 7.17 \\
\hline Edecañete & 12.68 & 12.68 & 12.68 \\
\hline Edegel & 11.34 & 13.65 & 7.87 \\
\hline Edelnor & 12.10 & 43.65 & 7.90 \\
\hline Eepsa & 13.71 & 14.69 & 10.87 \\
\hline Egasa & 8.32 & 19.94 & 8.11 \\
\hline Egemsa & 6.38 & 7.93 & 5.52 \\
\hline Egenor & 12.28 & 15.04 & 9.88 \\
\hline Electro Sur Este & 14.95 & 16.76 & 10.53 \\
\hline Electro Sur Medio & 13.82 & 20.61 & 9.83 \\
\hline Electro Ucayali & 13.57 & 13.57 & 13.57 \\
\hline Electroandes & 18.30 & 21.91 & 17.23 \\
\hline Electrocentro & 14.36 & 14.36 & 14.36 \\
\hline Electronoroeste & 14.67 & 15.25 & 14.65 \\
\hline Electronorte & 15.07 & 17.31 & 9.90 \\
\hline Electroperú & 20.22 & 60.39 & 2.85 \\
\hline Enesur & 20.15 & 104.58 & 8.16 \\
\hline Hidrandina & 12.40 & 12.44 & 12.31 \\
\hline Kallpa & 12.05 & 16.43 & 8.73 \\
\hline Luz del Sur & 14.98 & 71.14 & 10.89 \\
\hline San Gabán & 13.40 & 14.07 & 10.05 \\
\hline SDF Energía & 15.20 & 15.70 & 14.14 \\
\hline Seal & 16.16 & 84.49 & 13.81 \\
\hline Shougesa & 10.64 & 13.99 & 10.36 \\
\hline Sociedad Minera Corona & 12.13 & 15.99 & 5.54 \\
\hline Termoselva & 11.70 & 17.46 & 9.07 \\
\hline
\end{tabular}

A continuación, se muestra un gráfico en el que se comparan los precios medios de cada una de las empresas con el precio medio libre total. Cabe resaltar que los casos donde se observan precios medios elevados, corresponden a usuarios con demanda eléctrica muy variable en el año, o usuarios con factor de carga bastante bajo. 
Figura 2.14.

Precios medios del mercado libre por empresa

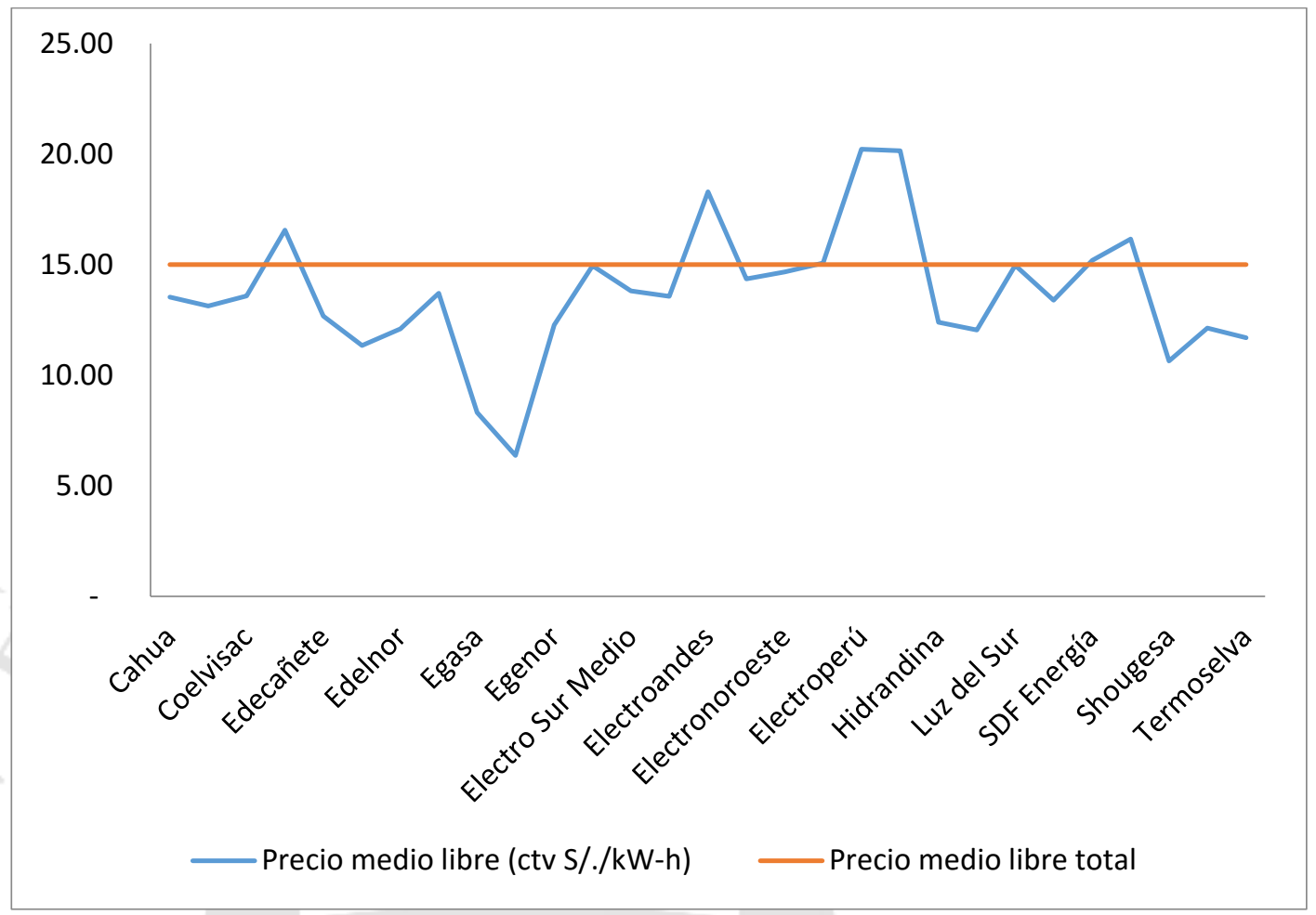

Fuente: MINEM

Por otro lado, es importante mencionar que los precios de la energía eléctrica también varían según el tipo de actividad económica del cliente libre. A continuación, se presenta un cuadro y un gráfico donde se muestran los precios medios, los más altos y los más bajos según el tipo de actividad económica. 
Tabla 2.8.

Precio de energía eléctrica por actividad económica

\begin{tabular}{crrr}
\hline \multirow{2}{*}{ Actividad } & \multicolumn{3}{c}{ Precio (ctm S//kW-h) } \\
& Medio & Más Alto & Más Bajo \\
\hline Agroindustria & 13.94 & 17.31 & 8.39 \\
Alimentos & 13.07 & 19.94 & 7.93 \\
Bancos y financieras & 14.28 & 17.10 & 13.28 \\
Bebidas & 15.36 & 19.46 & 12.21 \\
Cables & 14.16 & 43.65 & 13.74 \\
Cementos & 13.04 & 71.14 & 9.07 \\
Cerámicos & 11.63 & 13.02 & 9.77 \\
Comercio & 14.85 & 16.37 & 13.66 \\
Construcción & 18.45 & 18.45 & 18.45 \\
Fundición & 10.85 & 28.23 & 7.87 \\
Hidrocarburos & 12.28 & 14.69 & 8.56 \\
Industria Metalúrgica & 9.62 & 19.48 & 2.98 \\
Minería & 14.70 & 104.58 & 7.17 \\
Otros & 50.92 & 84.49 & 2.85 \\
Papel & 12.88 & 14.23 & 10.63 \\
Pesquería & 13.61 & 35.55 & 9.83 \\
Químicos & 8.39 & 13.72 & 5.52 \\
Salud & 15.61 & 15.61 & 15.61 \\
Saneamiento & 12.63 & 25.57 & 10.53 \\
Textiles & 12.11 & 17.46 & 7.90 \\
Transporte & 13.42 & 15.18 & 7.43 \\
Vidrios, cauchos y plásticos & 12.71 & 24.82 & 9.87 \\
\hline Fich & & &
\end{tabular}

Fuente: MINEM 
Figura 2.15.

Precio de energía eléctrica por actividad económica

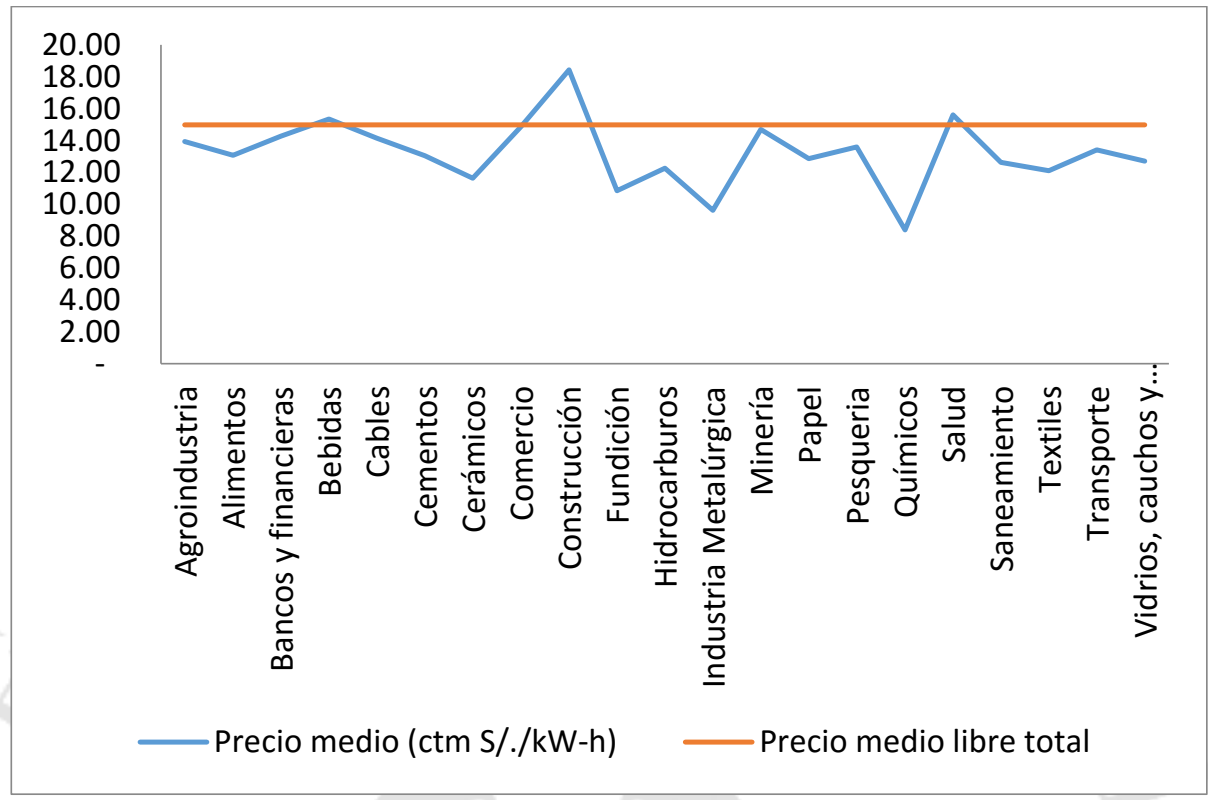

Fuente: MINEM

Es importante mencionar que los dos proyectos de energía eólica que se desarrollaran en la región de Ica en los próximos año ya han definido el precio medio ofertado de su energía producida; los valores se muestran en el siguiente cuadro.

Tabla 2.9.

Precio de energía eléctrica de proyectos eólicos en Ica

\begin{tabular}{cc}
\hline Proyecto & Precio de energía ofertado (ctv US\$/kW-h) \\
\hline Parque Eólico Marcona & 6.552 \\
Central Eólica Tres Hermanas & 8.9 \\
\hline Fuente: OSINERGMIN &
\end{tabular}

Observando los precios de ambos proyectos eólicos, se puede afirmar que los dos similares, y se encuentran dentro del promedio de precios de la mayoría de empresas generadoras del país. Es por ello, se puede concluir que para entrar a competir en el mercado, el precio de la energía ofrecida del presente proyecto deberá ser similar a la de los demás proyectos existentes. 


\subsection{Marketing del servicio}

\subsubsection{Características principales del servicio}

El servicio ofrecido consistirá en la generación de energía eléctrica a partir de una fuente eólica, para lo cual se utilizarán aerogeneradores, los cuales estarán interconectados y generaran una tensión de $0.69 \mathrm{kV}$, la cual será convertida hasta una tensión de $220 \mathrm{kV}$ por medio de transformadores, ya que las líneas de transmisión existentes en la zona solo soportan esa tensión. Luego, la potencia generada será inyectada al Sistema Eléctrico Interconectado Nacional existente en Ica, para la transmisión de la energía generada a los clientes, dándole al cliente un suministro entre 200 y $1000 \mathrm{~kW}$ o mayor a $1000 \mathrm{~kW}$ según lo requiera.

Además, dentro de los servicios ofrecidos, se contará con una línea de atención al cliente durante las 24 horas del día. En esta línea habrá personal calificado dispuesto a atender cualquier inconveniente que el cliente presente. Además, se contará con técnicos expertos que estarán disponibles para visitar a los clientes y atender personalmente sus inconvenientes, en caso de que sea necesario.

\subsubsection{Publicidad y promoción}

El proyecto contará con una Gerencia Comercial, la cual estará encargada de la publicidad y promoción del servicio. La gerencia contará con una división especializada en la venta de energía eléctrica, la cual contará con personas con conocimientos en los temas técnicos, con la capacidad de brindar atención personalizada, toma de decisiones y solución de problemas; y cada uno de los clientes se le asignará al menos una de éstas personas especializadas para tratar los temas comerciales.

La venta del servicio se realizará mediante ventas personales a los clientes. Es por ello que se contará con varios representantes de ventas especializados en temas de energía eléctrica, los cuales se reunirán directamente con los posibles compradores para tratar de establecer relaciones personales a corto y a largo 
plazo que agreguen convicción persuasiva a las prestaciones de ventas que relacionan los servicios ofrecidos con las necesidades de los clientes. Mediante este tipo de ventas, los representantes podrán llevar a cabo una explicación detallada del servicio, además de cultivar y mantener relaciones duraderas con los clientes y evaluar sus necesidades. 


\section{CAPÍTULO III: LOCALIZACIÓN DE PLANTA}

\subsection{Macro localización}

La instalación industrial de una nueva planta generadora de energía eólica cuenta con dos definiciones importantes: su localización y su diseño. Antes de iniciar con la fase de diseño, se debe planificar la localización del nuevo centro, con el objetivo de conseguir la mayor cuota de mercado posible. Como se mencionó en el capítulo anterior, la ubicación del mercado objetivo para el proyecto fue definida en base a dos factores importantes: el potencial eólico regional y el número de proyectos mineros de cada región. En base a estos dos factores se definió que la ubicación geográfica del mercado sería la región de Ica. Considerando las características del servicio ofrecido, es conveniente que la planta generadores de energía eólica sea ubicada en la región de Ica.

Figura 3.1.

Macro localización de la planta

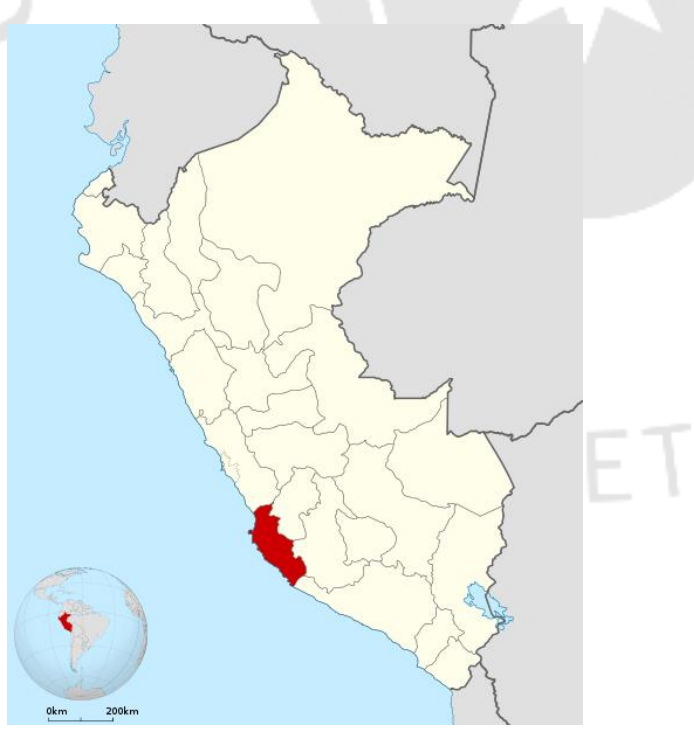

Fuente: Google maps 


\subsection{Micro localización}

\subsubsection{Definición de los factores de localización predominantes}

Para definir la micro localización de la planta generadora de energía eólica se deben establecer factores predominantes, los cuales servirán como guía para determinar las potenciales ubicaciones del proyecto. En este caso, se han determinado dos factores predominantes para la elección de la ubicación del proyecto: la disponibilidad de materia prima y la cercanía a los clientes. A continuación, se procederá a explicar cada uno de los factores predominantes.

- Disponibilidad de materia prima

La materia prima principal para la generación de energía eólica es el viento. En la industria eólica es muy importante poder describir la variación de las velocidades del viento. Este es el factor más importante no solo para definir la ubicación del parque, sino que también para seleccionar el mejor diseño de aerogeneradores y para que los inversionistas puedan estimar sus ingresos. Para comprender mejor este factor, a continuación se presenta una breve explicación sobre el comportamiento del viento.

Si se realizará una medición de las velocidades del viento a lo largo de un año, se observaría que en la mayoría de áreas del planeta los fuertes vendavales son raros, mientas que los vientos frescos y moderados son bastante comunes. La variación del viento en un emplazamiento típico suele ser descrita con la Distribución de Weibull, con una velocidad media de $7 \mathrm{~m} / \mathrm{s}$ (velocidad promedio de las observaciones), y con la forma de la curva determinada por un parámetro de forma de 2 . A continuación, se presenta una figura que muestra la descripción estadística del viento. 
Figura 3.2.

Distribución estadística de la velocidad del viento

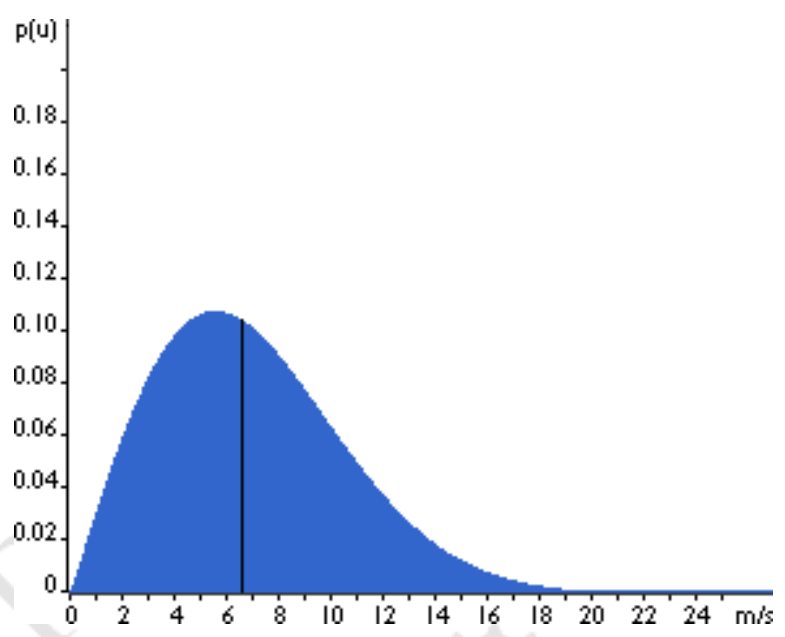

Fuente: MINEM

La línea negra que se observa en la figura representa la mediana de la distribución, que en este caso es de $6.6 \mathrm{~m} / \mathrm{s}$; esto significa que la mitad del tiempo el viento soplará a una velocidad menor a los $6.6 \mathrm{~m} / \mathrm{s}$, mientras que la otra mitad soplará a una velocidad mayor. Como se puede observar, la distribución que describe la velocidad del viento es sesgada. Esto se debe a que es muy raro encontrar velocidades de viento muy altas, pero es muy común tener velocidades de viento de $5.5 \mathrm{~m} / \mathrm{s}$ el cual representa un valor modal.

La distribución estadística de las velocidades del viento puede variar de un lugar a otro dependiendo de las condiciones climáticas locales, del paisaje y de la superficie, pero siempre será representada por la Distribución Weibull con variaciones en el valor medio. Además, si el parámetro de forma es exactamente 2, la distribución será conocida como distribución de Rayleigh, la cual es muy utilizada por los fabricantes de aerogeneradores para proporcionar gráficas de rendimiento de sus máquinas (Windpower, 2003). En el capítulo V se dará más detalle sobre la importancia de la distribución Weibull para el diseño de proyectos de instalación de parques eólicos. 
La importancia que tiene la velocidad del viento para la industria eólica es el contenido energético de las masas de aire que se mueven, mientras mayor sea la velocidad del viento, mayor será la energía cinética de éste.

Dentro de la región de Ica, existen dos zonas que poseen un alto potencial eólico que podría contribuir mucho con el proyecto. Una de esas zonas es el distrito de Marcona en la provincia de Nazca, y la otra zona es el distrito de Paracas provincia de Pisco.

- Cercanía a los clientes

Uno de los objetivos principales de este capítulo es minimizar la distancia que se recorre desde el parque eólico hasta llegar a los clientes. En este caso, la distancia recorrida es aquella en la cual se transporta la energía eléctrica producida en la planta, a través del Sistema Eléctrico Interconectado Nacional (SEIN) hasta los puntos de demanda de la energía eléctrica.

En el capítulo anterior, se definió que el mercado objetivo para el presente proyecto estaría compuesto por todos los proyectos mineros que se realizarán en la región de Ica, ya que la demanda de energía eléctrica de este sector industrial representa más del $50 \%$ de la demanda de energía eléctrica de los clientes libres. Por ello, para la determinación de la localización de la planta generadora se debe tener muy en cuenta la existencia de proyectos mineros cercanos.

Dentro de la región de Ica, el área que posee el mayor número de proyectos mineros a realizarse en los próximos años es el distrito de Marcona en la provincia de Nazca. Otra provincia en la que existen proyectos mineros es la de Pisco. 
3.2.2. Posibles ubicaciones de acuerdo a los factores predominantes

A partir de los factores predominantes descritos anteriormente, se han definido dos posibles localizaciones para la planta generadora de energía eólica. A continuación, se presenta una breve descripción de cada una de las áreas.

- Distrito de Marcona en la Provincia de Nazca

El distrito de Marcona es el distrito más extenso de los 5 distritos de la Provincia de Nazca. Tiene una superficie de $1955.36 \mathrm{~km}^{2}$, se encuentra a una altura de 45 metros sobre el nivel del mar y cuenta con 12709 habitantes. El distrito cuenta con dos puertos y un aeropuerto. Además, dentro del distrito existen yacimientos de hierro que son explotados a tajo abierto y a gran escala.

Figura 3.3.

Ubicación del Distrito de Marcona

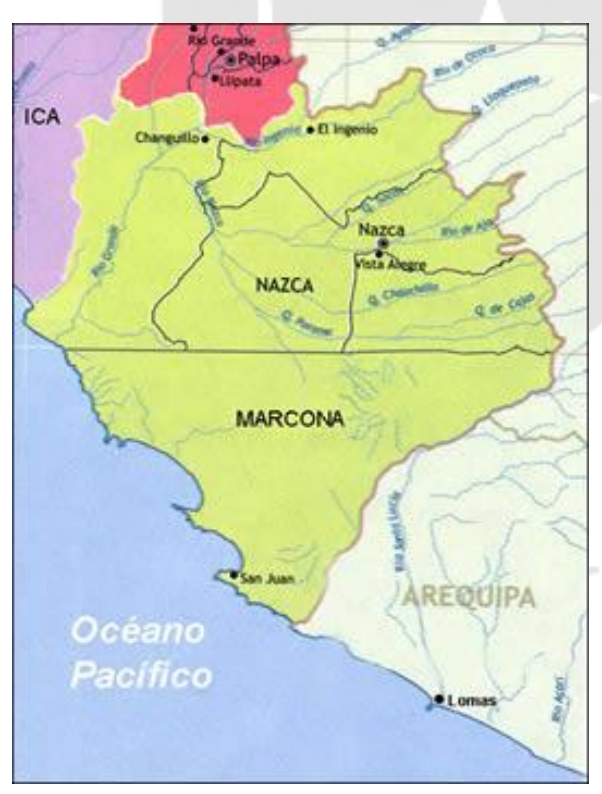

Fuente: Google maps 
- Distrito de Paracas en la Provincia de Pisco

El distrito de Paracas es el distrito más extenso de los 8 distritos de la Provincia de Pisco. Tiene una superficie de $1440.68 \mathrm{~km}^{2}$, y se encuentra a una altura de 7 metros sobre el nivel del mar. Su población total es de 7522 habitantes. Este distrito ha sido declarado reserva regional para aves migratorias, y gran parte de su desértico terreno es parte de la Reserva Nacional de Paracas.

Figura 3.4.

Ubicación del Distrito de Paracas

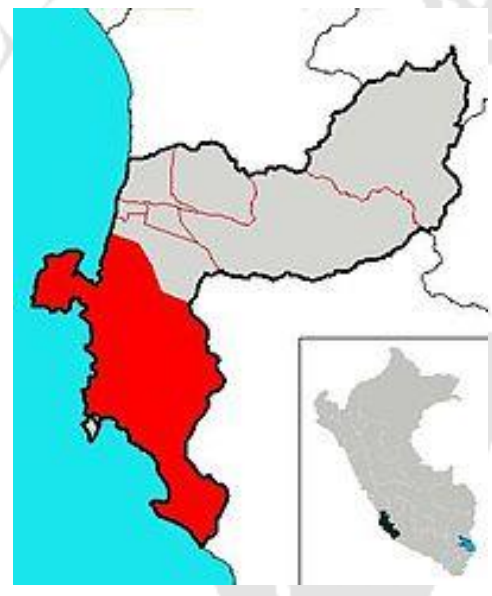

Fuente: Google maps

3.2.3. Análisis de los factores de localización en las posibles ubicaciones

Para la elección de la localización del proyecto, se realizará una evaluación de cada una de las posibles localizaciones, teniendo en cuenta los siguientes factores:

- Disponibilidad de materia prima

- Cercanía a los clientes

- Disponibilidad de terreno

- Características geográficas del terreno (Rugosidad del terreno) 
- Existencia de reservas naturales o parques nacionales cercanos

A continuación, se realizará la descripción de cada uno de los factores que intervienen en la elección de la localización de la planta. Además, se realizará una evaluación del estado de cada una de las posibles localizaciones, para ello se utilizará la siguiente escala de calificación:

$\begin{array}{ll}\text { Excelente } & 5 \\ \text { Muy bueno } & 4 \\ \text { Bueno } & 3 \\ \text { Regular } & 2 \\ \text { Malo } & 1\end{array}$

3.2.3.1. Disponibilidad de materia prima

El insumo principal para le generación de energía eólica es el viento, la velocidad con la que el viento sopla es determinante para generar energía eléctrica. La velocidad del viento en diferentes regiones geográficas varía según la estación del año, ya que debido a los cambios de la temperatura ambiental en algunos meses del año, las masas de aire se mueven más rápido que en otros.

A continuación, se presenta el mapa eólico de la región Ica, con las distintas velocidades de viento en las 4 estaciones del año. 
Figura 3.5.

Mapa eólico de Ica en primavera

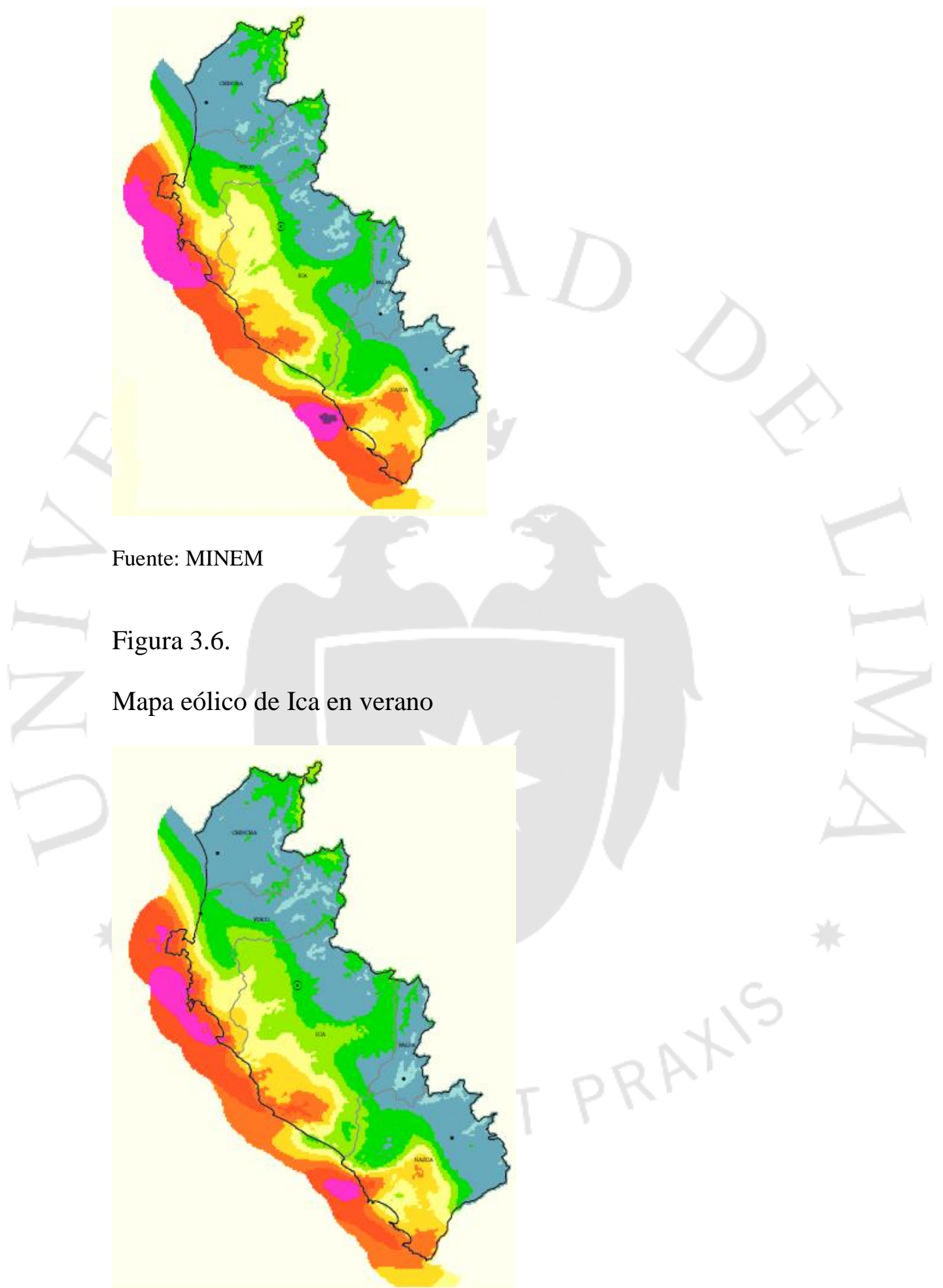

Fuente: MINEM 
Figura 3.7.

Mapa eólico de Ica en otoño

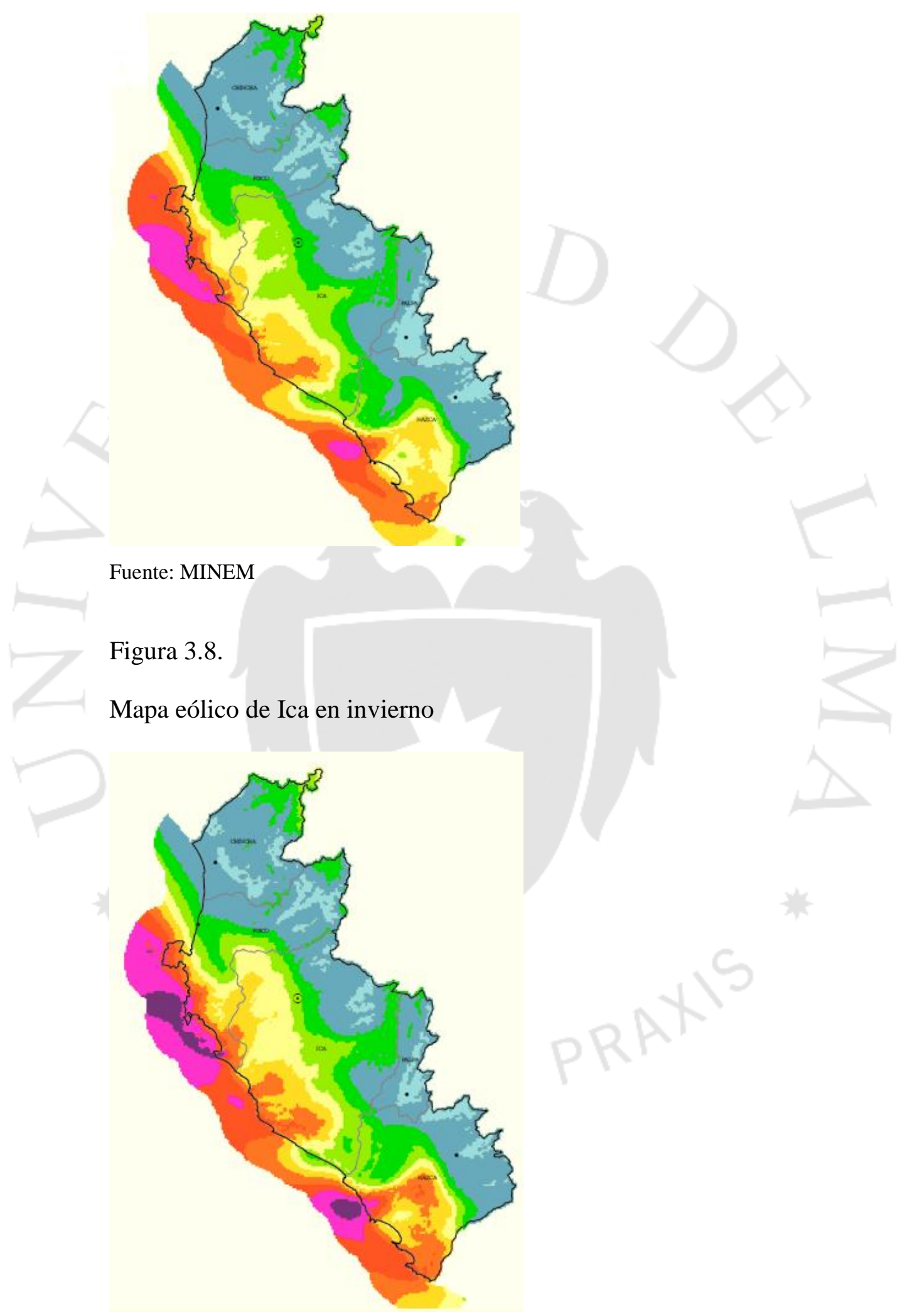

Fuente: MINEM 
Figura 3.9.

Escala de medición de viento

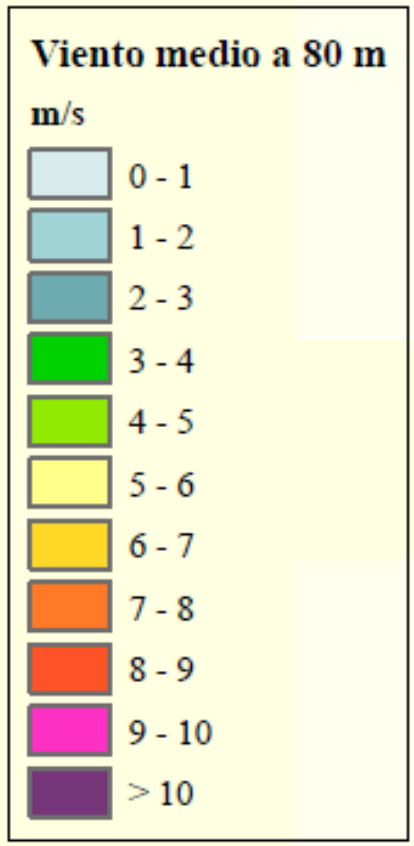

Fuente: MINEM

A partir de los gráficos mostrados anteriormente se pueden observar las distintas velocidades que se presentan en las zonas elegidas durante las distintas estaciones del año.

En el caso del distrito de Paracas, se observa que las zonas del litoral la velocidad del viento se encuentra entre los 8 y $10 \mathrm{~m} / \mathrm{s}$ durante la mayor parte del año, mientras que en invierno llega a superar los $10 \mathrm{~m} / \mathrm{s}$. Mientras que la zona costera, durante todo el año presenta velocidades de viento entre los $8 \mathrm{~m} / \mathrm{s}$ y $9 \mathrm{~m} / \mathrm{s}$. Dado que el presenta proyecto pretende evaluar la factibilidad de una planta generadora de energía on-shore, solo se van a considerar las velocidades de la zona costera, las cuales son excelentes para tal fin. La calificación de esta área es 5 puntos.

En el caso de Marcona, en promedio las velocidades de viento oscilan entre los $6 \mathrm{~m} / \mathrm{s}$ y $7 \mathrm{~m} / \mathrm{s}$, llegando a alcanzar en algunas épocas del año los $8 \mathrm{~m} / \mathrm{s}$. Es por ello, que se puede considerar que la velocidad del viento en esta área es muy buena para el proyecto que se pretende realizar. La calificación de esta área es de 4 puntos. 


\subsubsection{Cercanía a los clientes}

Marcona es una ciudad con un gran desarrollo comercial ya que existe una gran explotación mineral en la zona. De ellas sobresale la explotación del hierro a gran escala para el mercado internacional. La empresa Shougang Hierro Perú es la única productora de hierro a nivel nacional y realiza sus operaciones en este distrito. Según el Ministerio de Energía y Minas, esta empresa está registrando un incremento sostenido en su capacidad de producción gracias a las ventajas comparativas que existen en la mina, como el alto contenido de hierro (del orden de $47 \%$ a 58\%), la ubicación estratégica de la mina que facilita el transporte del mineral a través de una faja transportadora, las altas reservas probadas de hierro, y la existencia de un puerto propio. Además, la empresa pretende realizar un proyecto de expansión de la mina, así como un proyecto para procesar los relaves generados.

Figura 3.10.

Ubicación de Mina Shougang

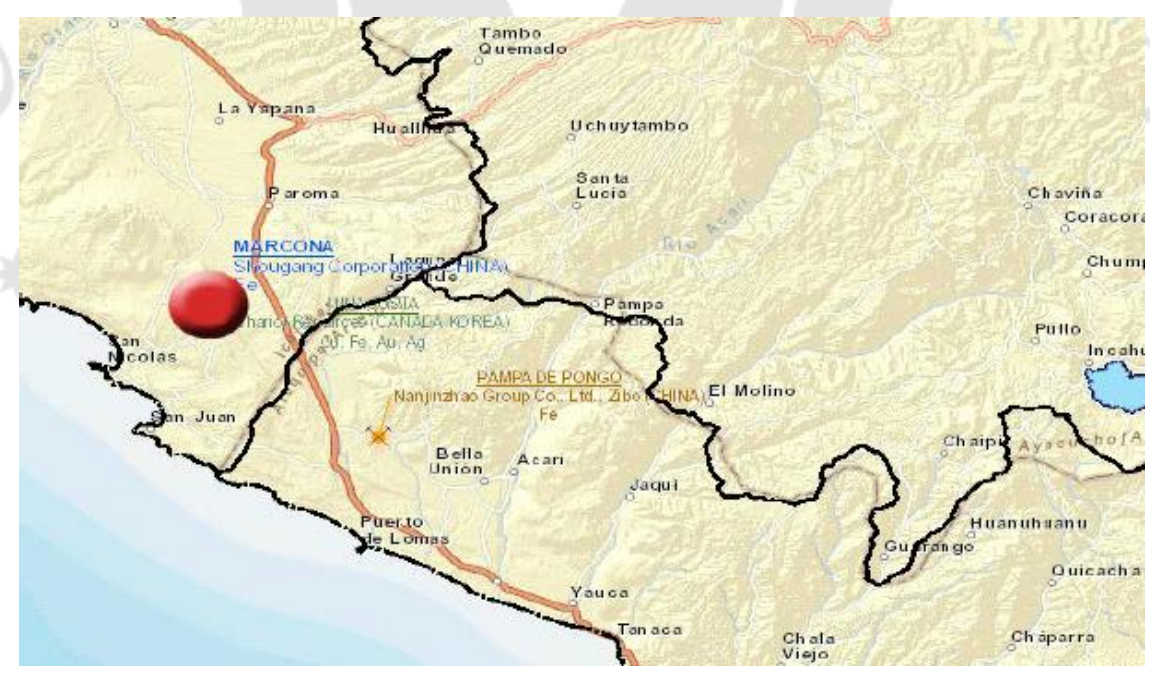

Fuente: MINEM

Además de los proyectos mineros de Shougang, existe otro proyecto de inversión minero que va a desarrollarse en el distrito, se trata del proyecto Mina Justa de Marcobre, que consistirá en la producción de 112 mil toneladas 
métricas finas de cobre anuales. Debido a la fuerte presencia de proyectos mineros en el área, se puede concluir que Marcona se encuentra en una excelente ubicación con respecto a la cercanía de sus clientes, por ello se le otorga una calificación de 5 puntos en este factor.

En el distrito de Paracas no se desarrolla ningún tipo de actividad minera formal. Sin embargo, en setiembre del 2013 se detectó la presencia de una planta minera ilegal en la zona de amortiguamiento de la Reserva Nacional de Paracas, esta planta procesaba material y relaves de minería ilegal provenientes de Huancavelica y Ayacucho. Por otro lado, el proyecto minero más cercano a la zona es el Proyecto Llama TY01, el cual será ejecutado por Jintong Mining Perú en el distrito de Pisco, el proyecto aún se encuentra en etapa de exploración y no se tiene fecha definida para el inicio de operaciones.

Figura 3.11.

Minera ilegal en Paracas

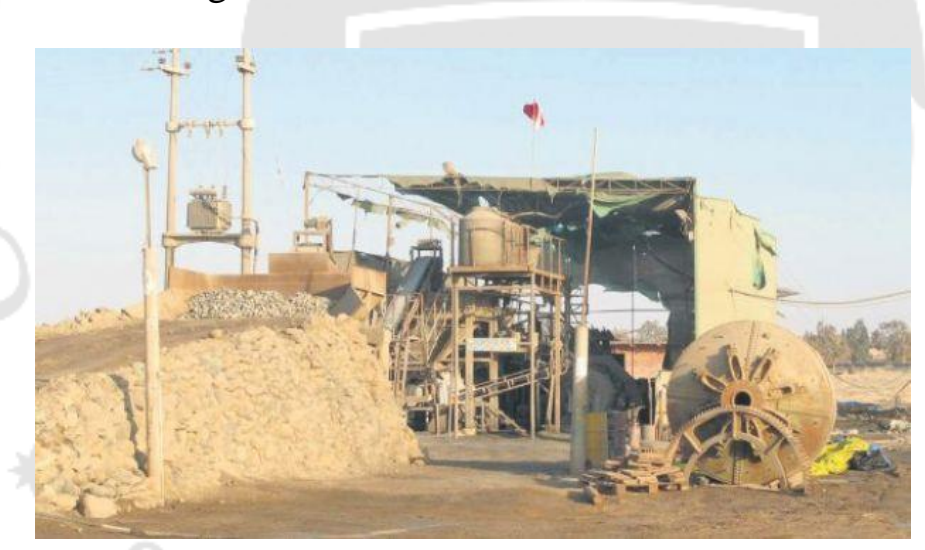

Fuente: El Comercio

Debido a que la única minera que se encuentra en el distrito de Paraca es informal y ya fue destruida, y el proyecto minero formal más cercano se encuentra en otro distrito a varios kilómetros de distancias de la posible localización de la planta; se puede concluir que Paracas tiene una cercanía regular a los clientes. Es por ello que para el factor de cercanía a los clientes, Paracas tiene una calificación de 2 puntos. 
3.2.3.3. Disponibilidad de terreno

Actualmente, el distrito de Paracas está experimentando un boom inmobiliario. Hace cuatro años empezaron a construirse y venderse los primeros departamentos y condominios en esta zona. Es más, se está llegando a considerar que Paracas se ha convertido en el nuevo punto de inversión costera y por ello los terrenos se han valorizado mucho. Además de ello, se debe tener en cuenta que es este distrito se encuentra ubicada la Reserva Natural de Paracas, lugar que ocupa un vasto espacio. Debido al reciente desarrollo inmobiliario de la zona y a la presencia de una Reserva Natural, se puede considerar que Paracas es un punto regular para la implementación del proyecto, por ende se le otorga una calificación de 2 puntos con respecto a este factor.

El distrito de Marcona es el distrito más grande dentro de la provincia de Nazca. Posee una gran cantidad de terrenos, algunos de los cuales han sido concesionados a las distintas mineras que operan en el área, y a algunos proyectos de desarrollo de energía eléctrica. Además, se trata de una localidad que está experimentando un crecimiento económico considerable, es por ello que se puede suponer que la ciudad también está experimentando un crecimiento demográfico; sin embargo al tener una amplia superficie, seguirá existiendo disponibilidad de terrenos. Por lo anterior se puede decir que Marcona es una ubicación buena con respecto a este factor, por ello se le otorgan 3 puntos.

\subsubsection{Características geográficas del terreno (Rugosidad del terreno)}

A una gran altura de la superficie del suelo, más o menos 1 kilómetro, la superficie terrestre casi no ejerce influencia alguna sobre el viento. Sin embargo, en las capas más bajas de la atmósfera, las velocidades del viento se ven afectadas por la fricción con la superficie terrestre. En la industria eólica, 
se distingue como rugosidad del terreno, a la influencia de los obstáculos, y a la influencia del contorno del terreno sobre la velocidad del viento (Windpower, 2003). Cuanto más pronunciada sea la rugosidad del terreno mayor será la ralentización que experimente el viento. Por ejemplo, los bosques y las grandes ciudades ralentizan mucho el viento, pero las pistas de hormigón de los aeropuertos lo ralentizan ligeramente.

En la industria eólica, se suele referir a la clase de rugosidad cuando se trata de evaluar las condiciones eólicas de un paisaje. Una alta rugosidad de clase 3 o 4 se refiere a paisajes con muchos árboles y edificios, mientras que la superficie del mar representa rugosidad de clase 0 , y las pistas de hormigón de los aeropuertos representan una rugosidad de clase 0.5 . A continuación, se presenta una tabla que describe los distintos tipos terreno para cada clase de rugosidad.

\section{Tabla 3.1.}

Clases de rugosidad

\begin{tabular}{|c|c|c|c|}
\hline $\begin{array}{c}\text { Clase de } \\
\text { rugosidad }\end{array}$ & $\begin{array}{c}\text { Longitud } \\
\text { de } \\
\text { rugosidad } \\
\text { m }\end{array}$ & $\begin{array}{c}\begin{array}{c}\text { Índice } \\
\text { de } \\
\text { energía } \\
(\%)\end{array} \\
\end{array}$ & Tipo de paisaje \\
\hline 0 & 0,0002 & 100 & Superficie del agua \\
\hline 0,5 & 0,0024 & 73 & \multirow{2}{*}{$\begin{array}{c}\text { Terreno completamente abierto con una superficie lisa, } \\
\text { p.ej., pistas de hormigón en los aeropuertos, césped } \\
\text { cortado, etc. } \\
\text { Área agrícola abierta sin cercados ni setos y con } \\
\text { edificios muy dispersos. Sólo colinas suavemente } \\
\text { redondeadas }\end{array}$} \\
\hline 1 & 0,03 & 52 & \\
\hline 1,5 & 0,055 & 45 & \multirow{3}{*}{$\begin{array}{c}\text { Terreno agrícola con algunas casas y setos } \\
\text { resguardantes de } 8 \text { metros de altura con una distancia } \\
\text { aproximada de } 1250 \mathrm{~m} \text {. } \\
\text { Terreno agrícola con algunas casas y setos } \\
\text { resguardantes de } 8 \text { metros de altura con una distancia } \\
\text { aproximada de } 500 \mathrm{~m} \text {. } \\
\text { Terreno agrícola con muchas casas, arbustos y plantas, } \\
\text { o setos resguardantes de } 8 \text { metros de altura con una } \\
\text { distancia aproximada de } 250 \mathrm{~m} \text {. } \\
\text { Pueblos, ciudades pequeñas, terreno agrícola, con } \\
\text { muchos o altos setos resguardantes, bosques y terreno } \\
\text { accidentado y muy desigual }\end{array}$} \\
\hline 2,5 & 0,2 & 31 & \\
\hline 3 & 0,4 & 24 & \\
\hline 3,5 & 0,8 & 18 & Ciudades más grandes con edificios altos \\
\hline 4 & 1,6 & 13 & Ciudades muy grandes con edificios altos y rascacielos \\
\hline
\end{tabular}


El distrito de Paracas se caracteriza por ser una zona costera, desértica y llana. Es un área donde no existe la presencia de montañas, presentando características uniformes de velocidad. A partir de esa descripción, se puede definir que Paracas tiene una clase de rugosidad de 1, lo que hace al terreno muy bueno para la implementación del proyecto. Esta zona tiene una calificación de 4 puntos para este factor.

Por otro lado, el distrito de Marcona se caracteriza geográficamente por ser un terreno desértico típico de la costa central y sur del Perú. En el área se hallan mesetas, pampas y altos cerros, además de una gran variedad de playas. Con estas características, se puede suponer que Marcona es un terreno con clase 1.5, lo que lo convierte en un terreno bueno para la implementación del proyecto, por ello tiene una calificación de 3 puntos en este factor.

\subsubsection{Existencia de reservas naturales o parques nacionales cercanos}

En el distrito de Paracas está ubicada la Reserva Natural de Paracas, la cual es una zona protegida del Perú. Esta zona fue declarada como reserva natural en setiembre del año 1975, y fue creada como tal a fin de conservar una porción de mar y del desierto de la zona, para dar protección a las diversas especies de flora y fauna silvestres que habitan allí. La Reserva Natural alberga una amplia variedad de especies migratorias y es muy importante para su alimentación y como refugio durante sus largas travesías anuales. La reserva tiene ambientes propicios en la costa para la conservación y tranquila reproducción de numerosas especies de aves residentes y migratorias. Entre las cuales se encuentran los pelícanos, la gaviota gris, el zarcillo, el rayador, el cóndor, el guanay, el pingüino de Humboldt y los flamencos. 
Figura 3.12.

Mapa de la Reserva Natural de Paracas

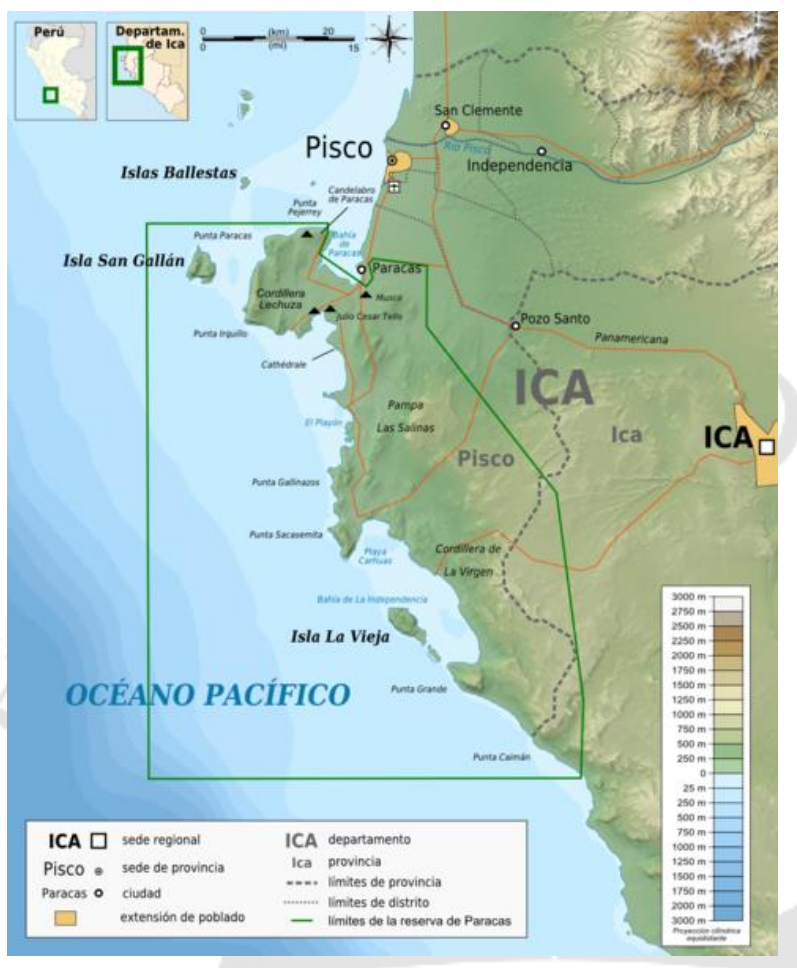

Fuente: Google maps

Las aves a menudo colisionan con líneas de alta tensión, postes y ventanas. A pesar de que las aves rara vez son molestadas por aerogeneradores, estos las obligan a cambiar su ruta de vuelo unos 100 o 200 metros antes de llegar a la turbina. Según un estudio del Ministerio de Medio Ambiente Danés, el mayor peligro de un parque eólico para las aves, se encuentra en las líneas de alimentación y transmisión ya que existe una alta probabilidad de colisión con estas; además este estudio concluye que la probabilidad de levantar parques eólicos al lado de santuarios de aves depende de la especie en cuestión, y se debe tener en cuenta las rutas migratorias de las aves. Debido a la gran existencia de aves migratorias existentes en la Reserva Natural, y al posible impacto que los aerogeneradores podrían tener en las aves, se puede concluir que Paracas es una mala ubicación para el proyecto, por ende se le da una calificación de 1 punto en este factor.

Con respecto al distrito de Marcona, posee una zona marina reservada llamada Reserva de Punta San Juan, en este refugio se pueden encontrar una gran 
cantidad de lobos marinos, variedad de aves guaneras y la colonia más numerosa de pingüinos de Humboldt en el Perú. Además, en Marcona se encuentra la Ensenada de San Fernando, la cual posee una gran biodiversidad marina, debido a sus aguas frías que albergan grandes bancos de sardinas y anchovetas, las cuales sirven como alimento a muchas de las aves guaneras que habitan en la zona. Debido a que las zonas naturales con alta biodiversidad en Marcona se encuentran dentro del mar, y el proyecto del parque eólico propuesto será on-shore, es decir en tierra firme, esta provincia es buena para la realización del proyecto, por ende se le otorga una calificación de 4 puntos.

3.2.4. Evaluación y selección de la micro localización

Para la evaluación de las alternativas propuestas se debe realizar una ponderación de los distintos factores de localización. El peso que se le asigne a cada factor determinará el grado de importancia de dicho factor en la elección de la localización.

3.2.4.1. Ponderación porcentual de los factores de localización

Los factores son:
A. Disponibilidad de materia prima
B. Cercanía a los clientes
C. Disponibilidad de terreno
D. Características geográficas del terreno (Rugosidad del terreno)
E. Existencia de reservas naturales o parques nacionales cercanos

A continuación, se presenta la tabla de enfrentamiento de los factores de localización, la cual ayudará a determinar cuáles son los factores más importantes para la elección de la localización del proyecto. 
Tabla 3.2.

Tabla de enfrentamiento de factores de localización

\begin{tabular}{|c|c|c|c|c|c|c|c|}
\cline { 2 - 9 } \multicolumn{1}{c|}{} & A & B & C & D & E & Conteo & Pond. \\
\hline A & & 1 & 1 & 1 & 1 & 4 & $33.3 \%$ \\
\hline B & 0 & & 1 & 1 & 1 & 3 & $25.0 \%$ \\
\hline C & 0 & 0 & & 1 & 1 & 2 & $16.7 \%$ \\
\hline D & 0 & 0 & 1 & & 0 & 1 & $8.3 \%$ \\
\hline E & 0 & 0 & 1 & 1 & & 2 & $16.7 \%$ \\
\hline
\end{tabular}

Elaboración propia

A partir de la tabla de enfrentamiento, se puede concluir que los factores más importantes para la elección de la ubicación de la planta son: la disponibilidad de materia prima y la cercanía a los clientes.

\subsubsection{Ranking de factores}

Para la selección final de la ubicación de la planta generadora de energía eólica, se utilizará el método de Ranking de Factores, considerando el peso obtenido en la tabla de enfrentamiento de cada uno de los factores, y la calificación otorgada a cada una de las posibles ubicaciones. A continuación, se muestra el cuadro.

Tabla 3.3.

Ranking de factores

\begin{tabular}{|c|c|c|c|c|c|}
\hline \multicolumn{2}{|c|}{ Candidatos } & \multicolumn{2}{|c|}{ Paracas } & \multicolumn{2}{|c|}{ Marcona } \\
\hline Factor & Peso & Calif. & Puntaj. & Calif. & Puntaj. \\
\hline Materia Prima & $33.3 \%$ & 5 & 1.667 & 4 & 1.333 \\
\hline Mercado & $25.0 \%$ & 2 & 0.500 & 5 & 1.250 \\
\hline Disponibilidad de Terreno & $16.7 \%$ & 2 & 0.333 & 3 & 0.500 \\
\hline Rugosidad de Terreno & $8.3 \%$ & 4 & 0.333 & 3 & 0.250 \\
\hline Reservas Naturales & $16.7 \%$ & 1 & 0.167 & 4 & 0.667 \\
\hline Total & & & 3.00 & & 4.00 \\
\hline
\end{tabular}

Elaboración propia 
A partir del ranking de factores, se obtiene que la mejor ubicación para la planta generadora de energía eólica es el distrito de Marcona, en la provincia de Nazca, en la región de Ica. A continuación, se presenta un mapa con la ubicación de la planta.

Figura 3.13.

Localización de la planta

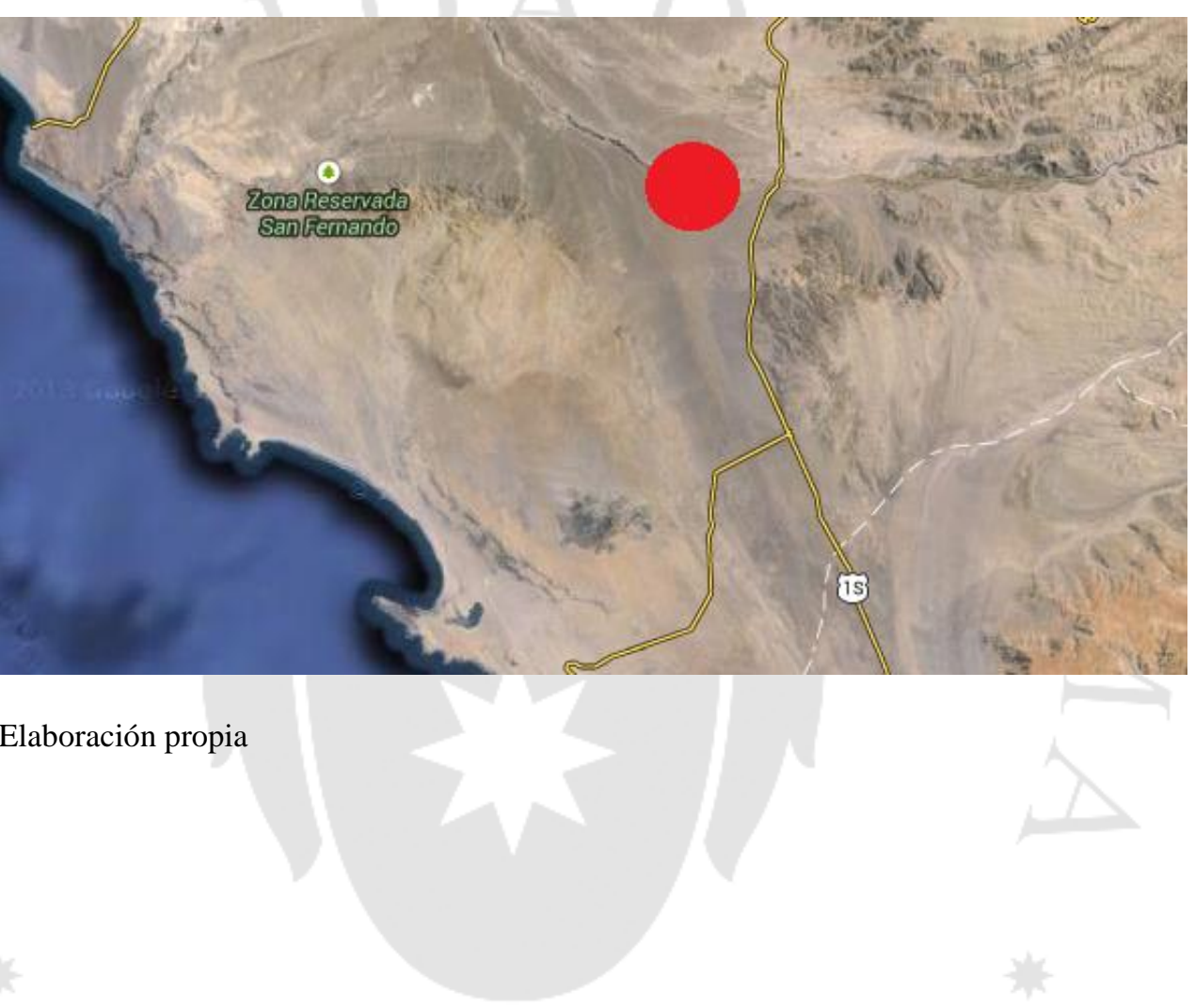




\section{CAPÍTULO IV: TAMAÑO DE PLANTA}

\subsection{Relación tamaño-mercado}

Como se definió en el capítulo 2 del presente estudio, se espera que el mercado del proyecto sean los proyectos mineros más cercanos de la zona establecida. En el caso del distrito de Marcona, existe una minera que opera en la zona, con plan de ampliación, además de un proyecto para el establecimiento de una planta procesadora de relaves y otro proyecto de explotación mineral.

Además, se identificó que en la zona existen otros dos proyectos similares de generación de energía eólica, por lo que se espera que alguno de estos proyectos también se encargue de proveer de energía eléctrica a las mineras de la zona. Es por ello que se definió que el tamaño de planta debería ser similar al tamaño de los proyectos existentes. Es así como se define que el tamaño de la planta según el mercado debe ser de $36.8 \mathrm{MW}$ de potencia.

\subsection{Relación tamaño-recursos productivos}

El principal recurso productivo de la energía eólica es la velocidad del viento. Las velocidades del viento en la zona elegida para la implementación del parque eólico oscilan entre los $6 \mathrm{~m} / \mathrm{s}$ y $\operatorname{los} 8 \mathrm{~m} / \mathrm{s}$, durante todo el año. Sin embargo, debido a que el viento es un recurso renovable e infinito, este factor no representa una limitante para determinar el tamaño del proyecto.

\subsection{Relación tamaño-tecnología}

Los equipos a utilizarse con los aerogeneradores horizontales de tres palas, marca Siemens, modelo SWT-2.3-108 con una potencia nominal de 2.3 MW. Además de estos equipos, se usará una línea de transmisión subterránea al transformador que consta de unos cables trifásicos conductores y un cable de línea a tierra. Por 
último, se implementará una subestación eléctrica con un transformador elevador de voltaje de $20 \mathrm{kV}$ a $220 \mathrm{kV}$.

Se espera que para el proyecto se utilicen 16 de los equipos SWT-2.3-108. Con estos equipos se espera que la planta tenga una capacidad instalada de $36.8 \mathrm{MW}$ de potencia.

\subsection{Relación tamaño-punto de equilibrio}

Para el cálculo del punto de equilibrio se debe definir un precio para la energía generada. Además se debe de considerar los costos variables de la generación de la energía y los costos fijos a los que incurre.

El concepto de punto de equilibrio se refiere al punto en donde los ingresos totales recibidos se igualan a los costos asociados con las ventas del producto, este concepto se expresa en la siguiente ecuación.

Punto de Equilibrio $=$ Costos Fijos Totales $/($ Precio - Costo Variable $)$

Costos fijos totales: Se obtiene sumando los costos de sueldos de personal y servicios que tienen un costo total de S/. 1,756,460 por año. Este monto se detalla más específicamente en el capítulo 7.

Precio: En el capítulo 2.5.2.2, se definió un precio de venta para que el parque pueda competir en el mercado y que sea rentable para la operación, este equivale a US\$ 0.089 por cada $\mathrm{kW}$-h que multiplicado a un tipo de cambio de 3.1 PEN/USD equivale a 0.2759 PEN/kW-h.

Costo variable: Se obtiene sumando los costos variables obtenidos a partir de los costos de operación, mantenimiento y seguros. En países como España o Alemania los costos de operación y mantenimiento se estiman entre USD 0,014 y USD 0,018 por kWh generado por el parque eólico. En el caso específico de España indica que el $60 \%$ de ese del monto es para operación y mantenimiento y el otro $40 \%$ comprende seguros, renta de la tierra y otros gastos (European Wind Energy Association, 2009). 
En el caso del parque se considera el peor escenario con un precio de USD 0.018 para efectos de cálculo que llevado a soles a un tipo de cambio de 3.1 PEN/USD equivale a $0.0558 \mathrm{PEN} / \mathrm{kW}-\mathrm{h}$.

Punto de equilibrio $=1,752,960 /(0.2759-0.0558)=7,980,282 \mathrm{~kW}-\mathrm{h}=$ 7,980 MW-año

Esto quiere decir que para lograr un punto de equilibrio sólo teniendo en cuenta los costos fijos, variables e ingresos anuales se necesita producir al menos 7,980 MW-año.

\subsection{Selección del tamaño de planta}

Para la selección del tamaño de planta se considerará la relación tamaño-mercado ya que al tratarse de un recurso renovable como el aire y al existir diferentes tipos de tecnología con diversas capacidades de generación, el factor más determinante para la definición del tamaño de la planta generadora de energía es el mercado. Los aerogeneradores son los principales equipos que se van a utilizar para la generación de energía eléctrica. El tamaño de la planta depende del número de aerogeneradores que se utilicen, por ello el tamaño de la planta será de 36.8 MW. 


\section{CAPÍTULO V: INGENIERÍA DEL PROYECTO}

5.1. Definición del servicio basada en sus características tecnológicas

El servicio consiste en la producción de energía eléctrica por medio de una planta eólica ubicada al norte del distrito de Marcona, provincia de Nazca en el departamento de Ica. La planta tendrá una potencia instalada de 36.8 MW y contara con 16 torres de 79.5 metros.

\subsubsection{Especificaciones técnicas del servicio}

La potencia generada se inyectará al SEIN mediante una Línea de Transmisión de aproximadamente $32 \mathrm{~km}$ en $220 \mathrm{kV}$ que conectará la S.E. Central Parque Eólico Marcona con la S.E. Marcona existente. En la figura 5.1 se puede observar un esquema representativo del parque eólico.

La construcción de la subestación se realizará de forma paralela a la del para que para que cuando se termine su construcción se pueda evacuar la energía generada. La subestación contará con un transformador de potencia de 26/38 MVA de 220/20 KV con regulación de tensión bajo carga. 
Figura 5.1.

Modelo simple de un parque eólico

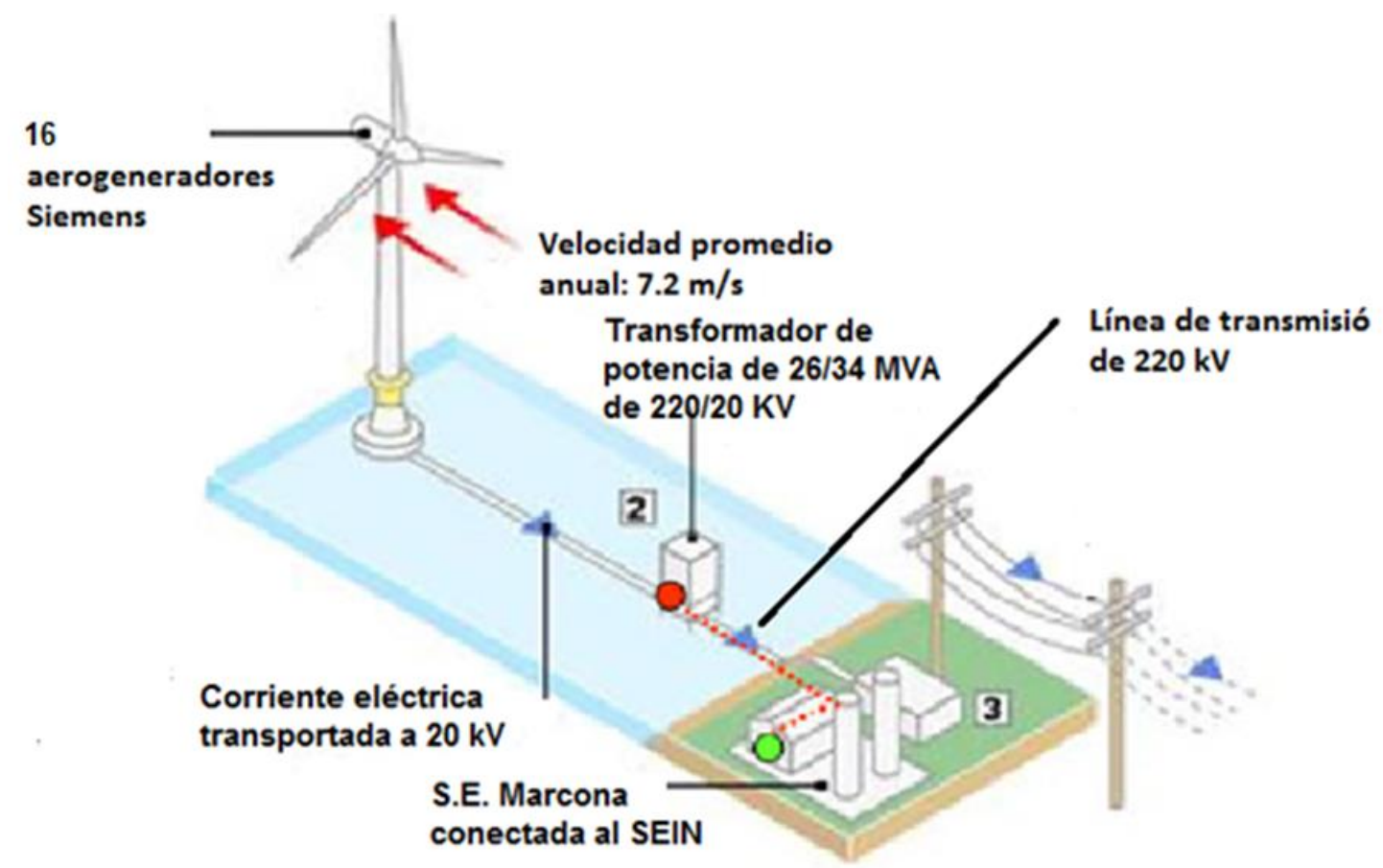

Elaboración propia

5.2. Tecnología existente y proceso de realización del servicio

5.2.1. Naturaleza de la tecnología requerida

Para la descripción de la tecnología existente se va a proceder a dividir los aerogeneradores en dos subtipos más: según el eje del motor y según la potencia suministrada. Según al eje del motor se puede subdividir en dos grupos más: aerogeneradores de eje vertical y aerogeneradores de eje horizontal. En el siguiente punto se mencionan los aerogeneradores utilizados por cada equipo de aerogenerador. 
5.2.1.1 Descripción de la tecnología existente

a) Según el eje del motor: Pueden subdividirse de ejes verticales y ejes horizontales. Es decir el eje principal donde se encuentra el buje tiene una orientación vertical u horizontal.

Eje vertical: Aerogeneradores de eje vertical tienen la ventaja de que no necesitan un sistema de orientación ya que las principales partes del aerogenerador (multiplicador, generador, etc.) son instaladas al ras del suelo, facilita su mantenimiento en el suelo y disminuye costes de montaje. Sin embargo, sus desventajas frente a los generadores horizontales son que tienen una menor eficiencia, tienen necesidad de sistemas exteriores de arranque en algunos modelos, y que al desmontaje del rotor por tareas de mantenimiento es necesaria que toda la máquina sea desmontada.

- Aerogenerador vertical con rotor Savonius: Es el modelo más simple de rotor; no obstante, no son útiles para la generación de electricidad debido a su elevada resistencia al aire. Su bajo coste y fácil construcción les hace útiles para aplicaciones mecánicas. Consiste en cilindros huecos desplazados respecto a su eje, de forma que ofrecen la parte cóncava al empuje del viento ofreciendo su parte convexa una menor resistencia al viento.

Figura 5.2.

Aerogenerador tipo Savonius

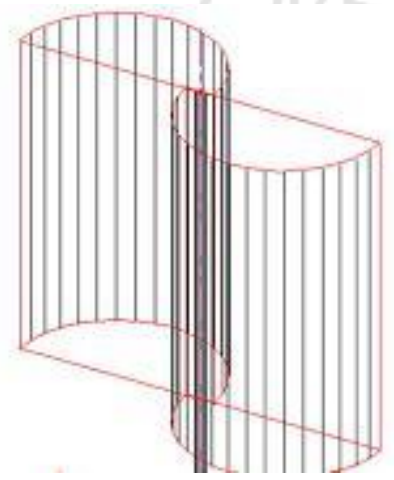

Fuente: EKOPLC 
- Aerogenerador con rotor Darrieus: que debe su nombre al ingeniero francés Georges Darrieus, quien patentó el diseño en 1931 (fue producida por la compañía estadounidense FloWind, que quebró en 1997). La máquina Darrieus se caracteriza por sus palas en forma de "C", que le hacen asemejarse a un batidor de huevos. Normalmente se construye con dos o tres palas. Las principales ventajas teóricas de una máquina de eje vertical son: puede situar el generador, el multiplicador, etc. en el suelo, y puede no tener que necesitar una torre para la máquina y no necesita un mecanismo de orientación para girar el rotor en contra del viento.

Las principales desventajas son: las velocidades del viento cerca del nivel del suelo son muy bajas, por lo que a pesar de que puede ahorrase la torre, sus velocidades de viento serán muy bajas en la parte más inferior de su rotor. También la eficiencia promedio de esta máquina no es impresionante comparadas con las de eje horizontal.

Además la máquina no es de arranque automático (es decir, una máquina Darrieus necesitará un "empuje" antes de arrancar. Sin embargo, esto es sólo un inconveniente sin importancia, ya que puede utilizar el generador como motor absorbiendo corriente de red para arrancar la máquina).

Por último, puede necesitar cables tensores que la sujeten, aunque esta solución no es practicable en áreas muy cultivadas y para sustituir el cojinete principal se necesita desmontar el rotor (Windpower, 2000). 
Figura 5.3.

Aerogenerador tipo Darrieus

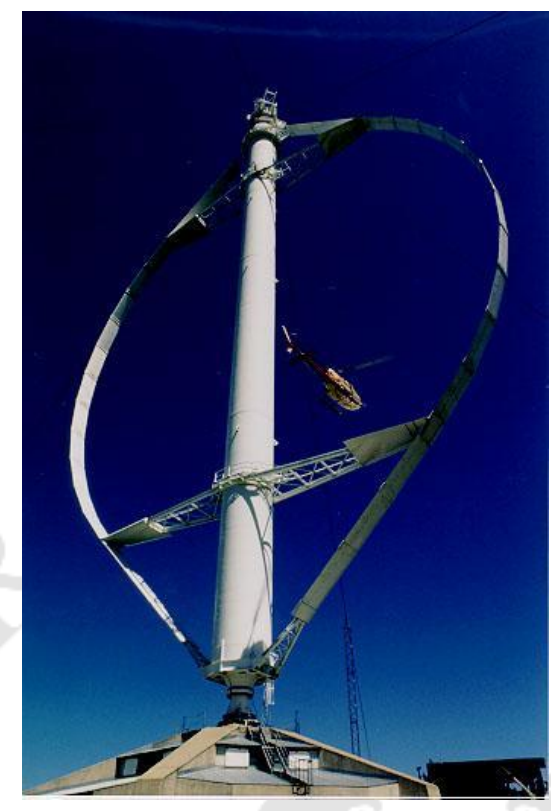

Fuente: EKOPLC

- Aerogenerador vertical con rotor tipo Giromil: Este tipo de generadores también fueron planteados por Darreus. Consiste en palas verticales unidas al eje por unos brazos horizontales, que pueden salir por los extremos del aspa e incluso desde su parte central. Las palas verticales cambian su orientación a medida que se produce el giro del rotor para un mejor aprovechamiento de la fuerza del viento. 
Figura 5.4.

Aerogenerador con rotor Giromil

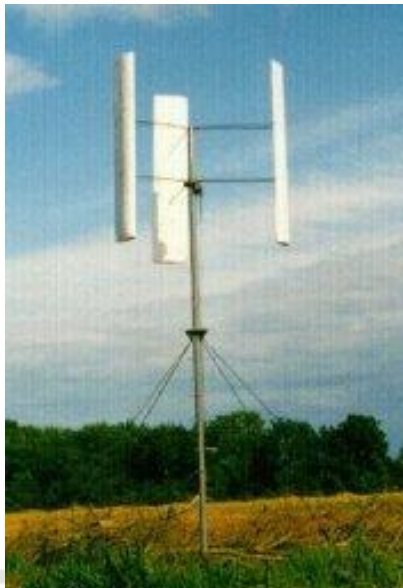

Fuente: EKOPLC

- Aerogenerador con rotor Windside: Tiene un sistema similar al rotor Savonius, en vez de la estructura cilíndrica para el aprovechamiento del viento. Consiste en un perfil alabeado por torsión que asciende por el eje vertical. La principal diferencia frente a los otros sistemas de eje vertical es el aprovechamiento aerodinámico, que le acerca a las eficiencias de los aerogeneradores de eje horizontal.

Figura 5.5.

Aerogenerador Windside

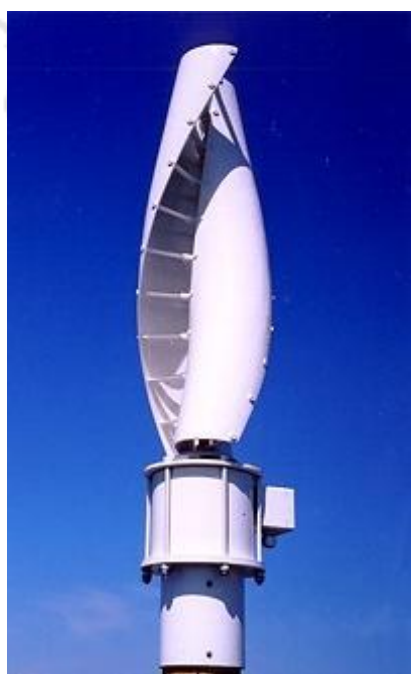

Fuente: EKOPLC 
Eje horizontal: En la actualidad la gran mayoría de los aerogeneradores comerciales conectados a la red se construyen con un rotor tipo hélice de eje horizontal (es decir, de eje principal horizontal).

Por supuesto, la finalidad del rotor es la de convertir el movimiento lineal del viento en energía rotacional que pueda ser utilizada para hacer funcionar el generador. Los aerogeneradores horizontales tienen una mayor eficiencia energética y alcanzan mayores velocidades de rotación por lo que necesitan cajas de engranaje con menor relación de multiplicación de giro. Además debido a su fabricación elevada aprovechan en mayor medida el aumento de la velocidad del viento con la altura. Los modelos de eje horizontal pueden subdividirse a su vez por el número de palas empleado por la orientación respecto a la dirección dominante del viento.

- Tripala: Es el más empleado, consta de 3 palas formando un ángulo e $120^{\circ}$ entre sí. Un mayor número de palas aumenta el peso y coste del aerogenerador, por lo que no se emplean diseños con mayor número de palas para fines comerciales (Windpower, 2000).

\section{Figura 5.6.}

Aerogenerador tripala

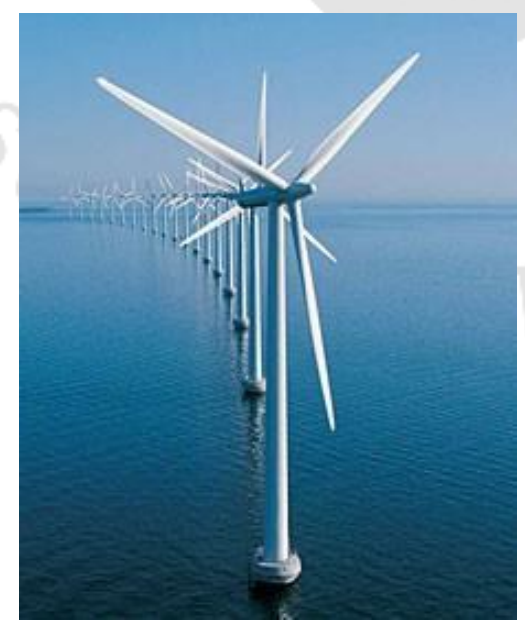

Fuente: EKOPLC 
- Aerogenerador bipala: Ahorran el peso y coste de una de las palas respecto a los aerogeneradores tripala, pero necesitan mayores velocidades de giro para producir la misma energía. Para evitar el efecto desestabilizador necesitan de un rotor basculante y amortiguadores para evitar que choquen con la torre.

Figura 5.7.

Aerogenerador bipala

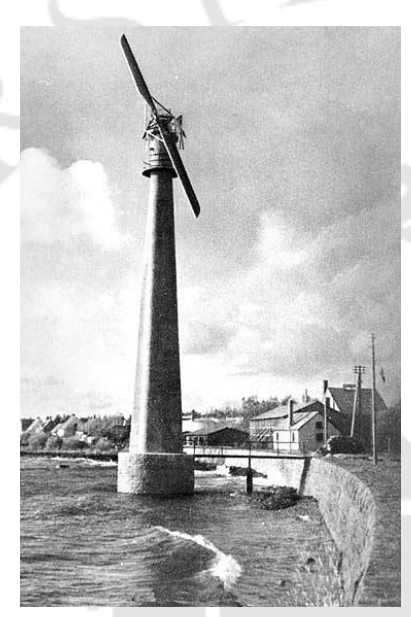

Fuente: EKOPLC

- Aerogenerador monopala: Tienen los mismos inconvenientes que los bipalas. aerogeneradores monopala no están muy extendidos comercialmente, pues los inconvenientes de los bipala también son aplicables, e incluso en mayor medida, a las máquinas monopala.

Además, de una mayor velocidad de giro, y de los problemas de ruido y de intrusión visual, necesitan un contrapeso en el lado del buje opuesto a la pala que equilibre el rotor. Obviamente, esto anula el ahorro de peso comparado con un diseño bipala. 
Figura 5.8.

Aerogenerador monopala

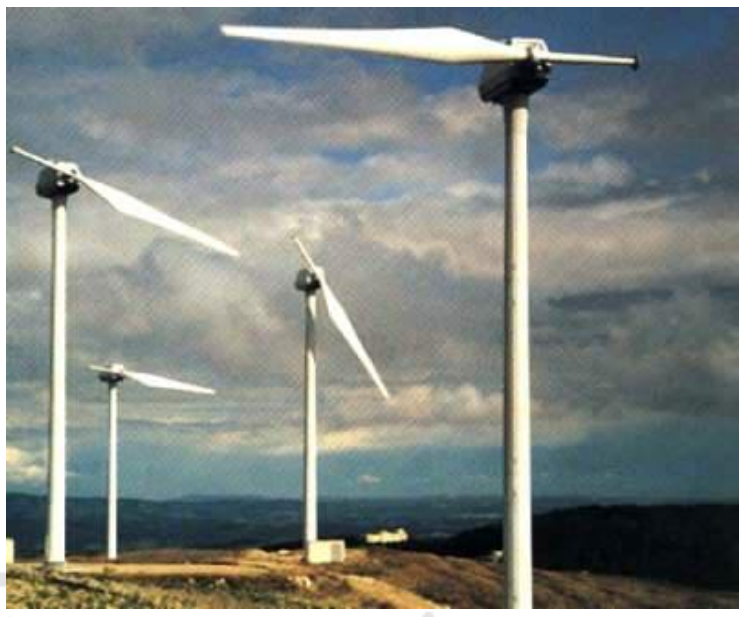

Fuente: EKOPLC

- Aerogeneradores horizontales orientados a barlovento: Se les llama así cuando el rotor está enfocado de frente a la dirección del viento. De esta manera se consigue un mayor aprovechamiento de la fuerza del viento que la opción contraria o sotavento, aunque necesita un mecanismo de orientación hacia el viento. Es el caso inmensamente preferido para el diseño actual de aerogeneradores.

Figura 5.9.

Aerogenerador tipo barlovento

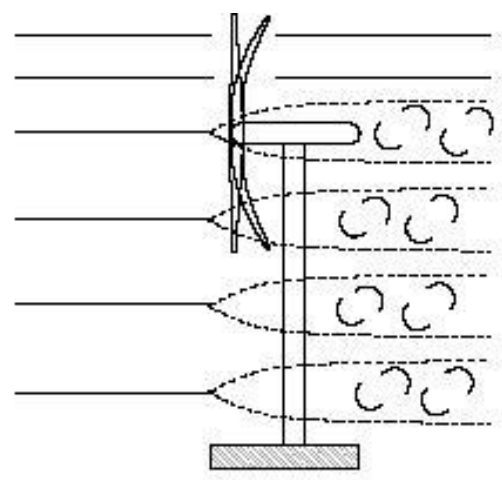

Fuente: Windpower.org 
- Aerogeneradores horizontales orientados a sotavento: Se les llama así cuando el rotor se encuentra en sentido contrario a la dirección del viento dominante, la estructura de la torre y la góndola disminuye el aprovechamiento del viento por el rotor. En este caso el viento es el que orienta con su propia fuerza la góndola, por lo que no son necesarios elementos de reorientación automatizada en la teoría, aunque si suelen utilizarse como elementos de seguridad. Las palas y las góndolas son construidas con una mayor flexibilidad que en el caso de orientados barloventos.

Figura 5.10.

Aerogenerador tipo sotavento

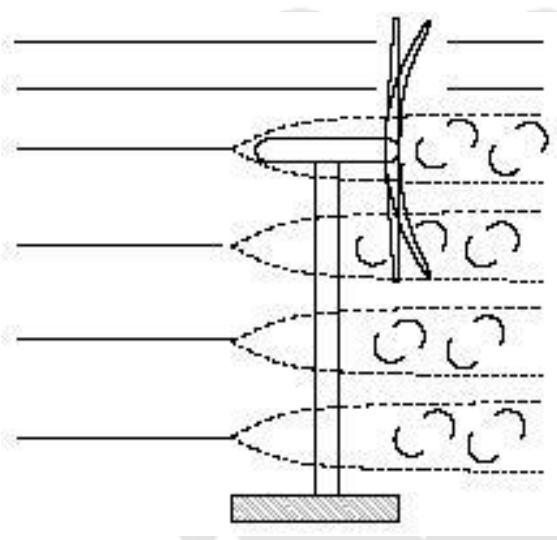

Fuente: Windpower.org

b) Según potencia suministrada:

- Equipos de baja potencia: Son los utilizados a la utilización mecánica como bombeo de agua, proporcionar potencias alrededor de $50 \mathrm{KW}$, aunque pueden utilizarse varios equipos adyacentes para aumentar la potencia suministrada. Hoy en día siguen utilizándose como fuente de energía para sistemas mecánicos o como suministro de energía de equipos aislados. 
Figura 5.11.

Aerogeneradores de baja potencia

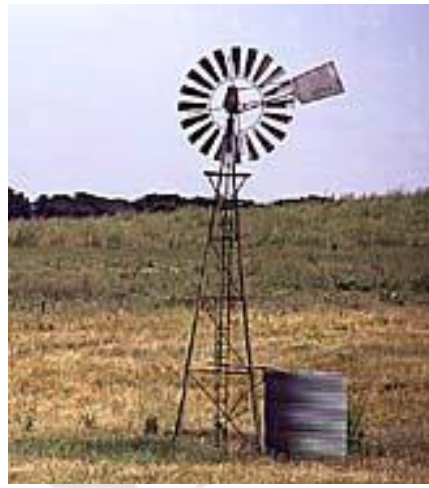

Fuente: Windpower.org

- Equipos de media potencia: Son los que se encuentran en el rango de producción de energía de $150 \mathrm{KW}$. Son utilizados de forma similar a los equipos de baja potencia pero para mayores requerimientos energéticos. No suelen estar conectados a baterías de almacenamiento, por lo que se utilizan a la red o junto con sistemas de respaldo.

- Equipos de alta potencia: Son los utilizados para producción de energía en forma comercial, aparecen conectados a red y grupos conformando centrales eolo eléctricas, ya sea en tierra como en entorno marino (offshore). Su producción llega hasta el orden del gigavatio. El diseño elegido mayoritariamente para estos equipos son los aerogeneradores de eje horizontal tripalas, orientados a barlovento con torre tubular (Windpower, 2000).

En la siguiente figura se pueden observar las diversas potencias suministradas por los aerogeneradores de acuerdo a la altura de las torres. Para elegir un aerogenerador se tiene que tener en cuenta factores como las necesidades energéticas, el presupuesto para el proyecto y las velocidades de vientos en la zona de instalación. Así mismo, para el cálculo de la velocidad se considera factores la rigurosidad del terreno, efecto estela ó efecto túnel de acuerdo a la ubicación de aerogeneradores, entre otros. 
Figura 5.12.

Aerogeneradores de potencia media y alta

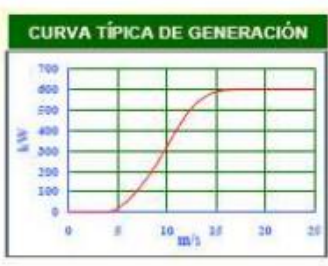

Capacidad, kW Altura, m Peso total, ton

Velocidad del viento, $\mathrm{m} / \mathrm{s}$ :

- De arranque

A potencia nominal

- De paro

Área barrida, $\mathrm{m}^{2}$

$\mathrm{M}$ Wh/año @ $9 \mathrm{~m} / \mathrm{s}$

$\mathrm{M} W \mathrm{~h} / \mathrm{m} 2$

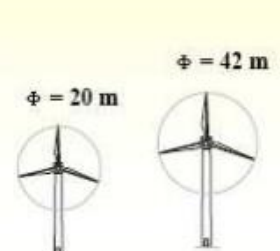

100

100
24
12

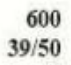

$39 / 50$
49

49

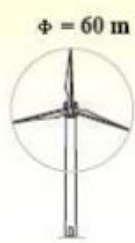

1300

$60 / 69$

125

$$
\begin{array}{r}
4 \\
15 \\
25
\end{array}
$$

2826

4867

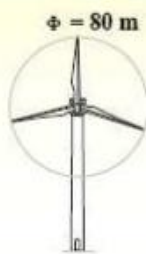

2000

$78 / 100$

225

$$
\begin{array}{r}
4 \\
15 \\
25 \\
5024 \\
8230 \\
1.6
\end{array}
$$$$
5024
$$$$
8230
$$

Fuente: Asociación Federal de Energía Eólica (BWE), Alemania

\subsubsection{Selección de la tecnología}

Para el presente proyecto, se tomará en consideración los criterios de diseño aplicados a los aerogeneradores que se refieren al tipo de ejes y al número de palas; mientras que los criterios de producción considerados se refieren a la cantidad de energía a producir y a la velocidad anual del viento.

- Tipo de ejes: Horizontales

Se eligió ejes horizontales en vez de verticales debido a que aerogeneradores con ejes horizontales permiten un mayor funcionamiento de las hélices para la producción de energía. Así también estas máquinas tienen otras desventajas ya que las velocidades del viento que utiliza cerca del nivel del suelo son muy bajas, la eficiencia promedio de las máquinas de eje vertical no es considerable comparadas con las horizontales, la máquina no es de arranque automático, puede necesitar cables tensores que la sujeten y para sustituir el cojinete implica desmontar toda la máquina. 
- Número de palas: Tres

No se utilizaran aerogeneradores con un número par de palas ya que puede dar problemas de estabilidad en una máquina que tenga una estructura rígida. Tampoco se utilizará aerogenerador monopala debido a que presentan problemas similares de estabilidad que los bipalas y otros problemas adicionales como mayor generación de ruido e intrusión visual.

De este modo los aerogeneradores tripalas permiten una producción óptima con vientos altos y bajos sin generar costes adicionales que se tendrían por tener un número mayor de palas. Además son los más usados en los parques eólicos de grandes dimensiones alrededor del mundo.

- Cantidad de energía a producir: Se producirá una potencia nominal de $36 \mathrm{MW}$.

Para tener esta potencia nominal se tomará turbinas de gran tamaño con una producción real de cada aerogenerador de 1.5 MW.

- Velocidad anual del viento: Se tendrá una velocidad anual de $7-8 \mathrm{~m} / \mathrm{s}$ La velocidad de viento medio a una altura de $80 \mathrm{~m}$ es de 7 a $8 \mathrm{~ms}$ y en algunas zonas alcanza incluso promedio de $8-9 \mathrm{~m} / \mathrm{s}$ según el Atlas Eólico del Perú 2008, publicado por el ministerio de Energía y Minas.

5.2.2. Proceso de realización del servicio

\subsubsection{Descripción del proceso}

La fase de operación comienza cuando el viento incide sobre el rotor. Este incluye las palas y el buje. El viento al incidir sobre las palas, provoca un movimiento rotacional, que se transfiere al buje. Éste, a su vez, está acoplado al eje de baja velocidad del aerogenerador, transmitiéndole la potencia del movimiento. 
Posteriormente la actividad se traslada a la góndola, allí el movimiento del eje de baja velocidad es amplificado mediante la caja de engranajes, o multiplicador, que aumenta la velocidad de rotación del rotor unas 50 veces, para que la velocidad de rotación que recibe el generador, a través del correspondiente eje, sea de unas 1.500 r. p. m.

En el generador se convierte la energía mecánica en energía eléctrica. Su potencia varía en función de las características técnicas del aerogenerador en cuestión.

Los demás componentes de la góndola son complementarios, pero imprescindibles. Así, la unidad de refrigeración contiene un ventilador utilizado para enfriar el generador eléctrico. Además contiene una unidad refrigerante por aceite empleada para enfriar el aceite del multiplicador. El controlador electrónico es una computadora que continuamente monitoriza las condiciones del aerogenerador y que controla el mecanismo de orientación. En caso de cualquier disfunción (por ejemplo, un sobrecalentamiento en el multiplicador o en el generador) detiene automáticamente el aerogenerador y envía una señal a la computadora del operario encargado de su mantenimiento. Por su parte, el anemómetro y la veleta son instrumentos de medición del viento, necesarios para la monitorización y orientación que lleva a cabo el controlador del aerogenerador. De este modo, el controlador electrónico conecta el aerogenerador cuando el viento alcanza aproximadamente $3 \mathrm{~m} / \mathrm{s}, \mathrm{y}$ lo parará cuando esta velocidad exceda $\operatorname{los} 25 \mathrm{~m} / \mathrm{s}$, con el fin de proteger a la turbina y sus alrededores. Las señales de la veleta son utilizadas por el controlador electrónico para girar el aerogenerador en contra del viento, utilizando el mecanismo de orientación.

El eje de alta velocidad está equipado de un freno de disco mecánico de emergencia, utilizado en caso de fallo del freno aerodinámico, o durante las labores de mantenimiento de la turbina. 
Figura 5.13.

Góndola de una Aerogenerador 0:1

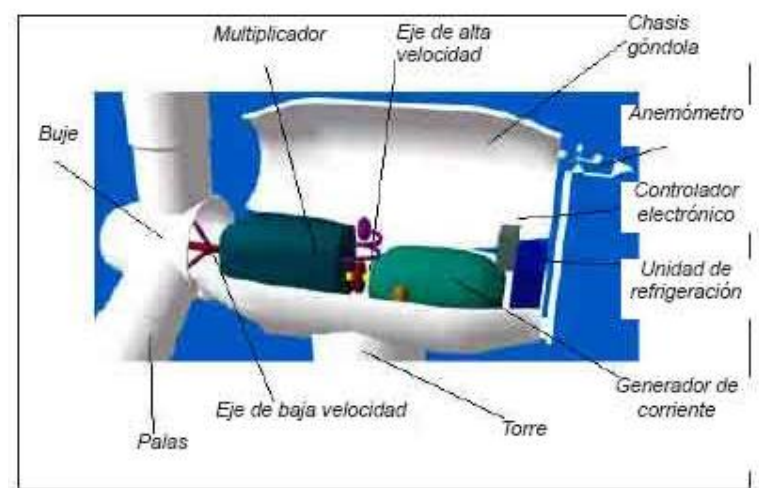

Fuente: Windpower.org

Posteriormente los cables se encargan de conducir la energía trifásica y alterna desde el aerogenerador hasta el regulador de cargas de las baterías. Éste detecta el estado de las baterías en cada momento, si en caso registrara una sobrecarga de energía, le cierra el paso y la disipa en forma de calor. Si es que no existe sobrecarga, la distribuye a las baterías, las que se encargan de almacenar la energía. Posteriormente la corriente pasa a un transformador que se encargara de convertir la energía eléctrica de $20 \mathrm{kV}$ a $220 \mathrm{kV}$. La electricidad a su vez pasa por un rectificador que transforma la energía alterna en continua y luego por un inversor que organiza el paso de la corriente que transforma la energía continua rectificada en energía alterna trifásica. Después de esto un filtro se encarga de depurar y modificar la onda sinodal de la corriente alterna y un contador registra la corriente producida en el parque eólico. Por último la corriente llega por una línea de transmisión de 32 km al SEIN en Marcona que se encargara de su distribución. 
5.2.2.1. Flujograma de procedimientos del parque eólico

Figura 5.14.

Flujograma del proceso

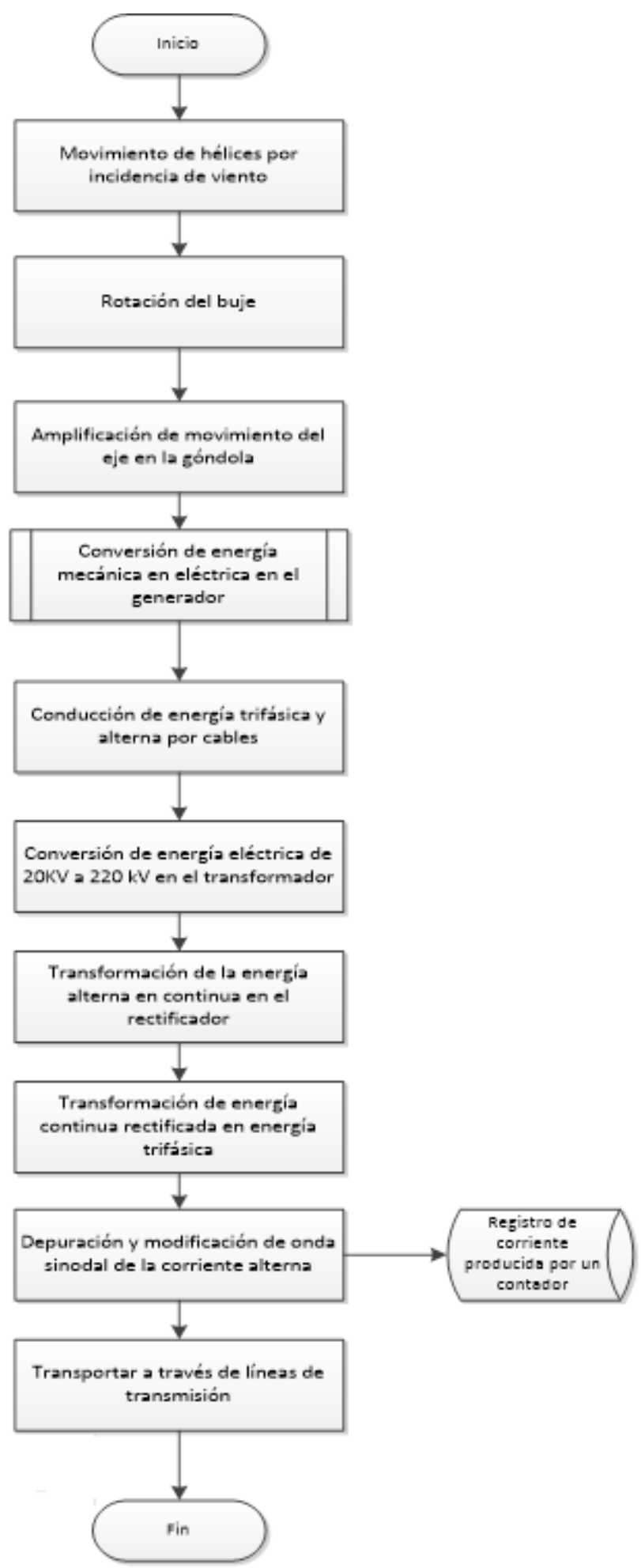

Elaboración propia 
5.3. Características de las instalaciones y equipo

\subsubsection{Selección de las instalaciones y equipo}

Según se determinó en los acápites 5.2.1.2. y 5.2.2.1, la elección del aerogenerador y demás equipos necesarios para la producción de energía eólica tienen que tener las siguientes características: ser aerogeneradores de alta potencia, tener una altura de 80 metros aproximadamente para alcanzar altas velocidades de viento, horizontales tripala, tipo barlovento, con torres tubulares, tener una potencia promedio por encima de los $2 \mathrm{MW}$ a velocidades promedio de $8 \mathrm{~m} / \mathrm{s}$.

Sin embargo, existen muchas alternativas en el mercado, en cuanto a capacidades y modelos. En base a ello, para tener una referencia en cuanto a qué modelo escoger, se necesita calcular la demanda total energética que se requiere de por encima de $35 \mathrm{KW}$.

Considerando los factores anteriores, para el siguiente proyecto se instalaran aerogeneradores con un diámetro de palas de $108 \mathrm{~m}$ a una altura aproximada de 80m de marca Siemens modelo SWT-108, los cuales serán de 2,3 MW de potencia nominal, con lo que la potencia nominal del parque será de 36,8 MW. De este modo, se conserva la potencia instalada y se estima superar la energía comprometida en un inicio de $35 \mathrm{MW}$.

El sistema de transmisión eléctrica se compone básicamente de una línea eléctrica de distribución circuito simple, corriente alterna trifásica. Los 16 aerogeneradores tendrán una tensión nominal de $0.69 \mathrm{KV}$ y se agruparán en 3 bloques conectados entre sí. Luego cada uno de estos bloques e conectará mediante 3 circuitos a la Subestación eléctrica de la central en el nivel de 20 KV. En esta subestación se instalará un transformador 20/220 KV, el cual se conectará a la Central Eléctrica de Marcona existente con una red de tendido de $32 \mathrm{~km}$. 
Tabla 5.1.

Especificaciones generales del modelo a utilizar

\begin{tabular}{cccccccc}
\hline $\begin{array}{c}\text { Modelo de } \\
\text { aerogenerador }\end{array}$ & $\begin{array}{c}\mathbf{N}^{\circ} \text { de } \\
\text { aerogeneradores }\end{array}$ & $\begin{array}{c}\text { Potencia } \\
(\mathbf{M W})\end{array}$ & $\begin{array}{c}\text { Altura } \\
(\mathbf{m})\end{array}$ & $\begin{array}{c}\text { Diámetro } \\
(\mathbf{m})\end{array}$ & $\begin{array}{c}\text { Velocidad } \\
\text { de arranque } \\
(\mathbf{m} / \mathbf{s})\end{array}$ & $\begin{array}{c}\text { Velocidad } \\
\text { nominal } \\
(\mathbf{m} / \mathbf{s})\end{array}$ & $\begin{array}{c}\text { Velocidad } \\
\text { de corte } \\
(\mathbf{m} / \mathbf{s})\end{array}$ \\
\hline SWT-2.3-108 & 16 & 2,3 & 80 & 108 & 3 a 4 & 11 a 12 & 25
\end{tabular}

Fuente: Siemens

\subsubsection{Especificaciones de las instalaciones y equipo}

La obra posee dieciséis máquinas marca Siemens, modelo SWT-108 de 2.3 MW. Cada uno está constituido por una turbina y un generador eléctrico situados en lo alto de una torre de acero, cimentada sobre una zapata de concreto armado. Además, en el interior del aerogenerador se incluye un centro de transformación de baja tensión a 20 kV.

El generador SWT-108 8 de 2.3 MW es de tipo DD PM asíncrono, y posee un intervalo de rotación de 600 a $1800 \mathrm{rpm}$. Tiene una tensión de $690 \mathrm{~V}$, frecuencia de red de $60 \mathrm{~Hz}$, factor de potencia de 0.9 cap -0.9 ind y clase de protección de IP 54. Su convertidor de frecuencia ostenta una operación de 4Q Full Scale converter, tipo de conmutación PW M y frecuencia de conmutación de 1,250/2,500 Hz. La turbina considera una potencia nominal de 2,300 kW, velocidad de conexión de 3 a 4 m por segundo y velocidad nominal de viento de 11 a $12 \mathrm{~m}$ por segundo. Su rotor posee tres palas, posición barlovento, diámetro de $105.2 \mathrm{~m}$, área barrida de $8,675 \mathrm{~m} 2$, y rango de velocidades de 6 a $16 \mathrm{rpm}$. Con relación a las palas, estas tienen una longitud de $52.6 \mathrm{~m}$ y son de resina epoxy reforzada con fibra de vidrio. Finalmente, dispone de una multiplicadora de tipo planetario/helicoidal de tres etapas y un ratio de 1:91, mientras que su torre es cilíndrica y/o cónica tubular y posee una altura de buje de $80 \mathrm{~m}$. (Siemens, 2009) 
Tabla 5.2.

Especificaciones del aerogenerador Siemens modelo SWT - 2.3- 108

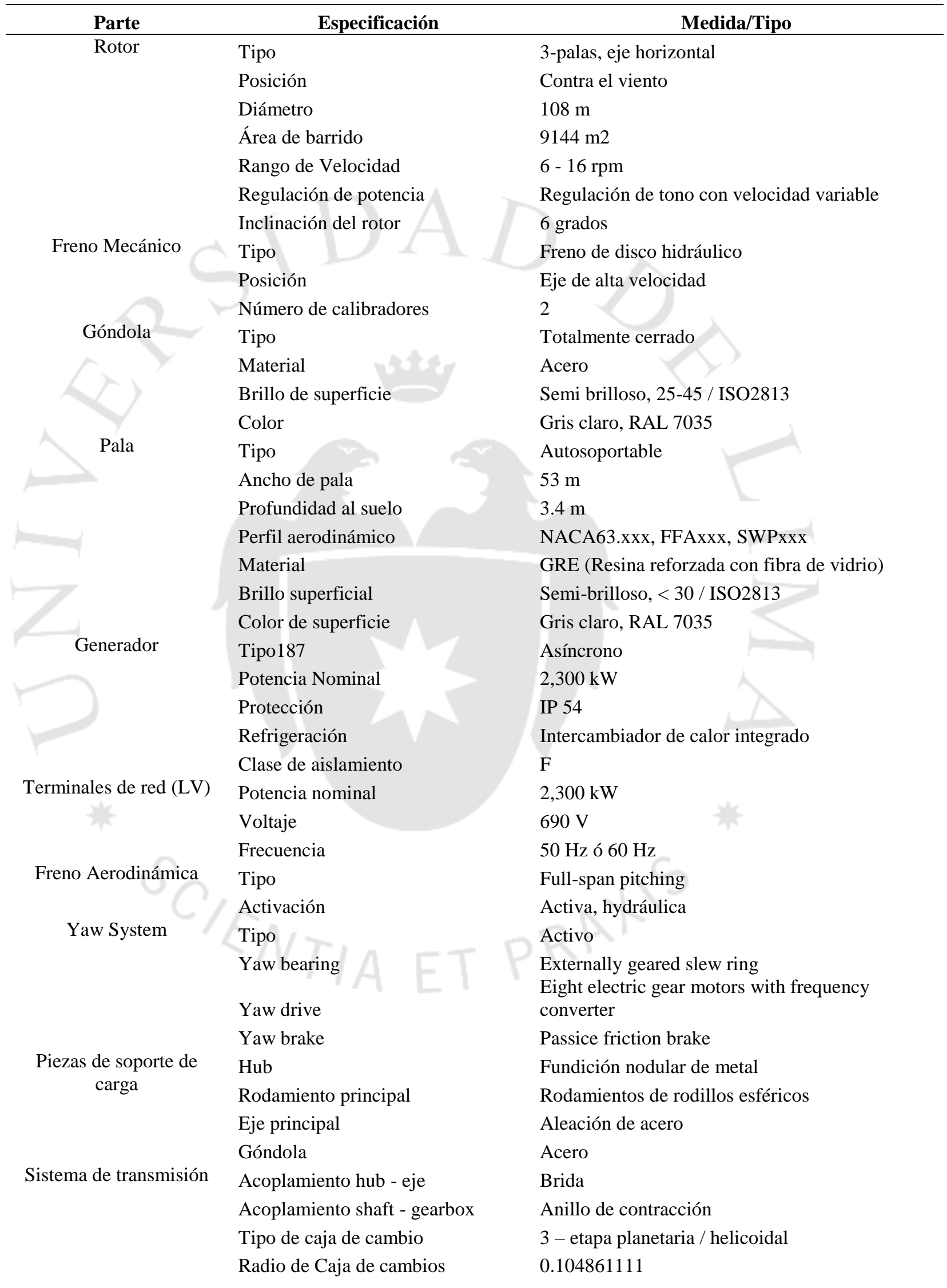


Lubricación de caja

Volumen de aceite

Aceite filtro de caja de cambios

Refrigeración de caja de cambios

Designación de caja de cambios

Acoplamiento engranajes generador

Controlador

Tipo

Sistema SCADA

Designación del controlador

Fabricante del controlador

Torre

Tipo

Altura de buje

Protección contra corrosión

Brillo de superficie

Color

Rotor

Góndola

Datos Adicionales

Velocidad de arranque

Velocidad nominal

Velocidad de corte

Ráfaga o viento máximo
Lubricación por salpicadura / forzada

Aprox. 4001.

Inline y offline

Enfriador de aceite separado

PEAB 4456 (Winergy) o EH851 (Hansen)

Acoplamiento flexible doble

Microprocesador

WPS via modem

WTC 3.0

KK Electronic A/S

Cilíndrica o tubular cónica

$80 \mathrm{~m}$

Pintado

Semi-brilloso, 25-45 / ISO2813

Light grey, RAL 793

$60,000 \mathrm{~kg}$

$82,000 \mathrm{~kg}$

$3-4 \mathrm{~m} / \mathrm{s}$

$11-12 \mathrm{~m} / \mathrm{s}$

$25 \mathrm{~m} / \mathrm{s}$

$59.5 \mathrm{~m} / \mathrm{s}$ (IEC version)

Fuente: Siemens

Figura 5.15.

Características generales del aerogenerador

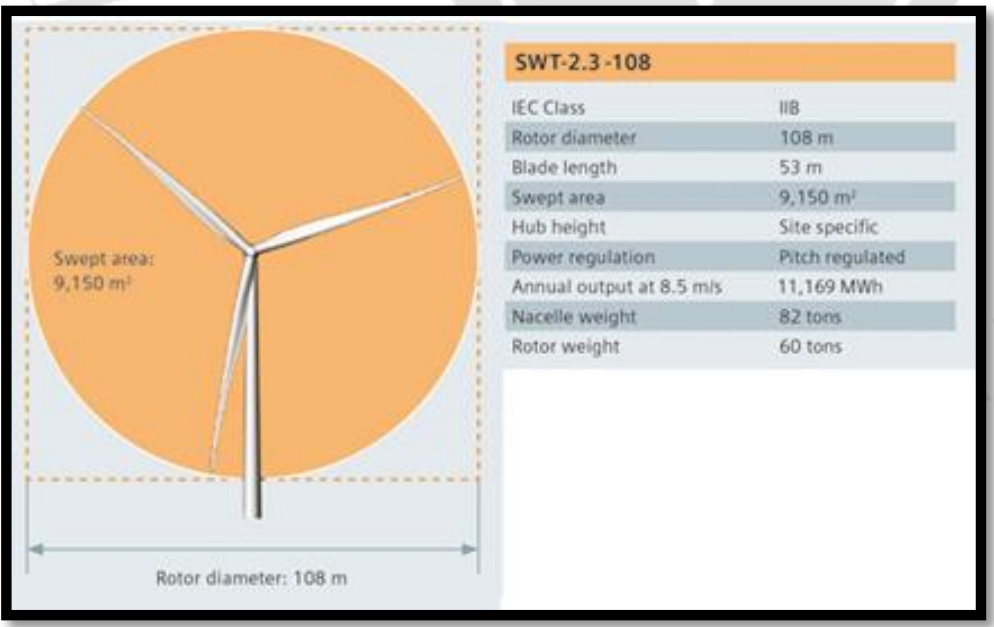

Fuente: Siemens 
Figura 5.16.

Parte interior de la góndola del aerogenerador Siemens SWT-2.3-108

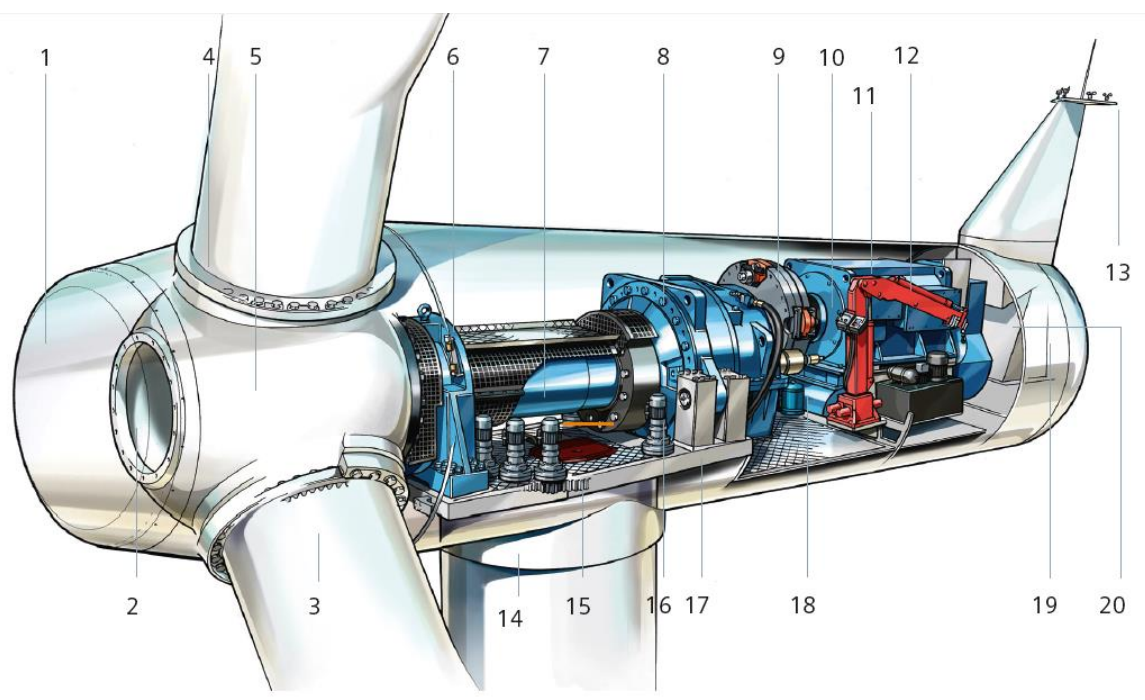

Fuente: Siemens

Rotor:

1. Carenado (nariz): es una cubierta frontal en forma de cono que sirve para desviar el viento hacia el tren motor y mejorar la ventilación en el interior, eliminar turbulencia indeseable en el centro frontal del rotor y mejorar el aspecto estético.

2. Soporte de carenado.

3. Palas: Transmiten la potencia del viento hacia el buje.

4. Soporte Pitch: Su función es unir las palas con el buje y que es de carácter giratorio para mantener las palas en dirección al viento.

5. Buje: Centro del rotor donde se encastran las palas y mediante el cual la potencia captada por el rotor se transmite al eje principal. La estructura es de forma cilíndrica, metálica y hueca que se construye en base a una fundición de acero nodular.

Góndola:

6. Soporte principal: Se encarga de unir la turbina eólica con el eje principal.

7. Eje principal: es aquel que tiene que sostener al rotor y es el encargado de trasmitir el par de giro a la caja de cambios. 
8. Caja de cambios: Sistema mecánico encargada de elevar la velocidad de giro del sistema mediante un conjunto de engranajes comunica al eje arrastrado o de salida una velocidad de giro mayor que la del eje motor o de entrada, desde la velocidad de la turbina a la velocidad del generador.

9. Freno del disco: Se aplica después que la velocidad de rotación del rotor se reduce considerablemente, y por consecuencia, el par motriz es mucho menor. Es utilizado para efectuar el paro forzado (medio principal de frenado).

10. Acoplador

11. Generador: Encargado de producir electricidad haciendo mover el eje de este rápidamente. Se encarga de transformar energía mecánica del movimiento del rotor en energía eléctrica.

12. Servicio de grúa

13. Sensores meteorológicos

14. Tower Torre: Estructura que sostiene y soporta el peso del aerogenerador

15. Anillo giratorio

16. Engranaje giratorio: Hace girar la góndola gire horizontalmente en dirección del viento.

17. Base de Nacelle

18. Filtro de aceite

19. Góndola: Es la estructura donde se ubican los principales componentes mecánicos del aerogenerador

20. Veleta-Anemómetro: la veleta mide la dirección del viento, envía señales al controlador electrónico de forma que hace girar el aerogenerador en contra del viento utilizando el mecanismo de orientación. Por otro lado el anemómetro es un sensor que indica la velocidad del viento.

\section{Línea de transmisión}

El sistema de transmisión tiene una estructura que consta de unos cables conductores agrupados en dos grupos de tres fases. Constituyendo cada grupo 
un grupo de circuito, por los que se transporta la electricidad. También consta de unos apoyos que sirven de soporte a las fases, manteniéndolas separadas del suelo y entre sí. La altura de estos apoyos es de 37 metros de altura construidos con perfiles angulares laminados y galvanizados que se unen en sí por medio de tornillos también galvanizados, material que presenta una resistencia elevada a la acción de agentes atmosféricos. El área directamente afectada por las acciones del proyecto abarca el área de la subestación, la cual comprende una extensión aproximada de $5000 \mathrm{~m} 2$.

\section{Línea de Interconexión eléctrica en 220 kV}

La estructura básica de una línea eléctrica se compone de unos cables conductores, agrupados en dos grupos de tres fases constituyendo cada grupo un circuito, por los que se transporta la electricidad, y de unos apoyos que sirven de soporte a las fases, manteniéndolas separadas del suelo y entre sí. La línea de interconexión se compone de unos cables conductores, agrupados en tres fases por circuito, por los que se transporta la energía eléctrica de una subestación a otra, y de unos apoyos que sirven de soporte a las fases, que mantienen a éstas separadas entre sí y del suelo.

Estructuras de la línea.

Las estructuras utilizadas son torres de celosía de acero galvanizado, de unos $37 \mathrm{~m}$ de altura, construidos con perfiles angulares laminados y galvanizados que se unen entre sí por medio de tornillos también galvanizados, material que presenta una resistencia elevada a la acción de los agentes atmosféricos.

La cimentación de los apoyos es del tipo de patas separadas, es decir la cimentación de cada pata es independiente. El sistema adoptado en general es el de macizos de hormigón, reservando la utilización de emparrillados metálicos para aquellos casos en que la magnitud de los esfuerzos lo haga aconsejable 
Hilos conductores

La línea está constituida por un circuito compuesto por 3 fases, con 1 conductor por fase. Los conductores se montan en disposición "delta" en el apoyo, con una separación de 5,7 m entre dos fases, estando estas distancias fijas definidas en función de la flecha máxima. Los conductores están constituidos por cables trenzados de aluminio y acero.

Figura 5.17.

Cable conductor de corriente

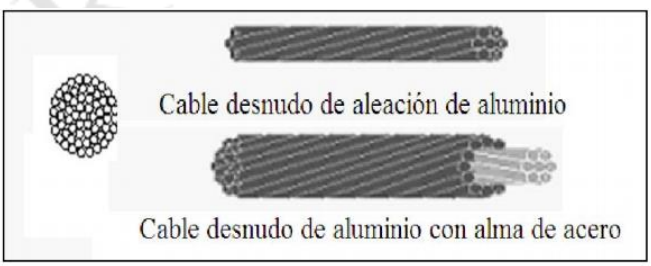

Fuente: Windpower.org

Los tipos de cable a utilizar en la línea de transmisión son dos, y se encuentran situados en los puntos más altos de los apoyos. Su función es proteger a la línea contra las sobretensiones debidas a descargas atmosféricas. De tal forma que si existe una tormenta, estos cables actúan de pararrayos evitando que las descargas caigan sobre los conductores y provoquen averías en las subestaciones y el corte de la corriente (Fiallos y Asociados, 2011).

\section{Aisladores}

Para que los conductores permanezcan aislados y la distancia entre los mismos permanezca fija, dichos conductores están unidos a los apoyos mediante los denominados aisladores, que mantienen los conductores sujetos y alejados de la torre. El núcleo de estos aisladores polímeros es de fibra de vidrio reforzada con resina epóxica de alta dureza, resistente a los ácidos y, por tanto, a la rotura frágil; tendrá forma cilíndrica y estará destinado a soportar los esfuerzos por carga mecánica. 
Figura 5.18.

Aislador polimérico

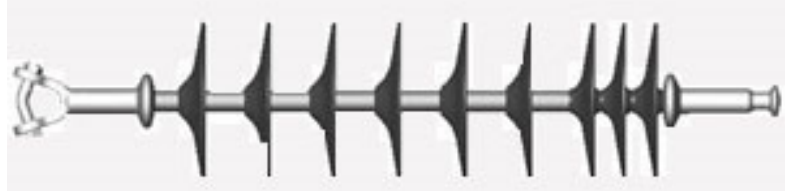

Fuente: Ensys S.A.

Los herrajes serán fabricados de acero forjado o hierro maleable de buena calidad; presentarán una superficie uniforme, libre de discontinuidades, fisuras, porosidades, crestas y cualquier otra alteración del material.

Para evitar el aflojamiento de los elementos roscados se utilizarán dispositivos de bloqueo tales como arandelas de presión, pasadores, etc. Todos los elementos que componen los accesorios serán resistentes a la corrosión, bien sea por la propia naturaleza del material o bien por la aplicación de una protección adecuada.

Figura 5.19.

Herrajes de acero forzado y hierro maleable

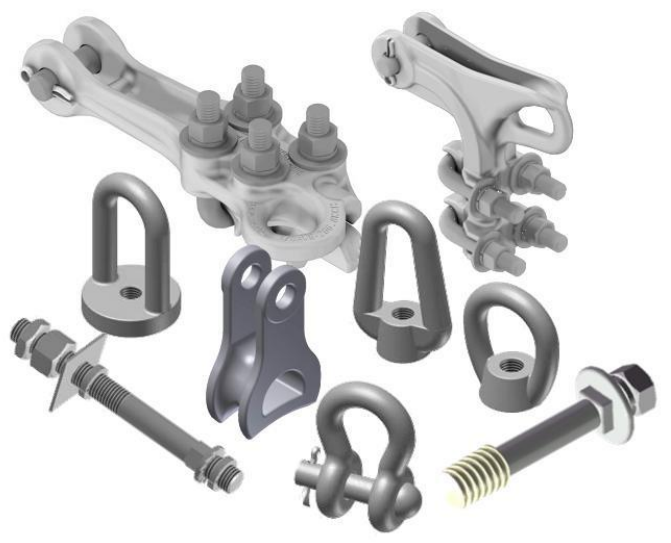

Fuente: Gamma insulator 
Subestación elevadora $220 \mathrm{KV}$

Se considera como subestación al conjunto de aparatos utilizados en la maniobra, protección, medida, regulación y control de instalaciones eléctricas, también llamados aparamenta eléctrica y edificios de control que sirven para realizar la función de enlace y transformación. Se diferencian dos zonas: el parque de intemperie eléctrico y los edificios. En el parque de intemperie se instalan los aparatos eléctricos, siguiendo una distribución ordenada en la que la distinta aparamenta queda separada por calles cuyas dimensiones están normalizadas y son dependientes del nivel de tensión. Los elementos de las subestaciones transformadoras elevadoras en los parques eólicos son los siguientes (Fiallos y Asociados, 2011):

\section{a) Barras colectoras}

Se llaman barras colectoras al conjunto de conductores eléctricos que se utilizan como conexión común de los diferentes circuitos de que consta una subestación. Los circuitos que se conectan o derivan de las barras pueden ser generadores, líneas de transmisión, bancos de transformadores, bancos de tierras, etc. En una subestación se pueden tener uno o varios juegos de barras que agrupen diferentes circuitos.

Figura 5.20.

Barras colectoras

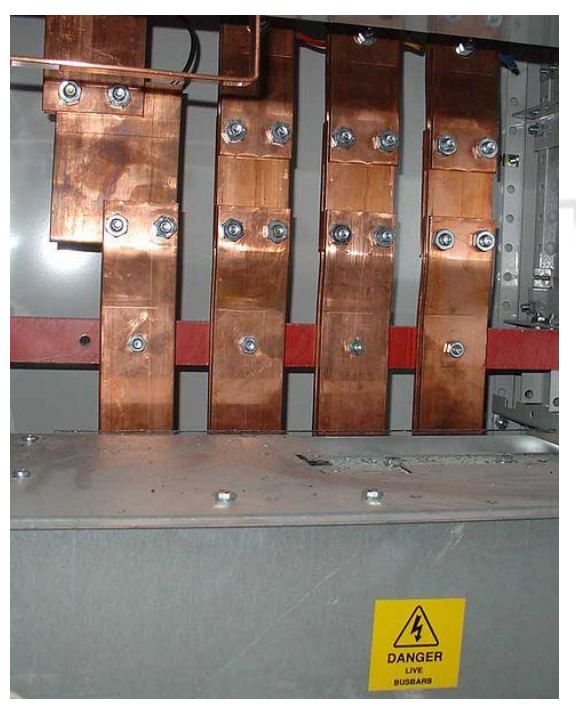

Fuente: Gamma insulator 
b) Interruptores

Los interruptores son la aparamenta de desconexión bajo carga, que pueden asegurar la "puesta en servicio" o "puesta fuera de servicio" de un circuito eléctrico y que, simultáneamente, están capacitados para garantizar la protección de la instalación en que han sido montados contra los efectos de las corrientes de cortocircuitos defectos en tierra, cortocircuitos entre fases (Fiallos y Asociados, 2011).

Figura 5.21.

Interruptores de potencia

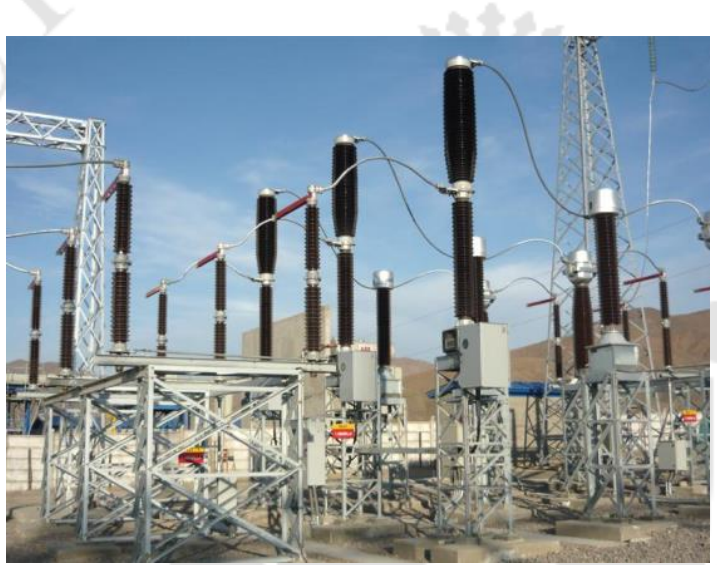

Fuente: ISASTUR

c) Transformadores elevadores

Este transformador será suministrado y transportado con llenado inicial de aceite tendrá una potencia instalada de 40 MVA y una relación de transformación de $20 \mathrm{KV}$ a $220 \mathrm{KV}$. El aceite drenado de partes removidas para facilitar el transporte será enviado en barriles en suficiente cantidad para rellenar el volumen disminuido de aceite del transformador y para reintegrar las pérdidas durante el procesamiento subsecuente en el emplazamiento. 
Figura 5.22.

Transformador elevador de voltaje

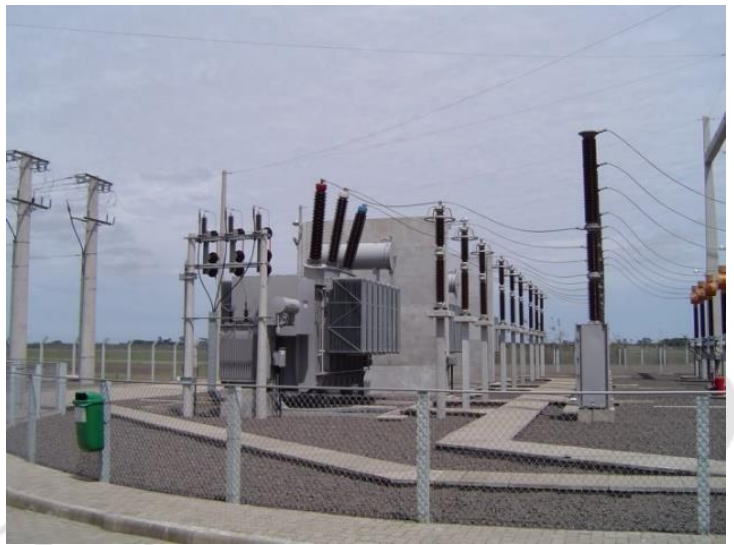

Fuente: RVRT Transformadores

d) Seccionadores

Se utilizan seccionadores deslizantes aptos para cortar las corrientes capacitivas que aparecen durante las maniobras de acoplamiento de partes de una instalación. Para optimizar la operación de estos en diferentes puntos de la instalación, las partes activas se encuentran dentro de envolventes diferentes, con lo que se reduce al mínimo el número de uniones embridadas.

Figura 5.23.

Seccionador

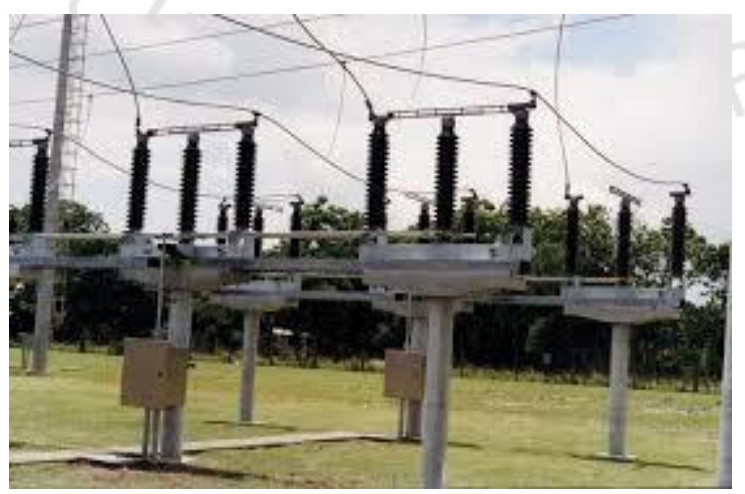

Fuente: Lago electromecánica 
e) Transformadores de instrumento. De tensión y de intensidad

Los transformadores de intensidad utilizados para este tipo de aparamenta son trifásicos y de tipo barra pasante, con núcleo anular y devanado secundario tipo toroide. Los núcleos se encuentran adheridos externamente a la envoltura metálica, fuera del recinto que contiene el gas SF6, separados por un blindaje cilíndrico de la región de alta tensión. El transformador de tensión inductivo tiene sus componentes alojados en una carcasa de aluminio fundido que forma un compartimiento propio de gas separado de los demás por un aislador cónico.

f) Autoválvulas

Los pararrayos o autoválvulas van encapsulados y tienen una tensión de descarga más baja que los convencionales, debido a la ausencia de contaminación y a su conexión directa con el aparato de corte. Cuando la conexión con la red se realiza a través de una línea aérea, el pararrayos situado a la entrada puede ser convencional o aislado en SF6. Si se conecta a través de un cable de alta tensión, es aconsejable integrar el descargador dentro del encapsulado de la subestación blindada.

Figura 5.24.

Autoválvulas
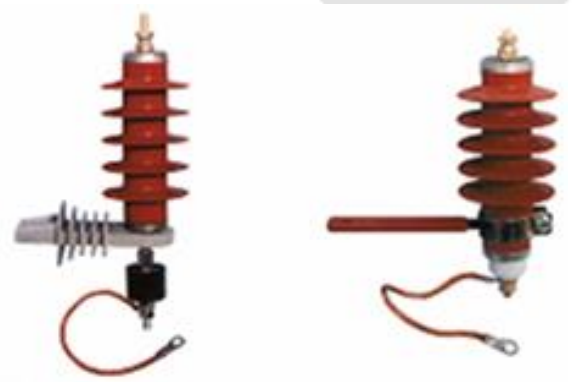

Fuente: Maixmail

g) Estructuras de soporte de barras y aparamenta

La estructura de barras del tipo celosía es aquella estructura basada en tracción- compresión de cada una de las piezas. Para ello, a las piezas no se 
les impide de manera directa la rotación respecto a los enlaces y por tanto, no son capaces de ejercer un par resistente. Se basa en el principio de triangulación y es que, dentro de un triángulo, los esfuerzos de barras son nulos. Sin embargo, en la práctica, las barras internas evitan el pandeo a compresión de las piezas.

Figura 5.25.

Estructura de barras

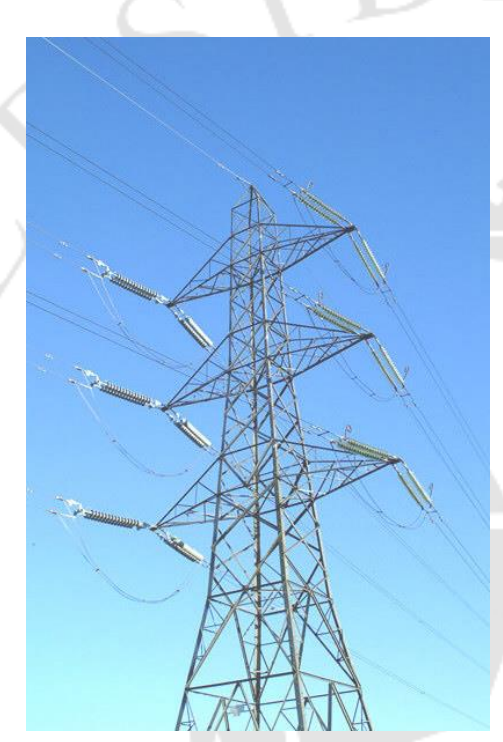

Fuente: Tuberas

h) Planta de emergencia, banco de baterías y cargadores

Para cubrir ciertas situaciones que pudieran producirse y si la importancia de la subestación lo aconseja, puede ser conveniente la utilización de un generador de emergencia. Este grupo no constituirá un apoyo del 100\%, sino que alimentaria únicamente los "servicios esenciales" para garantizar el funcionamiento de líneas, transformadores, etc.

i) Red de blindaje y red de tierras

La protección de las bahías de intemperie contra descargas atmosféricas deberá realizarse mediante la instalación de hilos de guardia. La altura de las puntinas para protección de la aparamenta de bahías se calculará a partir del ángulo de cobertura mediante alguno de los métodos de cálculo 
convencionales. La red de tierra, por estar enterrada, forma un elemento galvánico con los otros conductores o elementos metálicos con los que está en contacto (Fiallos y Asociados, 2011).

j) Edificios para sistemas de control, protección, medición y comunicación Tendrán facilidades de acceso de manera que se puedan hacer las tareas de mantenimiento del equipamiento allí instalado. Tendrán en cuenta la condición "atendida" o "no atendida" de la instalación. Cuando se proyecten edificios para control centralizado se deberá mantener el criterio de instalar distintos equipamientos en distintos locales, tales como salas de control, locales para equipos de comunicaciones, para equipos de baterías y cargadores, y para equipos de control y protecciones (Fiallos y Asociados, 2011).

\subsection{Capacidad instalada}

\subsubsection{Cálculo de la potencia efectiva}

"La potencia disponible en el viento depende de su energía cinética, es decir de la velocidad del mismo. Esta dependencia no es proporcional sino cúbica. Así un viento con un triple de velocidad que otro, contendrá, no tres, sino veintisiete veces más potencia disponible”. (Méndez y Rodríguez, 2012, p. 48)

"Existen 2 factores que determinan la producción energética de los aerogeneradores: los recursos eólicos existentes en el parque y las características de la maquinaria a utilizar. Más aún, el rendimiento de los aerogeneradores del parque eólico depende de dos parámetros fundamentales: velocidad del viento y en diámetro de su hélice”. (Sánchez 105, 2004).

Considerando lo explicado anteriormente y teniendo en cuenta la fórmula de volumen barrido de viento, caudal másico de aire y energía cinética en ese mismo aire se obtiene la siguiente formulación, cuya obtención es explicada más detalladamente en el apéndice. 


$$
P=C p\left(\frac{\rho}{2}\right)(\pi)\left(\frac{D^{2}}{4}\right)\left(V^{3}\right)
$$

Se utilizarán los siguientes datos en este cálculo de la potencia efectiva de un aerogenerador, que posteriormente se calculará.

Cp: Coeficiente de potencia del aerogenerador

p: densidad del aire

D: Diámetro de las hélices

V: Promedio anual de velocidades de viento

El coeficiente de potencia Cp tendrá un valor máximo de 16/27, aproximadamente 0,593. Dicho de otra forma, en un aerogenerador con un rotor en forma de disco, como máximo, se podrá aprovechar el 59\% de energía de viento que lo atraviesa según la Ley de Betz, enunciada por el físico alemán Albert Betz en el año1919.

En el caso de los aerogeneradores tripala de eje horizontal, las pérdidas en el rotor hacen que las modernas turbinas se muevan en valores de $\mathrm{Cp}$ de aproximadamente 0,5378 para los tipos de aerogeneradores Siemens SWT 2.3 - 108 .Se consideró una densidad de $1.099 \mathrm{~kg} / \mathrm{m}^{3}$, un diámetro de rotor de $108 \mathrm{~m}$ y una velocidad de viento media de $8.42 \mathrm{~m} / \mathrm{s}$. La determinación de estos parámetros se explica en los siguientes subcapítulos.

Así se procede a reemplazar el valor en la fórmula como sigue:

$$
\mathrm{P}=0.5378 * \frac{1.099}{2} * \frac{\pi}{4} * 108^{2} * 8.42^{3}=1.6161 \mathrm{MW}
$$

Esta sería la potencia que produce cada aerogenerador con los parámetros de cada lugar y que concuerda con los valores que se proporcionan en el catálogo de Siemens que se muestra en el siguiente gráfico: 
Figura 5.26.

Curva de potencia de aerogenerador Siemens SWT-2.3-108

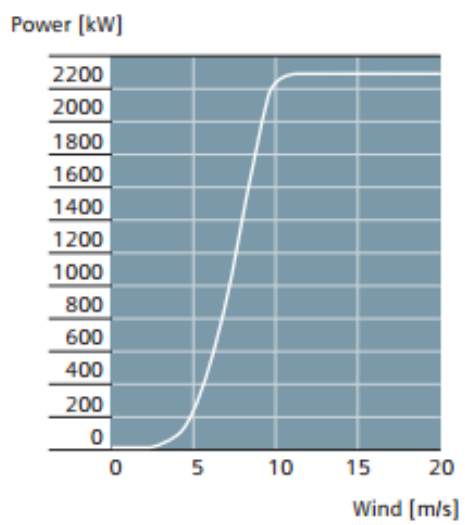

Fuente: Siemens

A este valor hay que multiplicarlo por el factor de utilización cuyo concepto consiste en dividir la energía anual producida por cada turbina entre la energía que produciría si funcionase a potencia nominal durante las 8760 horas de un año. El valor típico que suele tomar es de $35 \%$ en un parque eólico. Este valor considera acciones como: las operaciones de producción de energía se interrumpen debido a labores de mantenimiento de aerogeneradores (90\%), disponibilidad (98\%), suciedad en las palas (99,5\%), la histéresis del viento debido a las paradas y arranques de las máquinas en forma automática $(99,8 \%)$, las pérdidas eléctricas del parque (97\%), mantenimiento de la subestación $(99,7 \%)$ y pérdidas de producción por efecto estela (97\%), topografía, rugosidades y turbulencia generada (Mendez y Rodríguez 90, 2012). Sin embargo, para el presente proyecto se determinó que el factor a utilizarse es de $47,89 \%$, la determinación de este factor será explicada posteriormente en los subcapítulos siguientes.

$$
\mathrm{P}=2.3 * 0.4789=1.1015 \mathrm{MW}
$$

Entonces se tendría que la energía anual producida por cada aerogenerador anualmente sería de 1.1015 MW. 
5.4.2. Variables que influyen en la potencia aprovechable del viento

\subsubsection{Densidad del aire}

Como vimos en el apéndice, la energía cinética del viento dependerá de la densidad (p) - masa por unidad de volumen - del aire.

$\mathrm{p}=\mathrm{m} / \mathrm{v}$

Consecuentemente, cuanto mayor sea la velocidad del aire, es decir cuanta más masa tenga un determinado volumen, mayor cantidad de energía del viento podrá aprovecharse en el aerogenerador.

La densidad del aire no es un parámetro sobre el que se pueda actuar directamente, ya que dependerá de las condiciones meteorológicas, disminuyendo con el aumento de la temperatura (T) o la altitud- es decir aumentando con la presión $(\mathrm{P})$ - pudiendo aproximarse su valor de acuerdo con la siguiente expresión, donde $\mathrm{R}$ es la constante universal de los gases ideales:

$\mathrm{p}=\mathrm{P} /(\mathrm{R} * \mathrm{~T})$

$\mathrm{P}=$ Presión a una altura dada

$\mathrm{R}=$ Constante universal de los gases ideales

$\mathrm{T}=$ Temperatura a una altura dada

En el caso del presente proyecto las variables asumen los siguientes valores de acuerdo a las características geográficas de ubicación del parque eólico que será en la provincia de Nazca, la temperatura media anual de acuerdo al Ministerio de Turismo es de $25^{\circ} \mathrm{C}(298,15 \mathrm{~K})$. Además la presión atmosférica es dependiente de la altura, estas pampas están a una altura promedio de 600 m.s.n.m. y le corresponde una presión de 0.931 atm (Mendez y Rodríguez 93, 
2012). Por último el parámetro $\mathrm{R}$ es una constante que se expresará en las mismas unidades que las variables mencionadas anteriormente. Así este parámetro asume un valor de 2,8406 x $\left.10^{-3}(\operatorname{atm~x~m})^{3}\right) /(\mathrm{kg} \mathrm{x} \mathrm{K})$.

Reemplazando estos valores la fórmula quedaría de la siguiente forma:

$\mathrm{p}=$

$0.931 \mathrm{~atm}$ $=1,09927 \mathrm{~kg} / \mathrm{m} 3$

$2,8406 \times 10^{-3} \underline{\left(\mathrm{atm} \times \mathrm{m}^{3}\right)}$ x $298,15 \mathrm{~K}$

$\operatorname{kg} \times \mathrm{K}$

Así el valor de la densidad del aire para el presente proyecto es de 1,09927 $\mathrm{kg} / \mathrm{m} 3$ en la zona de influencia del proyecto en la provincia de Nazca, departamento de Ica.

\subsubsection{2. Área de barrido del motor}

A mayor área de barrido de rotor, mayor será la energía del viento que el aerogenerador será capaz de interceptar para su aprovechamiento. Una vez elegido el modelo de aerogenerador, su área de barrido será una constante para las máquinas (Mendez y Rodríguez 96, 2012).

La fórmula para determinar el área del círculo es:

$A=(\pi)\left(\frac{D^{2}}{4}\right)$

Para el presente proyecto ambos modelos de aerogeneradores: Siemens modelo SWT-2.3-108 y Siemens SWT-3.2-108 tienen un diámetro de 108 m.

$$
\mathrm{A}=\pi^{*} 108^{2} / 4=9160.88 \mathrm{~m}^{2}
$$




\subsubsection{Velocidad del viento}

5.4.2.3.1. Medición de las velocidades promedio anuales

El comportamiento del viento se determina en cuanto a la velocidad y dirección. El estudio del capítulo 3 indica que la instalación de los aerogeneradores debe realizarse en las pampas de Marcona, entre la mina de Marcona y reserva de San Fernando. Por ello, los recursos eólicos que se encuentran en este sitio serán explotados en beneficio de la generación eléctrica.

Para el presente proyecto se han obtenido los datos de los vientos del Ministerio de Energía y Minas.

En el anexo, se presenta la información obtenida sobre el estudio de vientos efectuado en la posible zona de influencia. Al contar con un registro de velocidades de vientos, se calculan los promedios mensuales de velocidades de viento del año 2008. Estos promedios se indican la siguiente tabla.

Tabla 5.3.

Promedios mensuales de velocidades de vientos a $80 \mathrm{~m}$ de altura en la zona de influencia

\begin{tabular}{lllllllllllll}
\hline Mes & Ene & Feb & Mar & Abr & May & Jun & Jul & Ago & Sep & Oct & Nov & Dic \\
\hline Velocidad(m/s) & 6.5 & 7.3 & 6.3 & 6.8 & 6.1 & 7.6 & 7.8 & 8.2 & 8.6 & 7.2 & 7.4 & 6.6 \\
\hline Fuente: MINEM, elaboración propia
\end{tabular}

El registro histórico de la tabla 5.3 indica que, el promedio anual de velocidades de viento es igual a $7.2 \mathrm{~m} / \mathrm{s}$. Para fines del proyecto se espera contar con este promedio anual de velocidades de viento. Este valor debe ser comprobado mediante mediciones de velocidades en el lugar mencionado.

Por otro lado, para que los aerogeneradores se sitúen en un espacio con vientos más veloces, deben ser colocados a una altura considerable del nivel del suelo. Por ejemplo para el área analizada en el proyecto, las velocidades de vientos a $50 \mathrm{~m}$ son de en promedio $6.3 \mathrm{~m} / \mathrm{s}$ anuales, mientras que en promedio las 
velocidades a $80 \mathrm{~m}$ son $7.2 \mathrm{~m} / \mathrm{s}$. Con lo cual se observa que las velocidades de viento son crecientes en función de la altura.

Con estas consideraciones, el parque eólico que se ubicará en Marcona tendrá una altura de $80 \mathrm{~m}$. sobre el nivel del terreno, en donde las velocidades de viento sean notablemente mayores. Cabe resaltar que, en la fase posterior al presente proyecto, se deben efectuar mediciones de velocidad de viento en dicha zona para confirmar el potencial eólico de dicho sitio.

\subsection{Dirección del viento}

Otro parámetro del viento a estimar es la dirección que éste toma. La importancia de este factor radica en que la dirección y sentido del viento son determinantes para realizar la distribución de espacios. En la figura 5.26 se muestra el sentido de los vientos en la zona de Ica. Como se observa, las flechas indican el sentido de los vientos, los cuales se desplazan en dirección de sureste en la provincia de Marcona.

Figura 5.27.

Sentido de los vientos en la provincia de Marcona

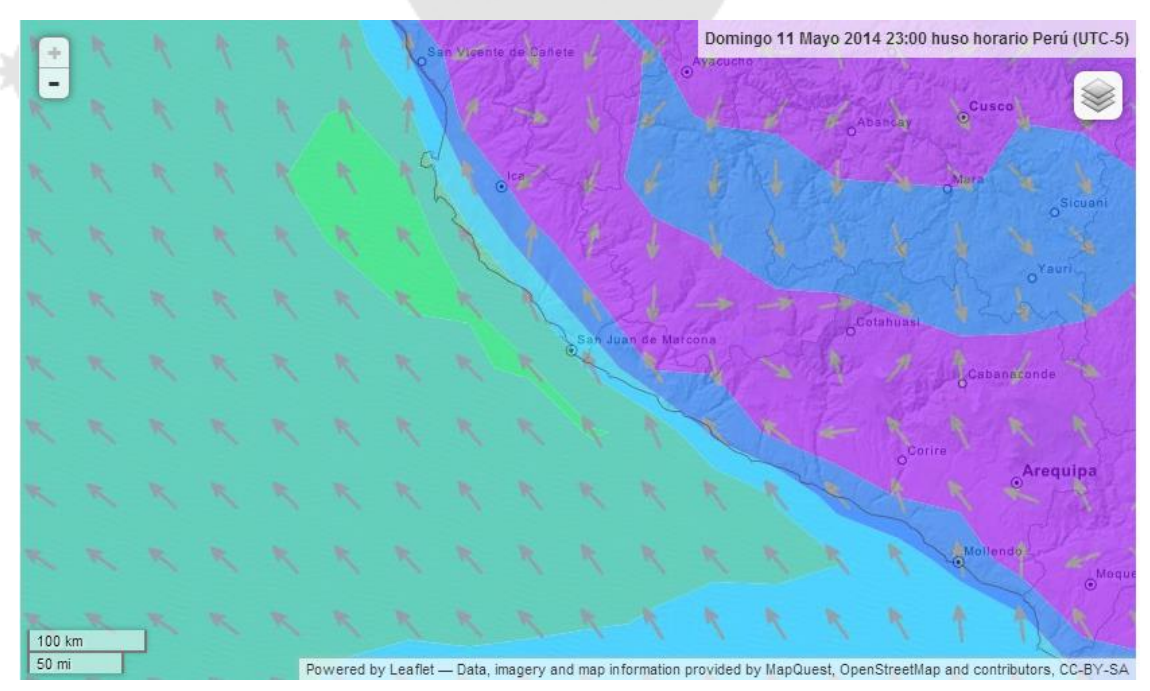

Fuente: Windfinder 
La rosa de los vientos es un gráfico que nos sirve para mostrar la información sobre las distribuciones de las velocidades de viento y la frecuencia de variación de las direcciones. En este caso se usó como referencia las rosa de vientos del parque de Tres Hermanas, muy cerca de donde estaría ubicado el parque del presente proyecto. Su ubicación cercana, similitudes superficiales y velocidad de viento parecida, así como una dirección similar son los factores que se tomaron en cuenta para usar el gráfico de rosa del viento.

"La rosa de los vientos es extremadamente útil para situar aerogeneradores. Si una gran parte de la energía del viento viene de una dirección particular, lo que deseará, cuando coloque una turbina eólica en el paisaje, será tener la menor cantidad de obstáculos posibles en esa dirección, así como un terreno lo más liso posible". (Windpower, 2001)

Figura 5.28.

Rosa de los vientos del parque eólico Tres Hermanas, Marcona

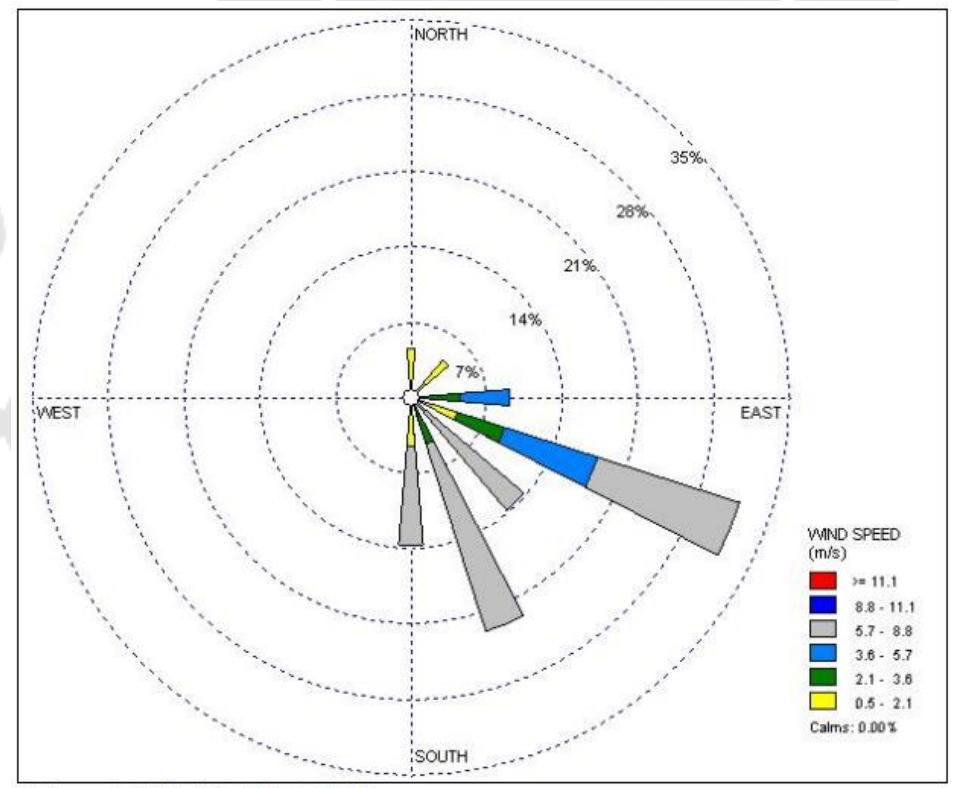

Fuente: Walsh Peru S.A., 2012 
5.4.2.3.3. Identificación de la distribución de probabilidad

Se determinó en el capítulo 3.2.1, que la distribución Weibull es la más apropiada para describir el comportamiento de los vientos. Lo importante es determinar que parámetros se van a utilizar para determinar el comportamiento de la curva. En el caso de la distribución Weibull, son 2 parámetros que hay que estimar son el parámetro de forma $(\mathrm{k})$ y el parámetro de escala $(\mathrm{C})$. Para determinar estos parámetros se utilizó los datos provistos por ADINELSA S.A.(2012) la cual es una empresa que se encarga de la administración de infraestructura eléctrica en el Perú que realizó estudio elaborado en la provincia de Marcona se estimó que estos parámetros toman los siguientes valores:

- $\quad$ Parámetro de forma $(\mathrm{k})=1.92$

- $\quad$ Parámetro de escala $(C)=9.03 \mathrm{~m} / \mathrm{s}$

Utilizando el programa de cálculo de gráfica de distribución del viento provisto por la organización Windpower en su página web. Se logró determinar la curva de distribución del viento en la zona de Marcona, la que se muestra en la siguiente figura.

Figura 5.29.

Distribución Weibull de vientos en la provincia de Marcona

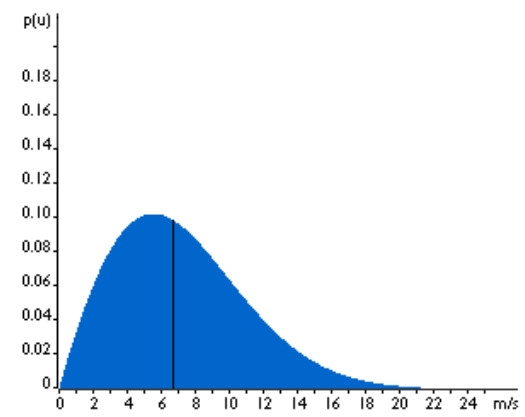

Escala $\mathrm{A}=8.120000000000001 ;$ Forma $\mathrm{k}=1.92 ;$ Media $=7.2 ;$ Mediana $=6.7$

Elaboración propia 
La gráfica nos sirve para observar los valores que tomarán la mediana y media en esta distribución. Así, la mediana tendrá un valor de $6,7 \mathrm{~m} / \mathrm{s}$ lo que significa que este es el valor medio que toman los valores, es decir la mitad del tiempo se tendrá un valor igual a la mediana. El otro dato es la media que toma un valor de 7,2 m/s y es el valor promedio, es mayor que la media debido a que valores extremos de vientos y que rara vez ocurren como vientos a velocidad de $18 \mathrm{~m} / \mathrm{s}$ al juntarse con datos promediados hacen que se eleve el valor promedio.

\subsection{Densidad de potencia}

Tal como se explicó anteriormente la potencia del viento varía con el cubo de su velocidad y además es directamente proporcional a la densidad del aire en el emplazamiento.

En consecuencia, para un emplazamiento concreto con una densidad del aire característica, la densidad de potencia disponible resultará de multiplicar la potencia que corresponde a cada velocidad del viento por la probabilidad de ocurrencia de cada velocidad.

La distribución de energía del viento disponible se obtendrá, respecto de la distribución de velocidades del viento, una curva desplazada hacia las velocidades altas, puesto a que a igual probabilidad de ocurrencia entre una velocidad alta y una baja, el efecto de éstas sobre la potencia es muy superior al de las pequeñas por ser una relación cúbica entre potencia y velocidad del viento.

$\mathrm{Si}$ bien es cierto que los aerogeneradores no producen energía hasta velocidades de $4 \mathrm{~m} / \mathrm{s}$ y tampoco superiores a los $25 \mathrm{~m} / \mathrm{s}$. En ambos casos la potencia desperdiciada resulta muy pequeña.

Para el caso del parque eólico que se desea implementar la velocidad media anual es de $7.22 \mathrm{~m} / \mathrm{s}$ y la velocidad multiplicada por la probabilidad de ocurrencia asume un valor de $8.43 \mathrm{~m} / \mathrm{s}$ y el valor de densidad de potencia que tomaría en promedio sería de $343,24 \mathrm{~W} / \mathrm{m}^{2}$. 
De hecho ya se realizó un estudio sobre la densidad promedio en la zona realizado por el Ministerio de Energía y Minas en el 2008. Cabe resaltar que los valores tienen un promedio parecido al valor hallado en base a la fórmula. Dando como resultado el siguiente mapa de densidad de potencia.

Figura 5.30.

Mapa de densidad de potencia en la zona seleccionada

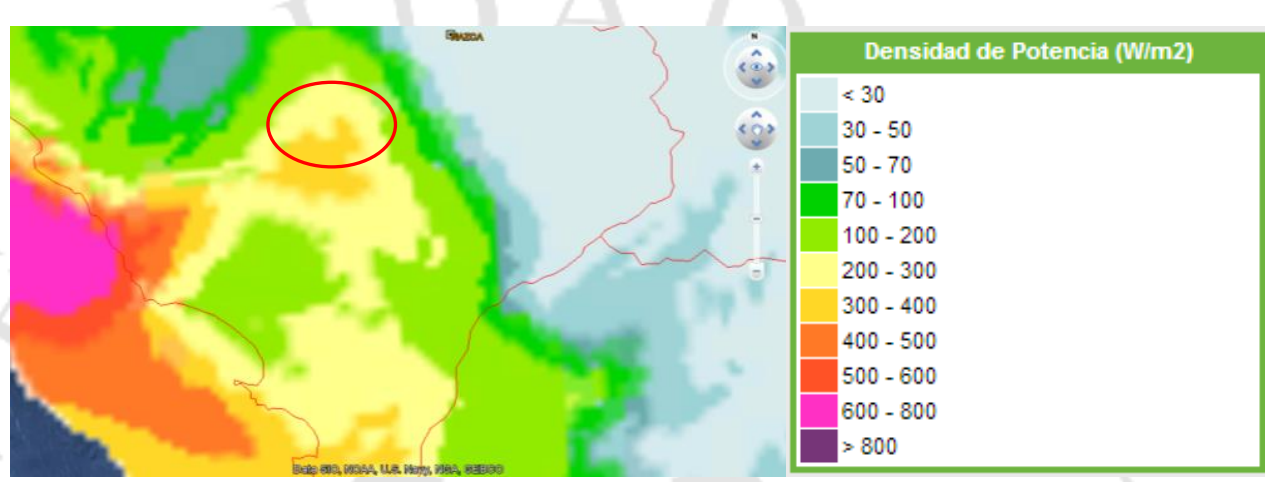

Fuente: MINEM

\subsection{Efecto colina}

Las pequeñas colinas y lomas que se encuentran en el desierto favorecen a que el fluido alcance mayores velocidades. La explicación de este evento es que en las colinas, siempre se aprecian velocidades de viento superiores a las de las áreas circundantes. Una vez más, esto es debido a que el viento es comprimido en la parte de la montaña que da al viento, y una vez el aire alcanza la cima de la colina puede volver a expandirse al descender hacia la zona de bajas presiones por la ladera a sotavento de la colina. 
Figura 5.31.

Efecto colina de los vientos
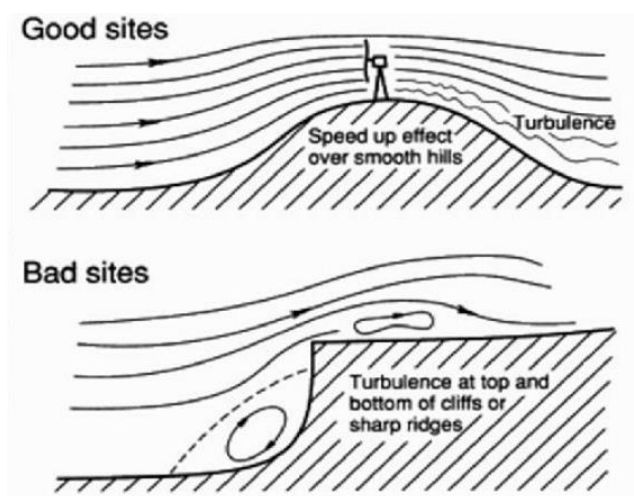

Fuente: Empresa DeltaVolt

Tal y como puede observar en el dibujo, el viento empieza a inclinarse algún tiempo antes de alcanzar la colina, debido a que en realidad la zona de altas presiones se extiende hasta una distancia considerable enfrente de la colina.

También se dará cuenta de que el viento se hace muy irregular una vez pasa a través del rotor del aerogenerador. Al igual que ocurría anteriormente, si la colina es escarpada o tiene una superficie accidentada, puede haber una cantidad de turbulencias significativa, que puede anular la ventaja que supone tener unas velocidades de viento mayores.

\subsection{Rugosidad y cizallamiento}

Otro parámetro a analizar es la rigurosidad del terreno no representa mayor inconveniente para la elaboración de la distribución. Esto se debe a que el área de influencia del proyecto está en el desierto de Ica donde no hay presencia de mayores obstáculos. Siendo estrictos el parámetro de rigurosidad que le corresponde a este proyecto sería un valor poco rugoso tomaría un valor de $\mathrm{z}=0.03$. 
Tabla 5.4.

Parámetro de rigurosidad z para diferentes tipos de terrenos

\begin{tabular}{lll}
\hline Calificación & Terrenos Típicos & Rugosidad Z \\
\hline Plano & Playa, hielo, océano. & $0.005 \mathrm{~m}$ \\
Abierto & $\begin{array}{c}\text { Grass corto, aeropuertos, colina } \\
\text { redondeadas }\end{array}$ & $0.03 \mathrm{~m}$ \\
Poco rugoso & Hierba alta, matas chicas. & $0.10 \mathrm{~m}$ \\
Rugoso & Matas grandes, arbolitos. & $0.25 \mathrm{~m}$ \\
Muy rugoso & Bosques, frutales. & $0.50 \mathrm{~m}$ \\
Cerrado & Caseríos, barrios alejados. & $1.0 \mathrm{~m}$ \\
Ciudades & Centro, claros en bosques. & $+2 \mathrm{~m}$ \\
\hline
\end{tabular}

Fuente: Universidad de Piura, elaboración propia

Este valor, nos sirve para determinar el cizallamiento del viento, definido como la ralentización de la velocidad del viento para alturas cada vez más cercanas al suelo, es una consecuencia directa de la rugosidad. Dicha ralentización puede cuantificarse de acuerdo a la siguiente expresión:

$\mathrm{V}=\mathrm{V}_{0} * \ln (\mathrm{h} / \mathrm{h} 1) / \ln \left(\mathrm{h}_{0} / \mathrm{h}_{1}\right)$

Para determinar este parámetro se necesita primero la velocidad del viento $\left(\mathrm{V}_{0}\right)$ a una altura determinada $\left(\mathrm{h}_{0}\right)$. En el presente caso el valor promedio del viento a una altura de $80 \mathrm{~m}$ es de $8.42 \mathrm{~m} / \mathrm{s}$.

Siendo (v) la velocidad del viento a una altura $(\mathrm{h})$ sobre el nivel del suelo y $\left(\mathrm{h}_{1}\right)$ el valor de la longitud de rugosidad en la dirección en que está soplando el viento. Para este caso se busca una altura de 79.5 metros que es la altura que posee el otro tipo de generador.

$$
\begin{gathered}
\mathrm{V}=8.42 \mathrm{~m} / \mathrm{s} * \ln (79.5 / 0.03) / \ln (80 / 0.03) \\
\mathrm{V}=8.41 \mathrm{~m} / \mathrm{s}
\end{gathered}
$$

Como se observa el cizallamiento no afecta en mayor medida la velocidad a 80 m y a $79.5 \mathrm{~m}$. Así para este proyecto la velocidad de cálculo que se usará será de $8.42 \mathrm{~m} / \mathrm{s}$. 
5.4.3. Cálculo del número de aerogeneradores

Para determinar el número de aerogeneradores que funcionarán en un parque eólico se tomará en cuenta la potencia instalada, que se determinó en el subcapítulo 2.3.4 acerca de la determinación de la demanda. En dicho capítulo se considera una potencia instalada de $35 \mathrm{MW}$ tomando en cuenta otro proyecto eólicos cercanos en la zona.

Así, la potencia instalada de cada aerogenerador es de 2.3 MW modelo Siemens SWT $-2.3-108$. Si se divide la potencia requerida entre la potencia de cada aerogenerador se obtendrá que el número de aerogeneradores necesarios de este modelo son 16, que sería el número de aerogeneradores requeridos para este proyecto. La potencia efectiva anual proveída por estos aerogeneradores en conjunto sería de 17.62 MW considerando un factor de utilización de 47.89\%.

\subsection{Resguardo de la calidad}

\subsubsection{Calidad del proceso y del servicio}

La calidad del proceso de la planta generadora de energía eléctrica se mide por medio de la continuidad de la operación de esta. Para ello es importante la continuidad del funcionamiento de los aerogeneradores. El modelo elegido de aerogeneradores es horizontal de tres paletas, el cual cuanta con una góndola la cual contiene elementos complementarios a la función principal, pero estos son imprescindibles para mantener la calidad de la operación; estos son: la unidad de refrigeración la cual enfría el aceite multiplicador del equipo para que no se sobre caliente, el controlador eléctrico el cual monitorea las condiciones del aerogenerador y ante cualquier disfunción detiene automáticamente al equipo y envía una señal al operario encargado del mantenimiento.

Asimismo, en la calidad del servicio final se refiere a la calidad de la energía eléctrica que se provee a los clientes finales. La calidad de este servicio puede definirse como la ausencia de interrupciones, es decir la continuidad del 
suministro del servicio eléctrico. Para mantener la calidad del servicio es necesario mantener la calidad del proceso, ya que la continuidad del suministro de energía eléctrica a los clientes finales depende directamente de la continuidad de generación de esta.

\subsubsection{Niveles de satisfacción del cliente}

Los niveles de satisfacción de un cliente de energía eléctrica pueden medirse el siguiente indicador: deterioro de la confiabilidad, disponibilidad y confort en el servicio. Este indicador se refiere a la continuidad del suministro de energía eléctrica, el cual está relacionado directamente con la productividad de los clientes finales, ya que la producción de estos depende en gran medida de la disponibilidad de energía eléctrica de manera continua para mantener en funcionamiento las máquinas y equipos.

\subsubsection{Medidas de resguardo de la calidad}

Para mantener la continuidad del funcionamientos de los aerogeneradores, estos cuentan con equipos de control que se encargan de realizar el monitoreo de las condiciones de estos. Cada aerogenerador cuanta con un controlador electrónico que es una computadora que continuamente monitorea las condiciones del aerogenerador y controla el mecanismo de orientación, ante cualquier disfunción como sobrecalentamientos, este detiene automáticamente al aerogenerador y envía una señal al ordenador del operario encargado de mantenimiento.

Cada aerogenerador cuenta con un anemómetro y una veleta, los cuales se encargan de la medición del viento, y son necesarios para la monitorización y orientación que lleva a cabo el controlador del aerogenerador. De este modo, el controlador electrónico conecta el aerogenerador cuando el viento se encuentra a velocidades de $3 \mathrm{~m} / \mathrm{s}$ y lo para cuando la velocidad excede los 25 $\mathrm{m} / \mathrm{s}$, con el fin de proteger la turbina y evitar que el equipo se dañe. Además, para mantener la calidad del proceso y del servicio es necesario realizar 
mantenimiento constante a los equipos para mantener el buen estado de los mismos y asegurar la continuidad de su funcionamiento, más adelante se explicará con más detalle este tema.

\subsection{Impacto ambiental}

El impacto ambiental es la alteración que se produce en el entorno ambiental, físico o social, por la acción de una determinada obra o actividad en un determinado emplazamiento dentro de dicho entono.

La instalación de una planta generadora de energía eólica puede generar deferentes tipos de impactos ambientales, positivos y negativos, dentro del entorno en el que se desarrolle el proyecto.

A continuación, se describen los principales efectos, su naturaleza y su magnitud por la construcción y funcionamiento de la actividad proyectada. En la identificación de los impactos, se determinan cuáles son las acciones del proyecto susceptibles de generar efectos y sobre qué variables ambientales los generan. Para la identificación de acciones potencialmente causantes de impactos de un proyecto se deben diferenciar las tres fases del mismo: construcción, explotación y abandono.

\subsubsection{Etapa de construcción}

Es una etapa reducida en el tiempo, pero es la que concentra gran parte de los impactos generados por la instalación del parque eólico. Se caracteriza por la necesidad de adaptar el relieve para facilitar el acceso y realizar la obra, así como el empleo de diversa maquinaria pesada. En esta etapa es necesario adecuar la pista de acceso al emplazamiento, construir una red de caminos de servicio al interior del parque eólico a cada uno de los aerogeneradores, la cimentación de los aerogeneradores, el izado de los aerogeneradores, y la excavación de zanjas para las líneas de evacuación de la energía. Todas estas acciones generan los siguientes impactos: 
- Alteración local de la geomorfología.

- Destrucción de la cubierta vegetal.

- Alteración del paisaje.

- Emisión de partículas y ruidos que ocasionen molestias en la fauna y en poblaciones cercanas.

- Ocupación de suelos.

- Riesgo de contaminación de suelos por vertidos y/o derrames accidentales así como excedentes de hormigón y de chatarra. Los materiales derramados que podrían ocasionar contaminación de suelos son los siguientes: aceites, combustibles, resinas, etc.

- Generación de escombros y sobrantes de excavación.

- Empleo directo e indirecto.

- Aumento de la actividad en el sector servicios.

\subsubsection{Etapa de explotación}

Se trata de la etapa más larga, y a pesar que en ella se generen menos impactos, estos tienen una mayor incidencia en el tiempo por lo que son más significativos e importantes para el medio ambiente. La presencia y el funcionamiento de los aerogeneradores en un territorio, así como la generación de la energía eléctrica suponen la aparición de los siguientes efectos:

- Modificación del paisaje.

- La afección de la avifauna, ya que se introducen elementos extraños en su hábitat natural lo cual puede conllevar huida a otras zonas o colisiones contra los aerogeneradores.

- Ruidos molestos para las poblaciones cercanas y para la fauna existente.

- Generación de energía eléctrica de un modo no contaminante. 
- La no emisión de gases contaminantes y residuos derivados de la generación de este volumen de electricidad con otro tipo de energías y consecuente reducción a escala global de los gases efecto invernadero.

\subsubsection{Fase de abandono}

El proyecto de construcción del parque eólico no comprende lo que ocurrirá cuando éste deje de estar en funcionamiento. En algún momento llegará un punto en el que el parque deje de funcionar, llegando este momento se procederá al desmantelamiento de dicho parque, desapareciendo los efectos generados de su instalación.

\subsection{Seguridad y salud ocupacional}

Durante la construcción, operación y desmantelamiento de un proyecto de implementación de un parque eólico, existen riesgos para la salud y seguridad ocupacional. Entre los principales riesgos que pueden aparecer se encuentran: riesgos físicos como el trabajo en altura, el trabajo con máquinas giratorias y la caída de objetos.

Para la construcción e instalación de los componentes de la torre eólica, así como para las actividades de mantenimiento general, puede ser necesario trabajar en altura. Lo que puede representar un riesgo de caída para el operario. A continuación, se presentan algunas medidas de prevención y control asociadas al trabajo en altura:

- Antes de emprender el trabajo, someter la estructura a pruebas de integridad.

- Implementar un programa de protección contra caídas que incluya capacitaciones técnicas de subida; uso de medidas de protección contra caídas; inspección, mantenimiento y reemplazo de los equipos de protección contra caídas y rescate de trabajadores que han quedado en el aire. 
- Establecer criterios respecto del uso de sistemas que ofrecen total protección contra caídas, el cual debe adecuarse a la estructura de la torre y a los movimientos de la misma.

- Instalar en los componentes de la torre dispositivos que faciliten el uso de sistemas de protección contra caídas.

- Establecer un sistema adecuado de dispositivos de posicionamiento en el lugar de trabajo para los obreros.

- Garantizar que los equipos elevadores estén adecuadamente calibrados y mantenidos y que los operadores de los equipos reciban la capacitación adecuada.

- Los cinturones de seguridad deben ser de nailon de 2 cabos de 15.8 milímetros como mínimo, o de un material con igual resistencia. Estos deberán ser reemplazados antes de que comiencen a observar señales de desgaste o ruptura de las fibras.

- Retirar las señales y otros obstáculos de postes y estructuras antes de iniciar las labores.

- Utilizar una bolsa de herramientas aprobada para elevar o bajar herramientas y materiales hasta los trabajadores en las estructuras.

- No llevar a cabo la instalación de las torres, ni las labores del mantenimiento de estas, en condiciones meteorológicas adversas.

Además, los aerogeneradores de un parque eólico pueden causar serios accidentes si no se instalan correctamente o no se trabaja adecuadamente con ellos. Asimismo, levantar una torre donde se instalaran los aerogeneradores representa un peligro potencial para los trabajadores. A continuación se presenta un cuadro con los principales riesgos junto con reglas que se deben cumplir para mantener la seguridad.

- Riesgos mecánicos

- No acercase a ninguna máquina en movimiento (hélices o sistemas rotatorios). 
- Detener las hélices de los aerogeneradores totalmente antes de trabajar con ellas.

- Para detener al aerogenerador, debe estar desviado de la dirección del viento, o se debe cortocircuitar sus cables antes de salida.

- Riesgos eléctricos

- Revisar las conexiones eléctricas, y mantenerlas limpias y secas.

- Evitar que los generadores giren sin propósito, porque generan voltaje en tensiones que pueden alcanzar valores muy altos.

- Usar fusibles para protegerse contra corrientes y voltajes altos.

- Verificar que los cables tengan el grosor adecuado.

- Antes de elevar el aerogenerador a la torre, comprobar que todo funciona perfectamente y hacer las correcciones oportunas, con el objeto de evitar el trabajo en alturas.

- Riesgos al instalar las torres en las plataformas

- No permitir el ingreso de personas fuera del equipo izado de torres en el área circundante a la plataforma de instalación.

- Evitar que el personal esté situado cerca de la torre, especialmente por el lado donde se está inclinando la torre, para que en caso de caída de la torre, lo haga por el lado donde no hay trabajadores.

- Comprobar la tensión de los cables que sostienen la torre. No deben estar demasiado tensos, ni demasiado flojos.

- Asegurar una buena comunicación entre el equipo de trabajadores a través del uso de radios de comunicación móviles.

- Una vez izada la torre, conectarla a tierra para protegerla contra posibles rayos.

- Evitar treparse por la torre sin el permiso correspondiente.

Además, es importante resaltar que todo el personal que trabaje en la planta deberá usar el equipo adecuado de protección personal como cascos, guantes 
aislantes, lentes de seguridad, y botas de seguridad con punta de acero. Asimismo, en la planta se instalarán extintores de dióxido de carbono, en caso se produzca algún incendio.

\subsection{Sistema de mantenimiento}

El programa de mantenimiento es de suma importancia puesto que permite la conservación del ciclo de vida de los aerogeneradores y la subestación que representan los principales activos de la empresa. Los principales tipos de mantenimiento que se pueden aplicar son el mantenimiento reactivo y el preventivo.

\subsubsection{Mantenimiento reactivo}

Este tipo de mantenimiento es el único que no es programado y por lo general tiene un elevado costo de operación puesto que no solo considera la reparación en sí, sino también los costos de paralización. Si bien es cierto, esto resuelve los problemas en el corto plazo, tiene la desventaja que le resta tiempo de vida a los equipos, por lo que con el paso del tiempo, puede significar la obsolescencia de los mismos con la consecuente necesidad de adquirir otros equipos, elevando los costos. Entre los tipos de mantenimiento que se pueden dar se dividen en dos grupos principalmente:

○ Pequeño correctivos:

- Pequeñas averías y cambios de componentes pequeños

- Grandes Correctivos:

- Cambio de rotor

- Cambio de generador

- Cambio de multiplicadora

- Cambio de corona 
- Cambio de nacelle (elemento que se sitúa en la parte superior de la torres y sobre la que giran las palas, formada por una estructura metálica que sirve de soportes para el conjunto de elementos que se sitúan en su interior y por paneles de fibra de vidrio que protegen los equipos internos).

- Cambio de tramo

5.8.2. Mantenimiento preventivo

Este tipo de mantenimiento consiste en un programa de actividades planificadas que se realizan en periodos establecidos con la finalidad de conservar el estado operativo de los equipos. Entre sus principales ventajas es que evita las paradas imprevistas y permite la organización de recursos humanos y materiales. Este tipo de mantenimiento consiste en las actividades sistemáticas de limpieza, lubricación, ajustes y reparaciones. Para poder establecer un programa de mantenimiento preventivo es necesario conocer cuáles son las posibles fallas que pueden presentarse en los equipos y las acciones para corregirlas. 
Tabla 5.5.

Posibles fallas por equipo y acciones a tomar

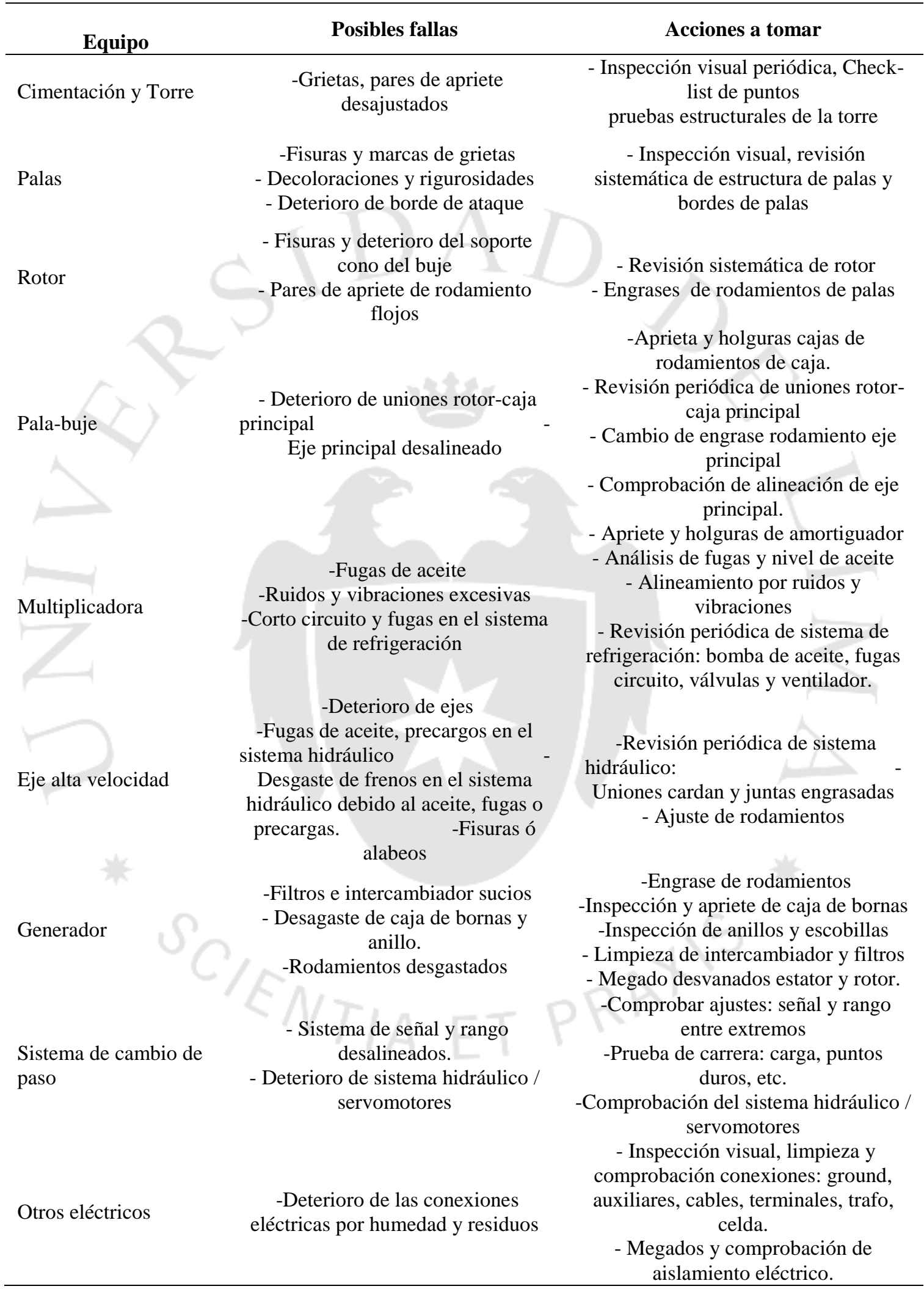




\begin{tabular}{|c|c|c|}
\hline Sistema de orientación & $\begin{array}{l}\text {-Sistema hidráulico descalibrado } \\
\text { - Desgaste de corona y superficie } \\
\text { - Discos y placas robados }\end{array}$ & $\begin{array}{l}\text { - Inspección dientes y prueba: carga, } \\
\text { ruidos, puntos duros. } \\
\text { - Engrase de corona y superficie } \\
\text { deslizantes } \\
\text { - Reapriete de discos y holguras } \\
\text { radiales de placas deslizantes } \\
\text { - Comprobación del sistema hidráulico }\end{array}$ \\
\hline
\end{tabular}

Una vez establecidas las posibles fallas en el parque, se procede a armar un programa de mantenimiento donde se consideran las principales partes de los aerogeneradores. A continuación se muestra un programa propuesto por la empresa española OPEX Energy.

Tabla 5.6.

Programa de mantenimiento preventivo propuesto

\begin{tabular}{|ll}
\hline Frecuencia & Acción \\
\hline Cada 3 meses & Reapriete y comprobación de pernos \\
\hline Menor & Comprobaciones de pares de pariete, engrases, engranajes. \\
Mayor & Revisión exhaustiva del aerogenerador \\
\hline Anual & Megado del generador \\
Cada 18 meses & Cambio de aceite en la multiplicadora: \\
Cada 5 años & Cambio aceite grupo hidráulico: \\
\hline Fuente: Global Energy Service, elaboración propia \\
\hline
\end{tabular}

\subsubsection{Mantenimiento predictivo}

Es el más difícil de todos los tres tipos de mantenimiento. Hay que diagnosticar de manera precoz posibles fallas o averías. Para ello juega un papel absolutamente esencial un sistema de monitoreo y telecontrol muy desarrollado, llamado SCADA. Sus objetivos son aumentar la disponibilidad de los aerogeneradores, planificar en forma más efectiva el mantenimiento al sustituir $\mathrm{y}$, por lo tanto parar la máquina únicamente en caso necesario, conseguir una mayor protección de los equipos industriales y así optimizar la producción que se haya realizado en ellos. Los tipos de análisis que se realizan son de aceites y vibraciones en los aerogeneradores. 
Analizando el caso de parques eólicos en España, se tiene una disponibilidad media de alrededor de $98 \%$, que significa una media de 8 días al año en los cuales el aerogenerador estará fuera de servicio. Se estima que 4 de ellas se dedicarán a mantenimiento preventivo y correctivo y el resto se corresponden al tiempo que se utiliza en detectar la posible avería, llegada del equipo de mantenimiento y obtención de repuestos.

\subsection{Programa de operaciones del servicio}

5.9.1. Consideraciones sobre la vida útil del proyecto

El proyecto contempla una vida útil de 20 años, determinada en función a:

- La vida útil de los aerogeneradores que tienen una vida útil máxima de 25 años, pero para efectos del proyecto se toma un valor de 20 años, que es la vida útil mínima de los aerogeneradores. Si bien es cierto después de este tiempo los aerogeneradores se pueden renovar, este implica un coste adicional extra al proyecto de inversión inicial.

- Debido a la alta inversión inicial que demanda este tipo de proyectos, el periodo de recupero también debe elevado y es por ello que se considera una vida útil de 20 años para poder cubrir dichos costos y obtener un retorno adecuado.

- Es el promedio de vida útil que recomiendan los grandes fabricantes de aerogeneradores y comprende el periodo desde su instalación en su emplazamiento correspondiente y puesta en marcha, hasta que finalmente son desmanteladas para ser adecuadamente gestionadas. (Gamesa, 2013)

5.9.2. Programa de operaciones del servicio durante la vida útil del proyecto

El programa de operación del servicio se calculará en base a la producción anual de energía eléctrica lo que se demuestra en la siguiente tabla. 
Tabla 5.7.

Producción den energía eléctrica en MWh anual de acuerdo a distintas velocidades del viento

\begin{tabular}{|c|c|c|c|}
\hline $\begin{array}{l}\text { Velocidad } \\
{[\mathrm{m} / \mathrm{s}]}\end{array}$ & $\begin{array}{c}\text { Curva de potencia } \\
{[\mathrm{kW}]}\end{array}$ & $\begin{array}{l}\text { Distribución de } \\
\text { viento [hr/año] }\end{array}$ & [MWh/año] \\
\hline 0 & 0 & 0 & 0 \\
\hline 1 & 0 & 253 & 0 \\
\hline 2 & 0 & 461 & 0 \\
\hline 3 & 0 & 626 & 0 \\
\hline 4 & 122 & 747 & 91 \\
\hline 5 & 200 & 820 & 164 \\
\hline 6 & 454 & 847 & 384 \\
\hline 7 & 744 & 835 & 621 \\
\hline 8 & 1,386 & 789 & 1094 \\
\hline 9 & 1,974 & 719 & 1,419 \\
\hline 10 & 2,210 & 634 & 1,401 \\
\hline 11 & 2,232 & 542 & 1,210 \\
\hline 12 & 2,245 & 450 & 1,011 \\
\hline 13 & 2,284 & 364 & 831 \\
\hline 14 & 2,294 & 286 & 657 \\
\hline 15 & 2,299 & 220 & 505 \\
\hline 16 & 2,300 & 164 & 378 \\
\hline 17 & 2,300 & 120 & 276 \\
\hline 18 & 2,300 & 86 & 197 \\
\hline 19 & 2,300 & 60 & 137 \\
\hline 20 & 2,300 & 41 & 93 \\
\hline 21 & 2,300 & 27 & 62 \\
\hline 22 & 2,300 & 18 & 40 \\
\hline 23 & 2,300 & 11 & 26 \\
\hline 24 & 2,300 & 7 & 16 \\
\hline 25 & 2,300 & 4 & 10 \\
\hline 26 & 0 & 3 & 0 \\
\hline 27 & 0 & 1 & 0 \\
\hline 28 & 0 & 1 & 0 \\
\hline 29 & 0 & 0 & 0 \\
\hline 30 & 0 & 0 & 0 \\
\hline
\end{tabular}

Fuente: MINEM

Producción anual bruta: 10,622 MWh/año

Para calcular la potencia neta, se considera las diversas pérdidas determinadas en el subcapítulo 5.4.1 y que se muestran a continuación: 
Tabla 5.8.

Tipo de pérdidas

\begin{tabular}{cc}
\hline Tipo de Pérdida & Porcentaje \\
\hline Pérdidas eléctricas & $3 \%$ \\
Pérdidas estelas del parque & $3 \%$ \\
Pérdidas de disponibilidad & $2 \%$ \\
Otras pérdidas & $1 \%$ \\
Total & $9 \%$ \\
\hline Elaboración propia &
\end{tabular}

Este porcentaje de pérdidas se descuenta de la producción anual bruta, después se procede a hallar la producción anual de todo el parque multiplicando el valor por los 16 aerogeneradores y finalmente; se determina así la producción neta anual del parque.

\section{Tabla 5.9.}

Producción del parque eólico

\section{Tipo de Producción}

Producción (MWh/año)

$\begin{array}{cc}\text { Producción anual bruta por aerogenerador } & 10,622 \\ \text { Producción anual bruta del parque } & 169,956 \\ \text { Producción anual neta del parque } & 154,660\end{array}$

Elaboración propia

De esta manera se logró determinar la producción anual neta del parque eólico que es de 154,660 MWh y que se mantendrá constante durante toda la vida útil del proyecto.

Tabla 5.10.

Porcentaje de Utilización de la Capacidad Instalada años 2015:2035

\begin{tabular}{lc}
\hline AÑO & $\mathbf{2 0 1 5 - 2 0 3 5}$ \\
\hline Capacidad disponible & 154,375 \\
Capacidad instalada & 322,368 \\
\% de Utilización & $47.89 \%$ \\
\hline Elaboración propia &
\end{tabular}


Como se observa, el porcentaje resultante es de $47,89 \%$, y ese porcentaje se mantendría así hasta el 2035.

5.10. Requerimientos de insumos, personal y servicios

5.10.1. Insumos y otros materiales

A continuación se presenta un listado de todos los materiales que serán necesarios para la operación óptima de la planta generadora de energía eólica a lo largo de su vida útil. Entre los distintos materiales, se encuentran los elementos que serán utilizados para realizar el mantenimiento de los aerogeneradores, y el transporte del personal y de los materiales.

- Grava

- Arena

- Aceros de carbono

- Cemento

- Materiales de hierro y acero

- Resinas y compuestos epoxi

- Cobre y aleaciones de cobre

- Imanes

- Fibra de vidrio

- Resinas y compuestos poliéster

- Plásticos

- Acero inoxidable

- Compuestos cerámicos

- Aluminio y aleaciones de aluminio

- Espuma de poliuretano 
- Barnices, lacas y similares

- Plomo

- Níquel

- Aceites y lubricantes

- Camionetas de diésel

- Grupo electrógeno

5.10.2. Operarios y trabajadores indirectos

Para la realización óptima de las operaciones del parque eólico es necesario contar con personal calificado que tenga los conocimientos técnicos necesarios para asegurarse que todo se realice con efectividad.

Entre el personal encargado de las operaciones de los aerogeneradores se encuentra: un jefe de operaciones y 2 controladores que se encarguen de la supervisión del buen funcionamiento y de la correcta generación de energía. Para el mantenimiento de los equipos se contará con un grupo liderado por un jefe de mantenimiento quien trabajará conjuntamente con dos encargados de mantenimiento, quienes deberán asegurarse de que los aerogeneradores no tengan fallas que comprometan la operación.

En las áreas de apoyo de la empresa se contará con un administrador, un encargado de las finanzas, un encargado de la logística y un encargado de marketing y ventas.

\subsubsection{Servicios de terceros}

Entre los servicios de terceros que se necesitarán durante la operación de la planta generadora de energía eólica se encuentran:

- Servicio de limpieza, el cual se encargará de mantener las instalaciones limpias en todo momento. 
- Servicio de vigilancia, el cual se encargará de vigilar y mantener seguro el parque eólico ante cualquier atentado que se presente.

- Servicio de contabilidad, el cual se encargará de apoyar con la contabilidad de la empresa.

- Asesoría legal, el cual se encargará de brindar asesoría legal necesaria durante el funcionamiento de la planta.

\subsubsection{Otros}

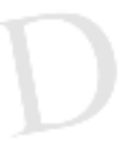

Para la correcta operación del parque eólico, también será necesario considerar servicios como agua potable, teléfono, electricidad, Internet y combustible. Además, deben considerarse los materiales que se utilizarán en las áreas administrativas de la empresa como: materiales de oficina, mesas, sillas, muebles, computadoras, teléfonos, celulares, impresoras, etc.

\subsection{Características físicas del proyecto}

\subsubsection{Factor edificio}

Al planear la distribución de una planta generadora de energía eléctrica se debe tener en cuenta que debido al tipo de proyecto, las maquinarias principales estarán al aire libre y sin ningún tipo de edificación que las cubra. Sin embargo, existirá un área de control y un área administrativa en la que estarán ubicados los operarios y el personal de apoyo respectivamente. La construcción de las áreas anteriormente mencionadas, deben brindar la seguridad y la comodidad para el desarrollo de las actividades dentro de ellas. Para ello, se deben tener en cuenta los siguientes factores:

- Suelo

El análisis y determinación de los tipos de suelos sobre los cuales se instalará la planta debe tomarse en cuenta debido a que influye de 
manera determinante en la cimentación, la altura de la construcción, su funcionamiento y la seguridad que brindará. En el presente caso, se trata de un tipo de suelo arenoso, ya que el proyecto se realizará en una zona desértica.

- Cimentación

Se denomina cimentación al conjunto de elementos estructurales cuya misión es transmitir las cargas de la edificación al suelo, distribuyéndolas de forma equitativa. El presente proyecto contará con una buena cimentación, para evitar que el terreno ceda bajo presión de una carga y se deforme.

- Material de construcción para paredes y pisos

Las áreas en cuestión serán construidas con material noble, es decir, cemento y ladrillos que le confieren consistencia a la edificación. Para los pisos, se utilizará concreto simple con acabados de cerámica.

- Niveles de edificación

Al tratarse de tan solo dos áreas de trabajo que necesitan techo, será conveniente que la edificación sea de un solo nivel debido a que permite una mayor facilidad de operación, mejor iluminación y ventilación para los ambientes, y flexibilidad.

- Techos

Este elemento cumple la función de protección, seguridad y resguardo ante la intemperie. La construcción del techo debe realizarse con material impermeable. Para ello se utilizarán planchas de fibra de cemento con estructuras metálicas que las sostengan.

\subsubsection{Factor servicio}

Dentro de la una planta, los principales factores de producción como lo son las personas, las máquinas y los materiales, a menudo requieren de servicios adicionales que apoyen y satisfagan las necesidades de los mismo. A 
continuación, se presentan los requerimientos y propósitos de los servicios que serán necesarios para el buen funcionamiento del parque eólico.

\subsubsection{Relativo al hombre}

Dentro de una unidad productiva, el elemento más importante es el hombre, y es necesaria la provisión de ciertos elementos que propicien el buen desarrollo de sus labores.

- Servicios higiénicos

Son instalaciones permanentes que satisfacen las necesidades primarias de las personas. Por ello, su planificación dentro de la empresa es esencial. El número de servicios a instalar depende del número de personas que harán uso de estos; para el caso de este proyecto, solo se requerirá de un servicio ya que se contará con un número reducido de personal.

Además, se deben tener en cuenta ciertas consideraciones en referencia a las instalaciones. Los espacios deben disponer de agua potable en cantidad suficiente y fácilmente accesible; asimismo es primordial que el servicio provea la privacidad, limpieza, ventilación e iluminación adecuadas.

- Servicios de alimentación

Las instalaciones deben contar con un espacio que atienda la alimentación de los trabajadores. Este espacio debe estar equipado con una refrigeradora en la que los trabajadores pueden dejar sus alimentas, y un horno microondas en el que calentarán los mismos. Esta zona debe estar ubicada en un ambiente que no esté propenso a la contaminación por olores, polvo, humo, entre otros. Además, se debe contar con una mesa y sillas en donde los trabajadores puedan ingerir sus alimentos a hora de refrigerio.

- Espacios de atención de emergencias 
Es necesario que en las instalaciones se cuente con un espacio de atención ante cualquier eventualidad o accidente inesperado que necesite pronto tratamiento. Para ello, el personal de la empresa deberá estar capacitado para atender casos leves que se presenten, y se debería contar con los medicamentos y equipos necesarios para atender las distintas eventualidades que pueden ocurrir en la planta generadora.

\subsubsection{Relativo a la maquinaria}

Las máquinas, en este caso los aerogeneradores, proveen la fuerza y capacidad necesaria para generar energía eléctrica durante el proceso. Estas requieren de algunos servicios para no interrumpir las operaciones por algunos desperfectos que puedan surgir. A continuación, se presentan los distintos servicios que se den considerar.

- Área de mantenimiento

Esta área involucra la supervisión de las máquinas durante la operación, para la planificación de la revisión periódica, que garantice su correcto funcionamiento.

- Almacén de herramientas

Las herramientas dentro de la planta sirven para atender los desperfectos que pueden surgir en las máquinas y equipos. Para este proyecto se considerará un almacén en el que se guarden los distintos repuestos y materiales de apoyo para el mantenimiento de las máquinas.

- Grupo electrógeno

El grupo electrógeno es una máquina que mueve un generador eléctrico a través de un motor de combustión interna. Estos equipos son comúnmente utilizados dentro de la planta para prevenir la interrupción del proceso por déficit de energía eléctrica. 
5.12. Disposición de la instalación del servicio

\subsubsection{Disposición general}

Para establecer la disposición de la planta de energía eólica se elaboró primeramente el diagrama unifilar. Este es una representación gráfica de una instalación eléctrica o de parte de ella. El esquema unifilar se distingue de otros tipos de esquemas eléctricos en que el conjunto de conductores de un circuito se representa mediante una única línea, independientemente de la cantidad de dichos conductores. Estos diagramas son muy útiles cuando se trata de interpretar de manera sencilla por donde se conduce y hasta donde llega la electricidad e incluye dispositivos de protección, control y medición de la misma.

En el gráfico a continuación se muestra dicho diagrama. En este se pueden diferenciar dos zonas. La primera es el parque eólico y la segunda es la Subestación eléctrica transformadora del parque. El proceso empieza con la generación, en donde la energía eléctrica producida es alterna trifásica. Luego pasan por unos switch de control y de allí a unos transformadores con una relación de transformación de 20/0.1 KV a una potencia 2,5 MVA. Estos pasan después por un interruptor de potencia a vacío y por un seccionador conectado a tierra. Ambos equipos permiten desconectar el circuito y trabajar en los equipos. La diferencia radica en que el seccionador trabaja sin carga y el interruptor si se desconecta con carga. Por ende, para su uso primero se debe desconectar el interruptor y luego el seccionador. Después se presenta un fusible que se usa como medida de protección cuando se vuelva a conectar al sistema, además se presenta un interruptor de línea el cual es utilizado para desconectar la línea en caso de mantenimiento o falla. Como se observa estos estarán conectados por medio de 4 circuitos a la subestación. Para la conexión se usa un transformador de corriente así como un interruptor de potencia y un seccionador para la desconexión del sistema. Estos están conectados a una línea principal de $20 \mathrm{kV}$. En el extremo derecho se observa un transformador de tensión que sirve para medir el voltaje en un momento dado. 
Posteriormente, esta línea se conecta por una línea principal en donde vuelve a pasar por un seccionador, un interruptor de potencia, un transformador de corriente. En esta hay una rama que se usa para medir el neutro en donde la configuración pasa de triángulo a estrella para poder medir la corriente después por un transformador de corriente. Luego tiene que haber un pararrayo que desvía tensiones superiores a $20 \mathrm{KV}$ que puedan afectar el transformador principal. El equipo principal de la subestación eléctrica es el transformador de potencia de $220+-10 \times 1 \% / 20 \mathrm{kV}$ de 26/34 MVA YNd11. Esto significa que dependiendo del tipo de generador transformará a una potencia de 26 a 34 MVA si es que el transformador es ONAN (Oil Natural, Air Natural) o ONAF (Oil Natural, Air Forced). YNd11 simboliza la conexión estrella triángulo que se configura para la entrada del transformador. La diferencia radica en que el sistema ONAF permite una mayor potencia ya que se tiene un sistema de ventiladores que brindan una mejor disipación del calor y por ende una mayor producción de potencia energética que en el caso del presente proyecto es de 40 MVA, por ello el tipo de transformador seleccionado es ONAF.

Posteriormente, el voltaje de salida es de $220 \mathrm{kV}$ pasa por un pararrayo, un interruptor de potencia, un transformador de corriente, un condensador y un medidor de voltaje que mide la calidad de voltaje suministrado de salida.

Estos vuelven a pasar por un transformador, un interruptor de potencia, un seccionador y un sistema identificador de onda sonora compuesto por una resistencia y un condensador. Este medio se coloca ya que los cables no sólo permiten transmitir energía eléctrica, sino también ondas sonoras WT. Finalmente, la energía sale del sistema y viajará directamente a la subestación del cliente o distribuidor.

Los aerogeneradores al producen energía eléctrica alterna trifásica y cada uno posee un transformador elevador de salida que eleva la corriente de $690 \mathrm{~V}$ a 20 $\mathrm{KV}$. En el transformador principal de la subestación el tipo de relación es estrella - triángulo (YNd11). 
Figura 5.32.

Diagrama unifilar del parque eólico y la subestación

\section{DIAGRAMA UNIFILAR DEL PARQUE EOLICO Y LA SUBESTACIÓN}

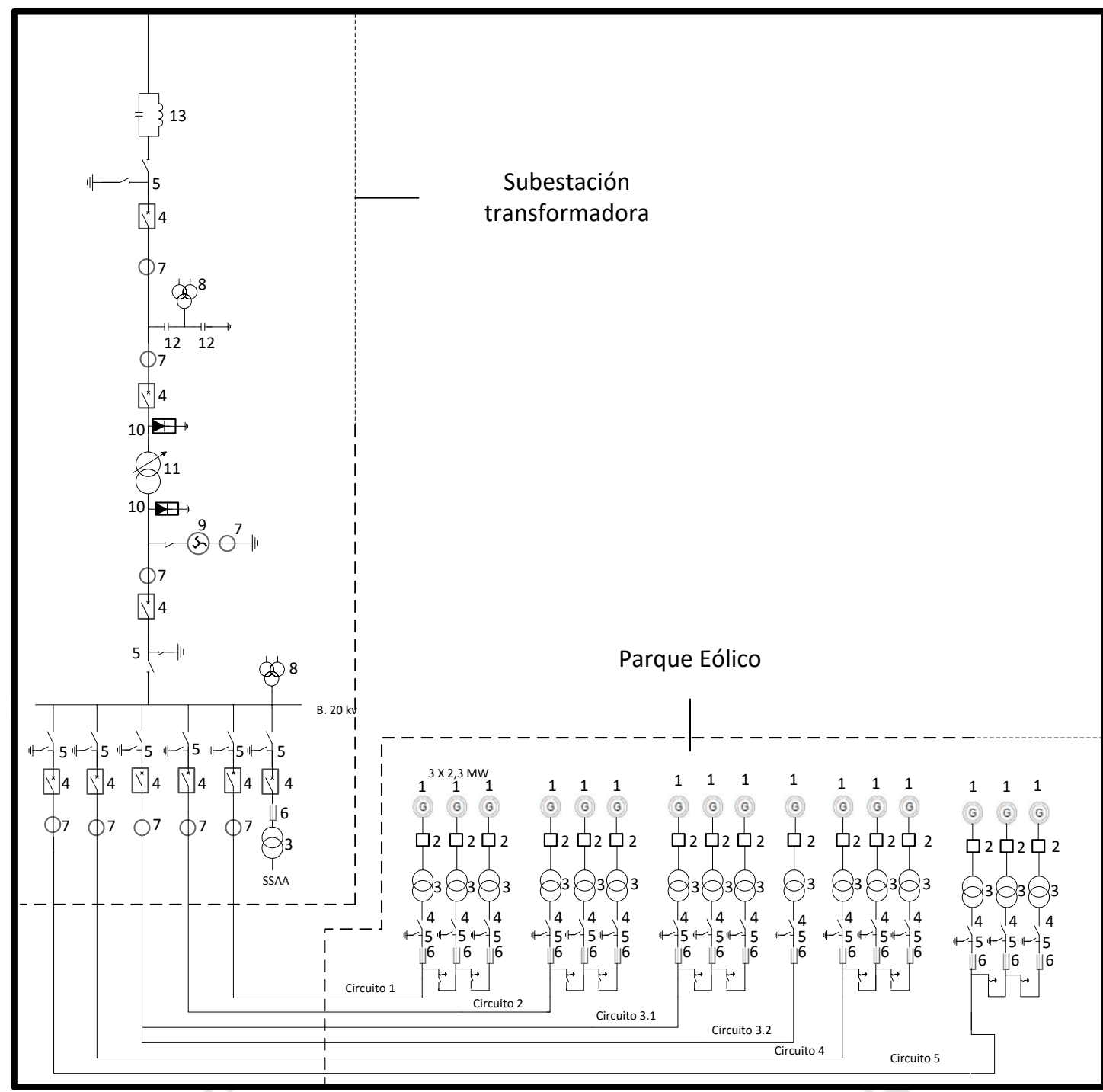

\section{LEYENDA}

1 Aerogenerador

2 Switch de control

3 Transformador 20/0.1 kV

4 Interruptor de potencia

5 Seccionador con conexión a tierra

6 Fusible

7 Transformador de corriente
8 Transformador de tensión (medidor de voltaje)

9 Transformador de triángulo a estrella

10 Pararrayo

11 Transformador de potencia 220 +/- 10x1\%/20kV 24/43 MVA YNd11

12 Condensador

13 Sistema identificador de onda sonora

Elaboración propia 
5.12.2. Disposición de detalle

"Un parque eólico consta de muchas turbinas todas ellas interconectadas a la red eléctrica, a la que aportan de manera individual. Pero dado el emplazamiento de un parque por sus buenos vientos tanto en intensidad como en frecuencia, se distribuye las turbinas en función a ciertas características como la rugosidad del terreno, la velocidad de viento predominante, la altura de la torre, el diámetro del área de la turbina, entre otros factores." (Mirez Tarrillo, 2002) La figura muestra un espaciamiento óptimo entre turbinas, pero son las particularidades de viento y geográficas del emplazamiento los que definen a que distancia colocar.

Figura 5.33.

Distribución óptima del parque en un terreno plano

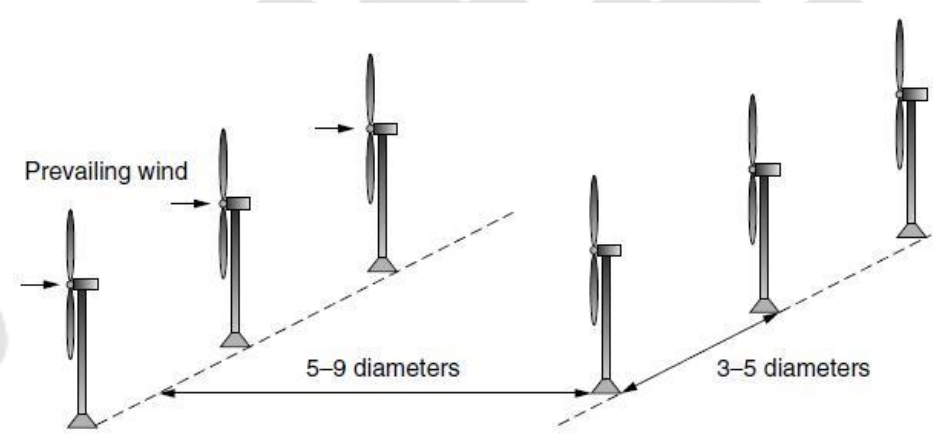

Fuente: Mirez Tarrillo, 2002

Dado que el viento entrega parte de su energía a la turbina, éste disminuye su presión y se expande luego de pasar por la turbina. Luego el viento que no interactuó con la turbina, va comprimiendo esta estela de baja presión de viento hasta nivelarlo con la presión ambiente, es en esta condición que nuevamente puede ingresar a una siguiente turbina eólica.

La configuración del parque eólico, como ya se mencionó anteriormente, dependerá de parámetros como dirección del viento, geografía (influye en la rugosidad), espacio disponible, variación del viento, tamaño de aerogeneradores y otros más. 
A continuación se muestra un gráfico de los tipos de configuración dependiendo de la geografía.

Figura 5.34.

Distribución de la configuración de un parque sobre colinas redondeadas

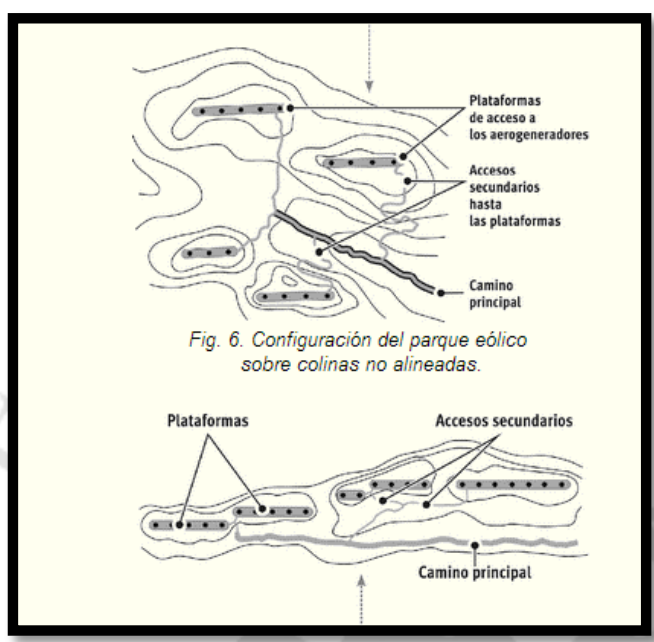

Fuente: Mirez Tarrillo, 2002

Si bien la zona de influencia del parque incluye colinas y pampas. Se decidió realizar el parque en la zona de pampa debido a que según el Atlas eólico del Perú, no hay mucha diferencia en las velocidades del viento. Además los costos de implantación son menores en zonas más planas. Para la distribución del parque se tiene que considerar una distancia entre aerogeneradores de mínimo 3 diámetros de palas y una distancia de alejamiento de mínimo 5 diámetros así como la geografía particular de la zona. Como resultado se elaboró el siguiente mapa de distribución que incluye el parque y la línea de transmisión.

Las coordinadas de la ubicación de la planta son las siguientes: $15^{\circ} 00^{\prime} 53.85^{\prime \prime}$ S y $75^{\circ} 06^{\prime} 3.10^{\prime \prime}$ o. A continuación, se presenta un mapa con la ubicación de la planta. 
Figura 5.35.

Mapa de ubicación del parque eólico en la provincia de Marcona- Ica

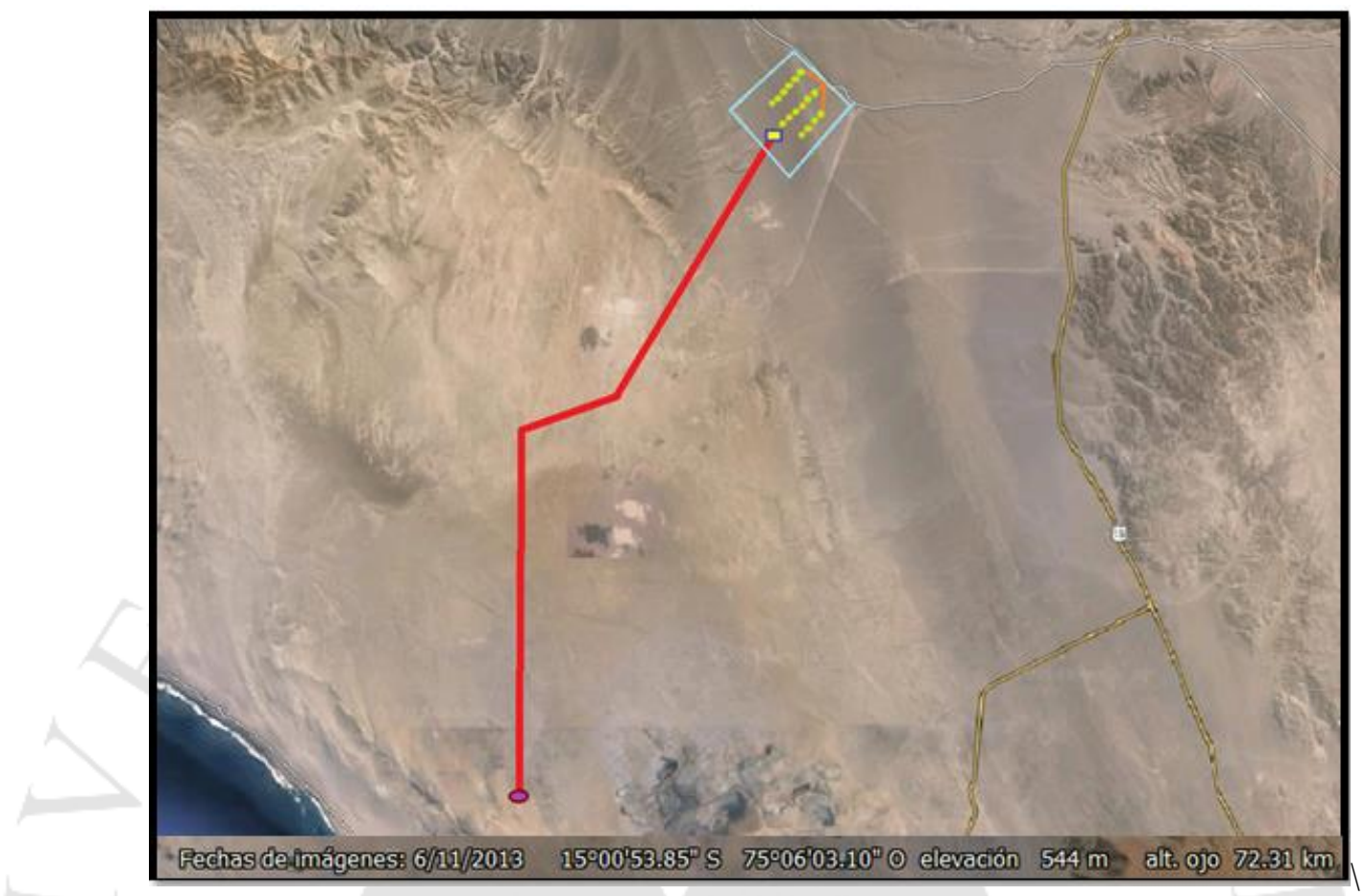

Fuente: Google maps, elaboración propia 
Figura 5.36.

Plano de distribución del parque

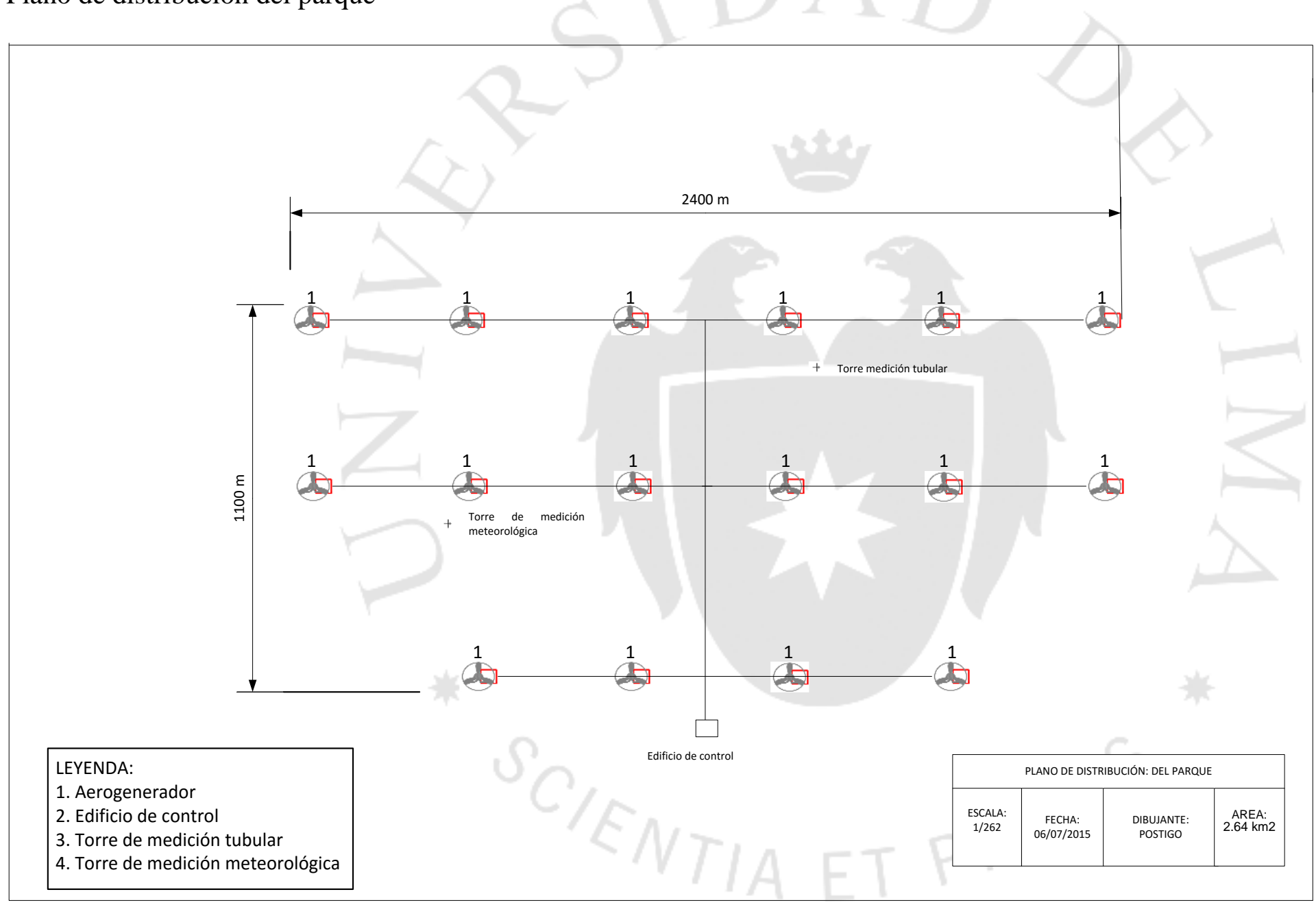


Figura 5.37.

Diagrama de dimensiones del aerogenerador

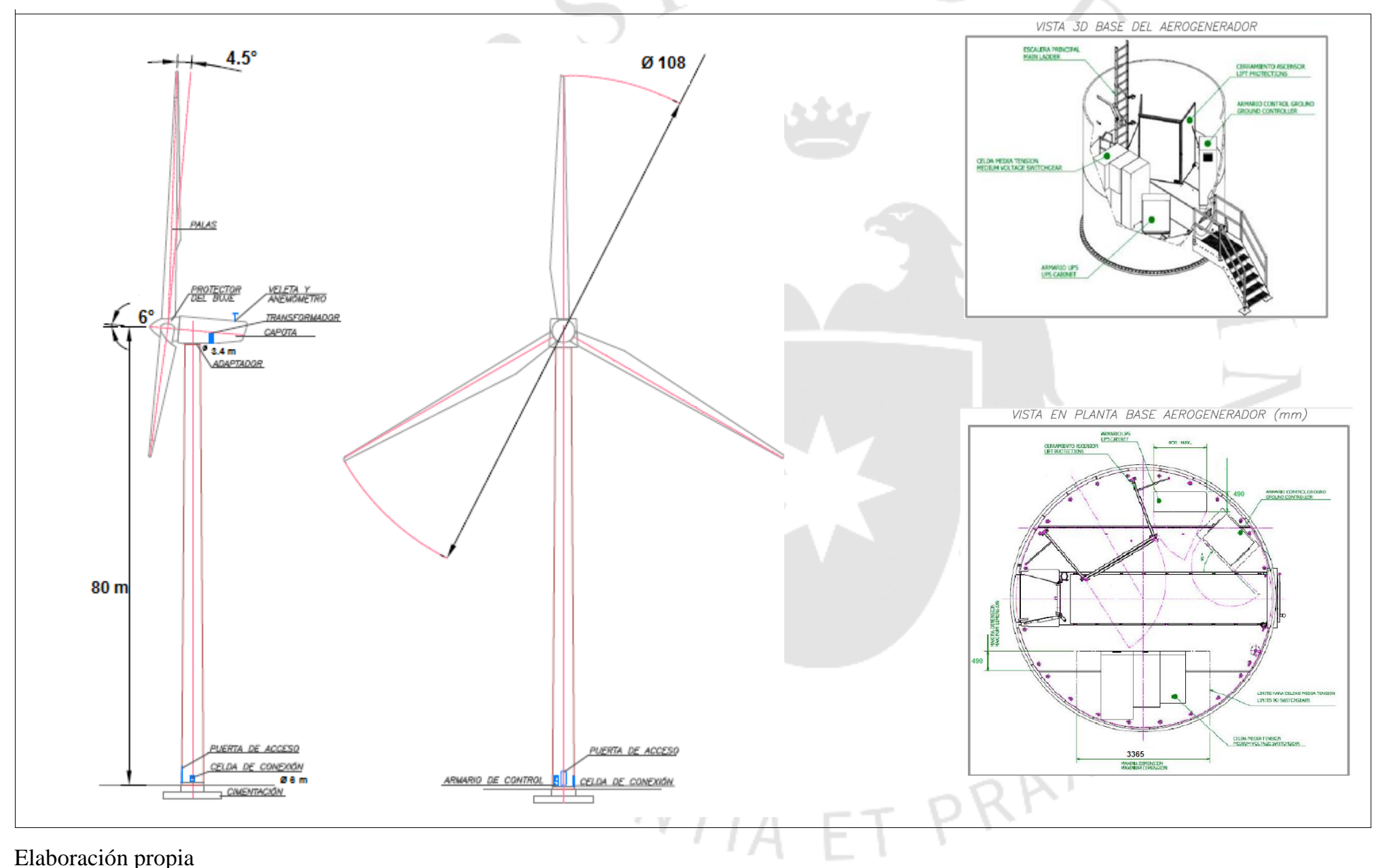

Elaboración propia 
Figura 5.38.

Plano de distribución: estación de control: 1er nivel

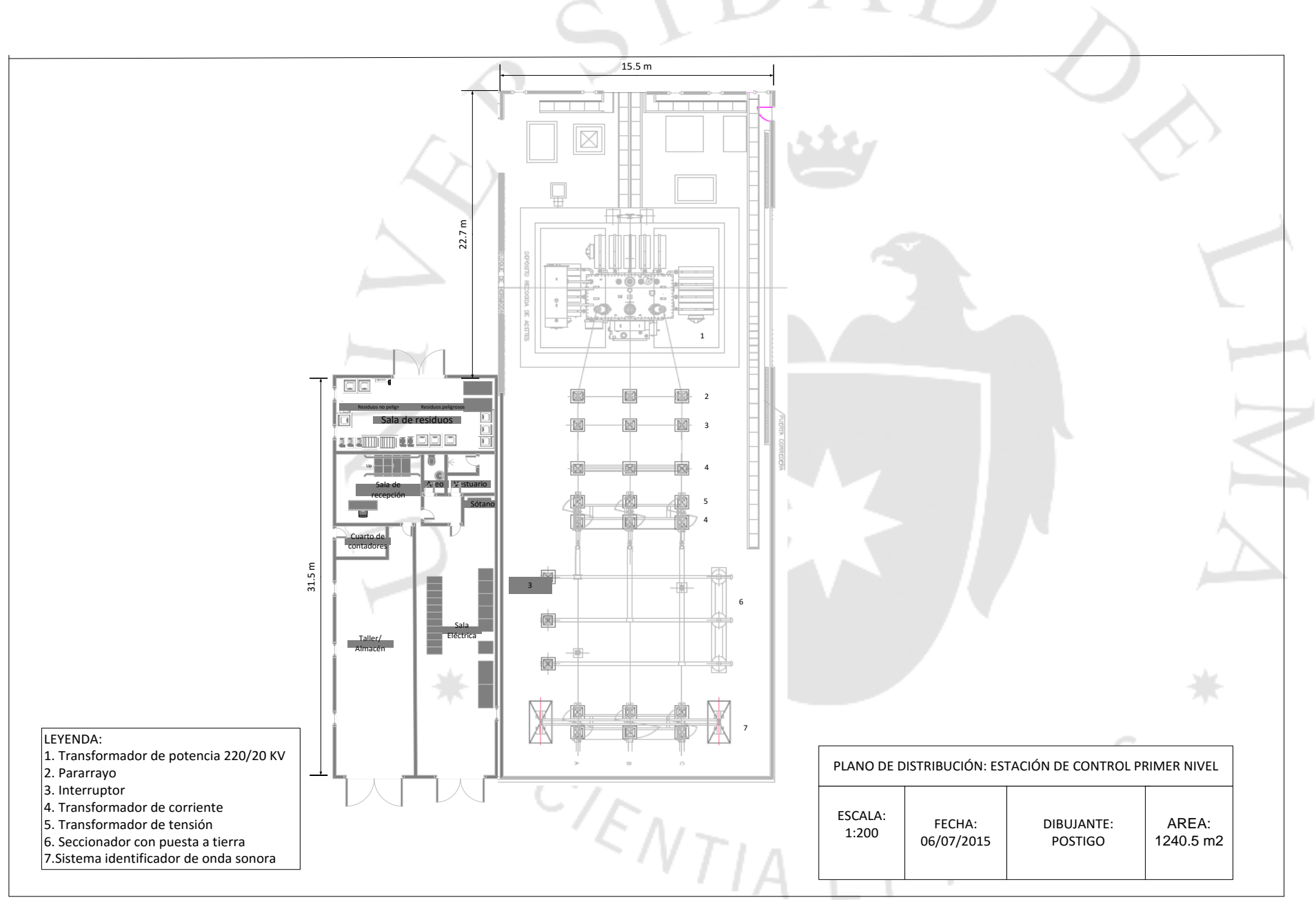


Figura 5.39.

Plano de distribución de la estación de control: 2do nivel

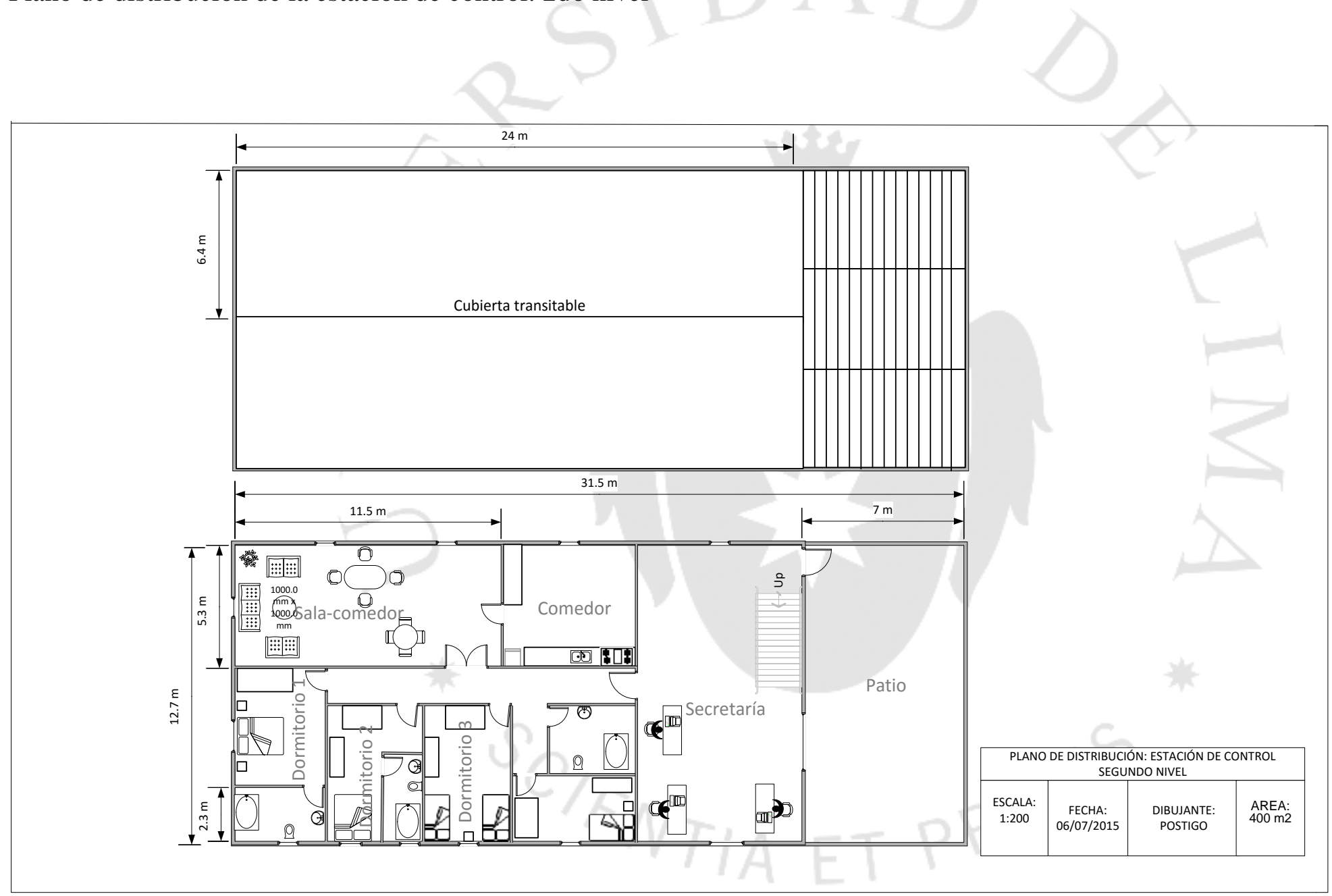


5.13. Cronograma de implementación del proyecto

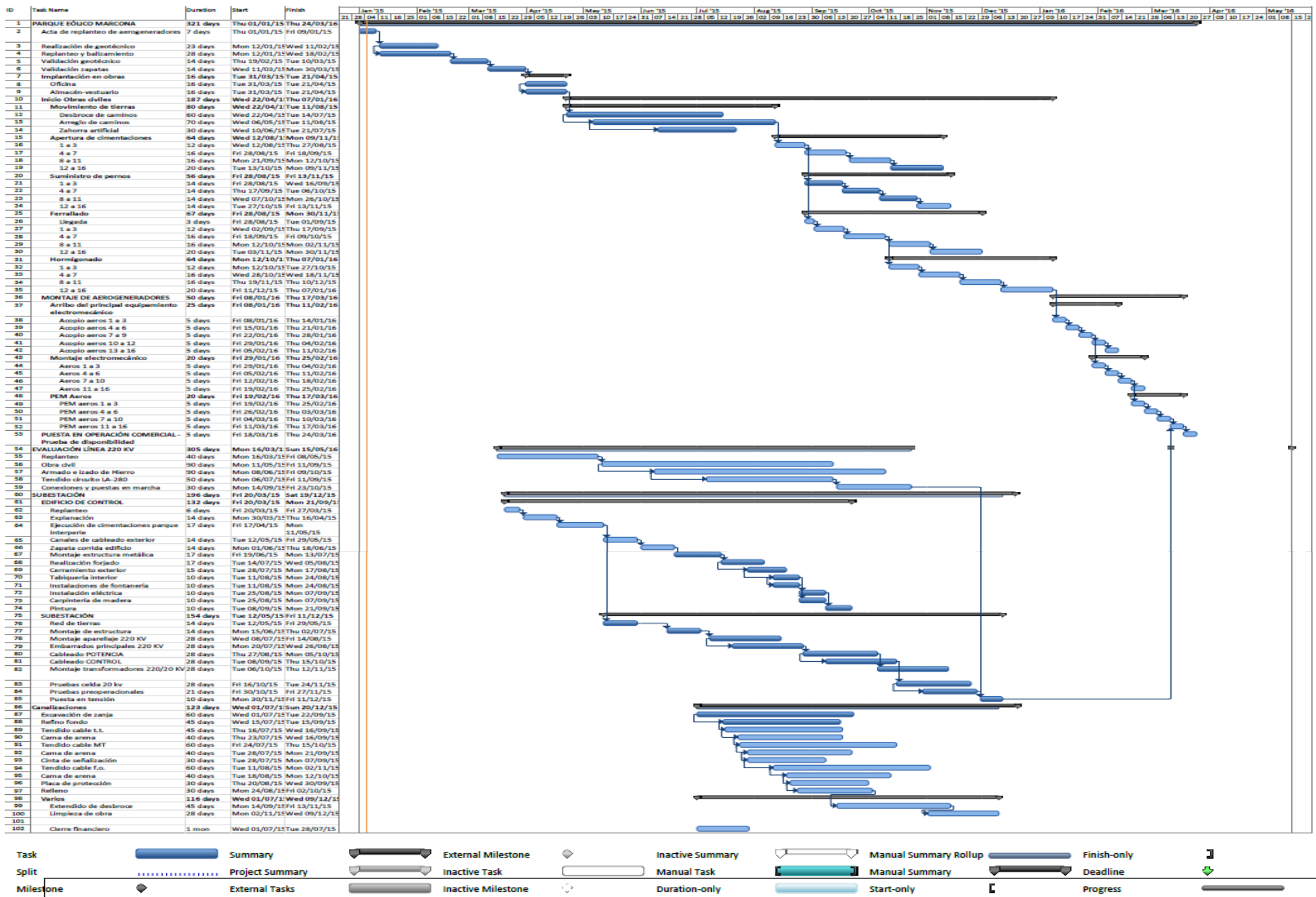




\section{CAPÍTULO VI: ORGANIZACIÓN ADMINISTRATIVA}

\subsection{Organización empresarial}

La organización empresarial es la manera en que la empresa agrupa y reúne personas dentro de sus escalones jerárquicos de tal forma que la comunicación se pueda dar de manera óptima.

La gestión en la organización se desarrollará a partir de su misión y visión y esta estará orientada hacia la mejora continua o las $5 \mathrm{~S}$ y que no requieren una inversión adicional en tecnología y teoría gerencial. Además, se promoverá una capacitación constante al personal para asegurar su buen desempeño.

\subsubsection{Misión}

El proyecto busca atender la creciente demanda energética, impulsando el uso de fuentes renovables con un enfoque responsable, eficiente y amigable con el medio ambiente. Cada actividad está encaminada a satisfacer las necesidades de nuestros clientes y a reflejar la alineación de la empresa hacia el logro de las metas de reducción de emisiones y mitigación del cambio climático globales.

\subsubsection{Visión}

Ser una empresa líder en el aprovisionamiento de energía renovable, limpia y eficiente en el Perú. Con el menor impacto ambiental, que a su vez esté encaminada a atender la demanda energética de la creciente población. 
6.2. Requerimientos de personal directivo, administrativo y de servicios

Para establecer los requerimientos de personal, se diferenciarán 2 partes en las fases de este proyecto:

- Organización y administración para la ejecución del proyecto

- Organización y administración para la operación de la empresa

Encada parte se determinará la organización requerida, a manera de establecer un diagrama más detallado del personal requerido.

6.2.1. Organización para la ejecución del proyecto

Cubre las actividades que van desde la concepción inicial hasta la puesta en marcha y entrega de las instalaciones. La implementación física la llevará a cabo una empresa contratista que deberá desarrollar el trabajo de acuerdo a su capacidad para asegurar la entrega de la obra. Para esto se tendrá en consideración el tiempo, el costo y calidad del trabajo realizado.

De esta manera, para el buen funcionamiento de la empresa el requerimiento de personal que se necesita estará organizado de la siguiente manera: gerente de proyecto, asesor financiero, asesor legal y área de ingeniería. Todo el equipo coordinará con terceros la ejecución de las obras y supervisión de las mismas, y la firma de contrato. 
Figura 6.1.

Organigrama para el funcionamiento para la ejecución

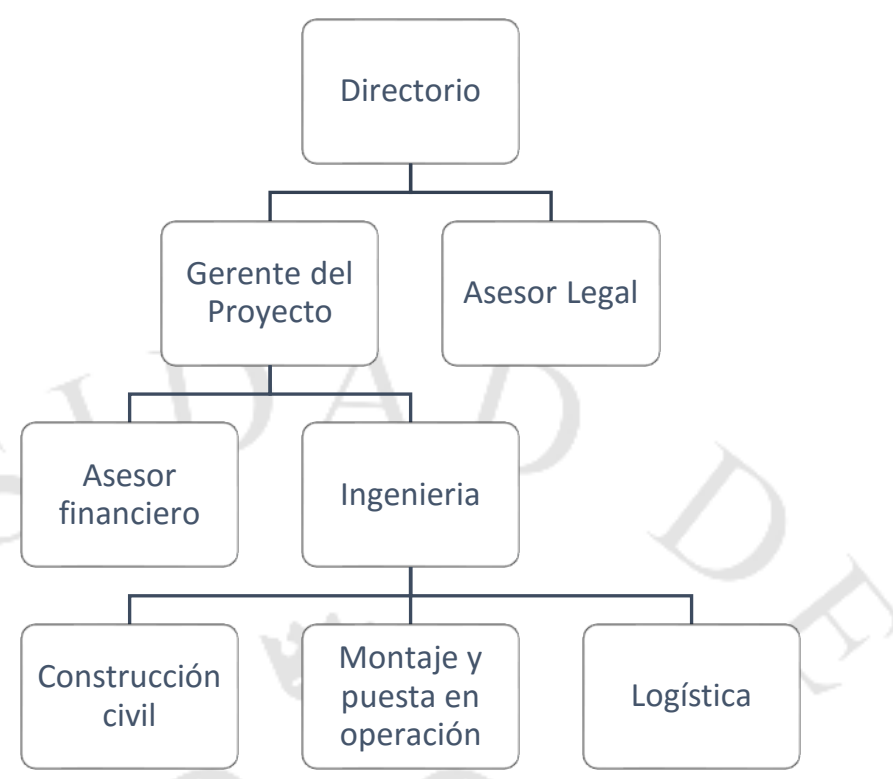

Elaboración propia

Las funciones que tendrán asignadas son:

a) Directorio: Responsable del proyecto. Selecciona el equipo de ejecución a través de su presidente, aprueba y firma los contratos con terceros.

b) Gerente del proyecto: Reporta al directorio y es el responsable directo de la ejecución administrativa del proyecto, así como de los recursos que el directorio le otorgue para dirigir todas las actividades en la etapa de obra. Durante el tiempo de la construcción estará ubicado en el lugar de la obra, llevará a cabo las coordinaciones con los contratistas. El gerente del proyecto tendrá las siguientes áreas a su cargo el personal que participa en la ejecución y asesoría en la etapa de ejecución.

c) Departamento de Ingeniería: Será el encargado de elaborar todo el diseño a detalle de la obra civil y el equipamiento electromecánico.

- Construcción civil: Estará conformado por el ingeniero residente en la obra, los constructores y todos los obreros de construcción civil. El ingeniero residente es el responsable de supervisar y administrar la 
construcción civil y asegurarse de cumplir el cronograma de construcción en el tiempo establecido y con la calidad ofrecida.

- Montaje y puesta en operación comercial: Un equipo de técnicos mecánicos y eléctricos serán los responsables del montaje y puesta en operación comercial de las centrales eólicas.

- Logística: Será el responsable de realizar la compra de materiales y equipos para la construcción así como hacer un planeamiento del proceso de compra, el seguimiento de compra, elaborar el plan de administración de materiales así como coordinar el transporte de personal, materiales y equipos.

d) Asesor financiero: Se encargan de asegurar que los gastos se mantienen dentro del presupuesto original y es el responsable de verificar el cumplimiento del cronograma de construcción y fabricación hasta la puesta en operación comercial de la planta. Será una preocupación del proyecto reducir el estimado y controlar el presupuesto asignado. Cualquier condición no prevista que genere un adicional deberá ser asumida por el contratista. El control de costos y cumplimiento de plazos será otra de sus responsabilidades. Él será el responsable del seguimiento del trabajo y de reportar en caso se incurran en sobrecostos.

e) Asesoría legal: Será necesario para la firma del contrato de ejecución de obra y para el trámite de licencias de construcción en la zona. En el caso de ser necesario se contratará los servicios de un abogado para resolver cualquier controversia legal. No está planeado contar con asesoría legal permanente.

6.2.2. Organización y administración para la operación de la empresa

La operación cubre las actividades diarias que se realizarán posteriores a la puesta en marcha y entrega de la empresa por el gerente de proyecto a los accionistas. Será dividido en cuatro áreas funcionales: dirección, administración, comercialización y mantenimiento. 
a) Dirección: Conformado por el Gerente General quien reporta al directorio. Son los responsables del desempeño económico de la empresa, realizando por uno de ellos, entre sus funciones están la de planificar, organizar y establecer los principales objetivos a alcanzar a corto, mediano y largo plazo. Define políticas y asigna personal entre otras funciones.

b) Administración: Conformado por el contador. Sus funciones corresponden al manejo diario de la empresa, el manejo financiero y contable, la estructura de sistemas y coordinación legal, también se encuentra a cargo de la caja

c) Comercialización: A cargo del ejecutivo de ventas, se encarga de coordinar los precios del servicio.

d) Mantenimiento y aseguramiento de calidad: A cargo del ingeniero, que junto con los técnicos se encargaran del soporte, reparación de los equipos instalados. Para el aseguramiento de la calidad se contratará unos técnicos que trabajarán junto con el área de mantenimiento para garantizar el funcionamiento del proyecto y asegurar los intereses de los accionistas

e) Personal operativo: Conformado por los operadores de la estación, comprende únicamente el personal cuyo trabajo está relacionado con la producción de energía en el parque.

f) Personal de servicio: Conformado por el vigilante y personal de limpieza, el vigilante dará el servicio de seguridad de la empresa mientras que el de limpieza se centrará en la limpieza diaria y programada de los centros de trabajo y planta en general. Cabe resaltar que este servicio estará tercerizado.

6.2.3. Manual de puestos

El manual de puestos describe las funciones que tendrían asignados cada una de las personas. Se desarrollará un perfil de lo que será el manual de puestos de la empresa.

a) Dirección: 
- Gerente General: Sus funciones consisten en realizar el plan estratégico de la empresa representada, aprobar los planes y presupuestos operativos de la empresa. Así también supervisar el desarrollo de los planes y objetivos trazados y selección del personal.

b) Administración:

- Contador: Sus funciones consisten en preparar y mejorar los presupuestos de la empresa, coordinar y dirigir actividades de la empresa. Además de llevar la contabilidad de la empresa, el control de gastos, pagar los tributos y trámites bancarios.

- Cobrador: Sus funciones corresponden al control y ejecución de las finanzas de la empresa.

c) Comercialización:

- Ejecutivo de ventas: Sus funciones consisten en manejar la distribución de los precios de los servicios y velar por el cumplimiento de las políticas comerciales de las mismas. Este puesto está a cargo del contador.

d) Mantenimiento y Aseguramiento de la Calidad

- Ingeniero: Su función es prevenir ante posibles fallas que presenten los equipos. Para ello será encargado de preparar y ejecutar un plan de mantenimiento preventivo de las máquinas equipos.

- Técnicos: Su función es la de reparar y dar un mantenimiento adecuado a las instalaciones.

e) Operaciones:

- Jefe de operaciones: Es el responsable de asegurar el normal funcionamiento del parque para asegurar una producción continua de energía eléctrica.

- Controladores: Es el personal encargado de monitorear el funcionamiento del parque mediante una serie de pantallas que mostrarán alertas y avisos ubicados en la estación. Estarán a cargo del jefe de operaciones. 
- Jefe de mantenimiento: Controlar la ejecución de las actividades de mantenimiento y reparaciones en las instalaciones del proyecto, distribuyendo, coordinando y supervisando los trabajos del personal a su cargo, para garantizar el buen funcionamiento y conservación de los bienes de la empresa.

- Técnicos de mantenimiento: Conformado por 2 operarios que lubrican la maquinaria, cambian piezas o ejecutan otras labores de mantenimiento de rutina a la maquinaria.

- Jefe de logística: Programar, coordinar, ejecutar y controlar el abastecimiento oportuno de bienes materiales y prestación de servicios que requieren las unidades funcionales de la institución, a fin que dispongan de los bienes materiales para cumplir su misión.

\subsection{Estructura organizacional}

Se divide en 4 áreas funcionales:

- Dirección

- Administración

- Comercialización

- Mantenimiento

- Operaciones

La estructura organizacional de la empresa será muy simple. Una vez puesta la operación comercial de la misma, la estructura organizacional tomará la siguiente forma: 
Figura 6.2.

Organigrama para el funcionamiento del proyecto

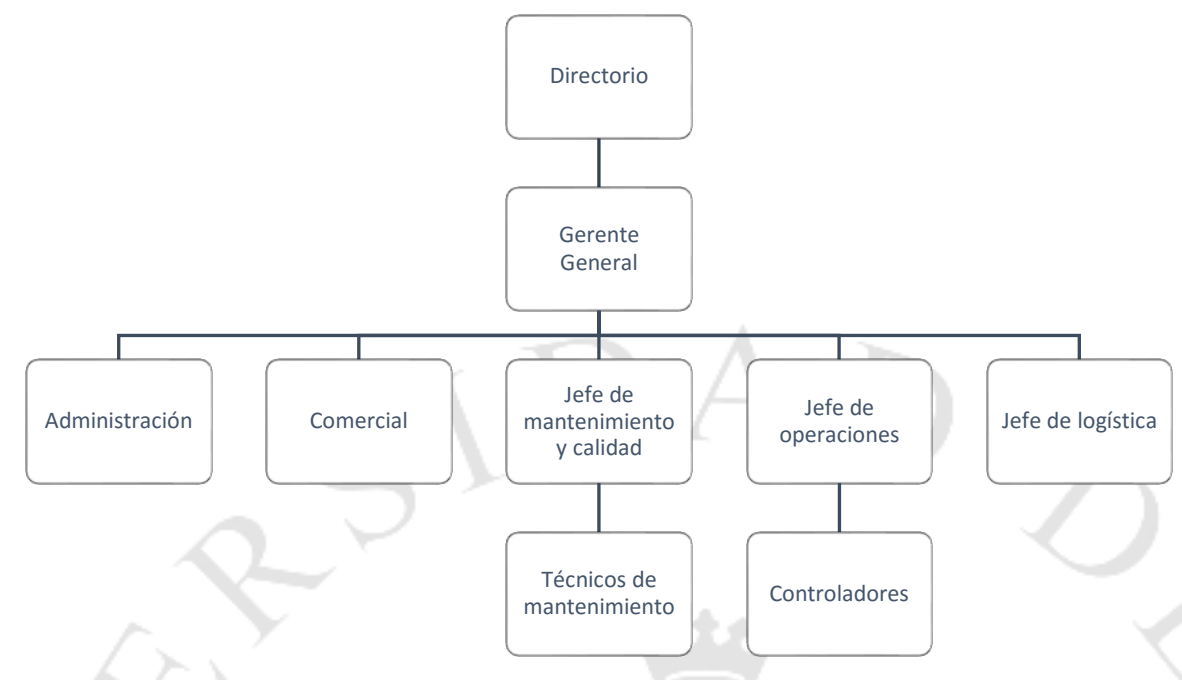

Elaboración propia 


\section{CAPÍTULO VII: ASPECTOS ECONÓMICOS}

\subsection{Inversiones}

\subsubsection{Inversión en la infraestructura para el servicio}

Para la puesta en marcha del proyecto, se requiere de dos tipos de inversión. La inversión tangible está conformada por los equipos de producción que incluye la base de hormigón, los aerogeneradores, cables de electricidad, subestación con todos sus equipos y la línea de transmisión. Por otro lado la inversión intangible está conformada por los estudios realizados para la constitución de la empresa, registros sanitarios, de marca, de capacitación de personal, entre otros.

Los costos estimados para inversión tangible incluyen los costos de obra civil, de la subestación, de los aerogeneradores y de las instalaciones eléctricas. Se detallan a continuación:

Tabla 7.1.

Costos de obra civil

\begin{tabular}{|c|c|c|c|c|}
\hline Obra civil & $\begin{array}{c}\text { Dimensión en } \\
\text { unid }\end{array}$ & $\begin{array}{c}\text { Costo } \\
\text { Unitario (S/.) }\end{array}$ & $\begin{array}{l}\text { Costo por } \\
\text { torre }(\mathrm{S} / .)\end{array}$ & $\begin{array}{c}\text { Totalizado de } \\
\text { torres }(\mathrm{S} / .)\end{array}$ \\
\hline $\begin{array}{c}\text { M2 desbroce y limpieza Terreno de } \\
\text { plataformas }\end{array}$ & 1,200 & & 2,523 & 40,372 \\
\hline $\begin{array}{l}\text { M2 desbroce y limpieza Terreno de } \\
\text { caminos }\end{array}$ & 19,100 & 2 & 36,511 & 584,170 \\
\hline $\begin{array}{c}\text { M3 excavación Pozos a máquina en } \\
\text { terrenos flojos }\end{array}$ & 303 & 27 & 8,095 & 129,527 \\
\hline M3 hormigón armado & 254 & 726 & 184,845 & $2,957,522$ \\
\hline $\begin{array}{l}\text { M3 relleno extendido y apisonado a } \\
\text { cielo abierto }\end{array}$ & 254 & 23 & 5,837 & 93,395 \\
\hline $\begin{array}{c}\text { M3 excavación y cierre de zanjas a } \\
\text { máquina }\end{array}$ & 964 & 54 & 51,591 & 825,459 \\
\hline $\begin{array}{c}\text { M3 de transporte a vertedero. } 20 \mathrm{~km} \\
\text { carga }\end{array}$ & 303 & 34 & 10,408 & 166,534 \\
\hline Total & & & & $4,796,978.70$ \\
\hline
\end{tabular}

Elaboración propia 
Tabla 7.2.

Costos de aerogenerador

\begin{tabular}{lcc}
\hline Costo aerogenerador & $\begin{array}{c}\text { Costo unitarios } \\
(\mathrm{S} / .)\end{array}$ & $\begin{array}{c}\text { Costo total de } \\
\text { aerogeneradores }(\mathrm{S} / .)\end{array}$ \\
\hline Aerogenerador & $7,000,000$ & $112,000,000$ \\
Transporte e instalación & 458,772 & $7,340,352$ \\
Equipos BT/MT & 191,155 & $3,058,480$ \\
Red de tierras & 22,939 & 367,018 \\
Total & & $122,765,850$ \\
\hline
\end{tabular}

Elaboración propia

Tabla 7.3.

Costos de la subestación

\begin{tabular}{lr}
\hline Tipo de costo & Costos PEN \\
\hline Adecuación terreno & 15,292 \\
Edificio control & 57,347 \\
canalizaciones eléctricas & 9,558 \\
Estructura metálica & 11,469 \\
Transformador & $2,240,000$ \\
Protección & 286,733 \\
Cuadro de control & 229,386 \\
Equipos auxiliares & 76,462 \\
Red de tierras & 28,673 \\
Alumbrado & 6,882 \\
Celdas de protección & 68,816 \\
Cableado de control & 34,408 \\
Celda de línea de aerogenerador & 9,558 \\
Celda de medida & 17,204 \\
Celda de llegada de línea 20 KV & 9,558 \\
Comedor & 10,000 \\
Servicios higiénicos & 15,000 \\
Total & $3,126,344$ \\
\hline Elaboración propia & \\
& \\
&
\end{tabular}


Tabla 7.4.

Costos de instalación eléctrica

\begin{tabular}{lcc}
\hline Instalación eléctrica & m totales & Costo PEN \\
\hline ML suministro RHZ 1x95 mm2 & 25 & 90,080 \\
ML suministro RHZ 1x300 MM2 & 11 & 39,270 \\
UD terminales & 287 & 4,588 \\
Total & & 133,938 \\
\hline
\end{tabular}

Elaboración propia

Tabla 7.5.

Costos totales de ejecución

\begin{tabular}{lc}
\hline Costo de Ejecución & Total PEN \\
\hline Compra de terreno & $50,000,000$ \\
Obra civil & $4,796,979$ \\
Subestación & $3,126,344$ \\
Aerogenerador & $122,765,850$ \\
Conexión eléctrica & 133,938 \\
Línea de conexión a red & $19,600,000$ \\
Seguridad y salud & 76,462 \\
Medidas correctoras de Impacto ambiental & $1,911,550$ \\
Costos de grúa & 243,840 \\
Costos de protección ambiental & 5,715 \\
Total ejecución & $202,660,677$ \\
\hline Elaboración propia &
\end{tabular}

Se determinó el costo total de ejecución en el proyecto es de S/. 202,660,667 que incluyen sólo los costos hasta la instalación del parque eólico y que el valor de los equipos principales es de S/. 7,000,000 de cada aerogenerador y de S/. 2,240,000 el valor de cada transformador.

Por otro lado, los costos estimados para la inversión intangible son: 
Tabla 7.6.

Inversión intangible

\begin{tabular}{lc}
\hline \multicolumn{1}{c}{ INVERSIÓN INTANGIBLE } & PEN \\
\hline Constitución de empresa & 800 \\
Registro sanitario & 200 \\
Denominación de origen & 1,000 \\
Registro de marca & 500 \\
Capacitación y asesoría & 25,000 \\
Costos de evaluación de recurso & $2,060,871$ \\
TOTAL & $2,088,371$ \\
\hline Elaboración propia &
\end{tabular}

Adicionalmente a este monto, se tiene que considerar los intereses preoperativos (IPO), que son los intereses que se pagarán durante el año de preparación de las operaciones. Como se verá en el cuadro siguiente, la inversión total considerando sólo las inversiones fijas tangibles, intangibles y el capital de trabajo ascienden a S/. 217,071,209. Este monto será financiado al $80 \%$ que hacen una deuda de S/. 173,656,967, el cual generará un interés pre operativo de S/. 11,480,237. Este IPO es considerado como un activo fijo intangible que deberá ser pagado por los accionistas y no formará parte de la inversión inicial.

Tabla 7.7.

Inversiones y financiamiento

\begin{tabular}{lr}
\hline \multicolumn{1}{c}{ Inversiones y financiamiento } & \multicolumn{1}{c}{ Total PEN } \\
\hline Total inversión fija tangible & $202,660,677.33$ \\
Inversión fija intangible (no incluye intereses) & $2,088,370.91$ \\
Intereses pre operativos & $11,480,237$ \\
Total inversión fija intangible & $13,568,608$ \\
Total inversión fija & $216,229,285.24$ \\
Capital de trabajo & $841,923.84$ \\
Total inversión & $217,071,209.09$ \\
\hline Elaboración propia &
\end{tabular}




\subsubsection{Capital de trabajo}

Para el cálculo del capital de trabajo se utilizará el método de ciclo de caja, el cual requiere el cálculo del gasto operativo anual (GOA). Para ello, se considera que los principales gastos que se muestran a continuación en el cuadro:

Tabla 7.8.

Costos de capital de trabajo

\begin{tabular}{lr}
\hline \multicolumn{1}{c}{ Gasto de operación anual } & \multicolumn{1}{c}{ Total } \\
\hline Costo de mantenimiento & $7,839,588$ \\
Pago de planilla & $1,752,960$ \\
Pago de servicios & 3,500 \\
Pago de seguro & 647,359 \\
Total & $10,243,407$ \\
\hline Elaboración propia &
\end{tabular}

Por lo tanto, se tiene que el gasto operativo anual asciende a S/. 10,243,407, el cual representa el dinero que se tendrá que gastar en el primer año de funcionamiento. Con este monto, se puede calcular el capital de trabajo mediante la siguiente relación:

Capital de trabajo $(\mathrm{KW})=\underline{\text { GOA }} \times$ ciclo de caja (días) 365

Si se cuenta que el ciclo de caja (tiempo en el que la empresa tardará en perder los ingresos por ventas), es de 30 días, resulta finalmente que el capital de trabajo (KW) es de S/. 841,924.00 como se muestra a continuación:

Capital de trabajo $=\frac{10,243,407 \times 30}{365}=841,924$




\subsection{Costos de producción}

Los costos de producción están compuestos por el costo de mantenimiento e insumos, costo de servicio y mano de obra.

7.2.1. Costos de materias primas, insumos y otros materiales

Como ya se mencionó anteriormente, no existe un costo de materia prima; sin embargo, si hay que considerar el costo de mantenimiento que incluye los insumos para el mantenimiento de los aerogeneradores, de la subestación y de las líneas de transmisión. Así, los costos de mantenimiento son de un total anual de S/. 7,473,707 en el primer añ, que incluye piezas de recambio, operación y transporte al parque. Este monto considera el mantenimiento de todo el proyecto, es decir, desde los aerogeneradores hasta las líneas de transmisión.

\subsubsection{Costo de los servicios}

Los costos de servicios se calculan en base a la tarifa actual y requerimiento de servicios calculados. Incluyen los servicios de agua, mano de obra de supervisión, costos de desmantelamiento y seguros. El costo de energía eléctrica es prácticamente inexistente ya que será provista por el mismo parque eólico; no obstante, se tendrá un aerogenerador en caso de emergencia de corte de suministro eléctrico para la subestación pero su costo de insumos es mínimo por lo que no se considera en el cálculo.

Costo de agua: S/. 500.00 mensual, que será proveído en partes semanalmente por un camión cisterna a un tanque a la subestación donde se encuentran los baños y el comedor.

Seguro por torre: S/. 54,720 anual, e incluye todas las torres. Este dato fue tomado de un proyecto eólico en España donde los costos de seguro son de EUR 900.00 al año por torre. 
Costo de desmantelamiento: S/. 2,989,483. Dicho costo se realizará sólo una vez y será al finalizar el proyecto.

7.2.3 Costo de la mano de obra

\subsubsection{Mano de obra directa}

Se va a tomar en cuenta un salario anual que será multiplicado por un factor de 1.56 que incluye los costos de CTS, gratificación anual y ESSALUD. Cabe mencionar que sólo se consideran trabajadores de la empresa que trabajan que laboran directamente en el proceso productivo, no se tomará en cuenta servicios de terceros como seguridad y que se excluyen como trabajadores de la empresa al estar estos servicios tercerizados. Los costos de mano de obra directa ascienden a S/. 776,160. El detalle de costos de mano de obra se muestra a continuación:

Tabla 7.9.

Mano de obra directa

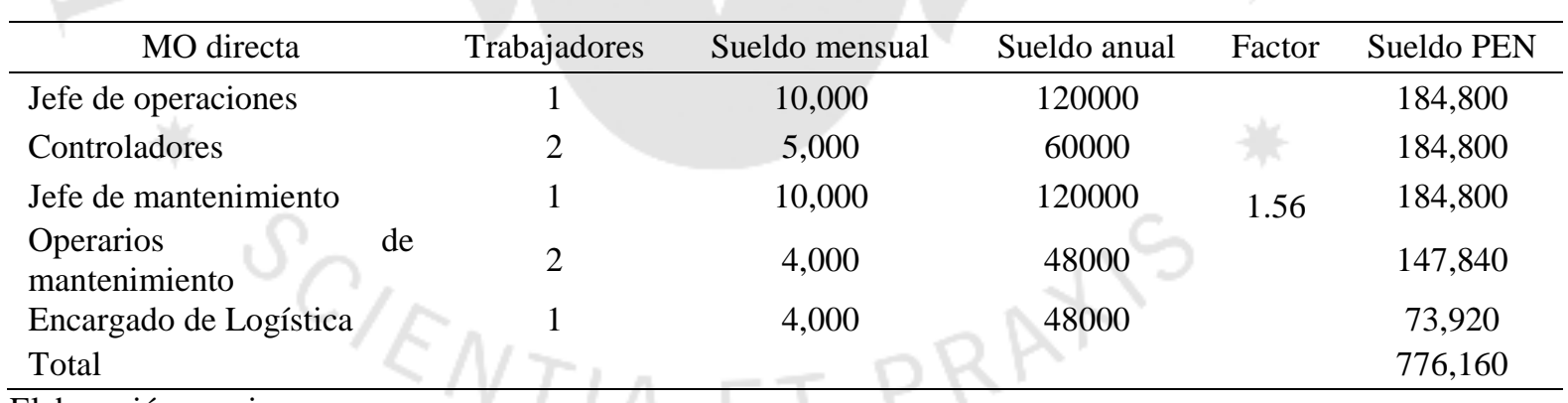

Elaboración propia

\subsubsection{Mano de obra indirecta}

En la mano de obra directa se va a considerar a los demás trabajadores cuyos salarios ascienden a S/. 976, 800 que se mostrará en el siguiente cuadro: 
Tabla 7.10.

Mano de obra indirecta

\begin{tabular}{lccccc}
\hline Personal & $\begin{array}{c}\text { Número de } \\
\text { personas }\end{array}$ & $\begin{array}{c}\text { Remuneración } \\
\text { mensual PEN }\end{array}$ & $\begin{array}{c}\text { Totalizado } \\
\text { anual PEN }\end{array}$ & $\begin{array}{c}\text { Factor de } \\
\text { multiplicación }\end{array}$ & $\begin{array}{c}\text { Total + } \\
\text { beneficios }\end{array}$ \\
\hline Gerente General & 1 & 20,000 & 240,000 & & 374,400 \\
Administrador & 1 & 8,000 & 96,000 & & 149,760 \\
Encargado de finanzas & 1 & 10,000 & 120,000 & 1.56 & 187,200 \\
Marketing y ventas & 1 & 7,000 & 84,000 & & 131,040 \\
\hline
\end{tabular}

Elaboración propia

7.3. Presupuesto de ingresos y egresos

\subsubsection{Presupuesto de ingresos por ventas}

Los ingresos de la empresa se realizarán por medio de las ventas de energía eléctrica. A continuación, se presenta el presupuesto de ingresos del proyecto por los próximos 20 años que durará el proyecto.

Tabla 7.11.

Datos técnicos de la instalación

\begin{tabular}{ccc}
\hline Datos técnicos instalación & & \\
\hline Producción bruta (MWh/año) & 169,643 & MWh/año \\
Producción a la red (MWh/año) & $\mathbf{1 5 4 , 3 7 5}$ & MWh/año \\
Valor electricidad & & \\
Precio promedio & 0.3 & PEN/KWh \\
\hline
\end{tabular}

Elaboración propia 
Tabla 7.12.

Presupuesto de ingresos

\begin{tabular}{|c|c|c|c|c|c|}
\hline AÑO & 1 & 2 & 3 & 4 & 5 \\
\hline Ingresos totales + inflación & $41,218,098$ & $41,012,008$ & $40,806,948$ & $40,602,913$ & $40,399,899$ \\
\hline AÑO & 6 & 7 & 8 & 9 & 10 \\
\hline Ingresos totales + inflación & 40,197,899 & $39,996,910$ & $39,796,925$ & $39,597,940$ & $39,399,951$ \\
\hline AÑO & 11 & 12 & 13 & 14 & 15 \\
\hline Ingresos totales + inflación & $39,202,951$ & $39,006,936$ & $38,811,901$ & $38,617,842$ & $38,424,753$ \\
\hline Ã̃NO & 16 & 17 & 18 & 19 & 20 \\
\hline Ingresos totales + inflación & $38,232,629$ & $38,041,466$ & $37,851,258$ & $37,662,002$ & $37,473,692$ \\
\hline
\end{tabular}

7.3.2. Presupuesto operativo de costos de materias primas

Los costos operativos son aquellos costos a los que se incurren para que las operaciones principales de la empresa funcionen con normalidad y se pueda obtener el servicio final. Entre estos costos, se incluyen los sueldos de la mano de obra directa, los costos de depreciación y otros costos indirectos relacionados con la producción del servicio. A continuación, se presenta el presupuesto de costos operativos del proyecto para los 20 años de operación.

Tabla 7.13.

Mano de obra

\begin{tabular}{lcc}
\hline & Sueldo mensual & Sueldo anual PEN \\
\hline Jefe de operaciones & 10,000 & 184,800 \\
Controladores & 5,000 & 184,800 \\
Jefe de mantenimiento & 10,000 & 184,800 \\
Operarios de mantenimiento & 4,000 & 147,840 \\
Encargado de logística & 4,000 & 73,920 \\
Total anual & & 776,160 \\
\hline
\end{tabular}

Elaboración propia 
Tabla 7.14.

Presupuesto de costos operativos

\begin{tabular}{|c|c|c|c|c|c|}
\hline Rubro & 1 & 2 & 3 & 4 & 5 \\
\hline Agua y otros servicios & 3,500 & 3,500 & 3,500 & 3,500 & 3,500 \\
\hline M.de Obra y supervisión (S/.) $* *$ & 776,160 & 776,160 & 776,160 & 776,160 & 776,160 \\
\hline Costo de operación y mantenimiento & $7,473,707$ & $7,511,075$ & $7,548,631$ & $7,586,374$ & $7,624,306$ \\
\hline Seguro por torre & 588,000 & 593,880 & 599,819 & 605,817 & 611,875 \\
\hline \multicolumn{6}{|l|}{ Costo de desmantelamiento } \\
\hline Depreciación fabril (S/.) & $6,294,610$ & $6,294,610$ & $6,294,610$ & $6,294,610$ & $6,294,610$ \\
\hline Total costo de producción (S/.) & $15,135,977$ & $15,179,225$ & $15,222,719$ & $15,266,461$ & $15,310,451$ \\
\hline 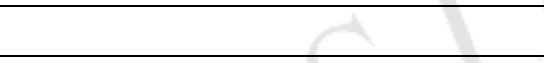 & 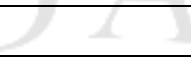 & & & & \\
\hline Rubro & 6 & 7 & 8 & 9 & 10 \\
\hline Agua y otros servicios & 3,500 & 3,500 & 3,500 & 3,500 & 3,500 \\
\hline M.de Obra y supervisión (S/.) $* *$ & 776,160 & 776,160 & 776,160 & 776,160 & 776,160 \\
\hline Costo de operación y mantenimiento & $7,662,427$ & $7,700,740$ & $7,739,243$ & $7,777,939$ & $7,816,829$ \\
\hline Seguro por torre & 617,994 & 624,174 & 630,416 & 636,720 & 643,087 \\
\hline \multicolumn{6}{|l|}{ Costo de desmantelamiento } \\
\hline Depreciación fabril (S/.) & $6,294,610$ & $6,294,610$ & $6,294,610$ & $6,294,610$ & $6,294,610$ \\
\hline Total costo de producción (S/.) & $15,354,691$ & $15,399,183$ & $15,443,929$ & $15,488,929$ & $15,534,186$ \\
\hline \multicolumn{6}{|c|}{ 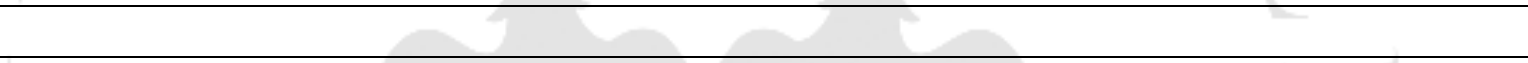 } \\
\hline 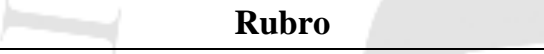 & 11 & 12 & 13 & 14 & 15 \\
\hline Agua y otros servicios & 3,500 & 3,500 & 3,500 & 3,500 & 3,500 \\
\hline M.de Obra y supervisión (S/.) ** & 776,160 & 776,160 & 776,160 & 776,160 & 776,160 \\
\hline Costo de operación y mantenimiento & $7,855,913$ & $7,895,193$ & $7,934,669$ & $7,974,342$ & $8,014,214$ \\
\hline Seguro por torre & 649,518 & 656,013 & 662,573 & 669,199 & 675,891 \\
\hline Costo de desmantelamiento & & & ( & & \\
\hline Depreciación fabril (S/.) & $6,294,610$ & $6,294,610$ & $6,294,610$ & $6,294,610$ & $6,294,610$ \\
\hline Total costo de producción (S/.) & $15,579,701$ & $15,625,476$ & $15,671,512$ & $15,717,811$ & $15,764,374$ \\
\hline Rubro & 16 & 17 & 18 & 19 & 20 \\
\hline Agua y otros servicios & 3,500 & 3,500 & 3,500 & 3,500 & 3,500 \\
\hline M.de Obra y supervisión (S/.) ** & 776,160 & 776,160 & 776,160 & 776,160 & 776,160 \\
\hline Costo de operación y mantenimiento & $8,054,285$ & $8,094,556$ & $8,135,029$ & $8,175,704$ & $8,216,583$ \\
\hline Seguro por torre & 682,650 & 689,476 & 696,371 & 703,335 & 710,368 \\
\hline Costo de desmantelamiento & & & & & $2,989,483$ \\
\hline Depreciación fabril (S/.) & $6,294,610$ & $6,294,610$ & $6,294,610$ & $6,294,610$ & $6,294,610$ \\
\hline Total costo de producción (S/.) & $15,811,204$ & $15,858,302$ & $15,905,670$ & $15,953,309$ & $18,990,703$ \\
\hline
\end{tabular}

Elaboración propia 
7.3.3. Presupuesto operativo de gastos administrativos

Los gastos administrativos son aquellos gastos a los que se incurren para darle soporte al negocio, entre estos gastos se encuentran los de gastos de ventas, los gastos logísticos, los gastos de administración y de otros servicios. A continuación, se presenta el presupuesto de gastos administrativos.

Tabla 7.15.

Presupuesto de gastos administrativos en personal

\begin{tabular}{lcccc}
\hline Personal & $\begin{array}{c}\text { Núm. de } \\
\text { personas }\end{array}$ & $\begin{array}{c}\text { Sueldo mensual } \\
\text { PEN }\end{array}$ & $\begin{array}{c}\text { Totalizado anual } \\
\text { PEN }\end{array}$ & $\begin{array}{c}\text { Total + } \\
\text { beneficios }\end{array}$ \\
\hline Gerente General & 1 & 20,000 & 240,000 & 374,400 \\
Administrador & 1 & 8,000 & 96,000 & 149,760 \\
Encargado de finanzas & 1 & 10,000 & 120,000 & 187,200 \\
Marketing y ventas & 1 & 7,000 & 84,000 & 131,040 \\
Servicios externos & & & & \\
- Limpieza & & & & 24,000 \\
- Seguridad & & & & 90,000 \\
- Asesoría Legal & & & & 6,000 \\
- Contabilidad & & & & 14,400 \\
Total anual & & & & $\mathbf{9 7 6 , 8 0 0}$ \\
\hline
\end{tabular}

Elaboración propia 
Tabla 7.16.

Presupuesto de gastos administrativos

\begin{tabular}{|c|c|c|c|c|c|}
\hline Rubro & 1 & 2 & 3 & 4 & 5 \\
\hline Pago al personal administrativo & 711,360 & 711,360 & 711,360 & 711,360 & 711,360 \\
\hline Pago de servicios & 134,400 & 134,400 & 134,400 & 134,400 & 134,400 \\
\hline Gastos de ventas & 131,040 & 131,040 & 131,040 & 131,040 & 131,040 \\
\hline Gastos por servicio al cliente & 12,000 & 12,000 & 12,000 & 12,000 & 12,000 \\
\hline Total gastos administrativos & 988,800 & 988,800 & 988,800 & 988,800 & 988,800 \\
\hline Rubro & 6 & 7 & 8 & 9 & 10 \\
\hline Pago al personal administrativo & 711,360 & 711,360 & 711,360 & 711,360 & 711,360 \\
\hline Pago de servicios & 134,400 & 134,400 & 134,400 & 134,400 & 134,400 \\
\hline Gastos de ventas & 131,040 & 131,040 & 131,040 & 131,040 & 131,040 \\
\hline Gastos por servicio al cliente & 12,000 & 12,000 & 12,000 & 12,000 & 12,000 \\
\hline Total gastos administrativos & 988,800 & 988,800 & 988,800 & 988,800 & 988,800 \\
\hline 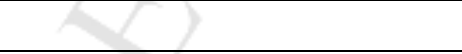 & \multicolumn{2}{|c|}{+2} & \multicolumn{3}{|c|}{ ve } \\
\hline Rubro & 11 & 12 & 13 & 14 & 15 \\
\hline Pago al personal administrativo & 711,360 & 711,360 & 711,360 & 711,360 & 711,360 \\
\hline Pago de servicios & 134,400 & 134,400 & 134,400 & 134,400 & 134,400 \\
\hline Gastos de ventas & 131,040 & 131,040 & 131,040 & 131,040 & 131,040 \\
\hline Gastos por servicio al cliente & 12,000 & 12,000 & 12,000 & 12,000 & 12,000 \\
\hline Total gastos administrativos & 988,800 & 988,800 & 988,800 & 988,800 & 988,800 \\
\hline 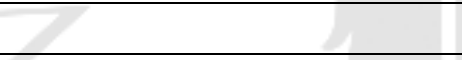 & & & & & + \\
\hline Rubro & 16 & 17 & 18 & 19 & 20 \\
\hline Pago al personal administrativo & 711,360 & 711,360 & 711,360 & 711,360 & 711,360 \\
\hline Pago de servicios & 134,400 & 134,400 & 134,400 & 134,400 & 134,400 \\
\hline Gastos de ventas & 131,040 & 131,040 & 131,040 & 131,040 & 131,040 \\
\hline Gastos por servicio al cliente & 12,000 & 12,000 & 12,000 & 12,000 & 12,000 \\
\hline Total gastos administrativos & 988,800 & 988,800 & 988,800 & 988,800 & 988,800 \\
\hline
\end{tabular}

Elaboración propia

7.4. Flujo de fondos netos

7.4.1. Flujo de fondos económicos

En los cuadros que se muestran a continuación, se presentan el estado de resultados y el flujo de fondos económicos. 
Tabla 7.17.

Estado de resultados del FCE (en miles)

\begin{tabular}{|c|c|c|c|c|c|}
\hline & 1 & 2 & 3 & 4 & 5 \\
\hline Ingresos & $41,218,098$ & $41,012,008$ & $40,806,948$ & $40,602,913$ & $40,399,899$ \\
\hline (-) Costos operativos & $15,135,977$ & $15,179,225$ & $15,222,719$ & $15,266,461$ & $15,310,451$ \\
\hline (-) Gastos administrativos & 988,800 & 988,800 & 988,800 & 988,800 & 988,800 \\
\hline Utilidad antes de impuestos & $25,093,322$ & $24,843,983$ & $24,595,428$ & $24,347,652$ & $24,100,648$ \\
\hline (-) Impuesto a la renta & $7,527,997$ & $7,453,195$ & $7,378,629$ & $7,304,296$ & $7,230,194$ \\
\hline \multirow[t]{2}{*}{ Utilidad neta } & $17,565,325$ & $17,390,788$ & $17,216,800$ & $17,043,357$ & $16,870,453$ \\
\hline & 6 & 1 & 8 & 9 & 10 \\
\hline Ingresos & $40,197,899$ & $39,996,910$ & $39,796,925$ & $39,597,940$ & $39,399,951$ \\
\hline (-) Costos operativos & $15,354,691$ & $15,399,183$ & $15,443,929$ & $15,488,929$ & $15,534,186$ \\
\hline (-) Gastos administrativos & 988,800 & 988,800 & 988,800 & 988,800 & 988,800 \\
\hline Utilidad antes de impuestos & $23,854,408$ & $23,608,926$ & $23,364,196$ & $23,120,211$ & $22,876,965$ \\
\hline (-) Impuesto a la renta & $7,156,322$ & $7,082,678$ & $7,009,259$ & $6,936,063$ & $6,863,089$ \\
\hline \multirow[t]{2}{*}{ Utilidad neta } & $16,698,086$ & $16,526,248$ & $16,354,938$ & $16,184,148$ & $16,013,875$ \\
\hline & \multicolumn{3}{|c|}{ 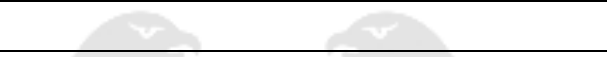 } & \multicolumn{2}{|c|}{$-1-2$} \\
\hline 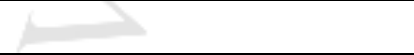 & 11 & 12 & 13 & 14 & 15 \\
\hline Ingresos & $39,202,951$ & $39,006,936$ & $38,811,901$ & $38,617,842$ & $38,424,753$ \\
\hline (-) Costos operativos & $15,579,701$ & $15,625,476$ & $15,671,512$ & $15,717,811$ & $15,764,374$ \\
\hline (-) Gastos administrativos & 988,800 & 988,800 & 988,800 & 988,800 & 988,800 \\
\hline Utilidad antes de impuestos & $22,634,450$ & $22,392,661$ & $22,151,590$ & $21,911,231$ & $21,671,578$ \\
\hline (-) Impuesto a la renta & $6,790,335$ & $6,717,798$ & $6,645,477$ & $6,573,369$ & $6,501,473$ \\
\hline Utilidad neta & $15,844,115$ & $15,674,862$ & $15,506,113$ & $15,337,862$ & $15,170,105$ \\
\hline \multirow[t]{2}{*}{ 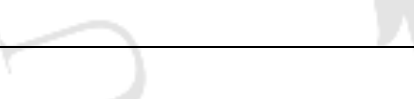 } & & & & \multicolumn{2}{|c|}{ 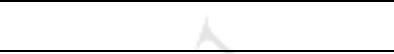 } \\
\hline & 16 & 17 & 18 & 19 & 20 \\
\hline Ingresos & $38,232,629$ & $38,041,466$ & $37,851,258$ & $37,662,002$ & $37,473,692$ \\
\hline (-) Costos operativos & $15,811,204$ & $15,858,302$ & $15,905,670$ & $15,953,309$ & $18,990,703$ \\
\hline (-) Gastos administrativos & 988,800 & 988,800 & 988,800 & 988,800 & 988,800 \\
\hline Utilidad antes de impuestos & $21,432,625$ & $21,194,364$ & $20,956,789$ & $20,719,893$ & $17,494,189$ \\
\hline (-) Impuesto a la renta & $6,429,787$ & $6,358,309$ & $6,287,037$ & $6,215,968$ & $5,248,257$ \\
\hline Utilidad neta & $15,002,837$ & $14,836,054$ & $14,669,752$ & $14,503,925$ & $12,245,932$ \\
\hline
\end{tabular}

Elaboración propia 
Tabla 7.18.

Flujo de fondos económicos (en miles)

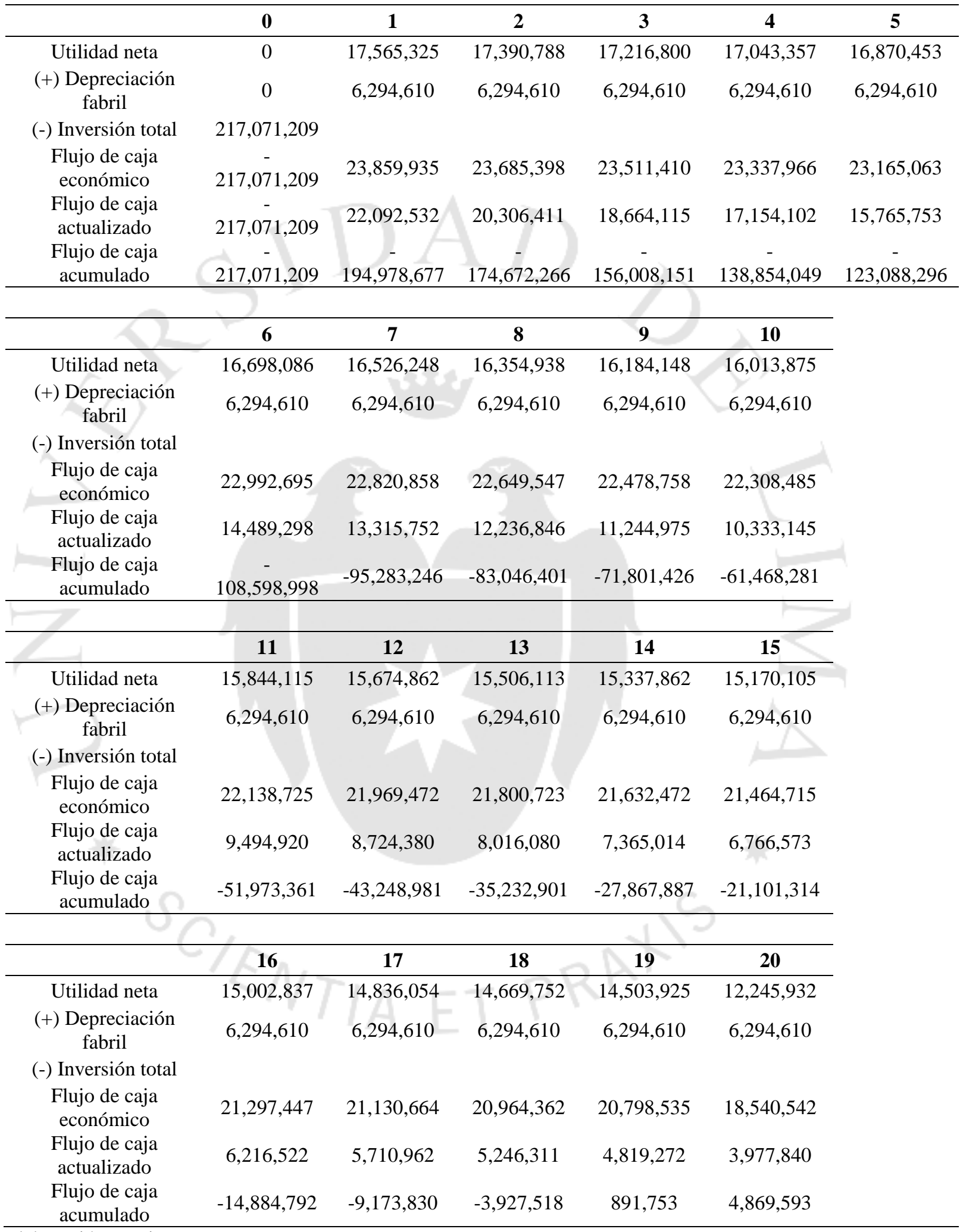

Elaboración propia 
7.4.2. Flujo de fondos financieros

Para realizar el análisis financiero, es necesario determinar el porcentaje de la inversión inicial que será financiada por una fuente externa de financiamiento y definir el tipo de pago que se realizará. Se realizará un financiamiento del $80 \%$ de la inversión total del proyecto, el cual será pagado por medio de cuotas crecientes con un año de gracia parcial y en un periodo de 12 años. A continuación, se presenta un cuadro de servicio de la deuda.

$\begin{array}{lr}\text { Financiamiento } & 173,656,967 \\ \text { Años } & 12 \\ \text { Gracia parcial } & 1 \text { año } \\ \text { Interés } & 7 \%\end{array}$

Tabla 7.19.

Cuadro de servicio de la deuda

\begin{tabular}{|c|c|c|c|c|c|}
\hline 8 & $\mathbf{0}$ & 1 & 2 & 3 & 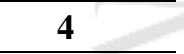 \\
\hline Deuda (S/.) & 173,657 & 173,657 & 171,431 & 166,978 & 160,299 \\
\hline $\begin{array}{c}\text { Amortización } \\
(\mathrm{S} / .)\end{array}$ & 0 & 2,226 & 4,453 & 6,679 & 8,905 \\
\hline Interés (S/.) & 12,156 & 12,156 & 12,000 & 11,688 & 11,221 \\
\hline Cuota (S/.) & 12,156 & 14,382 & 16,453 & 18,368 & 20,126 \\
\hline Saldo deuda (S/.) & 173,657 & 171,431 & 166,978 & 160,299 & 151,393 \\
\hline 78 & 5 & 6 & 7 & 8 & \\
\hline Deuda (S/.) & 151,393 & 140,261 & 126,903 & 111,319 & \\
\hline $\begin{array}{c}\text { Amortización } \\
\text { (S/.) }\end{array}$ & 32 & 13,358 & 15,585 & 17,811 & \\
\hline Interés (S/.) & 10,598 & 9,818 & 8,883 & 7,792 & \\
\hline Cuota (S/.) & 21,729 & 23,177 & 24,468 & 25,603 & \\
\hline Saldo deuda (S/.) & 140,261 & 126,903 & 111,319 & 93,508 & \\
\hline & 9 & 10 & 11 & 12 & \\
\hline Deuda (S/.) & 93,508 & 73,470 & 51,207 & 26,716 & \\
\hline $\begin{array}{c}\text { Amortización } \\
\text { (S/.) }\end{array}$ & 20,037 & 22,264 & 24,490 & 26,716 & \\
\hline Interés (S/.) & 6,546 & 5,143 & 3,584 & 1,870 & \\
\hline Cuota (S/.) & 26,583 & 27,407 & 28,075 & 28,587 & \\
\hline Saldo deuda (S/.) & 73,470 & 51,207 & 26,716 & 0 & \\
\hline
\end{tabular}


En los cuadros que se muestran a continuación, se presentan el estado de resultados y el flujo de fondos financieros.

Tabla 7.20.

Estado de resultados del FCF (en miles)

\begin{tabular}{|c|c|c|c|c|c|}
\hline & 1 & 2 & 3 & 4 & 5 \\
\hline Ingresos & 41,218 & 41,012 & 40,807 & 40,603 & 40,400 \\
\hline (-) Costos operativos & 15,136 & 15,179 & 15,223 & 15,266 & 15,310 \\
\hline (-) Gastos administrativos & 989 & 989 & 989 & 989 & 989 \\
\hline Utilidad antes de intereses & 25,093 & 24,844 & 24,595 & 24,348 & 24,101 \\
\hline (-) Intereses & 12,156 & 12,000 & 11,688 & 11,221 & 10,598 \\
\hline Utiliadad antes de impuestos & 12,937 & 12,844 & 12,907 & 13,127 & 13,503 \\
\hline (-) Impuetos a la renta & 3,881 & 3,853 & 3,872 & 3,938 & 4,051 \\
\hline Utilidad neta & 9,056 & 8,991 & 9,035 & 9,189 & 9,452 \\
\hline 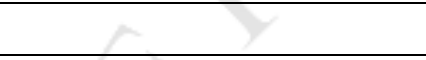 & & 8 & & 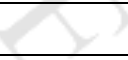 & \\
\hline 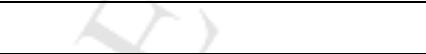 & 6 & 7 & 8 & 9 & 10 \\
\hline Ingresos & 40,198 & 39,997 & 39,797 & 39,598 & 39,400 \\
\hline (-) Costos operativos & 15,355 & 15,399 & 15,444 & 15,489 & 15,534 \\
\hline (-) Gastos administrativos & 989 & 989 & 989 & 989 & 989 \\
\hline Utilidad antes de intereses & 23,854 & 23,609 & 23,364 & 23,120 & 22,877 \\
\hline (-) Intereses & 9,818 & 8,883 & 7,792 & 6,546 & 5,143 \\
\hline Utiliadad antes de impuestos & 14,036 & 14,726 & 15,572 & 16,575 & 17,734 \\
\hline (-) Impuetos a la renta & 4,211 & 4,418 & 4,672 & 4,972 & 5,320 \\
\hline \multirow{2}{*}{ Utilidad neta } & 9,825 & 10,308 & 10,900 & 11,602 & 12,414 \\
\hline & & 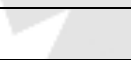 & & \multicolumn{2}{|c|}{ 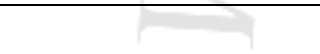 } \\
\hline+2 & 11 & 12 & 13 & 14 & 15 \\
\hline Ingresos & 39,203 & 39,007 & 38,812 & 38,618 & 38,425 \\
\hline (-) Costos operativos & 15,580 & 15,625 & 15,672 & 15,718 & 15,764 \\
\hline (-) Gastos administrativos & 989 & 989 & 989 & 989 & 989 \\
\hline Utilidad antes de intereses & 22,634 & 22,393 & 22,152 & 21,911 & 21,672 \\
\hline (-) Intereses & 3,584 & 1,870 & 0 & 0 & 0 \\
\hline Utiliadad antes de impuestos & 19,050 & 20,523 & 22,152 & 21,911 & 21,672 \\
\hline (-) Impuetos a la renta & 5,715 & 6,157 & 6,645 & 6,573 & 6,501 \\
\hline \multirow[t]{2}{*}{ Utilidad neta } & 13,335 & 14,366 & 15,506 & 15,338 & 15,170 \\
\hline & 16 & 17 & 18 & 19 & 20 \\
\hline Ingresos & 38,233 & 38,041 & 37,851 & 37,662 & 37,474 \\
\hline (-) Costos operativos & 15,811 & 15,858 & 15,906 & 15,953 & 18,991 \\
\hline (-) Gastos administrativos & 989 & 989 & 989 & 989 & 989 \\
\hline Utilidad antes de intereses & 21,433 & 21,194 & 20,957 & 20,720 & 17,494 \\
\hline (-) Intereses & 0 & 0 & 0 & 0 & 0 \\
\hline Utiliadad antes de impuestos & 21,433 & 21,194 & 20,957 & 20,720 & 17,494 \\
\hline (-) Impuetos a la renta & 6,430 & 6,358 & 6,287 & 6,216 & 5,248 \\
\hline Utilidad neta & 15,003 & 14,836 & 14,670 & 14,504 & 12,246 \\
\hline
\end{tabular}

Elaboración propia 
Tabla 7.21.

Flujo de fondos financiero FCF (en miles)

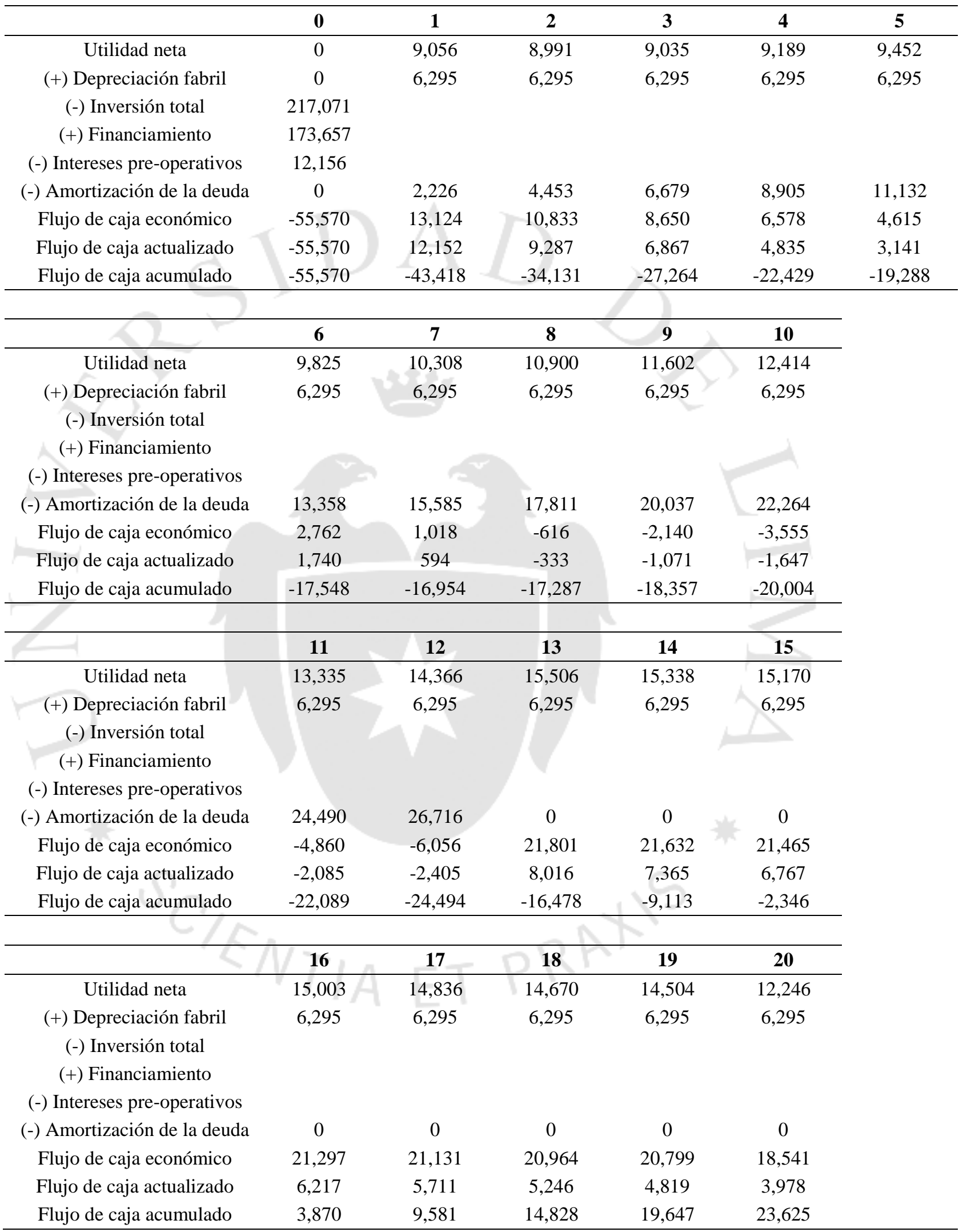

Elaboración propia 


\section{CAPÍTULO VIII: EVALUACIÓN ECONÓMICA Y FINANCIERA DEL PROYECTO}

\subsection{Evaluación económica}

A partir de la evaluación económica del proyecto, se obtienen los siguientes indicadores:
VAN $(8 \%)$
$4,869,593$
TIR $(8 \%)$
$8.31 \%$
$\mathrm{B} / \mathrm{C}(\mathbf{8 \%})$
0.022
Periodo de Recupero
18 años y 10 meses

\subsection{Evaluación financiera}

A partir de la evaluación financiera del proyecto, se obtienen los siguientes indicadores:

VAN $(8 \%)$

TIR $(8 \%)$

$\mathrm{B} / \mathrm{C}(\mathbf{8 \%})$

Periodo de Recupero
$23,624,832$

$12 \%$

0.43

15 años y 2 meses

8.3. Análisis de los resultados económicos y financieros del proyecto

Del flujo de fondos económico podemos determinar que el VAN es de S/. $4,869,593$ y la TIR es de $8.31 \%$ con una relación B/C de 0.022 y un periodo de recupero de 18 años y 10 meses. Bajo este flujo se puede determinar que el proyecto es viable económicamente. 
Del flujo de fondos financiero podemos determinar que el VAN es S/. 23,624,832 y la TIR es $12 \%$ con una relación de B/C de 0.43 y un periodo de recupero de 15 años y 2 meses. Bajo este flujo se puede determinar que el proyecto es viable financieramente.

A partir de los valores obtenidos en el análisis económico y financiero será medianamente rentable con respecto a la inversión total. Logrará retornar beneficios económicos a los inversionistas a largo plazo. El periodo para recuperar la inversión total es largo, y el beneficio obtenido no es tan alto, sin embargo, el proyecto no representará pérdidas. 


\section{CAPÍTULO IX: EVALUACIÓN SOCIAL DEL PROYECTO}

9.1. Identificación de las zonas y comunidades de influencia del proyecto

El proyecto será ubicado cerca del centro poblado San Juan de Marcona, capital administrativa del distrito de Marcona, provincia de Nazca, región Ica.

Para la identificación del área de influencia del proyecto se considerarán los siguientes criterios:

- Área de influencia directa: Se define como el área donde se instalarán los aerogeneradores, y los componentes auxiliares del proyecto (viales internos, zanjas, entre otros). Para el caso del presente proyecto, el área de influencia directa es una zona desértica, en la cual no hay evidencia de usos antrópicos actuales, por lo tanto no incluye ningún centro poblado.

- Área de influencia indirecta: Se define como aquellas áreas cercanas a las instalaciones del proyecto y que podrían ser fuente de servicios para el personal del proyecto durante las etapas de construcción y operación del Parque Eólico. En el área donde se encontrará ubicado el proyecto, no existen poblaciones asentadas o usos de éstas áreas por parte de alguna población. Por tanto, el área de influencia indirecta del proyecto es el área poblada más cercana del proyecto, que es el centro poblado San Juan de Marcona, capital del distrito de Marcona, y cuya población representa el 99.4\% de la población total del distrito.

Por lo tanto, se considerará que la comunidad de influencia es representada por el $99.4 \%$ de la población del distrito. No se considerará el otro $0.6 \%$ de la población ya que esta se encuentra asentada en lugares periféricos de San Juan de Marcona, y dicho porcentaje no influye de manera significativa en los resultados de nivel distrital, pues es poco representativo.

El distrito de Marcona, está ubicado al suroeste del departamento de Ica, entre las coordenadas $15^{\circ} 21^{\prime} \mathrm{S}$ y $75^{\circ} 09^{\prime} \mathrm{W}$, a $530 \mathrm{~km}$ al sur de la ciudad de Lima, entre 
0 - $800 \mathrm{msnm}$, con una superficie de $1955.36 \mathrm{~km}^{2}$. Pertenece a la jurisdicción de la provincia de Nazca. Se asienta sobre un desierto árido propio de la costa central del país, cuyas características topográficas son ligeramente accidentadas, tiene cerros, pampas y mesetas con altitudes que van desde 0 a 800 msnm.

El distrito se divide en tres áreas: San Juan, ciudad comercial y pesquera, residencia de los trabajadores mineros y sede administrativa de la empresa minera Shougang Hierro Perú, San Nicolás, puerto de embarque y procesamiento de la empresa Shougang, y la Mina, yacimiento donde se explota y se extrae el mineral de hierro.

9.2. Impacto de la zona de influencia del proyecto

\subsubsection{Impactos positivos}

La instalación del parque eólico traería como posibles impactos positivos en la zona de influencia lo siguiente:

- Fomento del empleo para los pobladores de la comunidad de influencia, lo que les asegurará un mejor futuro.

- Aumentará la posibilidad para que los egresados de carreras técnicas se inserten en el mercado laboral más fácilmente, debido al aumento de oferta.

- Aumentará la competencia en el mercado de suministro de energía eléctrica, lo cual será beneficioso para el distrito.

- El servicio ofrecido no contamina el medio ambiente.

- Contribuirá a que sea más atractivo para que instituciones educativas de nivel superior lleguen al distrito.

- Contribuirá al desarrollo de la industria local por el bajo costo de energía, consecuencia de la competencia del mercado. 


\subsubsection{Impactos negativos}

La instalación del parque eólico en la zona elegida, podría traer como consecuencia los siguientes impactos negativos en el área de influencia:

- Ingreso de mano de obra que no es originaría del distrito, cosa que podría ocasionar conflictos sociales entre los pobladores y la población inmigrante. Una solución a este problema, podría ser capacitar a pobladores de la localidad para realizar trabajos dentro del parque eólico.

- Impacto visual en el paisaje de la zona de influencia. La instalación del parque eólico ocasiona cambios visuales en el paisaje en el cual es instalado, para algunas personas esto podría ser visto como un impacto negativo.

- Impacto sonoro leve sobre el área de influencia. Durante el funcionamiento del parque eólico, el principal impacto sonoro es el producido por la actividad de las turbinas eólicas. Este sonido puede ser aerodinámico, producido por el flujo de viento sobre las aspas, o puede ser mecánico, debido a los motores y refrigeradores de ventilación. Para reducir estos impactos por ruido, es importante que el diseño de las estructuras de la góndola y las palas debe ser tal que evite las vibraciones de componentes.

- Impacto sobre la fauna de la zona. Las aves representan la fauna que más se vería afectada por la existencia y funcionamiento de los aerogeneradores ya que afectan su hábitat y costumbres, provocando su mayor impacto por la mortalidad de estas al chocar contra los rotores y las estructuras de las turbinas.

9.3. Impacto social del proyecto

Para medir el impacto social del proyecto, se hará uso de indicadores macroeconómicos que permitan una evaluación desde el punto de vista social. 
Mediante estos indicadores es posible cuantificar el impacto positivo del proyecto en el crecimiento económico del país.

\subsubsection{Valor agregado}

El valor agregado se refiere al beneficio marginal neto que recibe la economía como resultado del proyecto, es la contribución neta al crecimiento del producto bruto interno.

Para el cálculo del valor agregado que generará el proyecto se consideran los pagos a la mano de obra, los gastos por depreciación, amortización, intereses, impuestos y seguros.

Para el cálculo del valor agregado del proyecto durante toda su vida útil, es importante utilizar una tasa social de descuento. La tasa de descuento social es en análisis de costo beneficio de implementar obras públicas y/o de protección ambiental y que favorezcan a la sociedad a partir de la inversión pública. Esta debe ser menor a las tasas de descuento social que se utilizan para la mayoría de proyectos. Esto se debe a que los beneficios que se generan a partir de proyectos ambientales como el presente, son perceptibles después de periodos relativamente largos de haberse implementado el proyecto. Existen diferentes métodos para el cálculo de esta tasa, para el presente proyecto se utilizará el método de Feldstein cuya tasa social es de $3.77 \%$.

En el siguiente cuadro se muestra el valor agregado generado por el proyecto durante toda su vida útil. 
Tabla 9.1.

Valor agregado por años

\begin{tabular}{|c|c|c|c|c|c|}
\hline & 1 & 2 & 3 & 4 & 5 \\
\hline Costos operativos & $15,135,977$ & $15,179,225$ & $15,222,719$ & $15,266,461$ & $15,310,451$ \\
\hline $\begin{array}{c}\text { Gastos } \\
\text { administrativos }\end{array}$ & 988,800 & 988,800 & 988,800 & 988,800 & 988,800 \\
\hline Intereses & $12,155,988$ & $12,000,142$ & $11,688,450$ & $11,220,912$ & $10,597,528$ \\
\hline Impuestos & $3,881,200$ & $3,853,152$ & $3,872,094$ & $3,938,022$ & $4,050,936$ \\
\hline Utilidad & $9,056,134$ & $8,990,689$ & $9,034,885$ & $9,188,718$ & $9,452,184$ \\
\hline Valor agregado & 41,218,099 & $41,012,010$ & $40,806,951$ & $40,602,917$ & $40,399,904$ \\
\hline 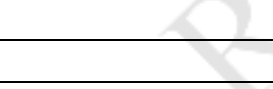 & 6 & 7 & 8 & 9 & 10 \\
\hline $\begin{array}{c}\text { Costos operativos } \\
\text { Gastos } \\
\text { administrativos }\end{array}$ & $15,354,691$ & $15,399,183$ & $15,443,929$ & $15,488,929$ & $15,534,186$ \\
\hline Intereses & $9,818,298$ & $8,883,222$ & $7,792,300$ & $6,545,532$ & $5,142,918$ \\
\hline Impuestos & $4,210,833$ & $4,417,711$ & $4,671,569$ & $4,972,404$ & $5,320,214$ \\
\hline Utilidad & $9,825,277$ & $10,307,993$ & $10,900,328$ & $11,602,276$ & $12,413,833$ \\
\hline Valor agregado & $40,197,905$ & $39,996,917$ & $39,796,933$ & 39,597,949 & $39,399,961$ \\
\hline & 11 & 12 & 13 & 14 & 15 \\
\hline $\begin{array}{c}\text { Costos operativos } \\
\text { Gastos } \\
\text { administrativos }\end{array}$ & $15,579,701$ & 988,800 & $15,671,512$ & $15,717,811$ & $15,764,374$ \\
\hline Intereses & $3,584,458$ & $1,870,152$ & - & - & - \\
\hline Impuestos & $5,714,998$ & $6,156,753$ & $6,645,477$ & $6,573,369$ & $6,501,473$ \\
\hline Utilidad & 13,3 & $14,365,756$ & $15,506,113$ & $15,337,862$ & $15,170,105$ \\
\hline Valor agregado & $39,202,962$ & $39,006,948$ & $\mathbf{3 8 , 8 1 1 , 9 1 4}$ & $38,617,856$ & $38,424,768$ \\
\hline & 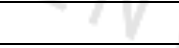 & 7 & $P$ & & \\
\hline & 16 & 17 & 18 & 19 & 20 \\
\hline Costos operativos & $15,811,204$ & $15,858,302$ & $15,905,670$ & $15,953,309$ & $18,990,703$ \\
\hline $\begin{array}{c}\text { Gastos } \\
\text { administrativos }\end{array}$ & 988,800 & 988,800 & 988,800 & 988,800 & 988,800 \\
\hline Intereses & - & - & - & - & - \\
\hline Impuestos & $6,429,787$ & $6,358,309$ & $6,287,037$ & $6,215,968$ & $5,248,257$ \\
\hline Utilidad & $15,002,837$ & $14,836,054$ & $14,669,752$ & $14,503,925$ & $12,245,932$ \\
\hline Valor agregado & $38,232,645$ & $38,041,483$ & $37,851,276$ & $37,662,021$ & $37,473,712$ \\
\hline
\end{tabular}


El valor agregado del proyecto es:

\section{Valor Agregado: $\quad$ S/. 548,727,698}

\subsubsection{Relación producto/capital}

La relación producto/capital o también llamado coeficiente de capital, mide la relación entre el valor agregado generado en el proyecto, versus el monto de inversión total. A continuación se muestra el valor de este coeficiente:

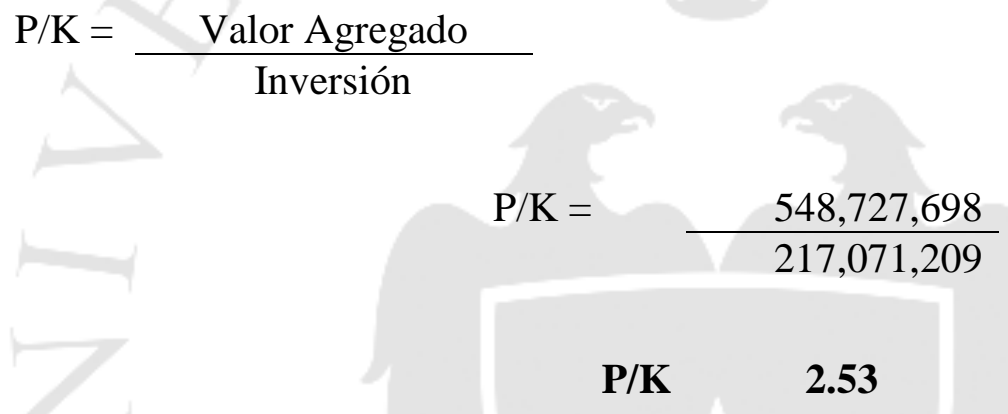

La relación producto/capital es mayor a 1, lo que significa que el proyecto generará un mayor valor al de la inversión inicial.

\subsubsection{Intensidad de capital}

La intensidad de capital muestra la relación de la inversión total versus el valor agregado del proyecto, permite medir el grado de aporte del proyecto a través del nivel de la inversión, para generar valor agregado sobre los insumos. A continuación, se muestra el valor del coeficiente:

$$
\mathrm{i}=\frac{\text { Inversión }}{\text { Valor Agregado }}
$$




$$
\mathrm{i}=\quad \frac{217,071,209}{548,727,698}
$$

$$
\text { i } \quad 0.40
$$

El valor del coeficiente es menor a 1, lo que demuestra que el valor agregado por el proyecto será mayor a la inversión total realizada.

\subsubsection{Densidad de capital}

La densidad de capital es la relación de la inversión del capital versus el empleo generado por el proyecto.

$\mathrm{d}=$ Inversión

Número de trabajadores

$\mathrm{d}=$ $217,071,209$

11

D

$19,733,746$ soles por trabajador

9.3.5. Productividad de la mano de obra

Es un índice que nos permite analizar cuál es la capacidad de la mano de obra empleada para generar producción para el proyecto.

$\mathrm{P}=\frac{\text { Valor de producción total }}{\text { Número de puestos de trabajo }}$ 


$$
P=\frac{154,375 M w h / a \tilde{n} o}{11 \text { Trajadores }}
$$

$\mathbf{P}$

14,034 MWh/año por trabajador 


\section{CONCLUSIONES}

- El viento es una fuente renovable de energía perdurable en el tiempo, prácticamente inagotable y gratuita. Esta representa una gran oportunidad para diversificar la matriz energética del Perú.

- Existen muchas fuentes de energía en el Perú. Sin embargo, la mayoría de estas son no renovables como las fuentes termoeléctricas. La implementación de una planta generadora de energía eólica representa una nueva fuente de energía para abastecer el mercado eléctrico de una manera más limpia y menos contaminante.

- El mercado objetivo que tendrá el proyecto será el mercado libre y en especial las mineras ya que este tipo de industria es la que tiene mayor necesidad de energía eléctrica.

- Es importante seleccionar el lugar más óptimo para ubicar la planta generadora de energía ya que la velocidad del viento es el factor más importante para el funcionamiento y este varía según la ubicación geográfica. En presente caso, la región de Ica es la más óptima para ubicar el proyecto ya que presenta mayor potencial eólico.

- Para la implementación de una planta eólica, es importante considerar varios factores además del potencial eólico. La cercanía a los clientes representa también un factor importante para determinar la ubicación del proyecto. Además, la existencia de reservas naturales puede limitar la selección de la ubicación para el proyecto.

- El principal factor relevante para seleccionar el tamaño de planta es el requerimiento del mercado ya que este representa la cantidad de energía que los potenciales clientes necesitarán, y en base a esa cantidad se adquirirá la tecnología necesaria para generar la potencia requerida por el mercado.

- La tecnología más apropiada para la implementación de este proyecto serán los aerogeneradores tripala marca Siemens modelo SWT-2.3-108 
debido a que reúnen las condiciones óptimas, que son: ser de alta potencia, tener una dirección barlovento, una potencia nominal de $2 \mathrm{MW}$ y con una altura aproximada de $80 \mathrm{~m}$ para aprovechar mejor las velocidades del viento.

- Es importante tener en cuenta que la instalación de la planta generadora de energía eólica no debe tener un impacto significativo en la flora y fauna que habite el lugar.

- Pese a que existe un elevado costo inicial de instalación de un parque eólico, éste presenta una serie de beneficios importantes: una baja frecuencia de mantenimiento, una vida estimada relativamente larga para los componentes, operación diaria y mantenimiento fácil de llevar a cabo.

- Se puede concluir que el presente proyecto generará muchos impactos positivos en la sociedad lo cual se puede observar en los ratios de impacto social tales como el alto valor agregado en comparación a la inversión que se realizará.

- El proyecto requerirá una inversión total de S/. 204,876,636 que considera las inversiones fijas tangibles, intangibles y el capital de trabajo. Así VAN financiero de PEN 28.6 MM, una TIR de $13 \%$ y un período de recupero ligeramente superior a los 14 años. 


\section{RECOMENDACIONES}

- Se recomienda buscar varias fuentes de financiamiento dispuestas a invertir grandes cifras de dinero, y dispuestas a esperar un largo plazo para percibir el retorno. Además que estén interesadas en apoyar proyectos favorables para el medioambiente.

- La construcción de un parque eólico para la generación de energía eléctrica requiere de un estudio de vientos que maneje un alto nivel de detalle, principalmente a lo que se refiere a recursos eólicos disponibles.

- Los planes logísticos y de seguridad industrial para construir el parque eólico deben contar con un seguimiento especial para que la nueva planta sea bien diseñada y para que la construcción se lleve a cabo correctamente.

- Es recomendable realizar los estudios de pre factibilidad y factibilidad antes de realizar la inversión en el proyecto. Debido a que el presente proyecto es sólo un estudio preliminar de la instalación de un parque eólico.

- Para asegurar el óptimo funcionamiento de los aerogeneradores y equipos, es importante realizar mantenimiento de estos con las frecuencias requeridas que varían dependiendo del equipo.

- Es recomendable tener bien definido la organización y distribución del trabajo para poder obtener el mayor beneficio con el número apropiado de personal. Así mismo, se sugiere tercerizar la etapa de construcción y transporte de equipos a empresas con mayor experiencia; y contratar personal propio para la parte de operación de la planta.

- Es importante asegurarse que el proyecto genere más impactos positivos que negativos dentro de su área de influencia ya que el valor agregado que se le da al proyecto es una alternativa más limpia para la generación de energía. Ésta alternativa debe generar mayor no sólo en el aspecto ambiental, sino también en el aspecto social y económico. 


\section{REFERENCIAS}

Altaeros Energies (2014) BAT: The Buoyant Airborne Turbine. Recuperado de http://www.altaerosenergies.com/bat.html

Alameda, T. (2014, 29 de Diciembre). Vortex, un molina de viento sin palas. MIT Technology Review. Recuperado de https://www.technologyreview.es/energia

Cox Harman, G. (2002). Estudio de pre-factibilidad para la generación de energía eléctrica mediante la instalación de dos centrales hidroeléctricas de $720 \mathrm{~kW} \mathrm{y}$ Ir330 kW aprovechando las rápidas artificiales de la irrigación Santa Rosa. (Tesis para optar por el grado de Ingeniero Industrial) Lima: Universidad de Lima.

Fiallos y Asociados S.A. (2011). Documento de impacto ambiental de línea de transmisión de alto voltaje y la subestación del parque eólico: Eólica Wind Power. Rivas, Nicaragua.

Gamesa. (2015, 10 de mayo). Desarrollo del nuevo aerogenerador onshore de 5 MW. Recuperado de http://www.gamesacorp.com/es/productos-servicios/iddesarrollo-de-la-plataforma-de-5-mw.html

Mateson, R. (2014). High-Flying Turbine Produces More Power. MIT Technology Review. Recuperado de http://www.technologyreview.com/aroundmit/527316/high-flying-turbineproduces-more-power/

Méndez Muñiz, J. (2012). Energía eólica. Madrid: Fundación Confemetal.

MINEM. (2008). Atlas Eólico del Perú. Lima.

MINEM. (2010). Estadística Eléctrica por Regiones. Lima.

MINEM. (Octubre de 2010). Matriz Energética del Perú al 2021. Lima.

MINEM. (2011). Estudio de Impacta Ambiental del Proyecto Parque Eólico Tres Hermanas. Lima: MINEM.

MINEM. (2013). Cartera Estimada de Proyectos Mineros. Lima.

MINEM. (2013). Perú: subsector eléctrico 2012. Lima. 
MINEM. (s.f.). Estádisticas Eléctricas Mensuales. Lima.

Mayorga Silva, L. (2005). Estudio de pre-factibilidad para la producción industrial de aerobombas. (Tesis para optar por el grado de Ingeniero Industrial) Lima: Universidad de Lima.

Mirez Tarrillo, J. (2002). Distribución óptima de torres de un parque eólico. Recuperado de https://jmirez.wordpress.com/2011/07/18/j286-distribucion-optima-de-torresen-un-parque-eolico/

Paredes Larroca, F. H. (2000). Estudio de pre-factibilidad para instalar una serie de pequenas plantas de energía solar en las zonas de Chepén y Pacasmayo. (Tesis para optar por el grado de Ingeniero Industrial) Lima: Universidad de Lima.

Siemens. (2013). Sistemas de barras conectoras. Recuperado de: http://w3.siemens.com/powerdistribution/global/es/lv/productportfolio/pages/sist emas-de-barras-colectoras.aspx

Windpower. (2000, 26 de noviembre). La energía eólica. Recuperado de http://www.windpowerenergiaeolica.com/ 


\section{BIBLIOGRAFÍA}

ABB. (2011). Transformadores elevadores de generación y transformadores de interconexión del sistema de Garantía de transmisión de CA de alta calidad. Recuperado de https://library.e.abb.com/public

ALLPE. (2014). Energía eólica y medio ambiente. Recuperado de http://www.allpe.com/seccion_detalle.php?idseccion=269.

Amador, D. (2011). Empresarios del viento. Revista Etiqueta Verde, (3), p. 40-48.

Ambientum (2002). Impacto Medioambiental Producido por los Parques Eólicos. Recuperado de http://www.ambientum.com/revista/2002_05

Angulo García, M. (2009). Parque Eólico Las Juncadas. (Tesis para optar por el grado de Ingeniero Industrial) Madrid: Universidad Pontificia Comillas.

Argüedas Penalba, M. (2013). Offshore y repowering: tendencias en el sector eólico. Automática e Instrumentación, (447), p. 44-47.

Baldovino Fernandini, E.; Ramos, G. y Calderón, V. (2008). Energía eólica en Perú. Lima: Pearson.

Carta González, J. (2009). Centrales de energía renovables: generación eléctrica con energías renovables. Mexico D.F.: Pearson.

Centro de Energías Renovables (2011, 24 de Octubre). Energía Eólica. Recuperado de http://cer.gob.cl/tecnologias/eolica/

Coronado Lara, J. (2012). OSINERGMIN. Recuperado de http://www.osinerg.gob.pe/newweb/uploads/Publico/SeminarioIntEFERP/Jueve s\%206.10.2011/3.\%20Generacion\%20Renovable\%20en\%20el\%20Peru\%20\%20Juan\%20Coronado.ppt.

Corporación Financiera Internacional. (2007). Guías sobre medio ambiente, salud y seguridad para la energía eólica. Grupo Banco Mundial. 
Ecoinventos (2014, 23 de diciembre). Proyecto Vortex. Aerogeneradores sin aspas. Recuperado de http://ecoinventos.com/proyecto-vortex/

Energías-renovables (2014, 23 de diciembre). Un aerogenerador sin palas. Recuperado de http://www.energias-renovables.com/articulo/un-aerogenerador-sin-palaspremiado-en-the-20141016.

Fernández Marín, I. (2008). Selección de estrategias de crecimiento empresarial en el sector de la industria eólica. Madrid: Universidad Pontificia de Comillas.

Fernandini Baldovino, E. (2008). Energía eólica en el Perú. México D.F.: Pearson.

García, Gregorio (2008). Energías del siglo XXI: de las energías fósiles a las alternativas. Madrid: Mundiprensa.

Lira Huerta, J. (1990). Energía eólica: solución al problema energético en el campo peruano (Tesis para optar por el grado de Ingeniero Industrial). Lima: Universidad de Lima.

Madrid Vicente, A. (2009). Energías renovables: fundamentos, tecnologías y aplicaciones. Madrid: AMV Ediciones.

Mantilla Penalba, L. (2012). Aerogeneradores: hacia los imanes permanentes. Energía: ingeniería energética y medioambiental, (234), p. 48-53.

Mendiola, A. , Aguilar, O., Suzete, C., Giglio, G. y Maldonado, W. (2012). Proyectos de generación eléctrica en el Perú. Lima: Universidad ESAN.

Miranda Gracía, J. (2008). Estudio y Planificación de un Parque Eólico. (Tesis para optar por el grado de Ingeniero en Organización Industrial) Madrid: Escuela Técnica Superior de Ingeniería.

Moragues, J., \& Rapallini, A. (2008). Aspectos Ambientales de la Energía Eólica. Revista Proyecto Energético, (23), p. 24-34.

Noticias de la ciencia (2014, 16 de mayo). Aerogeneradores flotando en el aire. Recuperado de http://noticiasdelaciencia.com/not/10394/aerogeneradoresflotando-en-el-aire/

Osinergmin. (2010). Reporte Estadístico de Mercado Libre de Electricidad. Lima. 
Osinergmin. (2010). Subasta de Suministros de Electricidad con Recursos Energéticos Renovables. Lima: Gart.

Osinergmin. (2011). Situación actual y perspectiva del mercado eléctrico peruano. Lima.

Osinergmin. (2013). Central Eólica Tres Hermanas. Lima.

Osinergmin. (2013). Central Parque Eólico Marcona. Lima.

Power technology. (2014). The world 10 biggest wind turbines. Revisado de http://powertechonology.com/features/featurethe-worlds-biggest-wind-turbines-4154395/

Prías Caicedo, O. (2009). Calidad de la Energía Eléctrica. Bogotá: Universidad Autónoma de Occidente.

Rivera, D. M., \& Toromoreno, D. D. (2008). Ubicación de un Parque de Energía Eólica en la Costa Ecuatoriana. (Tesis para optar por el grado de Ingeniero Industrial) Quito: Universidad San Francisco de Quito.

Romaní Aguirre, J. C., \& Arroyo Chalco, V. (2012). Matriz energética en el Perú y energías renovables. Lima: Sinco Editores.

Rondón Mestanza, M. (2011). Perfeccionamiento del sistema de apoyo en el Perú sobre la generación de electricidad: energía renovable eólica. (Tesis para optar por el título de Derecho) Lima: Universidad de Lima.

Sagardoy, I. (2012). Análisis del Ciclo de Vida de un Aerogenerador. (Tesis para optar por el título de Ingeniero Industrial) Buenos Aires: UCA.

Tech4CDM. (2009, 23 de Junio). La energía eólica en Perú. Lima, Perú. Recuperado de http://eeea.ca/wp-content/uploads/2013/09/La-Energia-Eolica-en-Peru.pdf. 


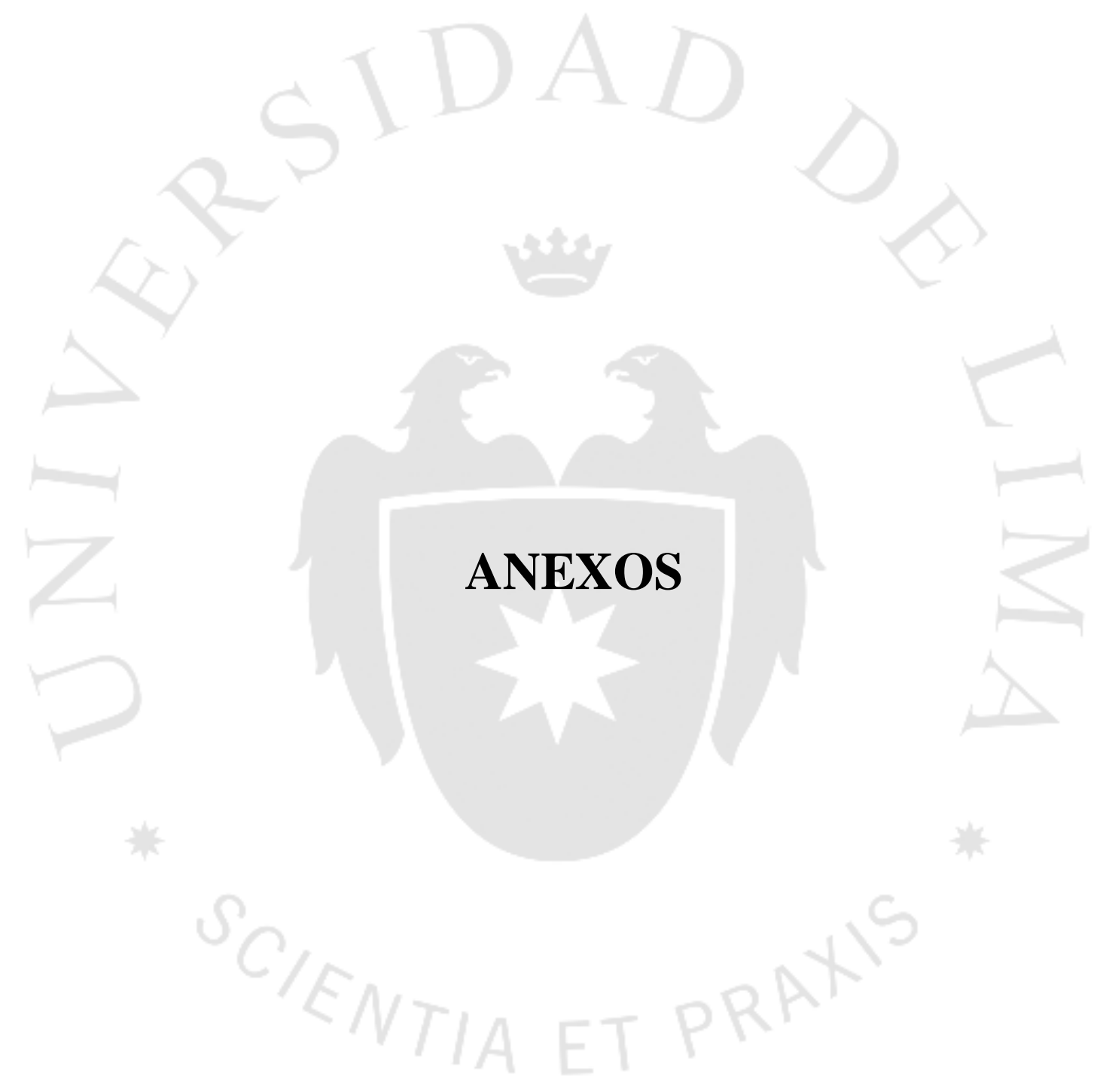




\section{ANEXO 1: DETERMINACIÓN DE LA POTENCIA DISPONIBLE}

Si suponemos un volumen de cilindro (V) que es barrido por el viento, en cada momento la masa de ese volumen será la densidad será la densidad (p) por la superficie barrida (A1) por la longitud del cilindro (L):

$$
\mathrm{m}=\mathrm{p}^{*} \mathrm{~V}=\mathrm{p}^{*} \mathrm{~A} 1 * \mathrm{~L}
$$

Consecuentemente, el caudal másico (masa por unidad de tiempo) de aire que atraviesa ese volumen de control con una velocidad (v1) será:

$$
\mathrm{m}=\mathrm{p} * \mathrm{~A} 1 * \mathrm{v} 1
$$

Por otro lado, la energía cinética de ese mismo aire será:

$$
\mathrm{E}=1 / 2 * \mathrm{~m} * \mathrm{v} 12
$$

Dado que la potencia es:

$$
\mathrm{P}=\Delta \mathrm{E} / \Delta \mathrm{t} * \mathrm{p} * \mathrm{~A} 1 * \mathrm{~V} 13
$$

Sustituyendo, obtenemos la potencia disponible del viento, que como vemos es función del cubo de su velocidad. Si no existiese aerogenerador que frenase el viento entonces la potencia del viento sería:

$$
\mathrm{P}=1 / 2 * \mathrm{p} * \mathrm{~A} 1 * \mathrm{~V} 13
$$

Por otro lado hay que considerar el coeficiente $\mathrm{Cp}$, definido como potencia aprovechable en el rotor entre la potencia disponible del viento se puede formular como:

$$
\mathrm{Cp}=1 / 2 *(1+\mathrm{v} 2 / \mathrm{v} 1) 2 *(1-\mathrm{v} 2 / \mathrm{v} 1)
$$

En esta fórmula v1 representa la velocidad del viento antes de que toque la turbina y V2 es la velocidad después de pasar por la turbina. 


\section{ANEXO 2: DISTRIBUCIÓN ÓPTIMA DE TORRES EN UN PARQUE EÓLICO}

Un parque eólico consta de muchas turbinas todas ellas interconextadas a la red eléctrica, a la que aportan de manera individual. Pero dado el emplazamiento de un parque por sus buenos vientos tanto en intensidad como en frecuencia, se distribuye las turbinas en función a ciertas características como la rugosidad del terreno, la velocidad de viento predominante, la altura de la torre, el diámetro del área de la turbina, entre otros factores. La figura muestra un espaciamiento óptimo entre turbinas, pero son las particularidades de viento y geográficas del emplazamiento los que definen a que distancia colocar.

Recuerden que la dado que el viento entrega parte de su energía a la turbina, éste disminuye su presión y se expande luego de pasar por la turbina... luego el viento que no interactuó con la turbina, va comprimiendo esta estela de baja presión de viento hasta nivelarlo con la presión ambiente, es en esta condición que nuevamente puede ingresar a una siguiente turbina eólica.

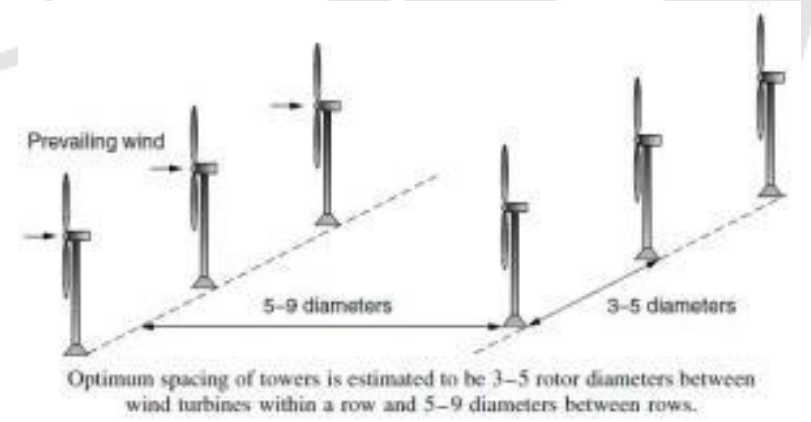
wind turbines within a row and 5-9 diameters between rows. 